FERNANDO TORRES PEREIRA DA SILVA

\title{
Estudo da integridade estrutural de transformadores de potência sob ação de carregamentos dinâmicos de transporte
}

Dissertação apresentada à Escola Politécnica da Universidade de São Paulo para obtenção do Título de Mestre em Ciências. 
FERNANDO TORRES PEREIRA DA SILVA

\section{Estudo da integridade estrutural de transformadores de potência sob ação de carregamentos dinâmicos de transporte}

Dissertação apresentada à Escola Politécnica da Universidade de São Paulo para obtenção do Título de Mestre em Ciências.

Área de concentração:

Engenharia Mecânica de Projeto e Fabricação

Orientador:

Prof. ${ }^{a}$ Dr. ${ }^{a}$ Larissa Driemeier 
Este exemplar foi revisado e alterado em relação à versão original, sob responsabilidade única do autor e com anuência de seu orientador.

São Paulo, 18 de Dezembro de 2013.

Assinatura do autor.

Assinatura do orientador.

\section{Ficha Catalográfica}

Silva, Fernando Torres Pereira da

Estudo da integridade estrutural de transformadores de potência sob ação de carregamentos dinâmicos de transporte/ F.T.P. da Silva -ed. rev.- São Paulo, 2013. 119 p.

Dissertação (Mestrado) - Escola Politécnica da Universidade de São Paulo. Departamento de Engenharia de Mecatrônica e de Sistemas Mecânicos.

1. Projeto Mecânico. 2. Dinâmica de Máquinas. 3. Integridade estrutural. 4. Sistemas dinâmicos I. Universidade de São Paulo. Escola Politécnica. Departamento de Engenharia de Mecatrônica e de Sistemas Mecânicos. II. t. 
Put off thy shoes from off thy feet, for the place whereon thou standest is holy ground.

(Exodus III, 5 apud LANCZOS) 


\section{Agradecimentos}

Aos meus pais, pela formação dada e pelas condições garantidas para que houvesse meu desenvolvimento. Aos meus irmãos, pela alegria de sua companhia.

À Prof. ${ }^{\text {a }}$ Dr. ${ }^{a}$ Larissa Driemeier pelo incentivo, ideias e valiosos direcionamentos propostos desde o momento em que se apresentou o projeto.

À empresa Siemens, na figura Glauco Cangane, e a Paulo Avelino pelas apresentação do problema e pelas condições dadas para o desenvolvimento do estudo aqui apresentado.

Aos meus amigos e colegas de trabalho Juliano Guarenghi, Carlos Santos, Luiz Jovelli e Alexandre Milagre. 


\section{Resumo}

Transformadores de potência, como produtos não seriados, estão sujeitos a uma série de possíveis desvios de processo. As divergências que transformadores podem apresentar em relação ao seu projeto original podem ter consequências em sua capacidade de suportar carregamentos mecânicos que lhe serão aplicados. Seu transporte da fábrica às subestações elétricas é um dos principais eventos durante o qual suas estruturas são carregadas. Este trabalho foca em descrever e analisar um transformador de potência genérico em um modelo bidimensional, sob o ponto de vista da Mecânica Analítica e da análise de variabilidades com o objetivo de identificar parâmetros importantes à integridade estrutural do equipamento, especialmente aqueles relacionados ao modo de falha de destacamento das chapas do núcleo nos step laps. O modelo numérico do transformador consiste na representação de corpos rígidos conectados entre si por elementos de rigidez e amortecimento, tendo o conjunto do núcleo ferromagnético particularmente mais detalhado de modo a descrever o atrito existente em suas junções. A avaliação dos esforços nesses locais é feita por meio do método dos multiplicadores de Lagrange, ao considerar o atrito como uma restrição ao movimento, sendo que as forças e momentos limites para que ocorra o deslizamento planar das chapas do núcleo são determinados utilizando-se Newton-Raphson ou outras técnicas de otimização.

Palavras-Chaves: Transformadores de Potência, Transporte, Mecânica Lagrangiana, Métodos Numéricos. 


\section{Abstract}

Power transformers, as non serialized products, are subject to a number of process deviations. The divergences that transformers present from their original design may have consequences on their ability to withstand mechanical loads which will be applied on them. Their transportation from workshop to power plants is one of the main events their structures are loaded. This work focuses on describing and analyzing a generic power transformer in a two-dimensional model, under the sight of Analytical Mechanics and Structural Reliability in order to identify important parameters related to their structural integrity, especially those concerning the failure mode of dismantling of the ferromagnetic core in the step-lap joints. The numerical model of the transformer consists of a representation of rigid bodies, connected to each other by stiffness and damping elements, having the assembly of the ferromagnetic core more detailed in order to describe the friction present on their step-lap joint. The evaluation of friction in these locations is made using the Lagrange Multipliers Method, by considering it as a movement restriction, and the limit values of forces and moments to which the planar sliding of the core sheets occurs, damaging the behavior of the electric machine, are determined using Newton-Raphson and Optimization Methods.

Keywords: Power Transformers, Transportation, Lagrangian Mechanics, Numerical Methods. 


\section{Conteúdo}

\section{Lista de Figuras}

1 Introdução

1.1 O Transformador Elétrico . . . . . . . . . . . . . . 19

1.1 .1 Construção . . . . . . . . . . . . . . . . . 19

1.1.2 Região de Estudo . . . . . . . . . . . . . . . 22

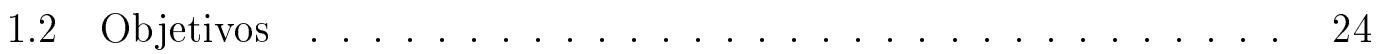

1.3 Revisão Bibliográfica . . . . . . . . . . . . . . . 24

$\begin{array}{llr}2 & \text { Modelagem Analítica } & 27\end{array}$

2.1 Detalhamento do Estudo . . . . . . . . . . . . . . . 27

2.2 Formalismo Lagrangiano do Problema . . . . . . . . . . . 29

2.2 .1 Energia Cinética . . . . . . . . . . . . . 29

2.2.2 Energia Potencial . . . . . . . . . . . . . . 30

2.2.3 Função de Dissipação de Rayleigh . . . . . . . . . . . . . 41

2.2.4 Vínculos Holônomos de Posição e Velocidade . . . . . . . . 42

2.2.5 Multiplicadores de Lagrange . . . . . . . . . . . 48

2.2.6 O Princípio de Hamilton . . . . . . . . . . . . 48

2.3 Deslizamento Planar . . . . . . . . . . . . . . 5 50

3 Implementação Numérica $\quad 53$

3.1 Avaliação de Integrais de Área nos Step Laps . . . . . . . . . . 53

3.2 Problema Inverso dos Parâmetros de Deslizamento . . . . . . . . . 54 
3.3 Resolução do Sistema Dinâmico . . . . . . . . . . . . . 56

3.3.1 Critérios de Escorregamento . . . . . . . . . 58

3.3.2 Procedimento de Resolução do Sistema Dinâmico . . . . . 60

4 Resultados e Discussões

4.1 Características Construtivas do Transformador Estudado . . . . . 62

4.2 Avaliação dos Efeitos da Duração de Impactos . . . . . . . . . . 64

4.2.1 Resultados de Acelerações Horizontais . . . . . . . . 65

4.2.2 Resultados de Reações sobre a Parte Ativa . . . . . . . . 70

4.2 .3 Discussões . . . . . . . . . . . . . . . . 75

4.3 Avaliação dos Efeitos da Amplitude de Impactos . . . . . . . . . 77

4.3.1 Resultados de Acelerações Horizontais . . . . . . . . . 77

4.3.2 Resultados de Reações sobre a Parte Ativa . . . . . . . . . 80

4.3.3 Discussões . . . . . . . . . . . . . . . . . 83

4.4 Avaliação dos Efeitos da Velocidade de Tráfego em Pista com So-

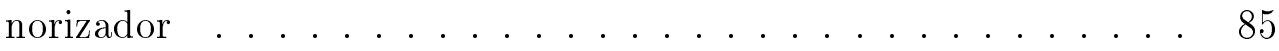

4.4.1 Resultados de Acelerações Verticais . . . . . . . . . . 85

4.4.2 Resultados de Acelerações Horizontais ....... 89

4.4.3 Resultados de Reações sobre a Parte Ativa . . . . . . . . . 93

4.4.4 Resultados de Força de Atrito . . . . . . . . . . . . . 97

4.4.5 Discussões . . . . . . . . . . . . . . . 101

4.5 Avaliação dos Efeitos da Rigidez das Sapatas em Pista com Sonorizador . . . . . . . . . . . . . . . . . . . 102

4.5.1 Resultado de Acelerações Verticais . . . . . . . . . . . 102

4.5.2 Resultados de Acelerações Horizontais . . . . . . . . . 105

4.5.3 Resultado de Reações sobre a Parte Ativa . . . . . . . . . 108

4.5.4 Resultados de Força de Atrito . . . . . . . . . . . . 111

4.5 .5 Discussões . . . . . . . . . . . . . . . . . . 114 
Referências 


\section{Lista de Figuras}

1.1 Transformador monofásico tipo nuclear $(2 / 0) \ldots \ldots 20$

1.2 Transformador trifásico tipo nuclear $(3 / 0) \ldots \ldots 20$

1.3 Transformador monofásico tipo encouraçado $(1 / 2) \ldots \ldots 21$

1.4 O Step Lap: região de união das colunas com o jugo . . . . . . . . 22

1.5 O Step Lap em um núcleo real . . . . . . . . . . . . . . . 23

2.1 Representação simplificada do modelo de um transformador em

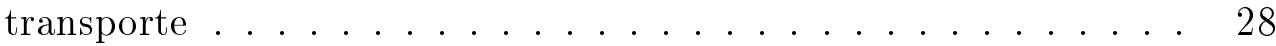

2.2 Ponto de Contato da Suspensão com a Pista . . . . . . . . . . . 31

2.3 Movimento relativo entre o fundo do tanque do transformador e uma sapata da parte ativa .................. 33

2.4 Elongamento dos blocos de madeira laminada . . . . . . . 35

2.5 Descrição do elongamento das fixações inferiores . . . . . . . . . 37

2.6 Descrição do elongamento das fixações superiores . . . . . . . . 38

2.7 Elongamento do elemento de rigidez do tanque . . . . . . . . . . 40

2.8 Região do Step Lap . . . . . . . . . . . . . . . . . . . . . . 45

2.9 Tensão de Atrito em um Corpo no Plano . . . . . . . . . . . . . 51

3.1 Processo de Determinação de Intersecção de Polígonos . . . . . . 54

4.1 Desaceleração do Veículo . . . . . . . . . . . . . . . . . . . 64

4.2 Acelerações Horizontais dos Corpos - Período de $10 \mathrm{~ms}$. . . . . 65

4.3 Acelerações Horizontais dos Corpos - Período de $15 \mathrm{~ms}$. . . . . 65

4.4 Acelerações Horizontais dos Corpos - Período de $20 \mathrm{~ms}$. . . . . 66

4.5 Acelerações Horizontais dos Corpos - Período de $30 \mathrm{~ms}$. . . . 66

4.6 Acelerações Horizontais dos Corpos - Período de $50 \mathrm{~ms}$. . . . . 67

4.7 Acelerações Horizontais dos Corpos - Período de $75 \mathrm{~ms}$. . . . . 67 
4.8 Acelerações Horizontais dos Corpos - Período de $100 \mathrm{~ms}$. . . . . 68

4.9 Acelerações Horizontais dos Corpos - Período de $200 \mathrm{~ms}$. . . . . 68

4.10 Acelerações Horizontais dos Corpos - Período de $250 \mathrm{~ms}$. . . . . 69

4.11 Reações (normalizadas) nas fixações superiores e inferiores da Parte Ativa e Atrito com o Fundo do tanque - Período de 10 ms . . . 70

4.12 Reações (normalizadas) nas fixações superiores e inferiores da Parte Ativa e Atrito com o Fundo do tanque - Período de $15 \mathrm{~ms}$. . . . 71

4.13 Reações (normalizadas) nas fixações superiores e inferiores da Parte Ativa e Atrito com o Fundo do tanque - Período de $20 \mathrm{~ms}$. . . . 71

4.14 Reações (normalizadas) nas fixações superiores e inferiores da Parte Ativa e Atrito com o Fundo do tanque - Período de $30 \mathrm{~ms}$. . . . 72

4.15 Reações (normalizadas) nas fixações superiores e inferiores da Parte Ativa e Atrito com o Fundo do tanque - Período de 50 ms . . . . 72

4.16 Reações (normalizadas) nas fixações superiores e inferiores da Parte Ativa e Atrito com o Fundo do tanque - Período de $75 \mathrm{~ms}$. . . . 73

4.17 Reações (normalizadas) nas fixações superiores e inferiores da Parte Ativa e Atrito com o Fundo do tanque - Período de 100 ms . . . .

4.18 Reações (normalizadas) nas fixações superiores e inferiores da Parte Ativa e Atrito com o Fundo do tanque - Período de 200 ms . . . .

4.19 Reações (normalizadas) nas fixações superiores e inferiores da Parte Ativa e Atrito com o Fundo do tanque - Período de $250 \mathrm{~ms}$. . . .

4.20 Acelerações Horizontais dos Corpos - Amplitude de 0.5g - Período de $200 \mathrm{~ms} \ldots \ldots \ldots \ldots \ldots \ldots \ldots$

4.21 Acelerações Horizontais dos Corpos - Amplitude de $1.0 \mathrm{~g}$ - Período de $100 \mathrm{~ms} \ldots \ldots \ldots \ldots \ldots \ldots \ldots \ldots$

4.22 Acelerações Horizontais dos Corpos - Amplitude de $2.0 g$ - Período

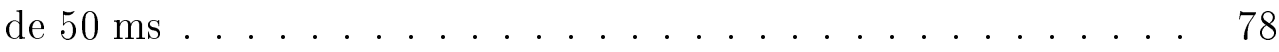

4.23 Acelerações Horizontais dos Corpos - Amplitude de $4.0 \mathrm{~g}$ - Período de $25 \mathrm{~ms} \ldots \ldots \ldots \ldots \ldots$

4.24 Reações (normalizadas) nas fixações superiores e inferiores da Parte Ativa e Atrito com o Fundo do tanque - Amplitude de $0.5 g$ - Período de $200 \mathrm{~ms} \ldots \ldots \ldots \ldots \ldots \ldots$ 
4.25 Reações (normalizadas) nas fixações superiores e inferiores da Parte Ativa e Atrito com o Fundo do tanque - Amplitude de 1.0g - Pe-

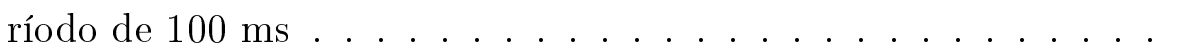

4.26 Reações (normalizadas) nas fixações superiores e inferiores da Parte Ativa e Atrito com o Fundo do tanque - Amplitude de $2.0 g$ - Período de $50 \mathrm{~ms} \ldots \ldots \ldots \ldots \ldots \ldots . \ldots \ldots$

4.27 Reações (normalizadas) nas fixações superiores e inferiores da Parte Ativa e Atrito com o Fundo do tanque - Amplitude de $4.0 g$ - Período de $25 \mathrm{~ms} \ldots \ldots \ldots \ldots \ldots \ldots \ldots \ldots$

4.28 Acelerações verticais do sistema para tráfego com diferentes velocidades em pista com irregularidades - Velocidade de $30 \mathrm{~km} / \mathrm{h}$. .

4.29 Acelerações verticais do sistema para tráfego com diferentes velocidades em pista com irregularidades - Velocidade de $40 \mathrm{~km} / \mathrm{h}$. .

4.30 Acelerações verticais do sistema para tráfego com diferentes velocidades em pista com irregularidades - Velocidade de $50 \mathrm{~km} / \mathrm{h}$. .

4.31 Acelerações verticais do sistema para tráfego com diferentes velocidades em pista com irregularidades - Velocidade de $60 \mathrm{~km} / \mathrm{h}$. .

4.32 Acelerações verticais do sistema para tráfego com diferentes velocidades em pista com irregularidades - Velocidade de $70 \mathrm{~km} / \mathrm{h}$. .

4.33 Acelerações verticais do sistema para tráfego com diferentes velocidades em pista com irregularidades - Velocidade de $80 \mathrm{~km} / \mathrm{h}$. .

4.34 Acelerações verticais do sistema para tráfego com diferentes velocidades em pista com irregularidades - Velocidade de $90 \mathrm{~km} / \mathrm{h}$. .

4.35 Acelerações horizontais do sistema para tráfego com diferentes velocidades em pista com irregularidades - Velocidade de $30 \mathrm{~km} / \mathrm{h}$.

4.36 Acelerações horizontais do sistema para tráfego com diferentes velocidades em pista com irregularidades - Velocidade de $40 \mathrm{~km} / \mathrm{h}$.

4.37 Acelerações horizontais do sistema para tráfego com diferentes velocidades em pista com irregularidades - Velocidade de $50 \mathrm{~km} / \mathrm{h}$.

4.38 Acelerações horizontais do sistema para tráfego com diferentes velocidades em pista com irregularidades - Velocidade de $60 \mathrm{~km} / \mathrm{h}$.

4.39 Acelerações horizontais do sistema para tráfego com diferentes velocidades em pista com irregularidades - Velocidade de $70 \mathrm{~km} / \mathrm{h}$. 
4.40 Acelerações horizontais do sistema para tráfego com diferentes velocidades em pista com irregularidades - Velocidade de $80 \mathrm{~km} / \mathrm{h}$. 92

4.41 Acelerações horizontais do sistema para tráfego com diferentes velocidades em pista com irregularidades - Velocidade de $90 \mathrm{~km} / \mathrm{h}$. 92

4.42 Reações em cada fixação inferior - Velocidade de $30 \mathrm{~km} / \mathrm{h}$. . . . 93

4.43 Reações em cada fixação inferior - Velocidade de $40 \mathrm{~km} / \mathrm{h}$. . . . 93

4.44 Reações em cada fixação inferior - Velocidade de $50 \mathrm{~km} / \mathrm{h}$. . . . 94

4.45 Reações em cada fixação inferior - Velocidade de $60 \mathrm{~km} / \mathrm{h}$. . . . 94

4.46 Reações em cada fixação inferior - Velocidade de $70 \mathrm{~km} / \mathrm{h}$. . . . 95

4.47 Reações em cada fixação inferior - Velocidade de $80 \mathrm{~km} / \mathrm{h}$. . . . 95

4.48 Reações em cada fixação inferior - Velocidade de $90 \mathrm{~km} / \mathrm{h}$. . . . 96

4.49 Força de atrito entre parte ativa e fundo - Velocidade de $30 \mathrm{~km} / \mathrm{h} \quad 97$

4.50 Força de atrito entre parte ativa e fundo - Velocidade de $40 \mathrm{~km} / \mathrm{h} \quad 97$

4.51 Força de atrito entre parte ativa e fundo - Velocidade de $50 \mathrm{~km} / \mathrm{h} \quad 98$

4.52 Força de atrito entre parte ativa e fundo - Velocidade de $60 \mathrm{~km} / \mathrm{h} \quad 98$

4.53 Força de atrito entre parte ativa e fundo - Velocidade de $70 \mathrm{~km} / \mathrm{h} \quad 99$

4.54 Força de atrito entre parte ativa e fundo - Velocidade de $80 \mathrm{~km} / \mathrm{h} \quad 99$

4.55 Força de atrito entre parte ativa e fundo - Velocidade de $90 \mathrm{~km} / \mathrm{h} \quad 100$

4.56 Acelerações verticais do sistema para tráfego em pista com irregularidades para diferentes valores de $k_{f}-33 \%$ da rigidez original da

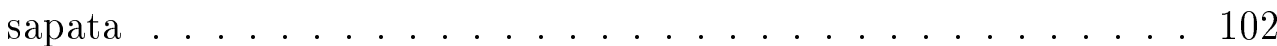

4.57 Acelerações verticais do sistema para tráfego em pista com irregularidades para diferentes valores de $k_{f}-66 \%$ da rigidez original da sapata ........................... 103

4.58 Acelerações verticais do sistema para tráfego em pista com irregularidades para diferentes valores de $k_{f}-133 \%$ da rigidez original

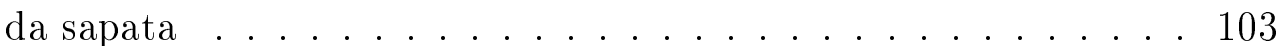

4.59 Acelerações verticais do sistema para tráfego em pista com irregularidades para diferentes valores de $k_{f}-166 \%$ da rigidez original da sapata ......................... 104 
4.60 Acelerações horizontais do sistema para tráfego em pista com irregularidades para diferentes valores de $k_{f}-33 \%$ da rigidez original da sapata ........................... 105

4.61 Acelerações horizontais do sistema para tráfego em pista com irregularidades para diferentes valores de $k_{f}-66 \%$ da rigidez original da sapata ........................... 106

4.62 Acelerações horizontais do sistema para tráfego em pista com irregularidades para diferentes valores de $k_{f}-133 \%$ da rigidez original da sapata . . . . . . . . . . . . . . . 106

4.63 Acelerações horizontais do sistema para tráfego em pista com irregularidades para diferentes valores de $k_{f}-166 \%$ da rigidez original da sapata . . . . . . . . . . . . . . . 107

4.64 Reações em cada fixação inferior - $33 \%$ da rigidez original da sapata108

4.65 Reações em cada fixação inferior - $66 \%$ da rigidez original da sapata109

4.66 Reações em cada fixação inferior - $133 \%$ da rigidez original da sapata109

4.67 Reações em cada fixação inferior - $166 \%$ da rigidez original da sapata110

4.68 Força de atrito entre parte ativa e fundo - 33\% da rigidez original da sapata . . . . . . . . . . . . . . . . 111

4.69 Força de atrito entre parte ativa e fundo - $66 \%$ da rigidez original da sapata . . . . . . . . . . . . . . . . . 112

4.70 Força de atrito entre parte ativa e fundo - $133 \%$ da rigidez original da sapata . . . . . . . . . . . . . . . . . 112

4.71 Força de atrito entre parte ativa e fundo - $166 \%$ da rigidez original da sapata . . . . . . . . . . . . . . . . 113 


\section{Lista de Símbolos}

$B_{J} \quad$ largura do maior pacote de chapas do jugo do núcleo ferromagnético

ESR distância entre centros da coluna de retorno para a coluna mais próxima

$H_{F} \quad$ distância vertical interna entre jugos do núcleo ferromagnético

$H_{b} \quad$ distância vertical do centro de gravidade da parte ativa às sapatas

$H_{t} \quad$ distância vertical do centro de gravidade da parte ativa até os blocos de madeira laminada

$J_{1} \quad$ momento de inércia de massa do corpo rígido 1 em relação ao eixo perpendicular ao plano analisado

$J_{2}$ momento de inércia de massa do corpo rígido 2 em relação ao eixo perpendicular ao plano analisado

$J_{3}$ momento de inércia de massa do corpo rígido 3 em relação ao eixo perpendicular ao plano analisado

$J_{4}$ momento de inércia de massa do corpo rígido 4 em relação ao eixo perpendicular ao plano analisado

$J_{5}$ momento de inércia de massa do corpo rígido 5 em relação ao eixo perpendicular ao plano analisado

$L_{f} \quad$ posição de cada sapata da parte ativa em relação ao centro de gravidade

$L_{v} \quad$ posição de cada eixo de suspensão do veículo em relação ao centro de gravidade

$L_{w} \quad$ posição de cada bloco de madeira laminada em relação ao centro de gravidade da parte ativa

$L_{a d b} \quad$ posição de cada dispositivo de fixação inferior em relação ao centro de gravidade da parte ativa

$L_{a d t}$ posição de cada dispositivo de fixação superior em relação ao centro de gravidade da parte ativa

$S_{S} \quad$ altura do empilhamento de chapas do núcleo ferromagnético

TKH altura nominal interna do tanque

TKL comprimento nominal interno do tanque

$T$ energia cinética do sistema mecânico 
$U_{f} \quad$ energia potencial elástica das sapatas da parte ativa

$U_{g} \quad$ energia potencial gravitacional do sistema mecânico

$U_{v} \quad$ energia potencial elástica do sistema de suspensão

$U_{w} \quad$ energia potencial elástica dos blocos de madeira laminada

$U_{a d b} \quad$ energia potencial elástica das fixações inferiores da parte ativa

$U_{a d t} \quad$ energia potencial elástica das fixações superiores da parte ativa

$U_{t k} \quad$ energia potencial elástica do tanque do transformador

$U \quad$ energia potencial do sistema mecânico

$\boldsymbol{\delta} \quad$ vetor de deflexões dos elementos de rigidez do sistema

$\lambda \quad$ vetor de multiplicadores de Lagrange associados a cada restrição do sistema mecânico

$\dot{\mathbf{q}} \quad$ vetor de velocidades generalizadas do sistema mecânico

f vetor de restrições ao movimento do sistema mecânico

q vetor de coordenadas generalizadas do sistema mecânico

$\mathcal{F}_{f} \quad$ função dissipação de Rayleigh das sapatas da parte ativa

$\mathcal{F}_{v} \quad$ função dissipação de Rayleigh do sistema de suspensão

$\mathcal{F}_{w} \quad$ função dissipação de Rayleigh dos calços de madeira laminada

$\mathcal{F}_{a d b}$ função dissipação de Rayleigh das fixações inferiores da parte ativa

$\mathcal{F}_{a d t}$ função dissipação de Rayleigh das fixações superiores da parte ativa

$\mathcal{F}_{t k} \quad$ função dissipação de Rayleigh do tanque do transformador

$\mathcal{F} \quad$ função dissipação de Rayleigh do sistema mecânico

$\mathcal{L} \quad$ função Lagrangiana Aumentada do sistema mecânico

$\mu_{\text {core }} \quad$ coeficiente de atrito existente no contato de cada chapa do núcleo ferromagnético

$\mu_{t k} \quad$ coeficiente de atrito existente entre o fundo do tanque e as sapatas da parte ativa

$\nabla^{q} \quad$ operador Nabla em relação ao vetor de coordenadas generalizadas

$\nabla^{\dot{q}} \quad$ operador Nabla em relação ao vetor de velocidades generalizadas

$\otimes \quad$ operador produto tensorial

$\theta_{1} \quad$ coordenada generalizada do ângulo de rotação do corpo rígido 1 em torno do eixo perpendicular ao plano analisado

$\theta_{2} \quad$ coordenada generalizada do ângulo de rotação do corpo rígido 2 em torno do eixo perpendicular ao plano analisado

$\theta_{3} \quad$ coordenada generalizada do ângulo de rotação do corpo rígido 3 em torno do eixo perpendicular ao plano analisado 


$$
\begin{aligned}
& \theta_{4} \quad \text { coordenada generalizada do ângulo de rotação do corpo rígido } 4 \\
& \text { em torno do eixo perpendicular ao plano analisado } \\
& \theta_{5} \quad \text { coordenada generalizada do ângulo de rotação do corpo rígido } 5 \\
& \text { em torno do eixo perpendicular ao plano analisado } \\
& c_{f} \quad \text { amortecimento de cada sapata da parte ativa } \\
& c_{v} \quad \text { amortecimento de cada elemento de suspensão do veículo } \\
& c_{w} \quad \text { amortecimento de cada bloco de madeira laminada } \\
& c_{a d b} \quad \text { amortecimento de cada dispositivo de fixação inferior } \\
& c_{a d t} \quad \text { amortecimento de cada dispositivo de fixação superior } \\
& c_{t k} \quad \text { amortecimento do tanque do transformador } \\
& k_{f} \quad \text { rigidez de cada sapata da parte ativa } \\
& k_{v} \quad \text { rigidez de cada elemento de suspensão do veículo } \\
& k_{w} \quad \text { rigidez de cada bloco de madeira laminada } \\
& k_{a d b} \quad \text { rigidez de cada dispositivo de fixação inferior } \\
& k_{a d t} \quad \text { rigidez de cada dispositivo de fixação superior } \\
& k_{t k} \quad \text { rigidez do tanque do transformador } \\
& m_{1} \quad \text { massa do corpo rígido } 1 \\
& m_{2} \quad \text { massa do corpo rígido } 2 \\
& m_{3} \quad \text { massa do corpo rígido } 3 \\
& m_{4} \quad \text { massa do corpo rígido } 4 \\
& m_{5} \quad \text { massa do corpo rígido } 5 \\
& m_{\text {tank }} \quad \text { massa do tanque do transformador } \\
& m_{\text {veiculo }} \text { massa do veículo } \\
& n_{v} \quad \text { quantidade de eixos de suspensão do veículo } \\
& p_{\text {design }} \quad \text { pressão de compactação aplicada às chapas do núcleo } \\
& x_{1} \quad \text { coordenada generalizada da posição horizontal do corpo rígido } 1 \\
& x_{2} \quad \text { coordenada generalizada da posição horizontal do corpo rígido } 2 \\
& x_{3} \quad \text { coordenada generalizada da posição horizontal do corpo rígido } 3 \\
& x_{4} \quad \text { coordenada generalizada da posição horizontal do corpo rígido } 4 \\
& x_{5} \quad \text { coordenada generalizada da posição horizontal do corpo rígido } 5 \\
& y_{1} \quad \text { coordenada generalizada da posição vertical do corpo rígido } 1 \\
& y_{2} \quad \text { coordenada generalizada da posição vertical do corpo rígido } 2 \\
& y_{3} \quad \text { coordenada generalizada da posição vertical do corpo rígido } 3 \\
& y_{4} \quad \text { coordenada generalizada da posição vertical do corpo rígido } 4 \\
& y_{5} \quad \text { coordenada generalizada da posição vertical do corpo rígido } 5
\end{aligned}
$$




\section{Introdução}

\section{$1.1 \quad$ O Transformador Elétrico}

Transformadores são dispositivos que transferem energia elétrica de um circuito a outro por meio de um campo magnético comum. Em todos os casos, excetuando-se autotransformadores, não há conexão elétrica direta entre os circuitos.

Quando uma corrente alternada flui por um condutor, um campo magnético surge ao redor do mesmo. Se um outro condutor é colocado dentro do campo magnético gerado pelo primeiro condutor, tal que as linhas de fluxo cruzem o segundo condutor, é induzida, então, uma tensão elétrica neste último. O uso do campo magnético de um enrolamento para induzir tensão em um segundo enrolamento é o princípio no qual a teoria e a aplicação de transformadores são baseadas (1).

\subsubsection{Construção}

A construção de transformadores de potência (classificação de transformadores com potência nominal acima de $500 \mathrm{kVA}$ ) varia de acordo com os fabricantes. Os arranjos básicos são essencialmente os mesmos e diferenças pouco significativas têm sido vistas nos últimos anos.

O elemento ativo (ou parte ativa) do transformador consiste basicamente do núcleo ferromagnético e dos enrolamentos.

O núcleo, que provê o circuito por onde passa o fluxo magnético, consiste de um empilhamento de chapas de aço-silício com grãos orientados, de espessuras entre $0.23 \mathrm{~mm}$ e $0.36 \mathrm{~mm}$, separadas eletricamente entre si por um revestimento de material isolante.

Há dois tipos básicos de construção do núcleo em transformadores de potência: tipo nuclear (core type) e tipo encouraçado (shell type). 
Em construções do tipo nuclear, há somente um caminho para o circuito magnético e os enrolamentos envolvem o núcleo. A figura 1.1 mostra um desenho esquemático de um núcleo de transformador monofásico tipo nuclear. Em aplicações monofásicas, os enrolamentos são normalmente colocados em ambas as pernas, como mostrado. Em aplicações trifásicas, os enrolamentos de uma determinada fase são tipicamente colocados na mesma perna, como ilustrado na figura 1.2.
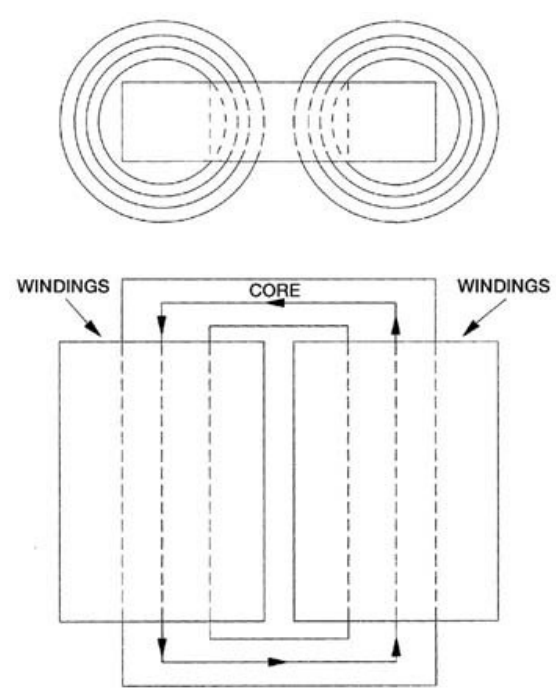

Figura 1.1: Transformador monofásico tipo nuclear $(2 / 0)$
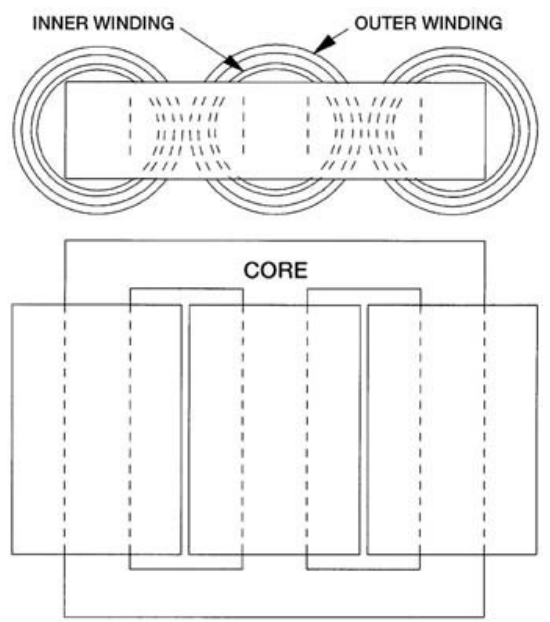

Figura 1.2: Transformador trifásico tipo nuclear $(3 / 0)$

Em construções do tipo encouraçado, o núcleo provê múltiplos caminhos para o circuito magnético. A figura 1.3 mostra o esquema de um transformador monofásico tipo encouraçado. Nesse tipo de construção ocorre o envolvimento dos enrolamentos pelo núcleo. Devido a vantagens no desempenho durante curtoscircuitos e efeitos transitórios de tensão, construções tipo encouraçado tendem a 
ser mais frequentes em transformadores de maior porte, em que essas condições possam ser mais severas.
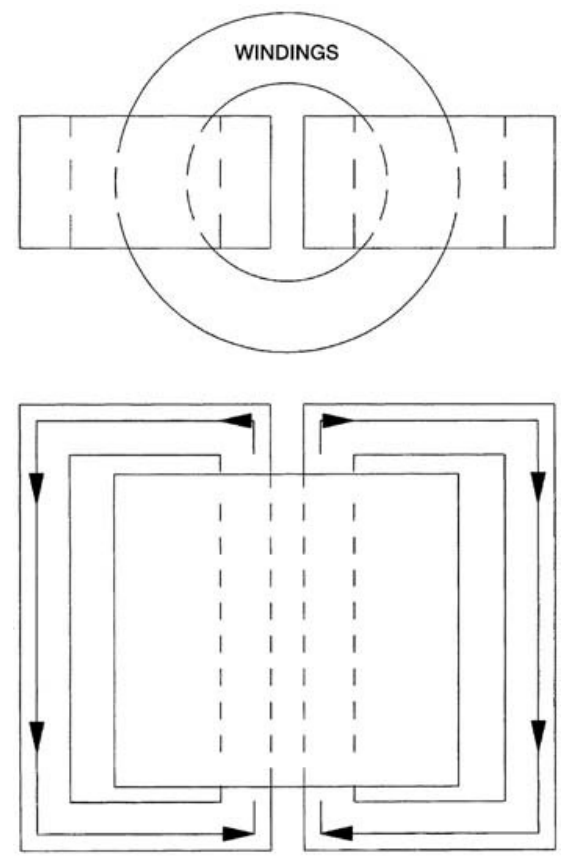

Figura 1.3: Transformador monofásico tipo encouraçado $(1 / 2)$

As formas usuais de núcleo para construções tipo nuclear são:

- Monofásico: possuem duas pernas em que são instalados os enrolamentos, também chamadas pernas principais. São chamados de maneira abreviada como 2/0 (por possuírem tão somente duas pernas principais);

- Trifásico: possuem tão somente três pernas principais $(3 / 0)$.

As formas usuais de núcleo para construções tipo encouraçado são:

- Monofásico:

- Com todos os enrolamentos montados em apenas uma perna e com duas pernas adicionais para o circuito magnético (também chamadas pernas de retorno). São chamadas de maneira abreviada como 1/2 (por possuírem uma perna principal e duas pernas de retorno);

- Com os enrolamentos montados em duas pernas principais e mais duas pernas de retorno $(2 / 2)$

- Trifásico: possuem três pernas principais e duas pernas de retorno (3/2). 
Já os enrolamentos consistem de condutores elétricos enrolados ao longo das pernas do núcleo, apropriadamente isolados, suportados e resfriados para suportar condições operacionais e de teste.

Cobre e alumínio são os principais materiais utilizados como condutores em enrolamentos de transformadores de potência. Enquanto o alumínio é menos denso e, em geral, mais barato que o cobre, é necessária uma seção transversal dos condutores de alumínio maior que a dos de cobre para conduzir correntes elétricas de intensidade similar.

\subsubsection{Região de Estudo}

A complexidade de modelagem do núcleo ferromagnético de um transformador de potência reside na sua construção, em que é necessário o empilhamento de chapas de aço-silício com espessura de $0.3 \mathrm{~mm}$ para núcleos que podem vir a ter de $900 \mathrm{~mm}$ a $1000 \mathrm{~mm}$ de altura empilhada.

Quando se trata de transformadores com núcleo tipo encouraçado, a ligação mecânica principal da coluna de retorno ao jugo será feita pelo empilhamento cruzado das chapas dessas duas partes, na região chamada junção. Existem diversas maneiras de se construir a junção das partes do núcleo. Transformadores de potência têm feito uso principalmente do tipo de junção chamado Step Lap, que pode ser visto na figura 1.4 e na Figura 1.5.

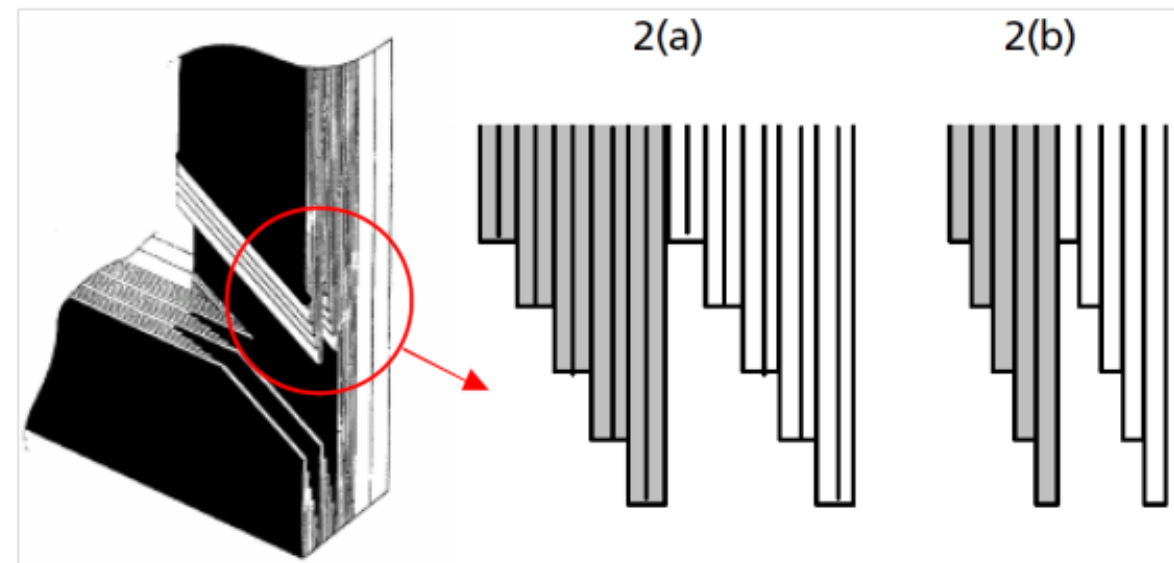

Figura 1.4: O Step Lap: região de união das colunas com o jugo

O projeto mecânico do núcleo faz a especificação de uma pressão a ser aplicada sobre as chapas, seja ela feita via bandagens de fibra de vidro, tirantes ou sistema de ferragens com funções puramente mecânicas.

A região do Step Lap, por ser uma região de junção entre trechos distintos do núcleo, não possui fácil acesso para a colocação de bandagens de fibra de vidro ou 


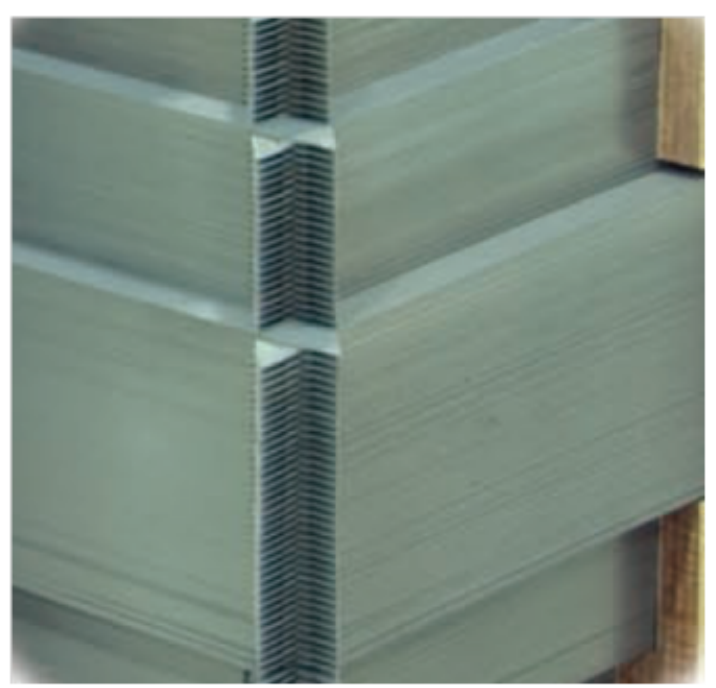

Figura 1.5: O Step Lap em um núcleo real

para que seja atravessada por algum tirante. Dessa forma, a prensagem aplicada a esta região é feita pelo sistema de ferragens.

A região do Step Lap possui funções tanto elétricas quanto mecânicas. Eletricamente, esta região faz a ligação de trechos por onde o fluxo magnético deverá passar no funcionamento do equipamento. Não havendo uma boa conexão nessa região, relutâncias magnéticas serão adicionadas ao núcleo, podendo assim fazer com que haja um desbalanceamento dos fluxos que percorrem cada uma das pernas do núcleo. Este desbalanceamento poderá vir a ser tal que, onde o fluxo se concentrar mais, possa haver uma saturação da magnetização do material, aumentando consideravelmente as perdas por histerese magnética do núcleo. Isto, por sua vez, fará com que o fluxo, que deveria passar por um ramo do circuito magnético que esteja saturado, seja disperso do núcleo para outras partes do equipamento que, por indução de correntes, venham a apresentar perdas adicionais e aquecimentos localizados, que são determinantes para a degradação de materiais isolantes próximos.

Por outro lado, mecanicamente, o Step Lap possui a função de unir fisicamente as colunas aos jugos do núcleo. A união mecânica entre as duas partes é suportada, num primeiro momento, pelo atrito existente entre as chapas dessas partes. Se este atrito não for suficiente para resistir aos carregamentos impostos à estrutura, sejam eles o peso próprio da coluna ou as acelerações provenientes do meio de transporte, por exemplo, poderá ocorrer a movimentação de trechos do núcleo, implicando na possibilidade das falhas elétricas aqui já apresentadas. 


\subsection{Objetivos}

Avaliar a influência que carregamentos dinâmicos diversos, decorrentes do transporte do transformador à planta em que será instalado, exercem sobre a estrutura da parte ativa do equipamento, com especial enfoque à estrutura do núcleo ferromagnético do mesmo.

Esta avaliação será feita tendo duas abordagens. Primeiramente, a modelagem do equipamento embarcado no veículo de transporte, fazendo uso de técnicas da mecânica analítica para a representação com certa complexidade das partes que são objeto do estudo. Em um segundo momento, o problema será abordado pela variação de parâmetros construtivos, verificando sua influência sobre o sistema mecânico.

\subsection{Revisão Bibliográfica}

A avaliação da integridade estrutural da parte ativa de um transformador vem recebendo especial atenção da indústria. Devido ao tamanho do equipamento e pela complexidade de seus detalhes construtivos, inspeções visuais das partes internas do mesmo podem não detectar o surgimento de falhas. Para melhor desempenhar esta atividade, diversas técnicas têm sido empregadas nessa avaliação.

Em (2), são apresentadas diversas técnicas para a identificação da condição de um transformador. São destacadas técnicas para avaliação do equipamento em funcionamento e fora de funcionamento. As técnicas para avaliação do equipamento em funcionamento têm o objeto de identificar falhas nas isolações elétricas, seja por gases dissolvidos ou por identificação e localização de descargas parciais. Técnicas de avaliação do equipamento fora de funcionamento são empregadas quando há riscos na reenergização do transformador, por exemplo, após um evento de transporte. Movimentações internas e perdas de isolação elétrica são os principais parâmetros a serem identificado com essas análises.

Em (3), é descrito um dos métodos de inspeção do estado do transformador sem a necessidade de abertura do equipamento, o SFRA (de Sweep Frequency Response Analysis - Análise de Resposta em Varredura de Frequência em tradução livre). Neste artigo é destacado o emprego especial desta técnica na detecção de movimentação e deformação dos enrolamentos, que, por meio da alteração geométrica dos mesmos, leva a uma alteração dos efeitos capacitivos do equipa- 
mento.

Em (4), é descrito o emprego desta mesma técnica na detecção de falhas do núcleo ferromagnético do transformador. É citada a dificuldade do uso desta técnica na detecção de falhas específicas do equipamento, uma vez que a resposta em frequência oferece um panorama do estado do transformador como um todo. Metodologias para a identificação específica de uma falha do núcleo são apresentadas.

Em (5), é descrita a aplicação de técnicas para a identificação de maneira automática das possíveis causas de falha a partir do diagnostico do SFRA.

Uma vez que o SFRA é uma metologia comparativa, uma assinatura inicial da condição do transformador é necessária para a avaliação de qualquer dano posterior. Em (6), é apresentada a modelagem do transformador em termos de resistências, indutâncias e capacitâncias tendo em vista a predição dos resultados do SFRA.

Em (7), são apresentados os resultados das primeiras aplicações do SFRA em transformadores de potência na indústria. São apresentadas as vantagens desse teste sobre o de Impulso de Baixa Tensão (LVI, do original Low Voltage Impulse), que é um método de detecção de movimentação relativa de enrolamentos em que se aplica um pulso de tensão de baixa amplitude (300 V) e duração em um dos enrolamentos e observa-se a corrente capacitiva acoplada em outro.

Em (8), são fornecidas indicações para a instalação de registradores de impacto para monitorar o período de transporte do equipamento. São feitas indicações sobre a partir de que classes de potências os transformadores deverão ter registradores instalados. São apresentadas também características sobre os meios de transporte possíveis de serem utilizados, despendendo uma atenção maior ao transporte ferroviário, citando, inclusive, a norma da Association of American Railroads (AAR), acerca dos métodos para amarração dos equipamentos ao vagão. São citados também procedimentos para inspeção interna e externa do transformador quando da chegada do mesmo ao destino.

Em (9), é apresentado um modelo computacional que avalia as propriedades magnéticas equivalentes dos pontos de junção dos núcleos ferromagnéticos, com enfoque especial às junções do tipo Step Lap. Nele é feito o levantamento do caminho feito pelo fluxo magnético através das chapas e dos espaços vazios na junção.

Em (10) e (11), são apresentadas análises numéricas e experimentais das 
junções tipo Step Lap, observando efeitos como saturação e correntes de Foucault em função da separação das chapas do núcleo. São mostrados resultados de simulação ilustrando as linhas de fluxo nas chapas da junção. 


\section{Modelagem Analítica}

\subsection{Detalhamento do Estudo}

A aparente incongruência observada distintamente em dois tipos de eventos durante o transporte de transformadores, sejam eles a ausência de dano mesmo quando há registros pontuais elevados de aceleração (obtidos por registradores de impacto instalados no equipamento) ou a verificação de danos quando, apesar de registradas baixas, porém frequentes, amplitudes de aceleração, ocorre movimentações internas em enrolamentos e núcleo, motivou a execução tanto do presente estudo, como de outros, anteriores ao mesmo.

Modelos de transformadores específicos, estudados via Método dos Elementos Finitos e Dinâmica de Sistemas Multicorpos, foram desenvolvidos em pesquisas internas da empresa Siemens Ltda. Os resultados de tais estudos forneceram base para as considerações apresentadas na presente investigação.

Para este estudo, a modelagem do sistema mecânico foi restrita ao caso bidimensional nas direções longitudinal e vertical de transporte. O modelo se propõe a resolver as equações de movimento de cinco corpos rígidos, cada um com três graus de liberdade (duas translações e uma rotação).

Os corpos rígidos utilizados nas simulações descrevem, de acordo com a figura 2.1:

- Corpo 1: o conjunto dos componentes da parte ativa (núcleo e enrolamentos), excluindo as colunas de retorno;

- Corpos 2 e 3: as duas colunas de retorno do equipamento;

- Corpo 4: a parte superior do tanque do transformador;

- Corpo 5: a parte inferior do tanque do transformador e o veículo de transporte. 


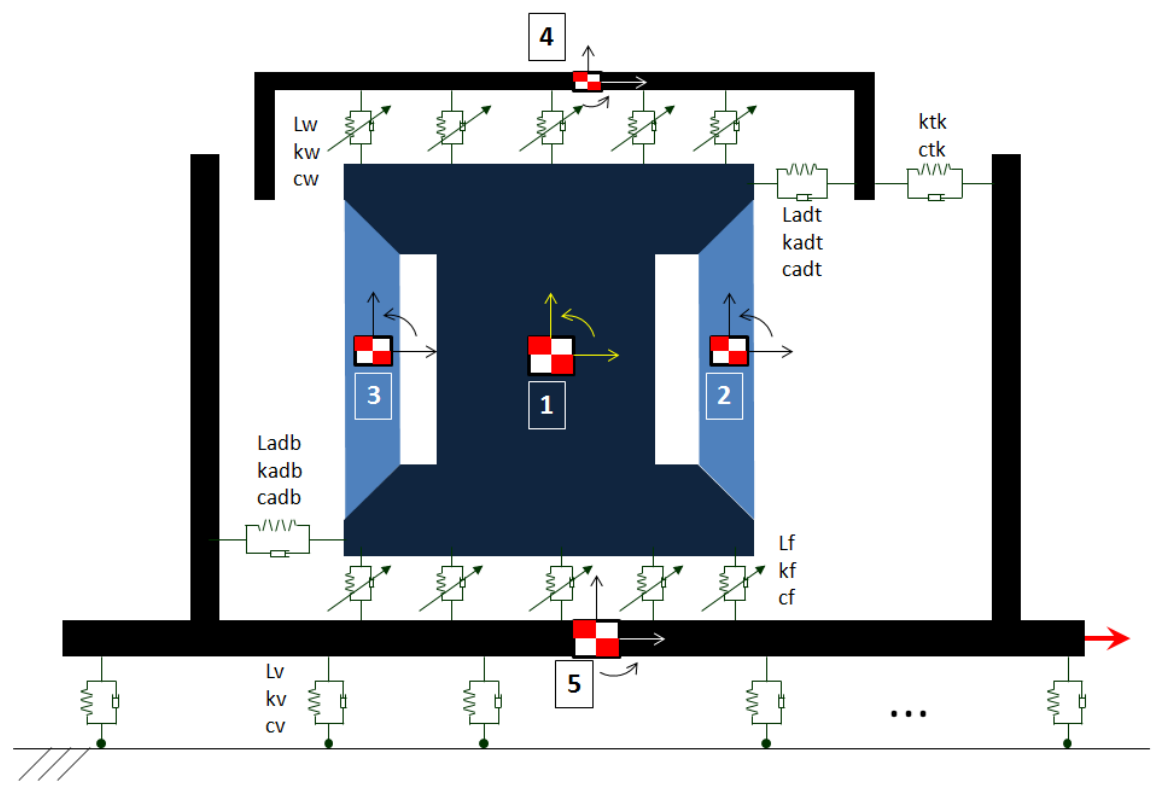

Figura 2.1: Representação simplificada do modelo de um transformador em transporte

O conjunto do tanque e do veículo de transporte foi modelado de modo a representar a flexibilidade de movimentação do tanque, sendo ele dividido em duas partes conectadas por um elemento de rigidez.

Os conjuntos de suspensão do veículo são modelados por molas e amortecedores distribuídos ao longo de seu comprimento. Dessa forma, existe a possibilidade de introdução de carregamentos pela geometria da pista.

A fixação da parte ativa no tanque na direção longitudinal é feita por elementos elásticos ( $k_{a d t}$ e $k_{a d b}$, conforme figura 2.1), em quantidade correspondente ao repasse total de carregamentos às mesmas na região superior e inferior da parte ativa.

Conforme já comentado, a união das colunas de retorno aos jugos da parte ativa é feita, principalmente, pelo atrito presente no empilhamento de chapas do Step Lap.

Na direção vertical, há conexões entre a parte ativa e o tanque, feitas por meio das sapatas sobre as quais ela se apoia sobre o fundo do tanque e que, consequentemente, representa um vínculo de contato com rigidez entre os mesmos. Para a representação do contato, foi utilizado um modelo de rigidez atuante apenas quando em compressão. Similarmente, os calços da parte ativa sobre os quais a tampa do transformador se apoia.

A representação do sistema mecânico, conforme descrita previamente, seria dada pelo uso de 15 graus de liberdade no total. Entretanto, alguns movimentos 
possibilitados por esse modelo não devem ser permitidos na resolução de suas equações no tempo.

Entre as restrições de movimento do sistema estão:

- As partes superior e inferior do tanque deverão descrever a mesma rotação;

- As partes superior e inferior do tanque não deverão possuir movimento vertical relativo;

- O movimento de translação da parte ativa em relação à parte inferior do tanque na direção horizontal é restrita pelo atrito seco entre as sapatas da parte ativa e o fundo;

- Os movimentos de translação das colunas de retorno em relação à parte ativa são restritos pelo atrito seco existente no Step Lap;

- O veículo possui sua velocidade prescrita.

\subsection{Formalismo Lagrangiano do Problema}

Na seção 2.1 foi dada uma visão geral do modelo de cálculo de transformadores durante o transporte. Desta forma, com o modelo descrito, para a obtenção das equações de movimento do sistema mecânico foram empregados os princípios da Mecânica Analítica de acordo com a abordagem Lagrangiana.

Para esta abordagem, é necessária a descrição das energias cinética e potencial do sistema mecânico, para que, a partir delas, sejam escritas as equações de movimento dos corpos que o constituem.

\subsubsection{Energia Cinética}

A figura 2.1 mostra os cinco corpos que pertencem ao sistema mecânico. Desconsiderando quaisquer vínculos de movimento existente entre eles, a equação da energia cinética do sistema é dada por:

$$
T=\sum_{i=1}^{5} \frac{m_{i}\left(\dot{x}_{i}^{2}+\dot{y}_{i}^{2}\right)}{2}+\frac{J_{i} \dot{\theta}_{i}^{2}}{2}
$$

em que:

- $m_{i}$ são as massas dos corpos; 
- $J_{i}$ são os momentos de inércia dos corpos em relação ao eixo perpendicular ao plano de movimento (eixo $z$ ) calculados nos seus baricentros;

- $\dot{x}_{i}$ são as velocidades dos corpos na direção horizontal;

- $\dot{y}_{i}$ são as velocidades dos corpos na direção vertical;

- $\dot{\theta}_{i}$ são as velocidades angulares dos corpos em relação ao eixo $z$.

\subsubsection{Energia Potencial}

A energia potencial do sistema apresentado na figura 2.1 é tanto de origem gravitacional quanto elástica.

Dentre os elementos do sistema de que podem armazenar energia potencial elástica, destacam-se:

- Os elementos do conjunto de suspensão do veículo;

- Os apoios das sapatas (feet) da parte ativa no fundo do tanque;

- Os dispositivos de fixação (arresting devices) da parte ativa do transformador ao seu tanque, tanto na parte superior quanto inferior;

- Os blocos de madeira laminada (wooden blocks) entre a parte superior da parte ativa e a tampa do tanque;

- A flexibilidade própria do tanque, neste modelo representada pelo elemento de rigidez que conecta suas partes inferior e superior.

\subsubsection{Energia Potencial Gravitacional}

A energia potencial gravitacional do sistema é escrita como:

$$
U_{g}=\sum_{i=1}^{5} m_{i} g y_{i}
$$

\subsubsection{Energia Potencial da Suspensão Veicular}

O perfil de pista é independente do tempo, porém o ponto de contato de um elemento de suspensão com a pista pode ser descrito como função das coordenadas do veículo $\left(x_{5}, y_{5}\right.$ e $\left.\theta_{5}\right)$ e da posição relativa do elemento de suspensão no veículo $\left(L_{v_{i}}\right)$, conforme pode ser visto na figura 2.2. 


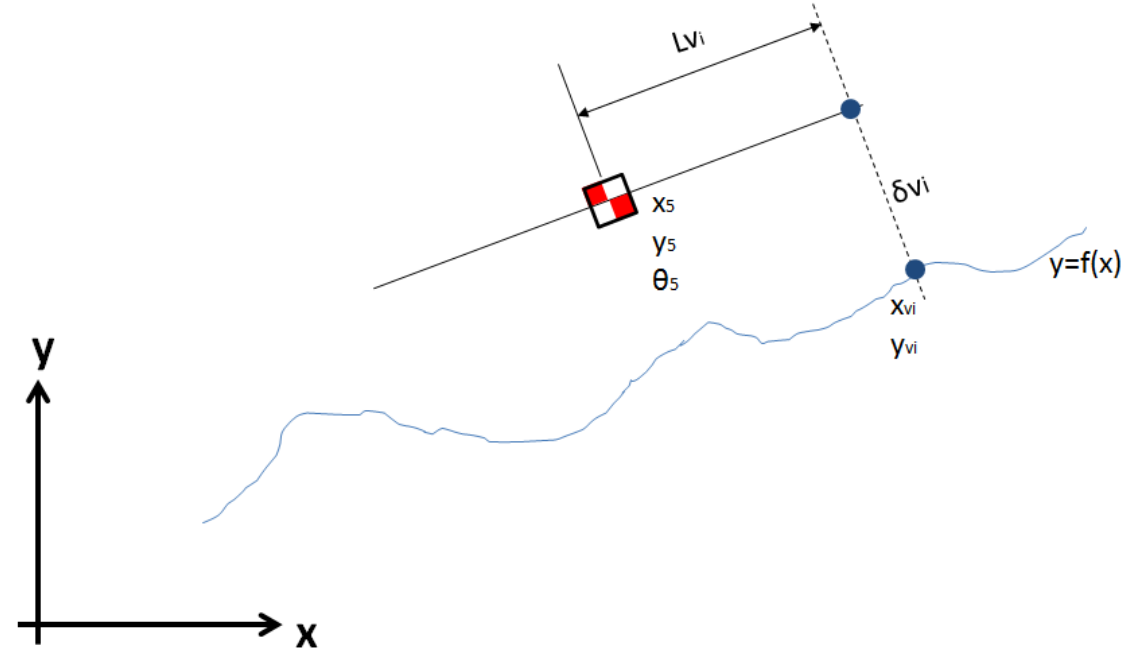

Figura 2.2: Ponto de Contato da Suspensão com a Pista

A equação da reta tracejada da figura 2.2 é dada por:

$$
\cos \theta_{5}\left(x-x_{5}-L_{v_{i}} \cos \theta_{5}\right)+\sin \theta_{5}\left(y-y_{5}-L_{v_{i}} \sin \theta_{5}\right)=0
$$

sendo que a mesma representa a orientação do elemento de suspensão daquela posição do veículo.

Portanto a solução do sistema de equações mostrado em 2.4 resulta no ponto de contato entre do elemento de suspensão com o solo.

$$
\left\{\begin{array}{l}
\cos \theta_{5}\left(x-x_{5}-L_{v_{i}} \cos \theta_{5}\right)+\sin \theta_{5}\left(y-y_{5}-L_{v_{i}} \sin \theta_{5}\right)=0 \\
y=f(x)
\end{array}\right.
$$

Admitindo o perfil da pista como arbitrário, o sistema de equações 2.4 é, via de regra, não linear. Sua solução é obtida pelo método de Newton-Raphson.

Consequentemente, este ponto de contato varia no tempo e é função dos graus de liberdade do veículo e da posição relativa do elemento de suspensão.

$$
\left\{\begin{array}{l}
x_{v_{i}} \\
y_{v_{i}}
\end{array}\right\}=\mathbf{x}_{\mathbf{v}_{\mathbf{i}}}\left(x_{5}, y_{5}, \theta_{5}, L_{v_{i}}\right)
$$

O elongamento do elemento de rigidez da suspensão do veículo é dado por:

$$
\delta_{v_{i}}=\sin \theta_{5}\left(x_{v_{i}}-x_{5}-L_{v_{i}} \cos \theta_{5}\right)-\cos \theta_{5}\left(y_{v_{i}}-y_{5}-L_{v_{i}} \sin \theta_{5}\right)
$$


A energia potencial elástica da suspensão veicular é função da distensão de cada um dos elementos da mesma.

$$
U_{v}=\sum_{i=1}^{n_{v}} \frac{k_{v_{i}} \delta_{v_{i}}^{2}}{2}
$$

sendo:

- $n_{v}$ a quantidade de elementos de suspensão no veículo;

- $k_{v_{i}}$ a rigidez do elemento de suspensão.

A descrição da energia cinética do conjunto de suspensão conforme a equação 2.7 carrega uma hipótese, que é a de que não haverá descolamento da suspensão do solo, ou seja, as forças nas suspensões são sempre compressivas.

\subsubsection{Energia Potencial da Sapatas da Parte Ativa}

Diferentemente da hipótese adotada na seção 2.2.2.2 para a suspensão do veículo, a modelagem das sapatas da parte ativa do transformador tem considerada em sua formulação a possibilidade de que haja separação entre elas e o fundo do tanque.

Esta consideração está diretamente presente na formulação da energia potencial da sapata, ao admitir-se que somente valores compressivos de deslocamento relativo das partes contribui para a variação da energia potencial.

Tal consideração é feita com a inclusão da Distribuição de Heaviside (também conhecida como degrau unitário).

A figura 2.3 mostra a descrição cinemática do movimento descrito pela sapata da parte ativa e seu ponto de contato com o fundo do transformador, sendo a distância relativa entre estes o valor associado à energia potencial da sapata da parte ativa.

O ponto de contato entre o fundo do tanque do transformador e a sapata da parte ativa é dado pela resolução em $x$ e $y$ do seguinte sistema linear:

$$
\left\{\begin{array}{c}
\cos \theta_{1}\left(x_{c_{f i}}-\left(x_{1}+H_{b} \sin \theta_{1}+L_{f_{i}} \cos \theta_{1}\right)\right)+ \\
+\sin \theta_{1}\left(y_{c_{f i}}-\left(H_{b}+y_{1}-H_{b} \cos \theta_{1}+L_{f_{i}} \sin \theta_{1}\right)\right)=0 \\
\sin \theta_{5}\left(x_{c_{f i}}-x_{5}\right)-\cos \theta_{5}\left(y_{c_{f i}}-y_{5}\right)=0
\end{array}\right.
$$




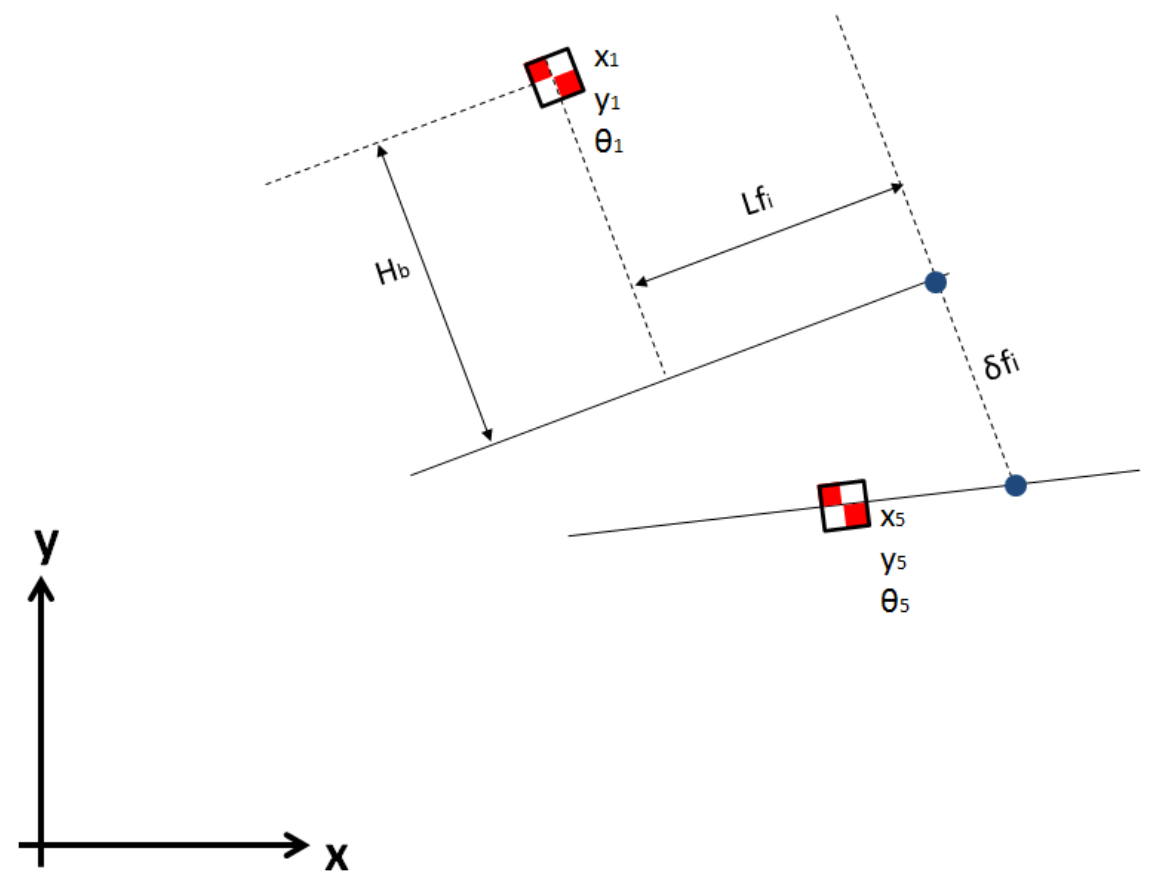

Figura 2.3: Movimento relativo entre o fundo do tanque do transformador e uma sapata da parte ativa

em que $H_{b}$ é a distância vertical do centro de gravidade da parte ativa às sapatas. resultando em:

$$
\begin{aligned}
\left\{\begin{array}{c}
x_{c_{f i}} \\
y_{c_{f i}}
\end{array}\right\}= & \sec \left(\theta_{1}-\theta_{5}\right)\left(\left(L_{f_{i}}+H_{b} \sin \theta_{1}+x_{1} \cos \theta_{1}+y_{1} \sin \theta_{1}\right)\left\{\begin{array}{c}
\cos \theta_{5} \\
\sin \theta_{5}
\end{array}\right\}+\right. \\
& \left.+\left\{\begin{array}{c}
\sin \theta_{1} \\
-\cos \theta_{1}
\end{array}\right\}\left\{\begin{array}{ll}
\sin \theta_{5}-\cos \theta_{5}
\end{array}\right\}\left\{\begin{array}{l}
x_{5} \\
y_{5}
\end{array}\right\}\right)
\end{aligned}
$$

A distância do ponto de contato com o fundo obtido na equação 2.9 e a posição da respectiva sapata, dada por:

$$
\left\{\begin{array}{c}
x_{p_{f i}} \\
y_{p_{f i}}
\end{array}\right\}=\left\{\begin{array}{c}
x_{1} \\
y_{1}+H_{b}
\end{array}\right\}+\left[\begin{array}{cc}
\cos \theta_{1} & -\sin \theta_{1} \\
\sin \theta_{1} & \cos \theta_{1}
\end{array}\right]\left\{\begin{array}{c}
L_{f_{i}} \\
-H_{b}
\end{array}\right\}
$$

é calculada pela projeção do vetor da diferença dos pontos no vetor perpendicular à sapata: 


$$
\begin{aligned}
\delta_{f_{i}}= & \left\{\sin \theta_{1}-\cos \theta_{1}\right\}\left(\left\{\begin{array}{c}
x_{c_{f i}} \\
y_{c_{f i}}
\end{array}\right\}-\left\{\begin{array}{c}
x_{p_{f i}} \\
y_{p_{f i}}
\end{array}\right\}\right) \\
= & \sec \left(\theta_{1}-\theta_{5}\right)\left[H_{b}\left(\cos \theta_{5}-\cos \left(\theta_{1}-\theta_{5}\right)\right)+L_{f_{i}} \sin \left(\theta_{1}-\theta_{5}\right)+\right. \\
& \left.-\left(x_{1}-x_{5}\right) \sin \theta_{5}+\left(y_{1}-y_{5}\right) \cos \theta_{5}\right]
\end{aligned}
$$

Este valor é, então, utilizado na formulação da energia potencial deste elemento do sistema, dada por:

$$
\begin{aligned}
U_{f}= & \sum_{i=1}^{n_{f}} \frac{k_{f_{i}} \delta_{f_{i}}^{2}}{2} \mathrm{H}\left(-\delta_{f_{i}}\right) \\
= & \sum_{i=1}^{n_{f}} \frac{k_{f_{i}} \sec ^{2}\left(\theta_{1}-\theta_{5}\right)}{2}\left[H_{b}\left(\cos \theta_{5}-\cos \left(\theta_{1}-\theta_{5}\right)\right)+\right. \\
& +L_{f_{i}} \sin \left(\theta_{1}-\theta_{5}\right)-\left(x_{1}-x_{5}\right) \sin \theta_{5}+ \\
& \left.+\left(y_{1}-y_{5}\right) \cos \theta_{5}\right]^{2} \mathrm{H}\left[-H_{b}\left(\cos \theta_{5}-\cos \left(\theta_{1}-\theta_{5}\right)\right)+\right. \\
& \left.-L_{f_{i}} \sin \left(\theta_{1}-\theta_{5}\right)+\left(x_{1}-x_{5}\right) \sin \theta_{5}-\left(y_{1}-y_{5}\right) \cos \theta_{5}\right]
\end{aligned}
$$

em que $\mathrm{H}($.$) é a distribuição de Heaviside.$

\subsubsection{Energia Potencial dos Blocos de Madeira Laminada}

Semelhante à formulação da energia potencial das sapatas da parte ativa, os blocos de madeira laminada não estão permanentemente em contato com a tampa do transformador. A formulação da energia potencial destes elementos deve levar em consideração a possibilidade da perda de contato, o que é feito de maneira idêntica à descrita na seção 2.2.2.3 ao se utilizar a distribuição de Heaviside.

A posição de um elemento é dada por:

$$
\left\{\begin{array}{c}
x_{p_{w i}} \\
y_{p_{w i}}
\end{array}\right\}=\left\{\begin{array}{c}
x_{1} \\
y_{1}+H_{b}
\end{array}\right\}+\left[\begin{array}{cc}
\cos \theta_{1} & -\sin \theta_{1} \\
\sin \theta_{1} & \cos \theta_{1}
\end{array}\right]\left\{\begin{array}{c}
L_{w_{i}} \\
H_{t}
\end{array}\right\}
$$

em que $H_{t}$ é a distância vertical do centro de gravidade da parte ativa até os blocos de madeira laminada.

O ponto de contato entre o bloco e a tampa é obtido pela resolução do sistema linear: 


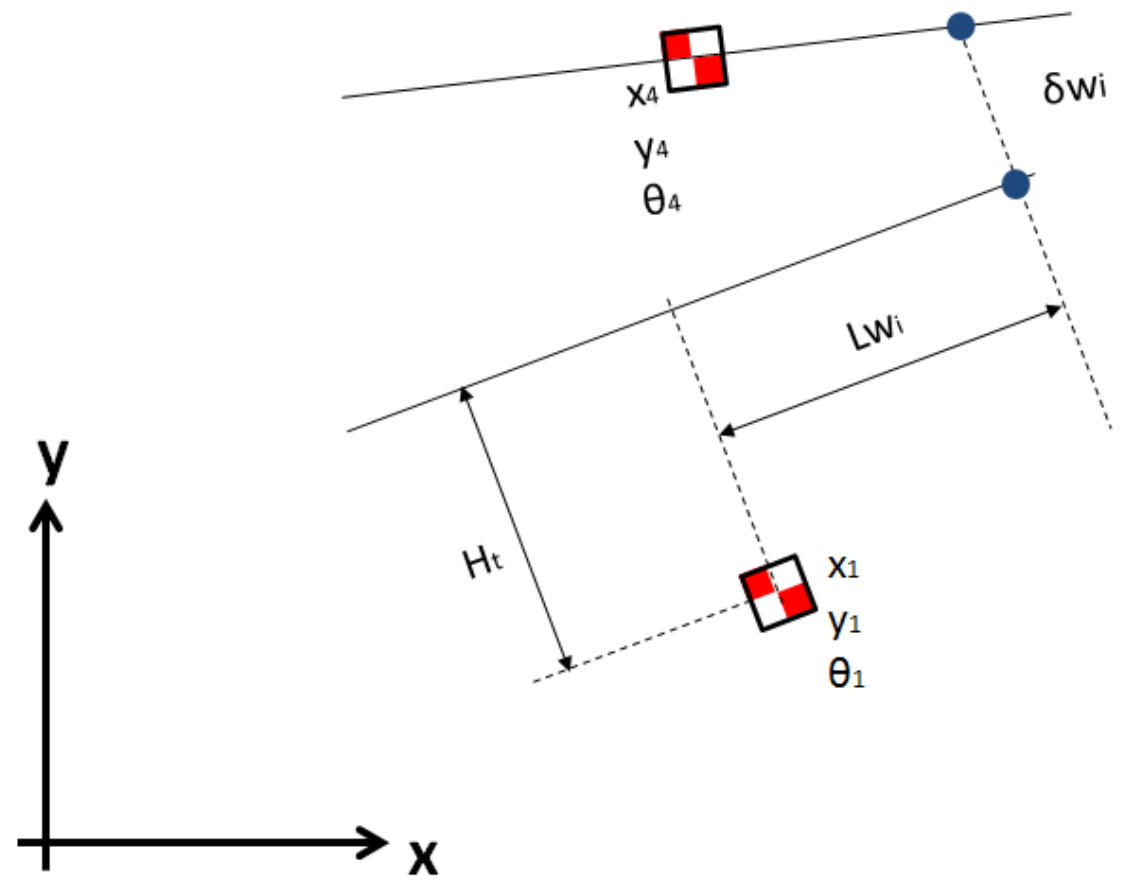

Figura 2.4: Elongamento dos blocos de madeira laminada

$$
\left\{\begin{array}{c}
\cos \theta_{1}\left(x_{c_{w i}}-\left(x_{1}-H_{t} \sin \theta_{1}+L_{w_{i}} \cos \theta_{1}\right)\right)+ \\
+\sin \theta_{1}\left(y_{c_{w i}}-\left(H_{b}+y_{1}+H_{t} \cos \theta_{1}+L_{w_{i}} \sin \theta_{1}\right)\right)=0 \\
\sin \theta_{4}\left(x_{c_{w i}}-x_{4}\right)-\cos \theta_{4}\left(y_{c_{w i}}-y_{4}-T K H\right)=0
\end{array}\right.
$$

em que $T K H$ é a altura nominal interna do tanque.

que resulta em:

$$
\begin{aligned}
\left\{\begin{array}{l}
x_{c_{w i}} \\
y_{c_{w i}}
\end{array}\right\}= & \sec \left(\theta_{1}-\theta_{4}\right)\left(\left(L_{w_{i}}+\left(H_{b}+y_{1}\right) \sin \theta_{1}+x_{1} \cos \theta_{1}\right)\left\{\begin{array}{c}
\cos \theta_{4} \\
\sin \theta_{4}
\end{array}\right\}+\right. \\
& \left.+\left(x_{4} \sin \theta_{4}-\left(y_{4}+T K H\right) \cos \theta_{4}\right)\left\{\begin{array}{c}
\sin \theta_{1} \\
-\cos \theta_{1}
\end{array}\right\}\right)
\end{aligned}
$$

A distância do ponto de contato com a tampa obtido na equação 2.15 e a posição do respectivo bloco é calculada pela projeção do vetor da diferença dos pontos no vetor perpendicular ao bloco: 


$$
\begin{aligned}
\delta_{w_{i}}= & \left\{\begin{array}{ll}
-\sin \theta_{1} & \cos \theta_{1}
\end{array}\right\}\left(\left\{\begin{array}{c}
x_{c_{w i}} \\
y_{c_{w i}}
\end{array}\right\}-\left\{\begin{array}{c}
x_{p_{w i}} \\
y_{p_{w i}}
\end{array}\right\}\right) \\
= & \sec \left(\theta_{1}-\theta_{4}\right)\left[-H_{t} \cos \left(\theta_{1}-\theta_{4}\right)-L_{w_{i}} \sin \left(\theta_{1}-\theta_{4}\right)+\left(x_{1}-x_{4}\right) \sin \theta_{4}+\right. \\
& \left.-\left(H_{b}-T K H+y_{1}-y_{4}\right) \cos \theta_{4}\right]
\end{aligned}
$$

Este valor é, então, utilizado na formulação da energia potencial deste elemento do sistema, dada por:

$$
\begin{aligned}
U_{w}= & \sum_{i=1}^{n_{w}} \frac{k_{w_{i}} \delta_{w_{i}}^{2}}{2} \mathrm{H}\left(-\delta_{w_{i}}\right) \\
= & \sum_{i=1}^{n_{f}} \frac{k_{w_{i}} \sec ^{2}\left(\theta_{1}-\theta_{4}\right)}{2}\left[-H_{t} \cos \left(\theta_{1}-\theta_{4}\right)-L_{w_{i}} \sin \left(\theta_{1}-\theta_{4}\right)+\right. \\
& \left.+\left(x_{1}-x_{4}\right) \sin \theta_{4}-\left(H_{b}-T K H+y_{1}-y_{4}\right) \cos \theta_{4}\right]^{2} \mathrm{H}\left[H_{t} \cos \left(\theta_{1}-\theta_{4}\right)+\right. \\
& \left.+L_{w_{i}} \sin \left(\theta_{1}-\theta_{4}\right)-\left(x_{1}-x_{4}\right) \sin \theta_{4}+\left(H_{b}-T K H+y_{1}-y_{4}\right) \cos \theta_{4}\right]
\end{aligned}
$$

\subsubsection{Energia Potencial das Fixações Inferiores}

Os dispositivos de fixação (arresting device) têm por objetivo restringir o movimento horizontal da parte ativa em relação ao tanque. No modelo de cálculo aqui proposto, estes dispositivos atuam principalmente de maneira a restringir o movimento longitudinal relativo da parte ativa.

Pode-se descrever a posição da fixação instalada na parte ativa da seguinte maneira:

$$
\left\{\begin{array}{c}
x_{a d b_{i}}^{p a} \\
y_{a d b_{i}}^{p a}
\end{array}\right\}=\left\{\begin{array}{c}
x_{1} \\
y_{1}+H_{b}
\end{array}\right\}+\left[\begin{array}{cc}
\cos \theta_{1} & -\sin \theta_{1} \\
\sin \theta_{1} & \cos \theta_{1}
\end{array}\right]\left\{\begin{array}{c}
L_{a d b_{i}} \\
-H_{b}
\end{array}\right\}
$$

Da mesma maneira, a posição correspondente da fixação inferior no tanque é dada por:

$$
\left\{\begin{array}{c}
x_{a d b_{i}}^{t k} \\
y_{a d b_{i}}^{t k}
\end{array}\right\}=\left\{\begin{array}{l}
x_{5} \\
y_{5}
\end{array}\right\}+\left[\begin{array}{cc}
\cos \theta_{5} & -\sin \theta_{5} \\
\sin \theta_{5} & \cos \theta_{5}
\end{array}\right]\left\{\begin{array}{c}
L_{a d b_{i}} \\
0
\end{array}\right\}
$$

A distensão do elemento de fixação inferior da parte ativa é dada como a 


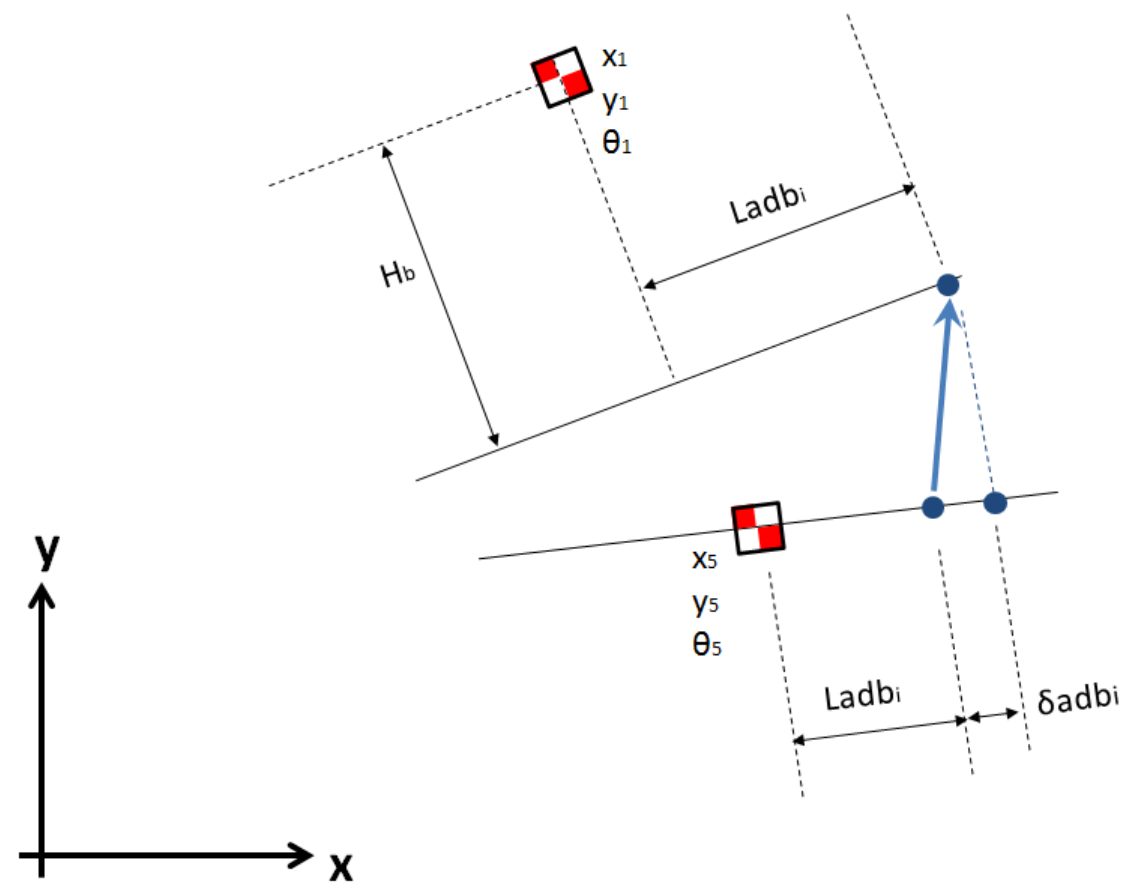

Figura 2.5: Descrição do elongamento das fixações inferiores

projeção no fundo do tanque da diferença entre a posição do elemento de fixação solidário à parte ativa e o solidário ao fundo do tanque. Ou seja:

$$
\begin{aligned}
\delta_{a d b_{i}}= & \left\{\begin{array}{ll}
\cos \theta_{5} & \sin \theta_{5}
\end{array}\right\}\left(\left\{\begin{array}{c}
x_{a d b_{i}}^{p a} \\
y_{a d b_{i}}^{p a}
\end{array}\right\}-\left\{\begin{array}{c}
x_{a d b_{i}}^{t k} \\
y_{a d b_{i}}^{t k}
\end{array}\right\}\right) \\
= & \left\{\begin{array}{ll}
\cos \theta_{5} & \sin \theta_{5}
\end{array}\right\}\left\{\begin{array}{c}
x_{1}-x_{5}+L_{a d b_{i}}\left(\cos \theta_{1}-\cos \theta_{5}\right)+H_{b} \sin \theta_{1} \\
y 1-y 5+L_{a d b_{i}}\left(\sin \theta_{1}-\sin \theta_{5}\right)+H_{b}\left(1-\cos \theta_{1}\right)
\end{array}\right\} \\
= & \left(x_{1}-x_{5}\right) \cos \theta_{5}+\left(y_{1}-y_{5}+H_{b}\right) \sin \theta_{5}+ \\
& +L_{a d b_{i}}\left(\cos \left(\theta_{1}-\theta_{5}\right)-1\right)+H_{b} \sin \left(\theta_{1}-\theta_{5}\right)
\end{aligned}
$$

Dado isto, obtém-se a energia potencial dos dispositivos de fixação inferiores:

$$
\begin{aligned}
U_{a d b}= & \sum_{i=1}^{N_{a d b}} \frac{k_{a d b_{i}} \delta_{a d b_{i}}^{2}}{2} \\
= & \sum_{i=1}^{N_{a d b}} \frac{k_{a d b_{i}}}{2}\left[\left(x_{1}-x_{5}\right) \cos \theta_{5}+\left(y_{1}-y_{5}+H_{b}\right) \sin \theta_{5}+\right. \\
& \left.+L_{a d b_{i}}\left(\cos \left(\theta_{1}-\theta_{5}\right)-1\right)+H_{b} \sin \left(\theta_{1}-\theta_{5}\right)\right]^{2}
\end{aligned}
$$




\subsubsection{Energia Potencial das Fixações Superiores}

De igual modo ao descrito na seção 2.2.2.5, os dispositivos de fixação superiores podem ser descritos como elementos elásticos que, neste modelo, atuam principalmente na direção longitudinal de transporte.

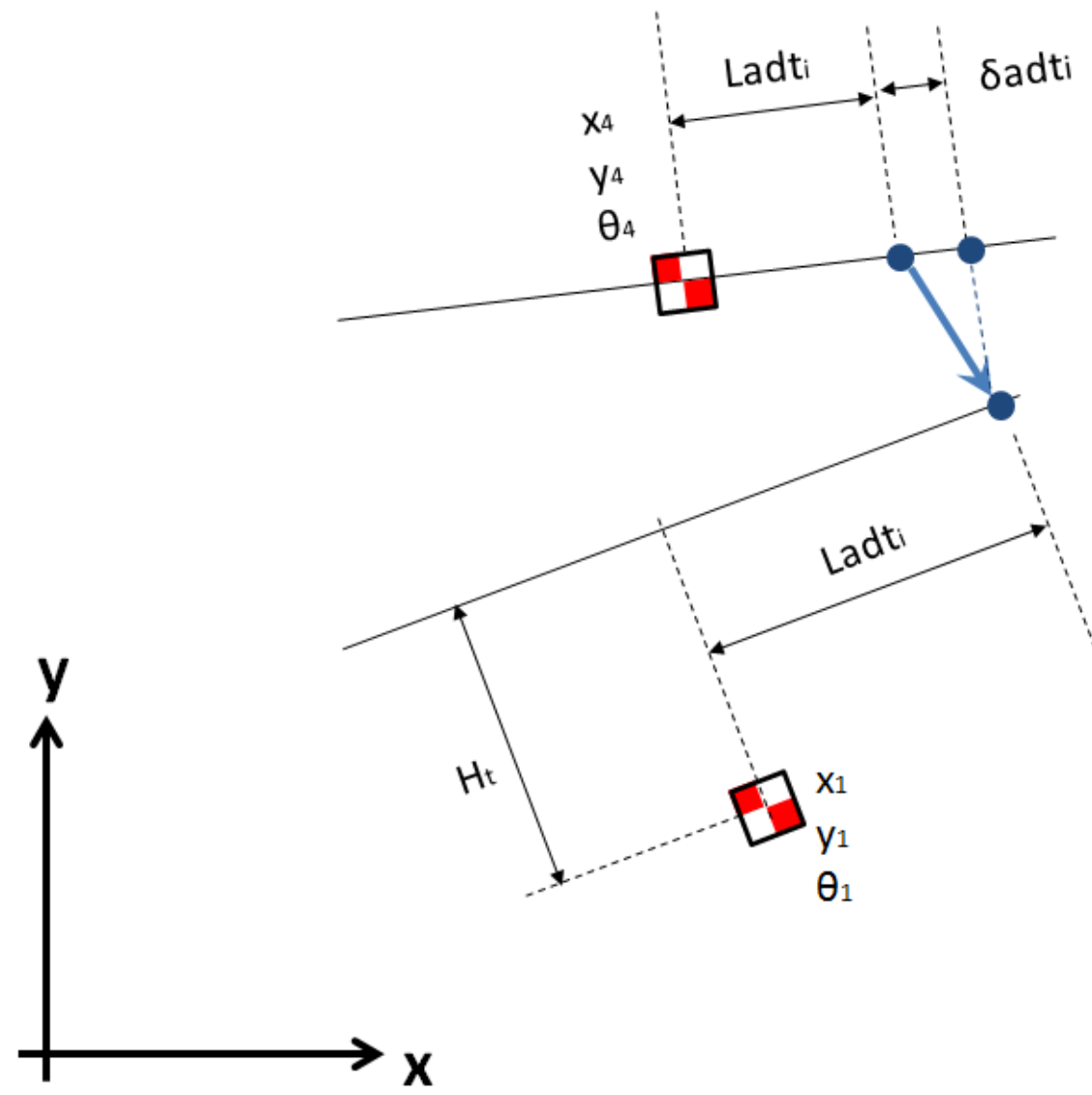

Figura 2.6: Descrição do elongamento das fixações superiores

A posição do elemento de fixação superior que é solidária à parte ativa pode ser expressa como:

$$
\left\{\begin{array}{c}
x_{a d t_{i}}^{p a} \\
y_{a d t_{i}}^{p a}
\end{array}\right\}=\left\{\begin{array}{c}
x_{1} \\
y_{1}+H_{b}
\end{array}\right\}+\left[\begin{array}{cc}
\cos \theta_{1} & -\sin \theta_{1} \\
\sin \theta_{1} & \cos \theta_{1}
\end{array}\right]\left\{\begin{array}{c}
L_{a d t_{i}} \\
H_{t}
\end{array}\right\}
$$

A posição solidária à parte superior do tanque é dada por:

$$
\left\{\begin{array}{l}
x_{a d t_{i}}^{t k} \\
y_{a d t_{i}}^{t k}
\end{array}\right\}=\left\{\begin{array}{c}
x_{4} \\
y_{4}+T K H
\end{array}\right\}+\left[\begin{array}{cc}
\cos \theta_{4} & -\sin \theta_{4} \\
\sin \theta_{4} & \cos \theta_{4}
\end{array}\right]\left\{\begin{array}{c}
L_{a d t_{i}} \\
0
\end{array}\right\}
$$

Da diferença entre as posições calculadas nas equações 2.22 e 2.23 tem-se o vetor cuja projeção na direção da tampa do transformador equivale à distensão 
do elemento de fixação. Assim:

$$
\begin{aligned}
\delta_{a d t_{i}}= & \left\{\begin{array}{ll}
\cos \theta_{4} & \sin \theta_{4}
\end{array}\right\}\left(\left\{\begin{array}{c}
x_{a d t_{i}}^{p a} \\
y_{a d t_{i}}^{p a}
\end{array}\right\}-\left\{\begin{array}{c}
x_{a d t_{i}}^{t k} \\
y_{a d t_{i}}^{t k}
\end{array}\right\}\right) \\
= & \left(x_{1}-x_{4}\right) \cos \theta_{4}+\left(y_{1}-y_{4}+H_{b}-T K H\right) \sin \theta_{4}+ \\
& +L_{a d t_{i}}\left[\cos \left(\theta_{1}-\theta_{4}\right)-1\right]-H_{t} \sin \left(\theta_{1}-\theta_{4}\right)
\end{aligned}
$$

Com isto, a energia potencial desse elemento de fixação é dada por:

$$
\begin{aligned}
U_{a d t}= & \sum_{i=1}^{N_{a d t}} \frac{k_{a d t_{i}} \delta_{a d t_{i}}^{2}}{2} \\
= & \sum_{i=1}^{N_{a d t}} \frac{k_{a d t_{i}}}{2}\left[\left(x_{1}-x_{4}\right) \cos \theta_{4}+\left(y_{1}-y_{4}+H_{b}-T K H\right) \sin \theta_{4}+\right. \\
& \left.+L_{a d t_{i}}\left[\cos \left(\theta_{1}-\theta_{4}\right)-1\right]-H_{t} \sin \left(\theta_{1}-\theta_{4}\right)\right]^{2}
\end{aligned}
$$

\subsubsection{Energia Potencial do Tanque}

A partir de um extenso histórico de instrumentações e análises, pôde-se verificar que a flexibilidade do tanque desempenha um papel fundamental em como se dá a distribuição de reações entre os componentes do transformador.

Assim sendo, para que se pudesse representar essa flexibilidade no modelo simplificado aqui proposto, é feita uma divisão do tanque do transformador em duas partes, sendo as mesmas conectadas por um elemento de rigidez.

Considerando que esta divisão é feita no topo do tanque, pode-se obter as coordenadas de onde o elemento de rigidez se conecta às partes superior e inferior do mesmo.

Tem-se, portanto, que o ponto de conexão do elemento de rigidez à parte inferior do tanque é dado por:

$$
\left\{\begin{array}{l}
x_{i n f} \\
y_{\text {inf }}
\end{array}\right\}=\left\{\begin{array}{l}
x_{5} \\
y_{5}
\end{array}\right\}+\left[\begin{array}{cc}
\cos \theta_{5} & -\sin \theta_{5} \\
\sin \theta_{5} & \cos \theta_{5}
\end{array}\right]\left\{\begin{array}{c}
\frac{T K L}{2} \\
T K H
\end{array}\right\}
$$

e que o ponto de conexão do elemento de rigidez à parte superior do tanque é dado por: 

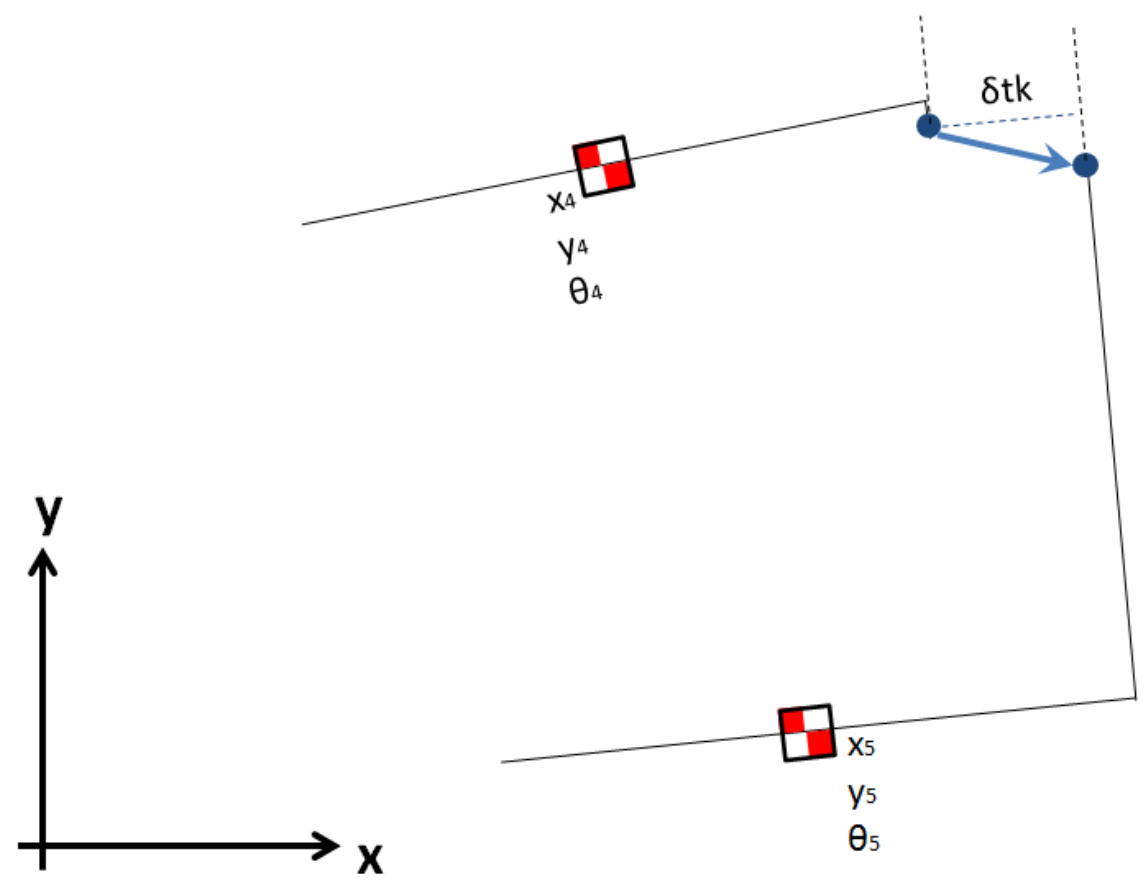

Figura 2.7: Elongamento do elemento de rigidez do tanque

$$
\left\{\begin{array}{l}
x_{\text {sup }} \\
y_{\text {sup }}
\end{array}\right\}=\left\{\begin{array}{c}
x_{4} \\
y_{4}+T K H
\end{array}\right\}+\left[\begin{array}{cc}
\cos \theta_{4} & -\sin \theta_{4} \\
\sin \theta_{4} & \cos \theta_{4}
\end{array}\right]\left\{\begin{array}{c}
\frac{T K L}{2} \\
0
\end{array}\right\}
$$

em que $T K L$ é o comprimento interno nominal do tanque.

Logo, a projeção da diferença entre esses dois pontos na direção paralela ao fundo do tanque resulta no elongamento do elemento de rigidez do tanque.

$$
\begin{aligned}
\delta_{t k}= & \left\{\begin{array}{ll}
\cos \theta_{5} & \sin \theta_{5}
\end{array}\right\}\left(\left\{\begin{array}{l}
x_{\text {sup }} \\
y_{\text {sup }}
\end{array}\right\}-\left\{\begin{array}{l}
x_{\text {inf }} \\
y_{\text {inf }}
\end{array}\right\}\right) \\
= & \left(x_{4}-x_{5}\right) \cos \theta_{5}+\left(T K H+y_{4}-y_{5}\right) \sin \theta_{5}+ \\
& +\frac{T K L}{2}\left(\cos \left(\theta_{4}-\theta_{5}\right)-1\right)
\end{aligned}
$$

E, portanto, a energia potencial elástica do tanque do transformador é dada por:

$$
\begin{aligned}
U_{t k}= & \frac{k_{t k} \cdot \delta_{t k}^{2}}{2} \\
= & \frac{k_{t} k}{2}\left[\left(x_{4}-x_{5}\right) \cos \theta_{5}+\left(T K H+y_{4}-y_{5}\right) \sin \theta_{5}+\right. \\
& \left.+\frac{T K L}{2}\left(\cos \left(\theta_{4}-\theta_{5}\right)-1\right)\right]^{2}
\end{aligned}
$$




\subsubsection{Energia Potencial Total}

Com as energias potenciais gravitacional e de cada um dos elementos elásticos do sistema mecânicos determinadas, tem-se que a energia potencial total do sistema é dada por:

$$
U=U_{g}+U_{v}+U_{f}+U_{w}+U_{a d b}+U_{a d t}+U_{t k}
$$

\subsubsection{Função de Dissipação de Rayleigh}

De maneira a representar a dissipação de energia existente no sistema, são modelados junto aos elementos de rigidez, elementos de dissipação viscosa. Assim, para que seja obtida a Função de Dissipação de Rayleigh (ou Rayleighiana) devem ser obtidas as velocidades de deflexão dos elementos de rigidez.

Tem-se que, para qualquer das deflexões dos elementos de rigidez do sistema mecânico, detalhadas na seção 2.2.2, as mesmas podem ser descritas como funções das coordenadas generalizadas do sistema.

$$
\delta_{i}=\delta_{i}(\mathbf{q})
$$

em que $\delta_{i}$ representa uma deflexão genérica e $\mathbf{q}=\left\{x_{1}, \cdots, x_{5}, y_{1}, \cdots, y_{5}, \theta_{1}, \cdots, \theta_{5}\right\}^{T}$ é o vetor de coordenadas generalizadas do sistema.

As velocidades de deflexão são obtidas ao derivar 2.31 no tempo.

$$
\frac{\mathrm{d} \delta_{i}}{\mathrm{~d} t}=\dot{\delta}_{i}=\left(\delta_{i} \otimes \nabla^{q}\right) \dot{\mathbf{q}}
$$

em que:

- $\nabla^{q}=\left\{\frac{\partial}{\partial x_{1}}, \cdots, \frac{\partial}{\partial x_{5}}, \frac{\partial}{\partial y_{1}}, \cdots, \frac{\partial}{\partial y_{5}}, \frac{\partial}{\partial \theta_{1}}, \cdots, \frac{\partial}{\partial \theta_{5}}\right\}^{T}$ é o operador Nabla em relação ao vetor de coordenadas generalizadas;

- $\otimes$ representa o operador produto tensorial;

- $\dot{\mathbf{q}}=\frac{\mathrm{dq}}{\mathrm{d} t}$ é o vetor de velocidades generalizadas.

Assim, tem-se que: 
- $\dot{\boldsymbol{\delta}}_{v}=\left(\boldsymbol{\delta}_{v} \otimes \nabla^{q}\right) \dot{\mathbf{q}}$

- $\dot{\boldsymbol{\delta}}_{f}=\left(\boldsymbol{\delta}_{f} \otimes \nabla^{q}\right) \dot{\mathbf{q}}$

- $\dot{\boldsymbol{\delta}}_{w}=\left(\boldsymbol{\delta}_{w} \otimes \nabla^{q}\right) \dot{\mathbf{q}}$
- $\dot{\boldsymbol{\delta}}_{a d b}=\left(\boldsymbol{\delta} a_{a d b} \otimes \nabla^{q}\right) \dot{\mathbf{q}}$

- $\dot{\boldsymbol{\delta}}_{a d t}=\left(\boldsymbol{\delta}_{a d t} \otimes \nabla^{q}\right) \dot{\mathbf{q}}$

- $\dot{\delta}_{t k}=\left(\delta_{t k} \otimes \nabla^{q}\right) \dot{\mathbf{q}}$

Com isso, pode-se avaliar cada um dos componentes da Rayleighiana.

$$
\begin{aligned}
\mathcal{F}_{v} & =\sum_{i=1}^{n_{v}} \frac{c_{v_{i}} \cdot \dot{\delta}_{v_{i}}^{2}}{2} \\
\mathcal{F}_{f} & =\sum_{i=1}^{n_{f}} \frac{c_{f_{i}} \cdot \dot{\delta}_{f_{i}}^{2}}{2} \mathrm{H}\left(-\delta_{f_{i}}\right) \\
\mathcal{F}_{w} & =\sum_{i=1}^{n_{w}} \frac{c_{w_{i}} \cdot \dot{\delta}_{w_{i}}^{2}}{2} \mathrm{H}\left(-\delta_{w_{i}}\right) \\
\mathcal{F}_{a d b} & =\sum_{i=1}^{N_{a d b}} \frac{c_{a d b_{i}} \cdot \dot{\delta}_{a d b_{i}}^{2}}{2} \\
\mathcal{F}_{a d t} & =\sum_{i=1}^{N_{a d t}} \frac{c_{a d t_{i}} \cdot \dot{\delta}_{a d t_{i}}^{2}}{2} \\
\mathcal{F}_{t k} & =\frac{c_{t k} \cdot \dot{\delta}_{t k}^{2}}{2}
\end{aligned}
$$

o que resulta em:

$$
\mathcal{F}=\mathcal{F}_{v}+\mathcal{F}_{f}+\mathcal{F}_{w}+\mathcal{F}_{a d b}+\mathcal{F}_{a d t}+\mathcal{F}_{t k}
$$

\subsubsection{Vínculos Holônomos de Posição e Velocidade}

Da maneira como está apresentada até este ponto, a formulação não inclui qualquer restrição ao movimento, necessária, por exemplo, para vincular as colunas de retorno à parte ativa.

Para a imposição de restrições ao sistema, foi utilizado o método dos multiplicadores de Lagrange. São impostas, no total, 10 restrições holonômicas na velocidade. Com isso, o sistema totaliza, entre coordenadas generalizadas e multiplicadores de Lagrange, 25 variáveis a serem calculadas em cada iteração.

Todos os vínculos apresentados nesta seção são deduzidos em termos de restrição de posição. Entretanto, de maneira a facilitar a implementação dos mesmos nas equações dinâmicas (tendo também em vista os vínculos relacionados a leis de atrito seco), sua implementação no sistema é feita na forma de restrições de 
velocidade.

\subsubsection{Atrito Seco entre sapatas e fundo do tanque}

Duas situações devem ser analisadas para essa restrição: quando a diferença dos ângulos de inclinação da parte ativa e do fundo do tanque é positiva, ponto onde o atrito irá agir é na sapata posterior (em relação ao sentido de transporte) da parte ativa; caso contrário, a força de atrito agirá na sapata anterior da parte ativa.

Função de vínculo:

$$
\begin{aligned}
f_{1}(\mathbf{q})= & \sec \left(\theta_{1}-\theta_{5}\right)\left(x_{1} \cos \theta_{1}+\left(y_{1}+H_{b}\right) \sin \theta_{1}+L_{f_{p}}\right)+ \\
& +\tan \left(\theta_{1}-\theta_{5}\right)\left(x_{5} \sin \theta_{5}-y_{5} \cos \theta_{5}\right)+ \\
& -\left(x_{5} \cos \theta_{5}+y_{5} \sin \theta_{5}\right) \\
= & \text { constante }
\end{aligned}
$$

em que $p=1$ se $\theta_{1} \geq \theta_{5}$, e $p=N_{f}$, caso contrário.

Reescrevendo essa restrição em termos de velocidade e aceleração:

$$
\begin{gathered}
\frac{\mathrm{d} f_{1}}{\mathrm{~d} t}=\left(\nabla^{q} \otimes f_{1}\right) \cdot \dot{\mathbf{q}}=0 \\
\frac{\mathrm{d}^{2} f_{1}}{\mathrm{~d} t^{2}}=\dot{\mathbf{q}} \cdot\left[\left(\nabla^{q} \otimes f_{1} \otimes \nabla^{q}\right) \dot{\mathbf{q}}\right]+\left(\nabla^{q} \otimes f_{1}\right) \cdot \ddot{\mathbf{q}}=0
\end{gathered}
$$

em que:

- $\left(\nabla^{q} \otimes f_{1}\right)$ é o gradiente da restrição em função das coordenadas generalizadas;

- $\left(\nabla^{q} \otimes f_{1} \otimes \nabla^{q}\right)$ é a matriz Hessiana das restrições em termos das coordenadas generalizadas.

\subsubsection{Movimento vertical relativo entre as partes superior e inferior do tanque}

O objetivo desta restrição é manter a altura do tanque constante. 


$$
\begin{aligned}
f_{2}(\mathbf{q}) & =-\sin \theta_{5}\left(x_{4}-x_{5}\right)+\cos \theta_{5}\left(T K H+y_{4}-y_{5}\right)-T K H \\
& =0
\end{aligned}
$$

Em termos de velocidade e aceleração, tem-se:

$$
\begin{gathered}
\frac{\mathrm{d} f_{2}}{\mathrm{~d} t}=\left(\nabla^{q} \otimes f_{2}\right) \cdot \dot{\mathbf{q}}=0 \\
\frac{\mathrm{d}^{2} f_{2}}{\mathrm{~d} t^{2}}=\dot{\mathbf{q}} \cdot\left[\left(\nabla^{q} \otimes f_{2} \otimes \nabla^{q}\right) \dot{\mathbf{q}}\right]+\left(\nabla^{q} \otimes f_{2}\right) \cdot \ddot{\mathbf{q}}=0
\end{gathered}
$$

\subsubsection{Rotação relativa entre as partes superior e inferior do tanque}

Objetivo: manter a mesma rotação entre as partes superior e inferior.

$$
f_{3}(\mathbf{q})=\theta_{5}-\theta_{4}=0
$$

Em termos de velocidade e aceleração, tem-se:

$$
\begin{gathered}
\frac{\mathrm{d} f_{3}}{\mathrm{~d} t}=\left(\nabla^{q} \otimes f_{3}\right) \cdot \dot{\mathbf{q}}=0 \\
\frac{\mathrm{d}^{2} f_{3}}{\mathrm{~d} t^{2}}=\dot{\mathbf{q}} \cdot\left[\left(\nabla^{q} \otimes f_{3} \otimes \nabla^{q}\right) \dot{\mathbf{q}}\right]+\left(\nabla^{q} \otimes f_{3}\right) \cdot \ddot{\mathbf{q}}=0
\end{gathered}
$$

\subsubsection{Atrito Seco entre as Colunas do Núcleo e a Parte Ativa}

Até o momento, nenhuma conexão foi definida entre a parte ativa do transformador e suas colunas mais extremas.

Isso porque essa conexão é definida principalmente pelo contato existente entre as chapas de aço-silício do núcleo desses corpos nas regiões superpostas (Step Lap).

Conforme pode ser visto na figura 1.5, os dois grupos de chapas de aço são empilhados alternadamente, o que define a região de superposição. Uma vez que essas chapas são comprimidas na sua espessura, o atrito existente entre as mesmas evita que ocorra algum deslocamento relativo até que um valor crítico seja atingido. 


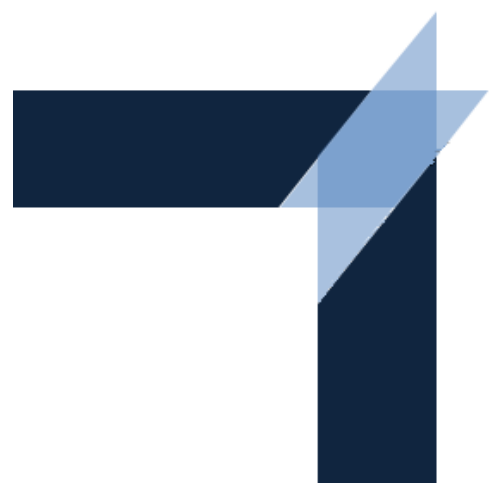

(a) Representação do Step Lap

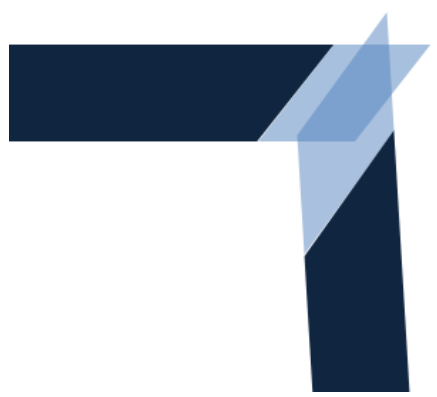

(b) Região do Step Lap danificada

Figura 2.8: Região do Step Lap

Para avaliar a magnitude dos esforços que deverão ser resistidos pelo atrito entre as chapas, impõem-se as seguintes restrições:

Coluna Frontal Sabendo que a distância horizontal original entre os centros de gravidade da coluna frontal e da parte ativa é dada por $L_{f_{n f}}$ (posição da última sapata da parte ativa, alinhada com a coluna frontal) e considerando o deslizamento acumulado entre essas partes como $\left\{d_{x_{f}}, d_{y_{f}}\right\}^{T}$, tem-se que a seguinte igualdade é valida:

$$
\left\{\begin{array}{c}
L_{f_{n f}}+x_{2} \\
y_{2}
\end{array}\right\}=\left[\begin{array}{cc}
\cos \theta_{1} & -\sin \theta_{1} \\
\sin \theta_{1} & \cos \theta_{1}
\end{array}\right]\left\{\begin{array}{c}
L_{f_{n f}}+d_{x_{f}} \\
d_{y_{f}}
\end{array}\right\}+\left\{\begin{array}{c}
x_{1} \\
y_{1}
\end{array}\right\}
$$

A equação 2.49 impõem a restrição sobre a posição dos corpos. Para que se obtenha a restrição em termos de velocidade e aceleração, deve-se diferenciar no tempo cada um dos componentes direcionais da equação.

$$
\begin{gathered}
f_{4}(\mathbf{q})=\left(L_{f_{n f}}+d_{x_{f}}\right) \cos \theta_{1}-d_{y_{f}} \sin \theta_{1}+x_{1}-L_{f_{n f}}-x_{2}=0 \\
\frac{\mathrm{d} f_{4}}{\mathrm{~d} t}=\left(\nabla^{q} \otimes f_{4}\right) \cdot \dot{\mathbf{q}}=0 \\
\frac{\mathrm{d}^{2} f_{4}}{\mathrm{~d} t^{2}}=\dot{\mathbf{q}} \cdot\left[\left(\nabla^{q} \otimes f_{4} \otimes \nabla^{q}\right) \dot{\mathbf{q}}\right]+\left(\nabla^{q} \otimes f_{4}\right) \cdot \ddot{\mathbf{q}}=0 \\
f_{5}(\mathbf{q})=\left(L_{f_{n f}}+d_{x_{f}}\right) \sin \theta_{1}+d_{y_{f}} \cos \theta_{1}+y_{1}-y_{2}=0
\end{gathered}
$$




$$
\begin{gathered}
\frac{\mathrm{d} f_{5}}{\mathrm{~d} t}=\left(\nabla^{q} \otimes f_{5}\right) \cdot \dot{\mathbf{q}}=0 \\
\frac{\mathrm{d}^{2} f_{5}}{\mathrm{~d} t^{2}}=\dot{\mathbf{q}} \cdot\left[\left(\nabla^{q} \otimes f_{5} \otimes \nabla^{q}\right) \dot{\mathbf{q}}\right]+\left(\nabla^{q} \otimes f_{5}\right) \cdot \ddot{\mathbf{q}}=0
\end{gathered}
$$

As equações 2.50 a 2.55 permitem a avaliação dos componentes da força de restrição nas direções horizontal e vertical. Para que se obtenha o momento, a seguinte restrição é necessária:

$$
\begin{gathered}
f_{6}(\mathbf{q})=\theta_{1}-\theta_{2}-\theta_{a c c}=0 \\
\frac{\mathrm{d} f_{6}}{\mathrm{~d} t}=\left(\nabla^{q} \otimes f_{6}\right) \cdot \dot{\mathbf{q}}=0 \\
\frac{\mathrm{d}^{2} f_{6}}{\mathrm{~d} t^{2}}=\dot{\mathbf{q}} \cdot\left[\left(\nabla^{q} \otimes f_{6} \otimes \nabla^{q}\right) \dot{\mathbf{q}}\right]+\left(\nabla^{q} \otimes f_{6}\right) \cdot \ddot{\mathbf{q}}=0
\end{gathered}
$$

em que $\theta_{a c c}$ é a diferença acumulada (escorregada) dos ângulos entre a parte ativa e a coluna frontal.

Coluna Posterior A distância horizontal original entre os centros de gravidade da parte ativa e da coluna posterior é dada por $L_{f_{1}}$, assim como os deslizamentos relativos acumulados por essa coluna são dados por $\left\{d_{x_{b}}, d_{y_{b}}\right\}^{T}$. Assim sendo, pode-se escrever as restrições de translação existentes entre esses corpos da seguinte maneira:

$$
\left\{\begin{array}{c}
L_{f_{1}}+x_{3} \\
y_{3}
\end{array}\right\}=\left[\begin{array}{cc}
\cos \theta_{1} & -\sin \theta_{1} \\
\sin \theta_{1} & \cos \theta_{1}
\end{array}\right]\left\{\begin{array}{c}
L_{f_{1}}+d_{x_{b}} \\
d_{y_{b}}
\end{array}\right\}+\left\{\begin{array}{c}
x_{1} \\
y_{1}
\end{array}\right\}
$$

A equação 2.59 restringe as posições dos corpos 1 e 3 . Com o objetivo de impor restrições sobre as velocidades e acelerações, os componentes de cada direção dessa equação deverão ser derivados em relação ao tempo.

$$
\begin{gathered}
f_{7}(\mathbf{q})=\left(L_{f_{1}}+d_{x_{b}}\right) \cos \theta_{1}-d_{y_{b}} \sin \theta_{1}+x_{1}-L_{f_{1}}-x_{3}=0 \\
\frac{\mathrm{d} f_{7}}{\mathrm{~d} t}=\left(\nabla^{q} \otimes f_{7}\right) \cdot \dot{\mathbf{q}}=0
\end{gathered}
$$




$$
\begin{gathered}
\frac{\mathrm{d}^{2} f_{7}}{\mathrm{~d} t^{2}}=\dot{\mathbf{q}} \cdot\left[\left(\nabla^{q} \otimes f_{7} \otimes \nabla^{q}\right) \dot{\mathbf{q}}\right]+\left(\nabla^{q} \otimes f_{7}\right) \cdot \ddot{\mathbf{q}}=0 \\
f_{8}(\mathbf{q})=\left(L_{f_{1}}+d_{x_{b}}\right) \sin \theta_{1}+d_{y_{b}} \cos \theta_{1}+y_{1}-y_{3}=0 \\
\frac{\mathrm{d} f_{8}}{\mathrm{~d} t}=\left(\nabla^{q} \otimes f_{8}\right) \cdot \dot{\mathbf{q}}=0 \\
\frac{\mathrm{d}^{2} f_{8}}{\mathrm{~d} t^{2}}=\dot{\mathbf{q}} \cdot\left[\left(\nabla^{q} \otimes f_{8} \otimes \nabla^{q}\right) \dot{\mathbf{q}}\right]+\left(\nabla^{q} \otimes f_{8}\right) \cdot \ddot{\mathbf{q}}=0
\end{gathered}
$$

De igual forma ao que foi visto para a coluna frontal, as equações 2.60 a 2.65 somente restringem translações relativas nas direções vertical e horizontal. Para que seja imposta restrições sobre as rotações dos corpos, deve-se definir:

$$
\begin{gathered}
f_{9}(\mathbf{q})=\theta_{1}-\theta_{3}-\theta_{a c c}=0 \\
\frac{\mathrm{d} f_{9}}{\mathrm{~d} t}=\left(\nabla^{q} \otimes f_{9}\right) \cdot \dot{\mathbf{q}}=0 \\
\frac{\mathrm{d}^{2} f_{9}}{\mathrm{~d} t^{2}}=\dot{\mathbf{q}} \cdot\left[\left(\nabla^{q} \otimes f_{9} \otimes \nabla^{q}\right) \dot{\mathbf{q}}\right]+\left(\nabla^{q} \otimes f_{9}\right) \cdot \ddot{\mathbf{q}}=0
\end{gathered}
$$

As restrições impostas ao movimento das colunas permitem o cálculo das forças e momentos necessários para mantê-las solidárias à parte ativa.

\subsubsection{Prescrição da Velocidade do Veículo}

Por meio desta restrição podem ser prescritas formas de acelerações verificadas durante o transporte do equipamento.

$$
\begin{aligned}
f_{10}(\mathbf{q}, t) & =x_{5}-x_{\text {presc }}(t)=0 \\
\frac{\mathrm{d} f_{10}}{\mathrm{~d} t} & =\left(\nabla^{q} \otimes f_{10}\right) \cdot \dot{\mathbf{q}}-\dot{x}_{\text {presc }}=0 \\
\frac{\mathrm{d}^{2} f_{10}}{\mathrm{~d} t^{2}} & =\left(\nabla^{q} \otimes f_{10}\right) \cdot \ddot{\mathbf{q}}-\ddot{x}_{\text {presc }}=0
\end{aligned}
$$




\subsubsection{Multiplicadores de Lagrange}

Tendo sido definidas as restrições ao movimento do sistema mecânico, pode-se fazer uso do Método dos Multiplicadores de Lagrange para resolução do problema sem que sejam eliminados os graus de liberdade excedentes, calculando-se, porém, os esforços necessários para que as restrições valham, conforme exposto em (12).

Para isso, dado o vetor de restrições holonômicas de posição:

$$
\mathbf{f}(\mathbf{q}, t)=\mathbf{0}
$$

obtêm-se, a partir de suas derivadas temporais, a seguinte relação:

$$
\begin{aligned}
& \left(\nabla^{q} \otimes \mathbf{f}\right)^{T} \dot{\mathbf{q}}+\frac{\partial \mathbf{f}}{\partial t}=\mathbf{0} \\
& \left(\nabla^{q} \otimes \mathbf{f}\right)^{T} \ddot{\mathbf{q}}+\frac{\partial^{2} \mathbf{f}}{\partial t^{2}}+\dot{\mathbf{q}} \cdot\left[\left(\nabla^{q} \otimes \mathbf{f} \otimes \nabla^{q}\right) \dot{\mathbf{q}}\right]=\mathbf{0}
\end{aligned}
$$

\subsubsection{O Princípio de Hamilton}

Definidas as energias potencial e cinética do sistema mecânico, bem como a função de dissipação de Rayleigh e as restrições ao movmento, é possível agora escrever as equações de movimento do sistema de acordo com o formalismo lagrangiano.

Define-se, então, a função Lagrangiana Aumentada, levando em consideração as restrições de velocidade apresentadas em 2.73:

$$
\mathcal{L}=T-U+\left[\left(\nabla^{q} \otimes \mathbf{f}\right)^{T} \dot{\mathbf{q}}+\frac{\partial \mathbf{f}}{\partial t}\right] \cdot \boldsymbol{\lambda}
$$

em que $\boldsymbol{\lambda}$ são os multiplicadores de Lagrange associados a cada restrição.

De 2.73 sabe-se que, ao se adicionar as restrições à formulação da lagrangiana, a mesma não foi alterada, posto que, sendo as restrições respeitadas, o termo somado à lagrangiana é nulo.

Assim sendo, a equação de movimento pode ser escrita da seguinte maneira:

$$
\frac{\mathrm{d}}{\mathrm{d} t}\left(\nabla^{\dot{q}} \otimes \mathcal{L}\right)-\nabla^{q} \otimes \mathcal{L}+\nabla^{\dot{q}} \otimes \mathcal{F}=\mathrm{Q}^{e x t}
$$

em que: 
- $\nabla^{\dot{q}}=\left\{\frac{\partial}{\partial \dot{x}_{1}}, \cdots, \frac{\partial}{\partial \dot{x}_{5}}, \frac{\partial}{\partial \dot{y}_{1}}, \cdots, \frac{\partial}{\partial \dot{y}_{5}}, \frac{\partial}{\partial \dot{\theta}_{1}}, \cdots, \frac{\partial}{\partial \dot{\theta}_{5}}\right\}^{T}$ é o operador Nabla em relação ao vetor de velocidades generalizadas;

- $\mathrm{Q}^{\text {ext }}$ é o vetor de carregamentos generalizados aplicados no sistema mecânico.

Sabendo-se que todos os carregamentos aplicados à estrutura são feitos ora por meio do perfil de pista, ora por meio da prescrição de velocidade do veículo, tem-se que:

$$
\mathrm{Q}^{e x t}=\mathbf{0}
$$

Tem-se que:

$$
\begin{aligned}
\frac{\mathrm{d}}{\mathrm{d} t}\left(\nabla^{\dot{q}} \otimes \mathcal{L}\right)= & \frac{\mathrm{d}}{\mathrm{d} t}\left(\nabla^{\dot{q}} \otimes T\right)+\left(\nabla^{q} \otimes \mathbf{f}\right) \dot{\boldsymbol{\lambda}}+ \\
& +\left[\left(\nabla^{q} \otimes \mathbf{f} \otimes \nabla^{q}\right) \dot{\mathbf{q}}\right] \boldsymbol{\lambda}
\end{aligned}
$$

uma vez que $\nabla^{\dot{q}} \otimes U=\mathbf{0}$ e que $\nabla^{\dot{q}} \otimes \frac{\partial \mathbf{f}}{\partial t}=\mathbf{0}$.

Por outro lado, tem-se que:

$$
\nabla^{q} \otimes \mathcal{L}=-\nabla^{q} \otimes U+\left[\left(\nabla^{q} \otimes \mathbf{f} \otimes \nabla^{q}\right) \dot{\mathbf{q}}\right] \boldsymbol{\lambda}+\left[\nabla^{q} \otimes \frac{\partial \mathbf{f}}{\partial t}\right] \boldsymbol{\lambda}
$$

De 2.70, sabe-se que $\left[\nabla^{q} \otimes \frac{\partial \mathbf{f}}{\partial t}\right]=\mathbf{0}$. Logo, a equação de movimento do sistema é dada por:

$$
\frac{\mathrm{d}}{\mathrm{d} t}\left(\nabla^{\dot{q}} \otimes T\right)+\nabla^{q} \otimes U+\nabla^{\dot{q}} \otimes \mathcal{F}+\left(\nabla^{q} \otimes \mathbf{f}\right) \dot{\boldsymbol{\lambda}}=\mathbf{0}
$$

em que $\left(\nabla^{q} \otimes \mathbf{f}\right) \dot{\boldsymbol{\lambda}}$ representam as forças necessárias para que as restrições sejam satisfeitas. Uma interpretação é a de que as forças vinculares são perpendiculares às restrições em si. Em outras palavras, paralelas ao gradiente das restrições.

A partir de 2.1, obtêm-se:

$$
\frac{\mathrm{d}}{\mathrm{d} t}\left(\nabla^{\dot{q}} \otimes T\right)=\underline{M} \ddot{\mathbf{q}}
$$

em que $\underline{M}$ é a matriz de massa generalizada (diagonal) do sistema. 
De igual forma, pode-se reescrever:

$$
\nabla^{\dot{q}} \otimes \mathcal{F}=\left(\nabla^{\dot{q}} \otimes \dot{\boldsymbol{\delta}}\right)\left(\nabla^{\dot{\delta}} \otimes \mathcal{F}\right)=\left(\nabla^{\dot{q}} \otimes \dot{\boldsymbol{\delta}}\right) \underline{C} \dot{\boldsymbol{\delta}}
$$

em que:

- $\boldsymbol{\delta}=\left\{\delta_{v}, \delta_{f}, \delta_{w}, \delta_{a d b}, \delta_{a d t}, \delta_{t k}\right\}^{T}$ é o vetor de deflexões dos elementos de rigidez do sistema;

- $\dot{\boldsymbol{\delta}}=\frac{\mathrm{d} \boldsymbol{\delta}}{\mathrm{d} t}$ é o vetor de velocidade de deflexão dos elementos de rigidez do sistema mecânico;

- $\underline{C}$ é a matriz de amortecimento do sistema definida em relação ao vetor velocidade de deflexões (diagonal).

Tem-se, também, que:

$$
\nabla^{\dot{q}} \otimes \dot{\boldsymbol{\delta}}=\nabla^{q} \otimes \boldsymbol{\delta}
$$

Pode-se reescrever:

$$
\nabla^{q} \otimes U=\left(\nabla^{q} \otimes \boldsymbol{\delta}\right)\left(\nabla^{\delta} \otimes U\right)=\left(\nabla^{q} \otimes \boldsymbol{\delta}\right) \underline{K} \boldsymbol{\delta}
$$

em que $\underline{K}$ é a matriz de rigidez do sistema definida em relação ao vetor de deflexões (diagonal).

Assim, 2.80 pode ser reescrita da seguinte maneira:

$$
\underline{M} \ddot{\mathbf{q}}+\left(\nabla^{q} \otimes \boldsymbol{\delta}\right)[\underline{C} \dot{\boldsymbol{\delta}}+\underline{K} \boldsymbol{\delta}]+\left(\nabla^{q} \otimes \mathbf{f}\right) \dot{\boldsymbol{\lambda}}=\mathbf{0}
$$

\subsection{Deslizamento Planar}

Conforme exposto em 2.2.4.4, o fator principal na prevenção aos deslocamentos que possam vir a ocorrer no núcleo ferromagnético de um transformador é a existência do atrito entre as chapas sobrepostas, na região do chamado Step Lap.

Para que sejam avaliados os limites para a ocorrência de deslizamento em um corpo no plano, é necessário computar as forças e momento resultante devido às tensões de atrito (cisalhamento) existentes nas regiões sobrepostas. Em (13) é 
apresentada uma metodologia de cálculo para a avaliação de forças resultantes e momento em um corpo deslizante no plano.

Então, considere um corpo no plano na iminência de deslizar. Nessa condição a tensão de atrito que atua pontualmente ao longo de todo o corpo tem a seguinte amplitude:

$$
\|\tau\|=\mu p
$$

em que $\mu$ é o coeficiente de atrito e $p$ e a pressão aplicada ao corpo.

Para determinar a direção em que a tensão de atrito atua, considere a figura 2.9. O movimento instantâneo do corpo no plano pode ser definido como um movimento de rotação em torno de um centro de rotação.

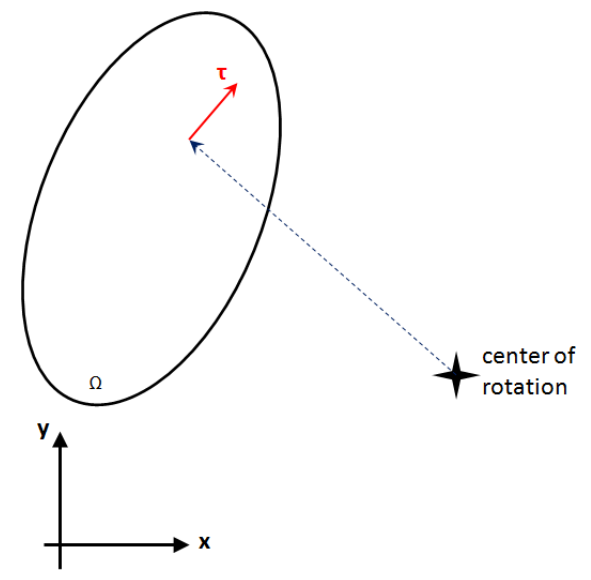

Figura 2.9: Tensão de Atrito em um Corpo no Plano

Logo, para um centro de rotação arbitrário $\left\{x_{c}, y_{c}\right\}^{T}$, a direção da tensão de atrito em um dado ponto do corpo pode ser definida como:

$$
\hat{\boldsymbol{\tau}}=\frac{1}{\sqrt{\left(x-x_{c}\right)^{2}+\left(y-y_{c}\right)^{2}}}\left\{\begin{array}{l}
y-y_{c} \\
x_{c}-x
\end{array}\right\}
$$

As forças resultantes e momento (em relação à origem do sistema de coordenadas), são, então, definidas da seguinte maneira:

$$
\begin{aligned}
F_{x}\left(p, x_{c}, y_{c}\right) & =\iint_{\Omega} \frac{\mu p\left(y-y_{c}\right)}{\sqrt{\left(x-x_{c}\right)^{2}+\left(y-y_{c}\right)^{2}}} \mathrm{~d} x \mathrm{~d} y \\
F_{y}\left(p, x_{c}, y_{c}\right) & =\iint_{\Omega} \frac{-\mu p\left(x-x_{c}\right)}{\sqrt{\left(x-x_{c}\right)^{2}+\left(y-y_{c}\right)^{2}}} \mathrm{~d} x \mathrm{~d} y \\
M\left(p, x_{c}, y_{c}\right) & =\iint_{\Omega} \frac{-\mu p\left[x\left(x-x_{c}\right)+y\left(y-y_{c}\right)\right]}{\sqrt{\left(x-x_{c}\right)^{2}+\left(y-y_{c}\right)^{2}}} \mathrm{~d} x \mathrm{~d} y
\end{aligned}
$$


em que $\Omega$ é a área do corpo sobre a qual atua o atrito.

Os componentes da força de atrito e o momento são determinados, no que aqui se define problema direto, pelo valor da pressão aplicada no corpo e pelas coordenadas do centro instantâneo de rotação $(C I R)$.

Por outro lado, são conhecidos, por meio do método dos multiplicadores de Lagrange, quais são as magnitudes dos esforços necessários para que os corpos se mantenham solidários.

Define-se o Problema Inverso do deslizamento planar a determinação dos parâmetros de cálculo das equações 2.88, 2.89 e 2.90 dados os valores de cada um dos esforços:

$$
\left\{\begin{array}{l}
F_{x} \\
F_{y} \\
M
\end{array}\right\}=\left\{\begin{array}{l}
F_{x}\left(p, x_{c}, y_{c}\right) \\
F_{y}\left(p, x_{c}, y_{c}\right) \\
M\left(p, x_{c}, y_{c}\right)
\end{array}\right\}
$$




\section{Implementação Numérica}

\subsection{Avaliação de Integrais de Área nos Step Laps}

As áreas em que deverão ser avaliadas as integrais 2.88 a 2.90, definidas em 2.3 são dependentes de uma dada configuração do sistema dinâmico.

Como pode ser visto na figura 2.8, caso o estado do sistema indique movimentação relativa entre a parte ativa e as colunas extremas do núcleo, ocorre uma variação da área sobreposta, que é resultante da intersecção dos paralelogramos formados pelos diferentes comprimentos de chapa do núcleo.

A metodologia empregada na determinação do polígono resultante da intersecção baseia-se nos algoritmos descritos por Weiler e Atherton ((14) e (15)) e Vatti (16), que solucionam o problema da determinação do polígono resultante de intersecção por meio de recorte de polígonos. Ambos procedimentos podem ser aplicados a polígonos convexos ou côncavos, com eficiência de processamento considerável. Sendo a aplicação deste trabalho restrita à intersecção de paralelogramos, a implementação de algoritmos de recorte foi feita de maneira simplificada.

Tendo em vista a minimização de erros de truncamento e tentando manter a mesma escala de precisão, independentemente das diferenças dimensionais entre diversos casos de transformador, é feita uma isoparametrização dos paralelogramos, determinando os vértices das intersecções nas variáveis paramétricas para, somente então, determinar os vértices das intersecções na escala real do equipamento.

Determinados os vértices dos polígonos resultantes, tem-se determinada a região em que devem ser feitas as integrais 2.88 a 2.90. Entretanto, em geral, esta região forma um domínio poligonal irregular. A estratégia adotada para a avaliação das integrais nesse domínio é subdividi-lo em triângulos, realizando as integrais nos subdomínios triangulares e acumulando os resultados. Essa subdivisão é feita de acordo com as seguintes condições: 


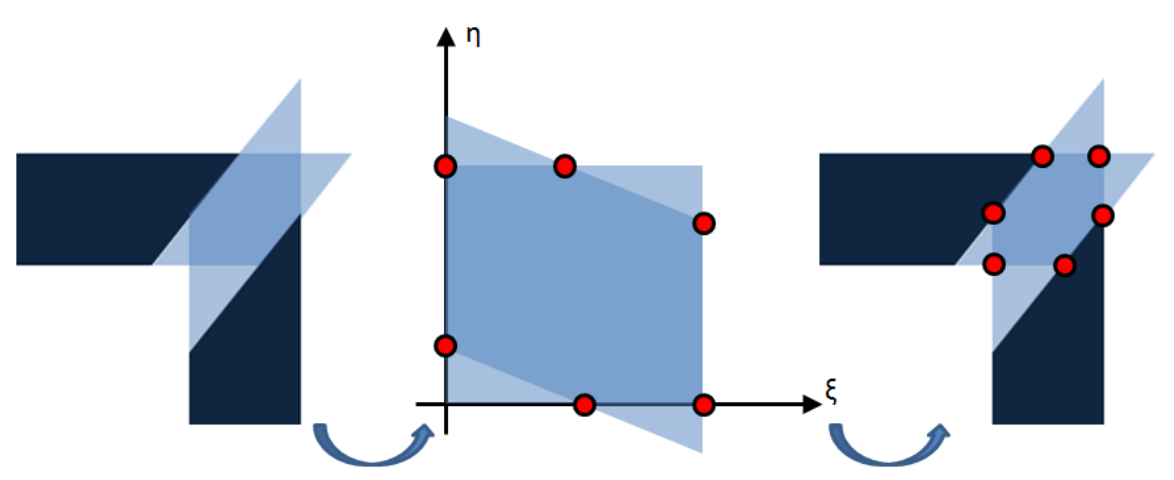

Figura 3.1: Processo de Determinação de Intersecção de Polígonos

a. Caso o centro de rotação esteja dentro do domínio de integração, os triângulos serão formados pelo centro de rotação e pelos vértices de cada aresta do polígono. Itera-se o cálculo, percorrendo a lista de arestas do polígono;

b. Caso o centro de rotação esteja fora do domínio de integração, os triângulos serão formados pelo primeiro vértice da lista de vértices do polígono e pelos pertencentes às arestas não contíguas a este primeiro vértice. Iterase o cálculo, percorrendo a lista das arestas a que o primeiro vértice não pertença.

Em cada um dos subdomínios são avaliadas as integrais por meio da quadratura de Gauss-Legendre com dez pontos de integração, parametrizando-se estes subdomínios.

\subsection{Problema Inverso dos Parâmetros de Desliza- mento}

O conjunto de equações definido em 2.91 representa um sistema não linear de três equações a três incógnitas. Entretanto, a maneira como inicialmente foi definido faz com que sua resolução seja extremamente custosa.

Como exemplo, considere o caso em que a coluna tenda a simplesmente a fazer um movimento relativo de translação. Neste caso, o momento de atrito é nulo e, consequentemente, o centro de rotação da coluna da parte ativa tende ao infinito.

Por esse motivo, a aplicação do método de Newton-Raphson para este problema não é conveniente, uma vez que, sem grandes esforços, o determinante do gradiente das funções $2.88,2.89$ e 2.90 tende a zero.

Assim, outras abordagens para a resolução deste problema foram procuradas. 
Com o intuito de fazer uso de algoritmos de minimização de funções, obteve-se a função da norma quadrática da diferença entre os vetores de esforços 2.91 .

$$
\begin{aligned}
S\left(p, x_{c}, y_{c}\right)= & {\left[F_{x}^{\text {restr }}-F_{x}\left(p, x_{c}, y_{c}\right)\right]^{2}+\left[F_{y}^{r e s t r}-F_{y}\left(p, x_{c}, y_{c}\right)\right]^{2}+} \\
& +\left[M^{\text {restr }}-M\left(p, x_{c}, y_{c}\right)\right]^{2}
\end{aligned}
$$

Uma vez que os valores obtidos de esforços calculados pelos multiplicadores de Lagrange e aqueles obtidos pelas funções integrais 2.88, 2.89 e 2.90 são reais, a função norma quadrática 3.1 é real, não-negativa e possui mínimo global.

Um algoritmo amplamente utilizado para minimização funções sem restrição de domínio é o método de Nelder-Mead ou Downhill Simplex (17), que, para o presente problema, apresenta a vantagem de não depender do gradiente da função a ser minimizada. Sua principal desvantagem, porém, é sua lenta convergência quando aplicado a este problema.

A lenta convergência do método Downhill Simplex, ou qualquer outro para minimização de funções, deve-se ao fato de que, dependendo do ponto em que se encontra o centro de rotação, o gradiente da função-objetivo tem determinante muito próximo a zero. Para tentar contornar o problema, é pode-se reparametrizar as coordenadas do centro de rotação, de tal forma que o domínio possível do centro de rotação $\left(\Re^{2}\right)$ possa ser descrito por um domínio menor. Um exemplo possível de reparametrização pode ser visto na equação 3.4 .

$$
\begin{aligned}
x_{c} & =\tan ^{9} \beta_{x} \\
y_{c} & =\tan ^{9} \beta_{y} \\
\beta_{x}, \beta_{y} & \in]-\frac{\pi}{2}, \frac{\pi}{2}[
\end{aligned}
$$

A regularização apresentada, em conjunto com outros algoritmos de minimização modificados que permitam restrições no domínio pode apresentar melhoras na velocidade de convergência.

Outro algoritmo que, modificado para que leve em consideração restrições no domínio, apresenta convergência mais rápida é o método de Levenberg-Marquardt (18), amplamente utilizado em ajuste de curvas.

Uma observação quanto ao valor dos parâmetros obtidos por meio das técnicas aqui apresentadas é que a pressão calculada pode ser tanto positiva, quanto 
negativa. O sinal da pressão calculada, no entanto, é função do sentido de rotação relativa da coluna do núcleo. Caso o sentido de rotação seja oposto ao considerado na figura 2.9 e nas funções 2.88, 2.89 e 2.90, o valor da pressão é negativo.

\subsection{Resolução do Sistema Dinâmico}

O sistema de equações diferenciais do sistema mecânico será resolvido explicitamente. O uso do método de Runge-Kutta de $4^{a}$ ordem (dentre outros testados) foi, num primeiro instante, implementado, levando em consideração não somente as restrições sobre a velocidade, mas também sobre a aceleração das coordenadas generalizadas. Caso não houvesse restrições que modelassem o comportamento de atrito seco entre partes, essa abordagem de resolução se mostraria suficientemente adequada.

Entretanto, quando das transições entre condições estáticas e dinâmicas do atrito, tal abordagem de resolução do problema não retornava valores coerentes com a dinâmica do sistema.

Dessa forma, mantendo-se a ideia de resolução do problema por um esquema explícito de integração, foi adotada a abordagem descrita nesta seção, conforme descrito em (24).

Considere o período de tempo em que serão resolvidas as equações de movimento do sistema uniformemente discretizado com passo $\Delta t$.

Por meio de expansões em séries de Taylor, tem-se para o instante $t_{n}$ as seguintes aproximações:

$$
\begin{aligned}
\dot{\mathbf{q}}^{(n)} & =\frac{\mathbf{q}^{(n+1)}-\mathbf{q}^{(n-1)}}{2 \Delta t} \\
\ddot{\mathbf{q}}^{(n)} & =\frac{\mathbf{q}^{(n+1)}-2 \mathbf{q}^{(n)}+\mathbf{q}^{(n-1)}}{(\Delta t)^{2}} \\
\dot{\boldsymbol{\lambda}}^{(n)} & =\frac{\boldsymbol{\lambda}^{(n+1)}-\boldsymbol{\lambda}^{(n-1)}}{2 \Delta t}
\end{aligned}
$$

Sabendo-se que: 


$$
\begin{aligned}
\boldsymbol{\delta} & =\boldsymbol{\delta}\left(\mathbf{q}, \mathbf{x}_{\mathbf{v}}, \mathbf{y}_{\mathbf{v}}\right) \\
\dot{\boldsymbol{\delta}} & =\left(\nabla^{q} \otimes \boldsymbol{\delta}\right)^{T} \dot{\mathbf{q}}+\left(\nabla^{x_{v}} \otimes \boldsymbol{\delta}\right)^{T} \dot{\mathbf{x}}_{\mathbf{v}}+\left(\nabla^{y_{v}} \otimes \boldsymbol{\delta}\right)^{T} \dot{\mathbf{y}}_{\mathbf{v}}
\end{aligned}
$$

em que:

- $\mathbf{x}_{\mathbf{v}}=\left\{x_{v_{1}}, \cdots, x_{v_{n_{v}}}\right\}^{T}$ é o vetor das coordenadas horizontais dos pontos de contato de cada suspensão do veículo com a pista;

- $\mathbf{y}_{\mathbf{v}}=\left\{y_{v_{1}}, \cdots, y_{v_{n_{v}}}\right\}^{T}$ é o vetor das coordenadas verticais dos pontos de contato de cada suspensão do veículo com a pista;

- $\nabla^{x_{v}}=\left\{\frac{\partial}{\partial x_{v_{1}}}, \cdots, \frac{\partial}{\partial x_{v_{n_{v}}}}\right\}^{T}$ é o operador nabla referente às coordenadas horizontais dos pontos de contato de cada suspensão do veículo com a pista;

- $\nabla^{y_{v}}=\left\{\frac{\partial}{\partial y_{v_{1}}}, \cdots, \frac{\partial}{\partial y_{v_{v}}}\right\}^{T}$ é o operador nabla referente às coordenadas verticais dos pontos de contato de cada suspensão do veículo com a pista.

Logo, pode-se reescrever 2.85 da seguinte maneira:

$$
\begin{gathered}
\underline{M}\left(\frac{\mathbf{q}^{(n+1)}-2 \mathbf{q}^{(n)}+\mathbf{q}^{(n-1)}}{(\Delta t)^{2}}\right)+ \\
+\left(\nabla^{q} \otimes \boldsymbol{\delta}\right)^{(n)} \underline{C}\left[\left(\boldsymbol{\delta} \otimes \nabla^{q}\right)^{(n)}\left(\frac{\mathbf{q}^{(n+1)}-\mathbf{q}^{(n-1)}}{2 \Delta t}\right)+\right. \\
+\left(\boldsymbol{\delta} \otimes \nabla^{x_{v}}\right)^{(n)} \dot{\mathbf{x}}_{\mathbf{v}}^{(n)}+ \\
\left.+\left(\boldsymbol{\delta} \otimes \nabla^{y_{v}}\right)^{(n)} \dot{\mathbf{y}}_{\mathbf{v}}^{(n)}\right]+ \\
+\left(\nabla^{q} \otimes \boldsymbol{\delta}\right)^{(n)} \underline{K} \boldsymbol{\delta}^{(n)}+\left(\nabla^{q} \otimes \mathbf{f}\right)^{(n)}\left(\frac{\boldsymbol{\lambda}^{(n+1)}-\boldsymbol{\lambda}^{(n-1)}}{2 \Delta t}\right)=\mathbf{0}
\end{gathered}
$$

Rearranjando a equação 3.10, obtem-se a estimativa para o próximo instante de tempo:

$$
\begin{array}{r}
\left(\underline{M}+\frac{\Delta t}{2}\left(\nabla^{q} \otimes \boldsymbol{\delta}\right)^{(n)} \underline{C}\left(\boldsymbol{\delta} \otimes \nabla^{q}\right)^{(n)}\right) \mathbf{q}^{(n+1)}+\frac{\Delta t}{2}\left(\nabla^{q} \otimes \mathbf{f}\right)^{(n)} \boldsymbol{\lambda}^{(n+1)}= \\
\frac{\Delta t}{2}\left(\nabla^{q} \otimes \boldsymbol{\delta}\right)^{(n)} \underline{C}\left[\left(\boldsymbol{\delta} \otimes \nabla^{q}\right)^{(n)} \mathbf{q}^{(n+1)}-\left(\boldsymbol{\delta} \otimes \nabla^{x_{v}}\right)^{(n)} \dot{\mathbf{x}}_{\mathbf{v}}^{(n)}-\left(\boldsymbol{\delta} \otimes \nabla^{y_{v}}\right)^{(n)} \dot{\mathbf{y}}_{\mathbf{v}}^{(n)}\right] \\
\underline{M}\left(2 \mathbf{q}^{(n)}-\mathbf{q}^{(n-1)}\right)+(\Delta t)^{2}\left(\nabla^{q} \otimes \boldsymbol{\delta}\right)^{(n)} \underline{K} \boldsymbol{\delta}^{(n)}-\frac{\Delta t}{2}\left(\nabla^{q} \otimes \mathbf{f}\right)^{(n)} \boldsymbol{\lambda}^{(n-1)}
\end{array}
$$


Do lado esquerdo da equação 3.11 tem-se os termos referentes ao próximo instante, enquanto que os termos do lado direito são referentes ao próprio instante ou ao anterior.

A equação 3.11 está subdeterminada. Para que se possa resolver o sistema dinâmico, impõem-se a restrição de velocidade 2.73 .

$$
\begin{aligned}
\left(\mathbf{f} \otimes \nabla^{q}\right)^{(n)}\left(\frac{\mathbf{q}^{(n+1)}-\mathbf{q}^{(n-1)}}{2 \Delta t}\right)= & -\left(\frac{\partial \mathbf{f}}{\partial t}\right)^{(n)} \\
\frac{\Delta t}{2}\left(\mathbf{f} \otimes \nabla^{q}\right)^{(n)} \mathbf{q}^{(n+1)}= & \frac{\Delta t}{2}\left(\mathbf{f} \otimes \nabla^{q}\right)^{(n)} \mathbf{q}^{(n-1)}+ \\
& -(\Delta t)^{2}\left(\frac{\partial \mathbf{f}}{\partial t}\right)^{(n)}
\end{aligned}
$$

Deve-se tomar cuidados especiais na avaliação do passo inicial. Por se tratar de um sistema de equações diferenciais de segunda ordem, são fornecidos os valores iniciais $\mathbf{q}^{(0)}$ e $\dot{\mathbf{q}}^{(0)}$. Atribuem-se os valores iniciais dos multiplicadores de Lagrange $\boldsymbol{\lambda}^{(0)}=\mathbf{0}$. Para se determinar os valores de $\ddot{\mathbf{q}}^{(0)}$ e $\dot{\boldsymbol{\lambda}}^{(0)}$ resolve-se 2.85 em conjunto com a equação de restrição 2.74 .

Com isso, por meio de expansão em série de Taylor, estima-se $\mathbf{q}^{(-1)}$ e $\boldsymbol{\lambda}^{(-1)}$.

$$
\begin{aligned}
\mathbf{q}^{(-1)} & =\mathbf{q}^{(0)}-\Delta t \dot{\mathbf{q}}^{(0)}+\frac{(\Delta t)^{2}}{2} \ddot{\mathbf{q}}^{(0)} \\
\boldsymbol{\lambda}^{(-1)} & =\boldsymbol{\lambda}^{(0)}-\Delta t \dot{\boldsymbol{\lambda}}^{(0)}
\end{aligned}
$$

\subsubsection{Critérios de Escorregamento}

Para impor as condições de escorregamento da parte ativa em relação ao fundo do tanque e das colunas extremas em relação à parte ativa, deve-se avaliar as inequações correspondentes a cada critério.

\subsubsection{Deslizamento da Parte Ativa em relação ao Fundo}

Definindo-se a força normal de apoio da parte ativa no fundo, $N$, como:

$$
N=-\sum_{i=1}^{n_{f}}\left[k_{f_{i}} \delta_{f_{i}}+c_{f_{i}} \dot{\delta}_{f_{i}}\right] \mathrm{H}\left(-\delta_{f_{i}}\right)
$$

Por outro lado, a força de restrição atuante sobre parte ativa é dada por: 


$$
\mathbf{F}_{1}^{r e s t r}=\left\{\begin{array}{l}
\frac{\partial f_{1}}{\partial x_{1}} \\
\frac{\partial f_{1}}{\partial y_{1}}
\end{array}\right\} \dot{\lambda}_{1}
$$

Sabendo que esta força atua na direção dada pelo vetor $\left\{\cos \theta_{5}, \sin \theta_{5}\right\}^{T}$, ao fazer-se o produto escalar deste vetor com a força de restrição, quem dará o sentido em que a força atua será o sinal de $\dot{\lambda}_{1}$.

Segundo a definição de Coulomb do atrito seco, a magnitude da força de atrito será limitada por uma proporção da força normal existente no contato:

$$
\left(\frac{\partial f_{1}}{\partial x_{1}} \cos \theta_{5}+\frac{\partial f_{1}}{\partial y_{1}} \sin \theta_{5}\right) \dot{\lambda}_{1} \operatorname{sign}\left(\dot{\lambda}_{1}\right) \leq \mu_{t k} N
$$

em que $\mu_{t k}$ é o coeficiente de atrito do contato entre a parte ativa e o fundo do tanque.

Quando a desigualdade 3.17 não é satisfeita, recalcula-se o passo, deixando de impor a restrição 2.41 e forçando a igualdade de 3.17 .

A primeira vista, ao se impor a igualdade de 3.17 , seria obtida uma equação não linear, uma vez que a mesma depende de $\left|\dot{\lambda}_{1}\right|$. Entretanto, como já se tem uma estimativa do valor de $\dot{\lambda}_{1}$ quando da imposição de 2.41 , impõem-se que o sinal da incógnita será o mesmo do anteriormente calculado.

Assim:

$$
\begin{array}{r}
\left(\frac{\partial f_{1}}{\partial x_{1}} \cos \theta_{5}+\frac{\partial f_{1}}{\partial y_{1}} \sin \theta_{5}\right) \operatorname{sign}\left(\dot{\lambda}_{1}\right)\left(\frac{\lambda_{1}^{(n+1)}-\lambda_{1}^{(n-1)}}{2 \Delta t}\right)+ \\
\mu_{t k} \sum_{i=1}^{n_{f}} c_{f_{i}}\left(\dot{\delta}_{f_{i}} \otimes \nabla^{q}\right)^{(n)}\left(\frac{\mathbf{q}^{(n+1)}-\mathbf{q}^{(n-1)}}{2 \Delta t}\right) \mathrm{H}\left(-\delta_{f_{i}}\right)= \\
-\mu_{t k} \sum_{i=1}^{n_{f}} k_{f_{i}} \delta_{f_{i}}^{(n)} \mathrm{H}\left(-\delta_{f_{i}}\right)
\end{array}
$$

\subsubsection{Deslizamento das Colunas da Parte Ativa}

Determinados os esforços para manter solidárias as colunas à parte ativa, calcula-se por meio de algum dos procedimentos apresentados na seção 3.2 os parâmetros de deslizamento de cada uma das colunas.

De projeto, conhece-se o valor de pressão aplicado na prensagem das chapas do núcleo. A partir dessa informação, caso o modulo do valor de pressão calculada 
supere o valor da pressão de projeto (ou existente), os multiplicadores de Lagrange associados ao movimento daquela coluna devem ser escalados da razão $\frac{p_{\text {design }}}{|p|}$.

Para que não haja escorregamento:

$$
\left|p_{\text {frontal }}\right|,\left|p_{\text {post }}\right| \leq p_{\text {design }}
$$

Caso 3.19 não se verifique:

\section{Para a Coluna Frontal}

$$
\left\{\begin{array}{l}
\dot{\lambda}_{4} \\
\dot{\lambda}_{5} \\
\dot{\lambda}_{6}
\end{array}\right\} \leftarrow \frac{p_{\text {design }}}{\left|p_{\text {frontal }}\right|}\left\{\begin{array}{l}
\dot{\lambda}_{4} \\
\dot{\lambda}_{5} \\
\dot{\lambda}_{6}
\end{array}\right\}
$$

Para a Coluna Posterior

$$
\left\{\begin{array}{l}
\dot{\lambda}_{7} \\
\dot{\lambda}_{8} \\
\dot{\lambda}_{9}
\end{array}\right\} \leftarrow \frac{p_{\text {design }}}{\left|p_{\text {post }}\right|}\left\{\begin{array}{l}
\dot{\lambda}_{7} \\
\dot{\lambda}_{8} \\
\dot{\lambda}_{9}
\end{array}\right\}
$$

em que:

- $p_{\text {frontal }}$ é o valor da pressão calculado para a coluna frontal manter-se solidária à parte ativa;

- $p_{\text {post }}$ é o valor da pressão calculado para a coluna posterior manter-se solidária à parte ativa;

- $p_{\text {design }}$ é o valor de pressão considerado como limite para o deslizamento de chapas do núcleo, podendo ser tanto aquele considerado em projeto, como o efetivamente aplicado.

\subsubsection{Procedimento de Resolução do Sistema Dinâmico}

Feitas estas definições, o procedimento de resolução do sistema dinâmico é como segue:

1. Avalia-se 2.85 e 2.74 e obtem-se $\ddot{\mathbf{q}}^{(0)}$ e $\dot{\lambda}^{(0)}$;

2. Avalia-se 3.13 e 3.14 ; 
3. Enquanto não se estiver no último passo;

3.1. Avalia-se 3.11 e 3.12;

3.2. Verifica-se 3.17;

3.2.1. Caso não seja satisfeita, elimina-se a restrição 2.41 e impõem-se 3.18 ;

3.3. Verifica-se 3.19;

3.3.1. Caso não seja satisfeita para alguma das colunas (ou ambas), eliminam-se as restrições correspondentes e escala-se os multiplicadores de Lagrange, conforme 3.20 e 3.21;

3.4. Caso alguma das verificações 3.17 ou 3.19 não tenha sido satisfeita;

3.4.1. Reavalia-se 3.11 e 3.12 ;

3.5. Prossegue para o próximo passo 


\section{Resultados e Discussões}

\subsection{Características Construtivas do Transforma- dor Estudado}

A tabela 4.1 apresenta as características construtivas mecânicas de um transformador real (448 MVA - $345 \mathrm{kV}$ e dimensões conforme tabela 4.1) que será utilizado como exemplo.

Tabela 4.1: Caracteristicas Construtivas do Sistema Estudado

\begin{tabular}{l|l|l}
\hline Variável & Valor & Unidade \\
\hline \hline$m_{1}$ & 84.3 & {$[\mathrm{t}]$} \\
$m_{2}$ & 19.4 & {$[\mathrm{t}]$} \\
$m_{3}$ & 19.4 & {$[\mathrm{t}]$} \\
$m_{\text {tank }}$ & 27 & {$[\mathrm{t}]$} \\
$m_{\text {veiculo }}$ & 72.55 & {$[\mathrm{t}]$} \\
$m_{4}$ & 18.9 & {$[\mathrm{t}]$} \\
$m_{5}$ & 80.65 & {$[\mathrm{t}]$} \\
$T K H$ & 4255 & {$[\mathrm{~mm}]$} \\
$T K L$ & 6590 & {$[\mathrm{~mm}]$} \\
$H_{b}$ & 2019.8 & {$[\mathrm{~mm}]$} \\
$H_{t}$ & 2205.3 & {$[\mathrm{~mm}]$} \\
Forma construtiva da Parte & 1 coluna principal e 2 de re- & {$[-]$} \\
Ativa & torno & \\
$E S R$ & 1967 & {$[\mathrm{~mm}]$} \\
$H_{F}$ & 2210 & {$[\mathrm{~mm}]$} \\
$B J$ & 920 & {$[\mathrm{~mm}]$} \\
$S_{S}$ & 847 & {$[\mathrm{~mm}]$} \\
$n_{v}$ & 8 & {$[-]$} \\
\hline
\end{tabular}


Tabela 4.1 - Continuação da página anterior

\begin{tabular}{|c|c|c|}
\hline Variável & Valor & Unidade \\
\hline$L_{v}$ & $\begin{array}{l}\{-10058.4,-8229.6,-6400.8, \\
-4572,4572,6400.8,8229.6, \\
10058.4\}^{T}\end{array}$ & {$[\mathrm{~mm}]$} \\
\hline$k_{v}$ & 2249.935 & {$[\mathrm{~N} / \mathrm{mm}]$} \\
\hline$c_{v}$ & 350.32 & {$[\mathrm{~N} \cdot \mathrm{s} / \mathrm{mm}]$} \\
\hline$J_{1}$ & 115724678 & {$\left[\mathrm{t} \cdot \mathrm{mm}^{2}\right]$} \\
\hline$J_{2}$ & 14439109 & {$\left[\mathrm{t} \cdot \mathrm{mm}^{2}\right]$} \\
\hline$J_{3}$ & 14439109 & {$\left[\mathrm{t} \cdot \mathrm{mm}^{2}\right]$} \\
\hline$J_{4}$ & 123504136 & {$\left[\mathrm{t} \cdot \mathrm{mm}^{2}\right]$} \\
\hline$J_{5}$ & 2480313614 & {$\left[\mathrm{t} \cdot \mathrm{mm}^{2}\right]$} \\
\hline$L_{f}$ & $\{-1967,0,1967\}^{T}$ & {$[\mathrm{~mm}]$} \\
\hline$k_{f}$ & 290000000 & {$[\mathrm{~N} / \mathrm{mm}]$} \\
\hline$c_{f}$ & 21.8171 & {$[\mathrm{~N} \cdot \mathrm{s} / \mathrm{mm}]$} \\
\hline$L_{w}$ & $\{-1967,0,1967\}^{T}$ & {$[\mathrm{~mm}]$} \\
\hline$k_{w}$ & 1200000 & {$[\mathrm{~N} / \mathrm{mm}]$} \\
\hline$c_{w}$ & 14.0342 & {$[\mathrm{~N} \cdot \mathrm{s} / \mathrm{mm}]$} \\
\hline$L_{a d t}$ & $\begin{array}{l}\{-1200,-1200,-600,-600, \\
600,600,1200,1200\}^{T}\end{array}$ & {$[\mathrm{~mm}]$} \\
\hline$k_{a d t}$ & 372000 & {$[\mathrm{~N} / \mathrm{mm}]$} \\
\hline$c_{a d t}$ & 191.4016 & {$[\mathrm{~N} \cdot \mathrm{s} / \mathrm{mm}]$} \\
\hline$L_{a d b}$ & $\begin{array}{l}\{-2400,-2400,-710,-710, \\
710,710,2400,2400\}^{T}\end{array}$ & {$[\mathrm{~mm}]$} \\
\hline$k_{a d b}$ & 372000 & {$[\mathrm{~N} / \mathrm{mm}]$} \\
\hline$c_{a d b}$ & 191.4016 & {$[\mathrm{~N} \cdot \mathrm{s} / \mathrm{mm}]$} \\
\hline$k_{t k}$ & 1273885.35 & {$[\mathrm{~N} / \mathrm{mm}]$} \\
\hline$c_{t k}$ & 196.2710 & {$[\mathrm{~N} \cdot \mathrm{s} / \mathrm{mm}]$} \\
\hline$\mu_{t k}^{1}$ & 0.4 & {$[-]$} \\
\hline$\mu_{\text {core }}{ }^{1}$ & 0.1 & {$[-]$} \\
\hline$p_{\text {design }}$ & 0.15 & {$[\mathrm{MPa}]$} \\
\hline
\end{tabular}

O máximo passo de tempo adotado para a resolução do sistema dinâmico foi de $50 \mu$ s, escolhido ao se notar que não havia alterações significativas nos resultados com a sua redução.

\footnotetext{
${ }^{1}$ valores obtidos em literatura, da empresa Siemens Ltda.
} 


\subsection{Avaliação dos Efeitos da Duração de Impactos}

Para este estudo foi aplicada sobre o transformador em transporte uma desaceleração com valor máximo de $1 g\left(9810 \mathrm{~mm} / \mathrm{s}^{2}\right)$, fazendo-o chegar ao repouso, variando-se o período de desaceleração entre $10 \mathrm{~ms}$ e $250 \mathrm{~ms}$. Uma forma de onda de amplitude $1 g$ e duração de $100 \mathrm{~ms}$ pode ser vista na figura 4.1.

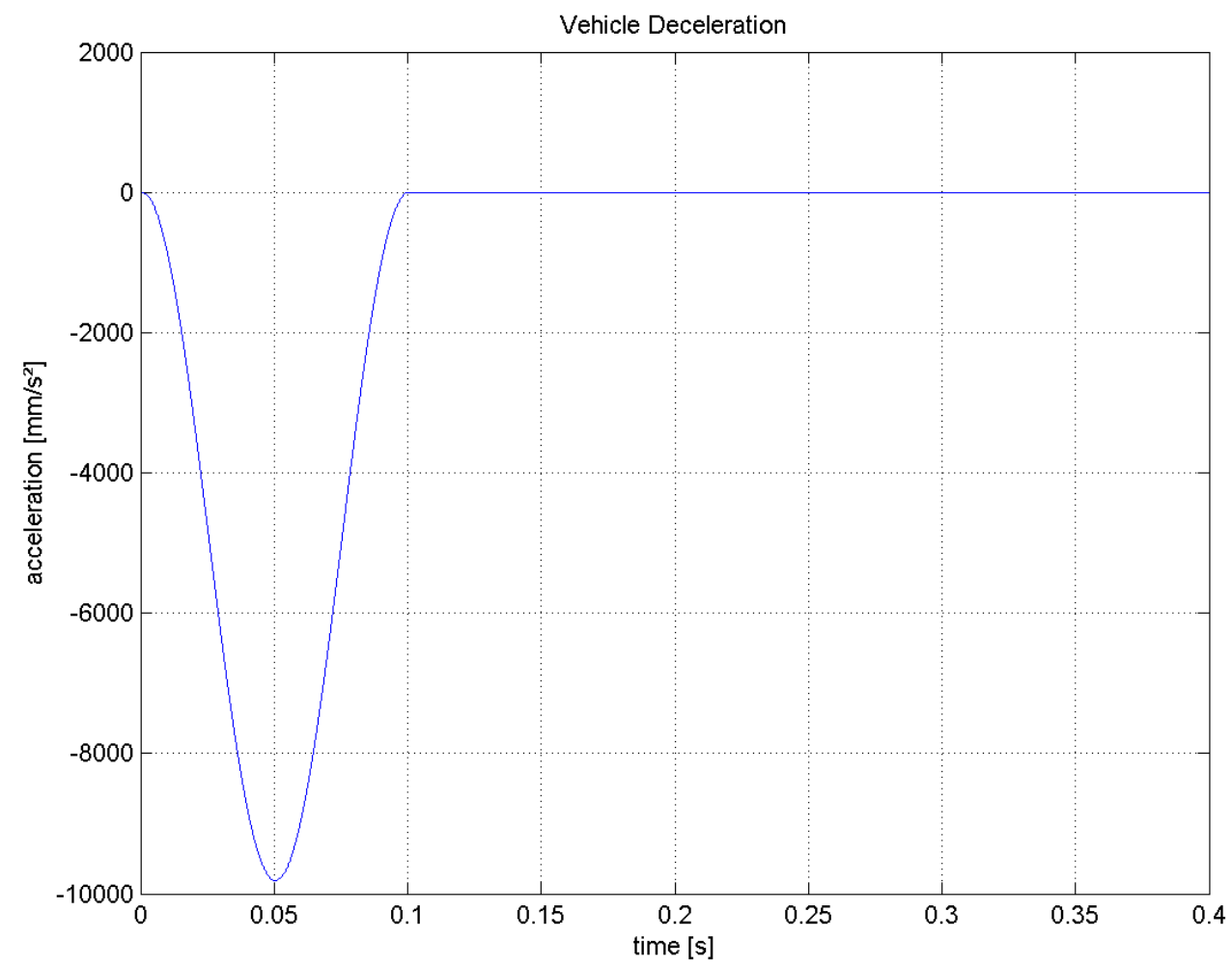

Figura 4.1: Desaceleração do Veículo 


\subsubsection{Resultados de Acelerações Horizontais}

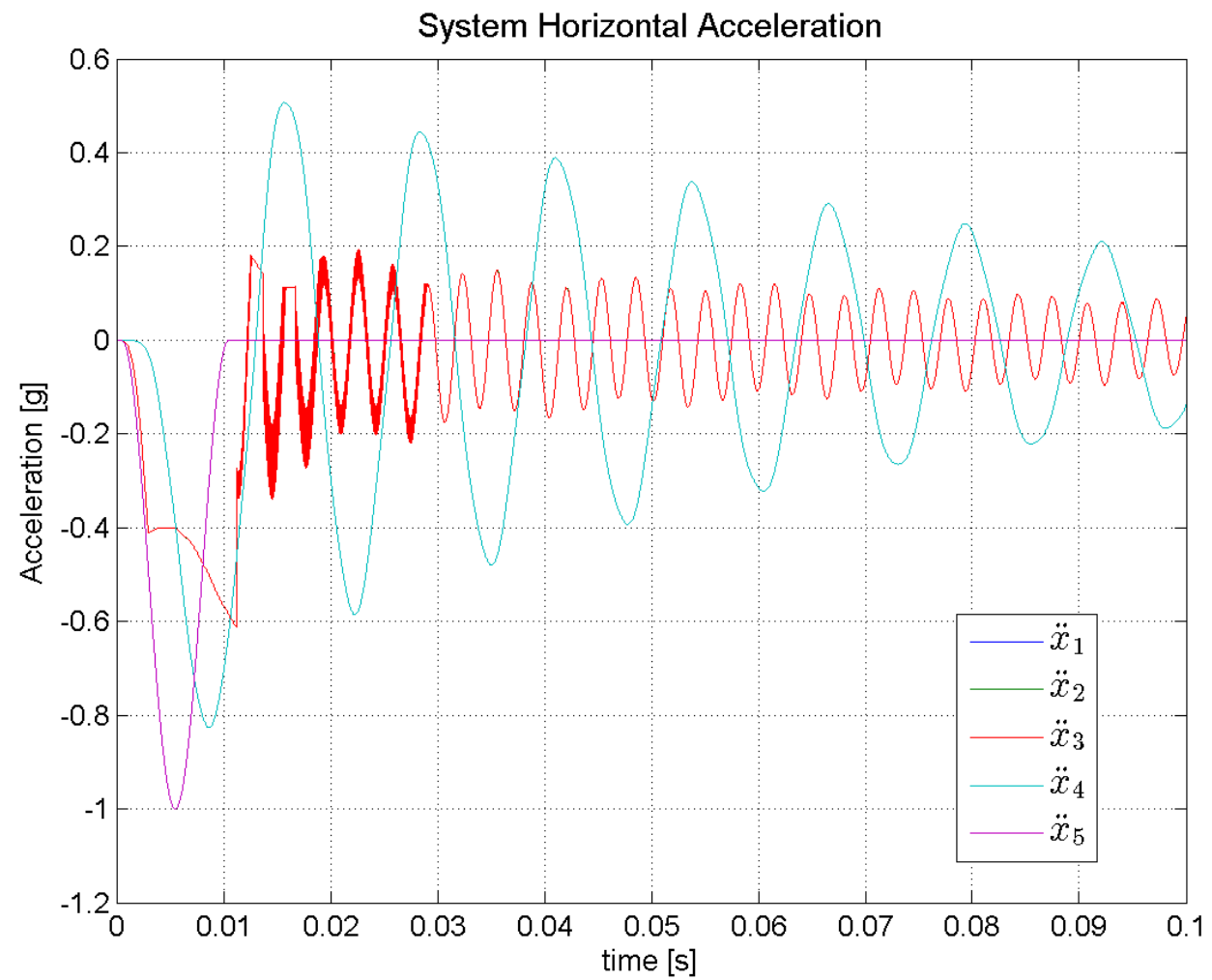

Figura 4.2: Acelerações Horizontais dos Corpos - Período de $10 \mathrm{~ms}$

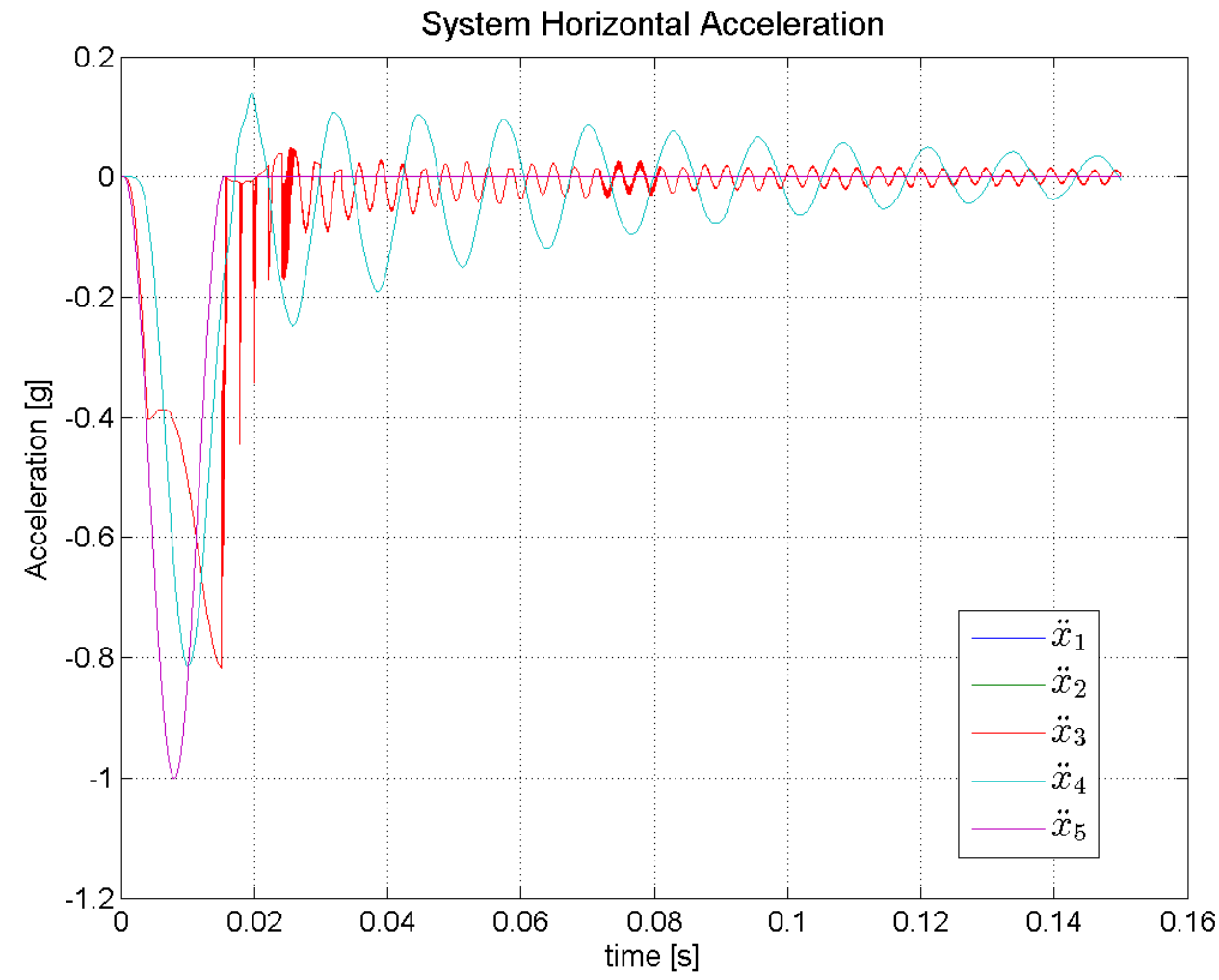

Figura 4.3: Acelerações Horizontais dos Corpos - Período de 15 ms 


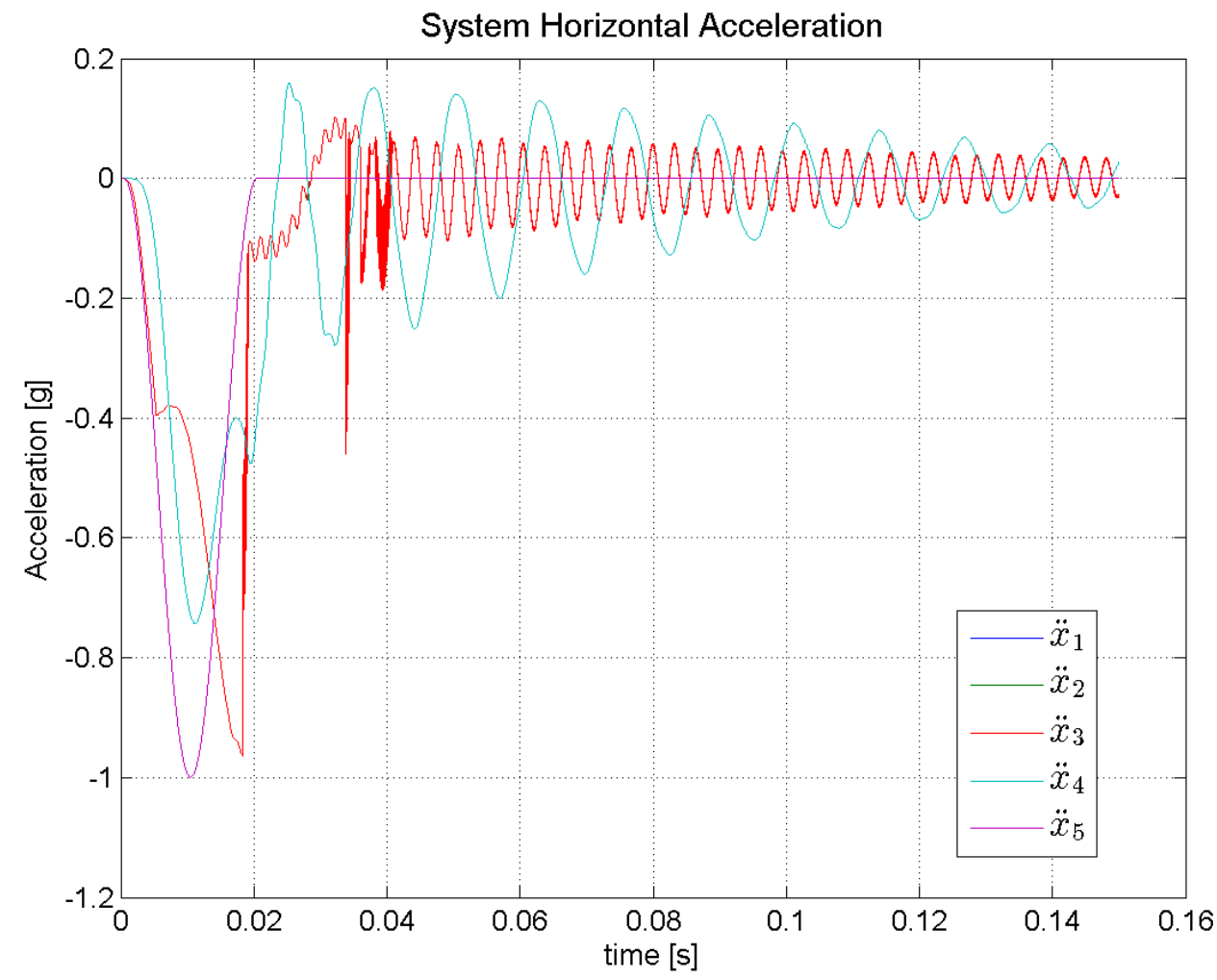

Figura 4.4: Acelerações Horizontais dos Corpos - Período de $20 \mathrm{~ms}$

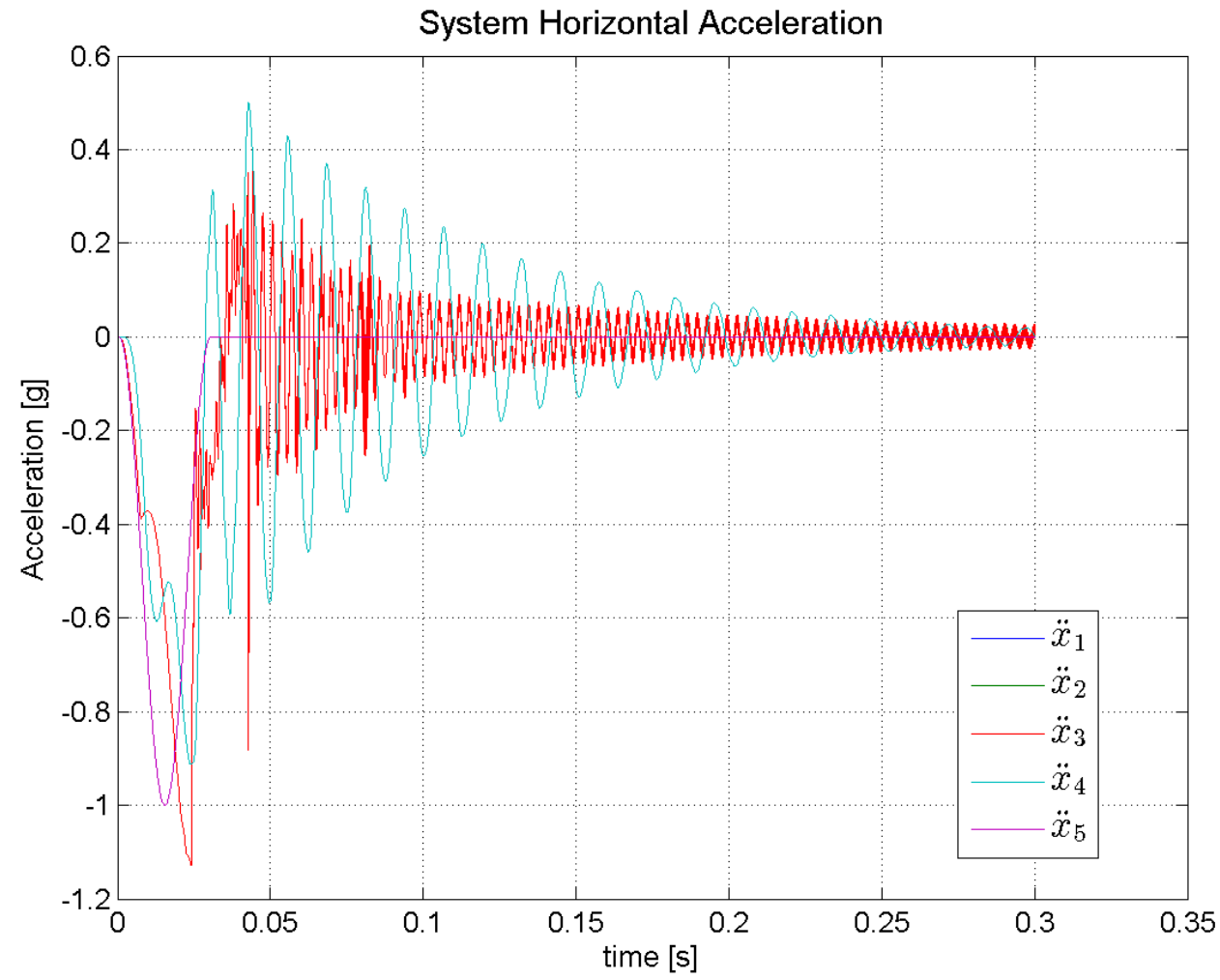

Figura 4.5: Acelerações Horizontais dos Corpos - Período de 30 ms 


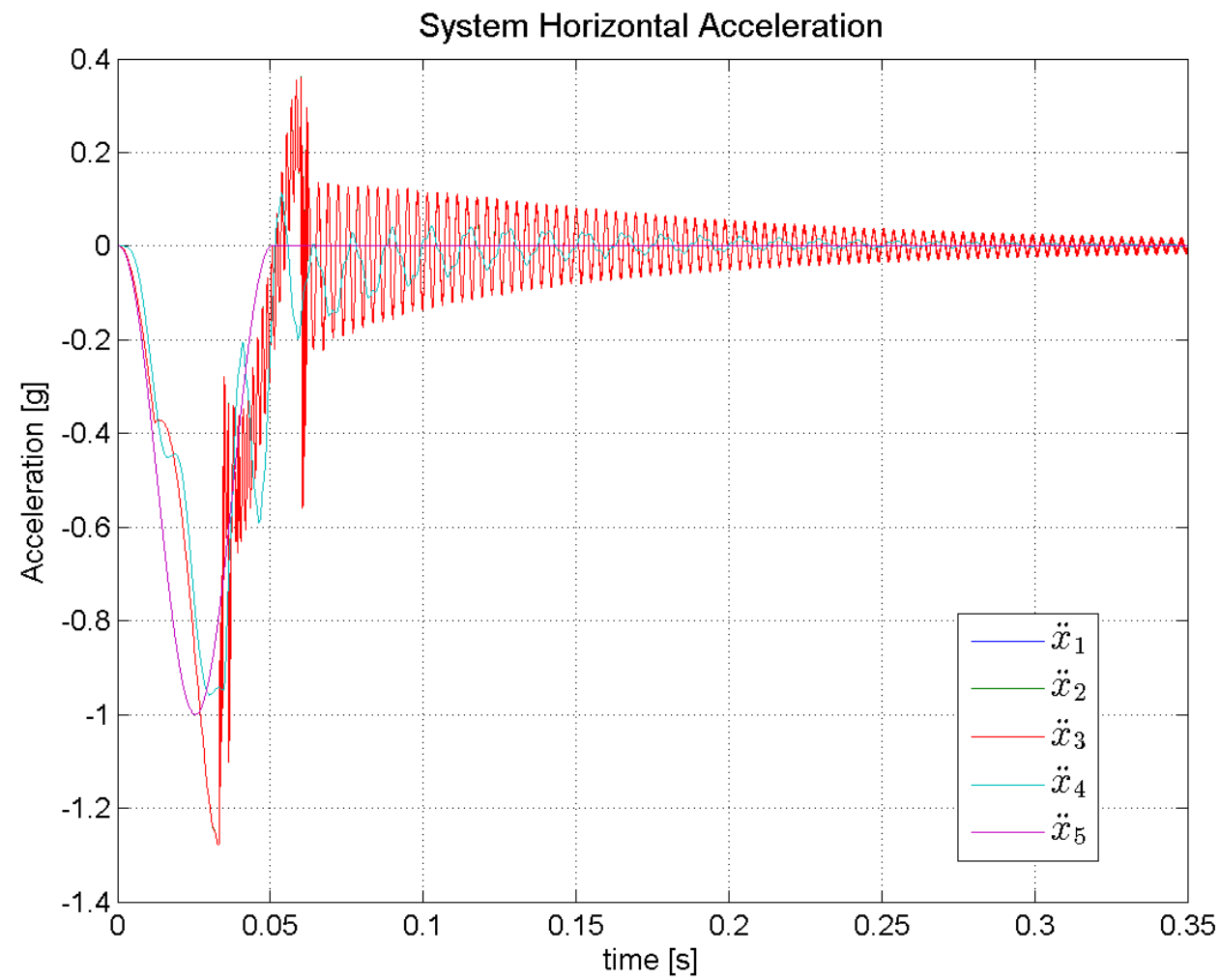

Figura 4.6: Acelerações Horizontais dos Corpos - Período de $50 \mathrm{~ms}$

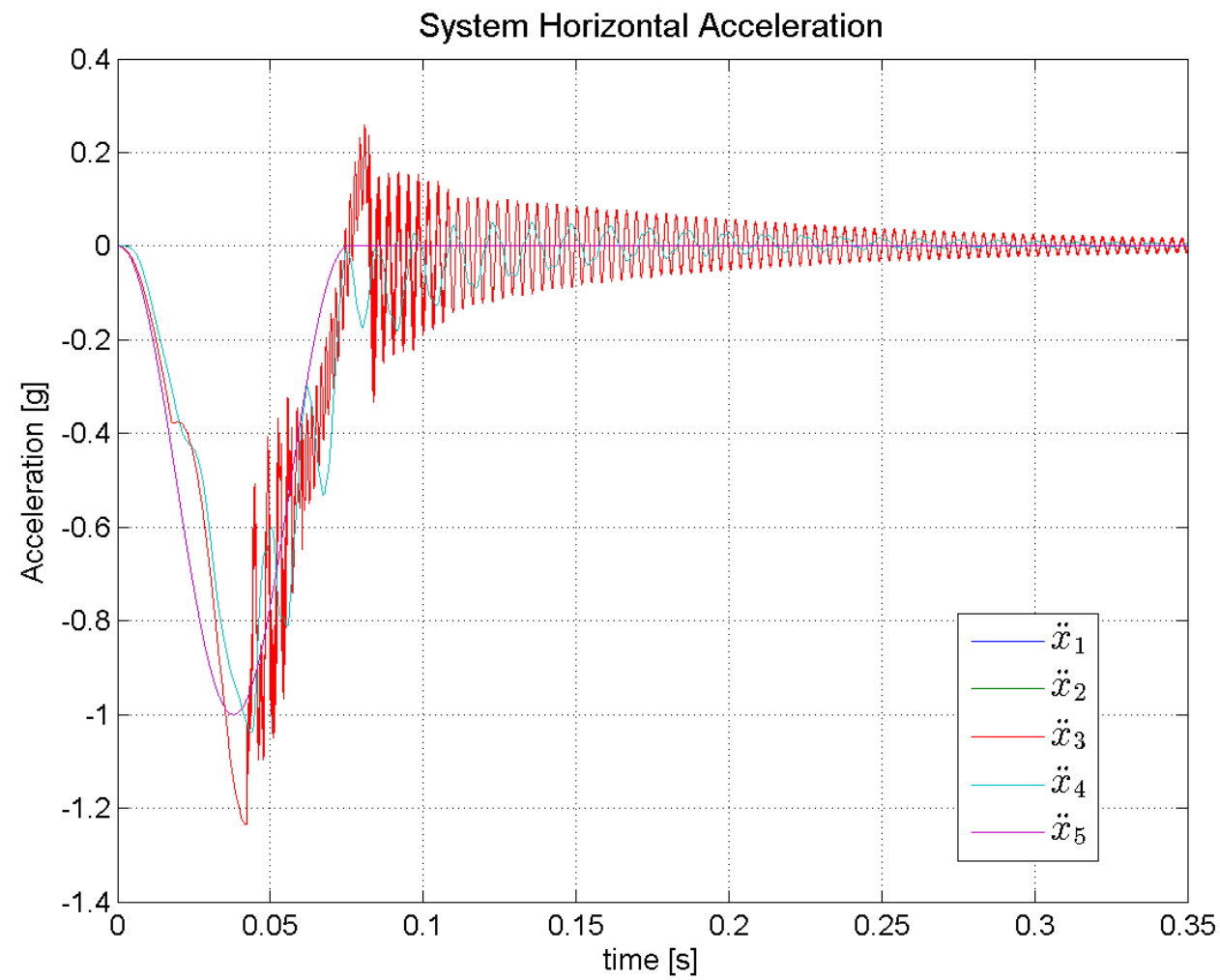

Figura 4.7: Acelerações Horizontais dos Corpos - Período de 75 ms 


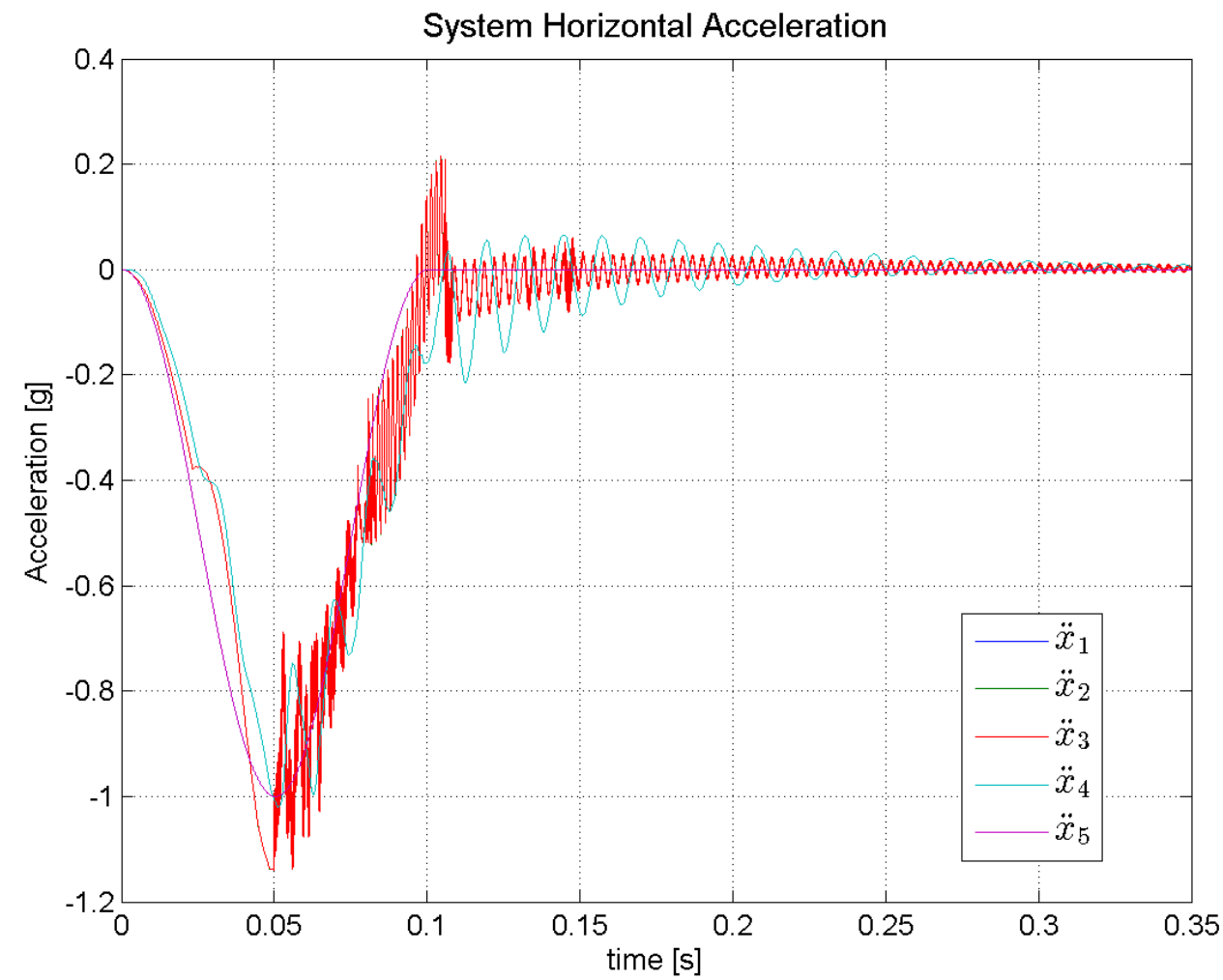

Figura 4.8: Acelerações Horizontais dos Corpos - Período de $100 \mathrm{~ms}$

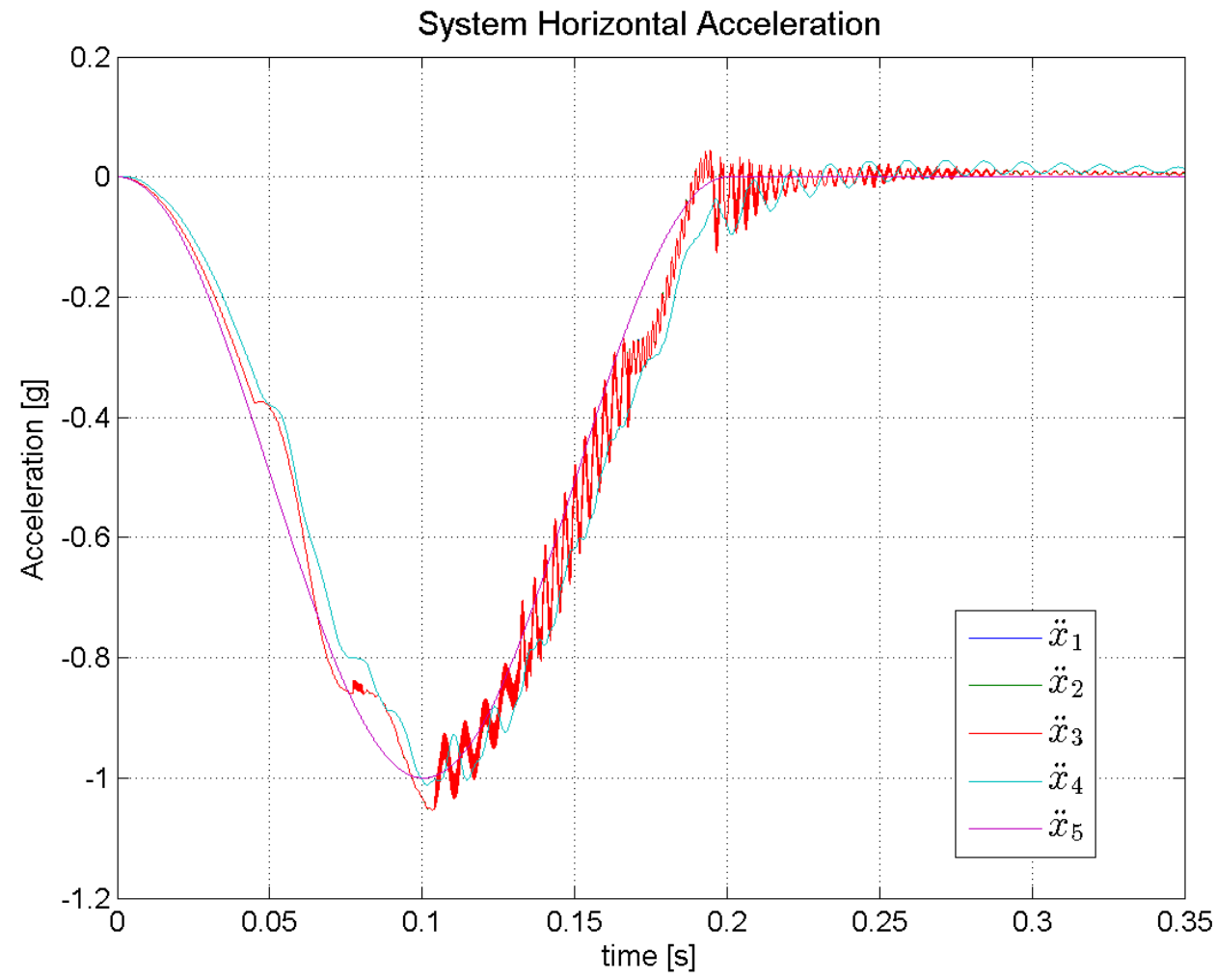

Figura 4.9: Acelerações Horizontais dos Corpos - Período de 200 ms 


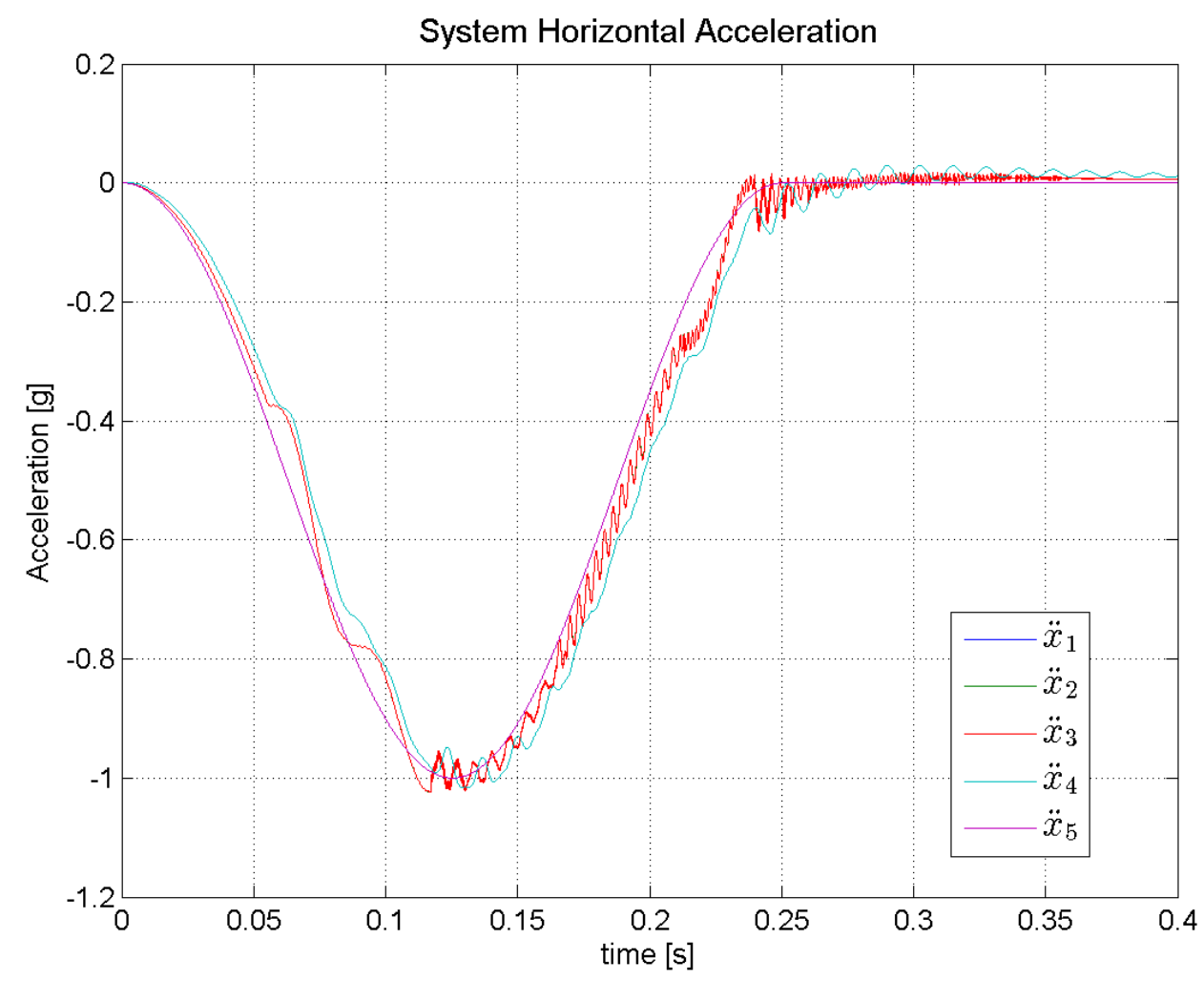

Figura 4.10: Acelerações Horizontais dos Corpos - Período de 250 ms 


\subsubsection{Resultados de Reações sobre a Parte Ativa}

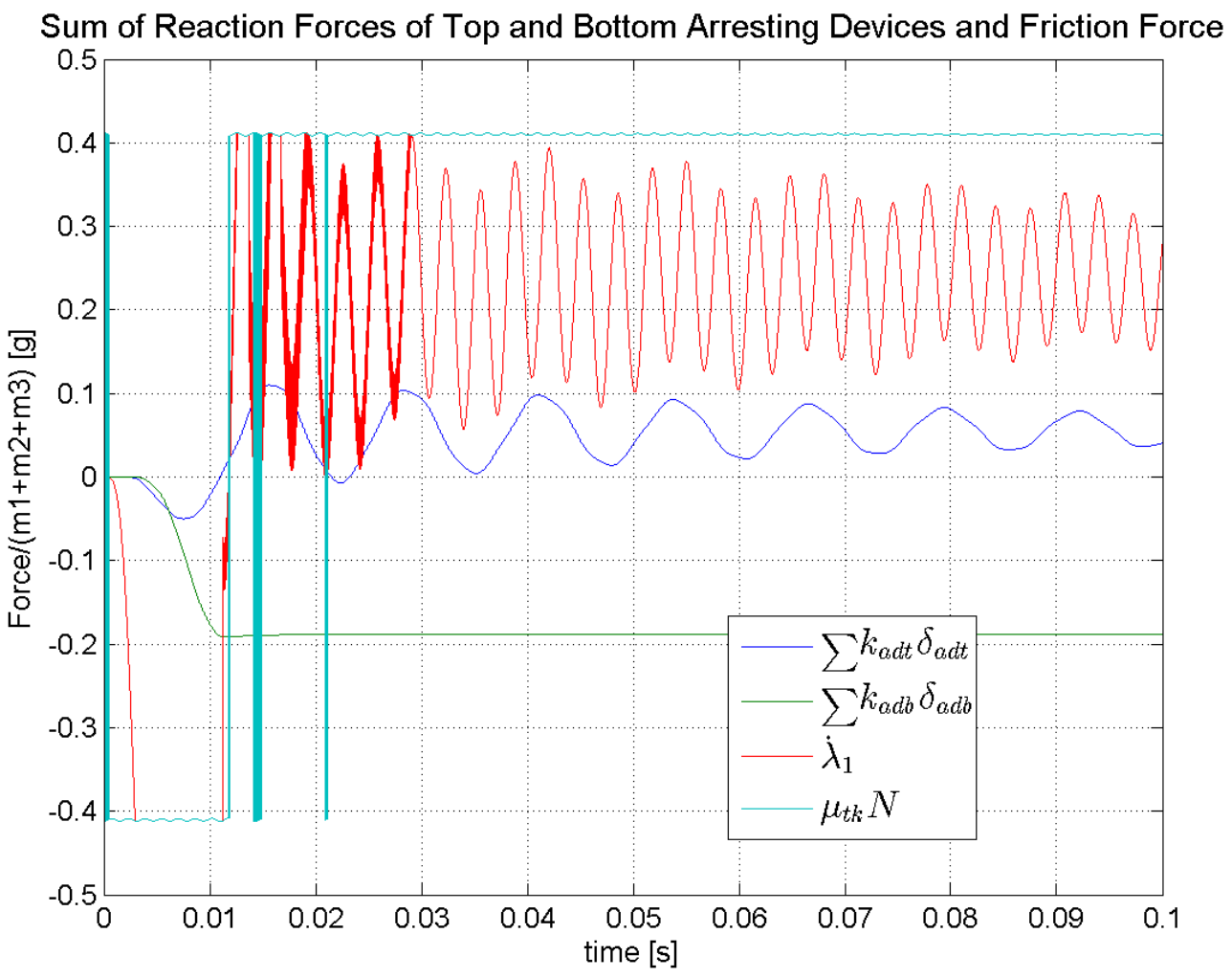

Figura 4.11: Reações (normalizadas) nas fixações superiores e inferiores da Parte Ativa e Atrito com o Fundo do tanque - Período de $10 \mathrm{~ms}$ 


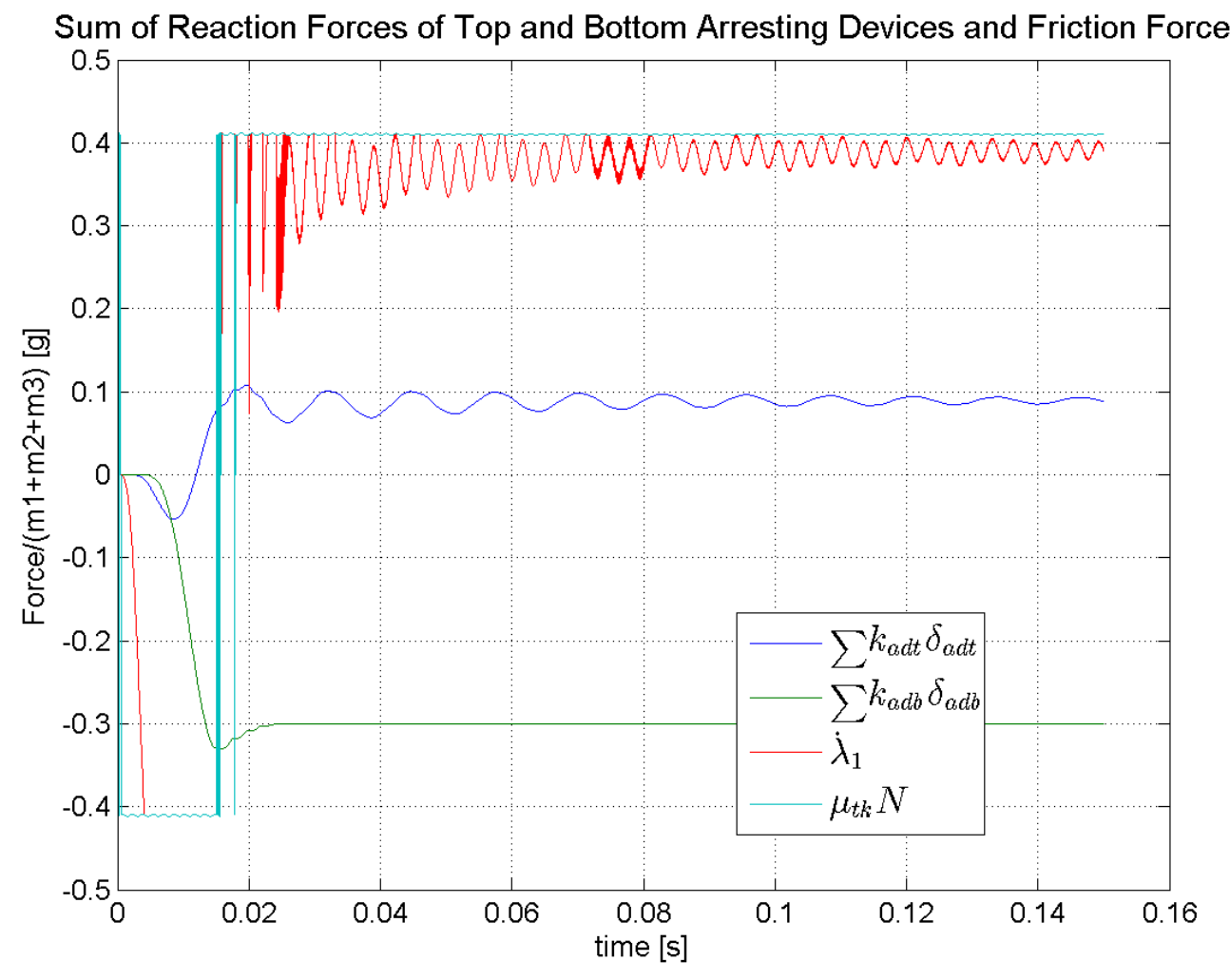

Figura 4.12: Reações (normalizadas) nas fixações superiores e inferiores da Parte Ativa e Atrito com o Fundo do tanque - Período de 15 ms

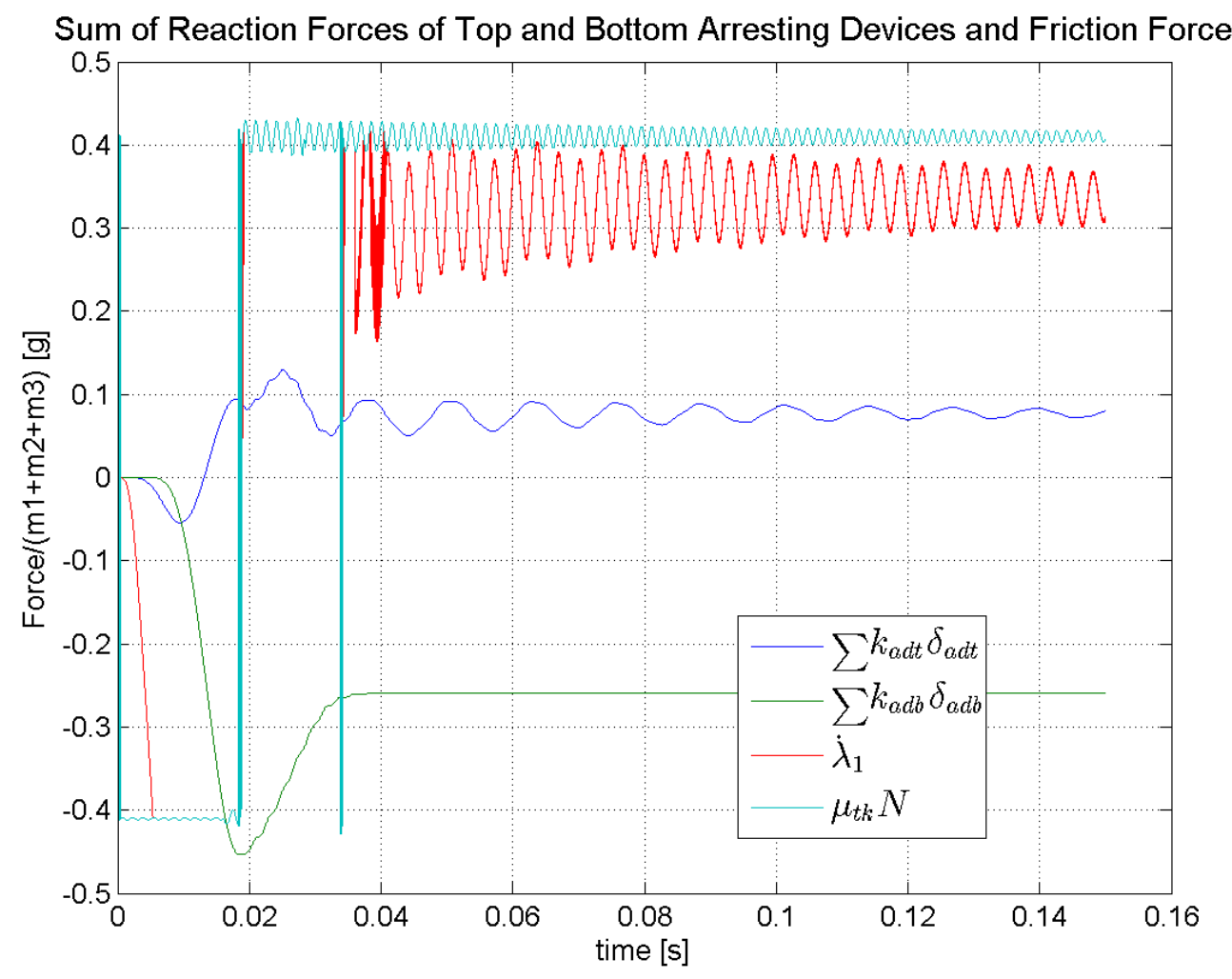

Figura 4.13: Reações (normalizadas) nas fixações superiores e inferiores da Parte Ativa e Atrito com o Fundo do tanque - Período de 20 ms 


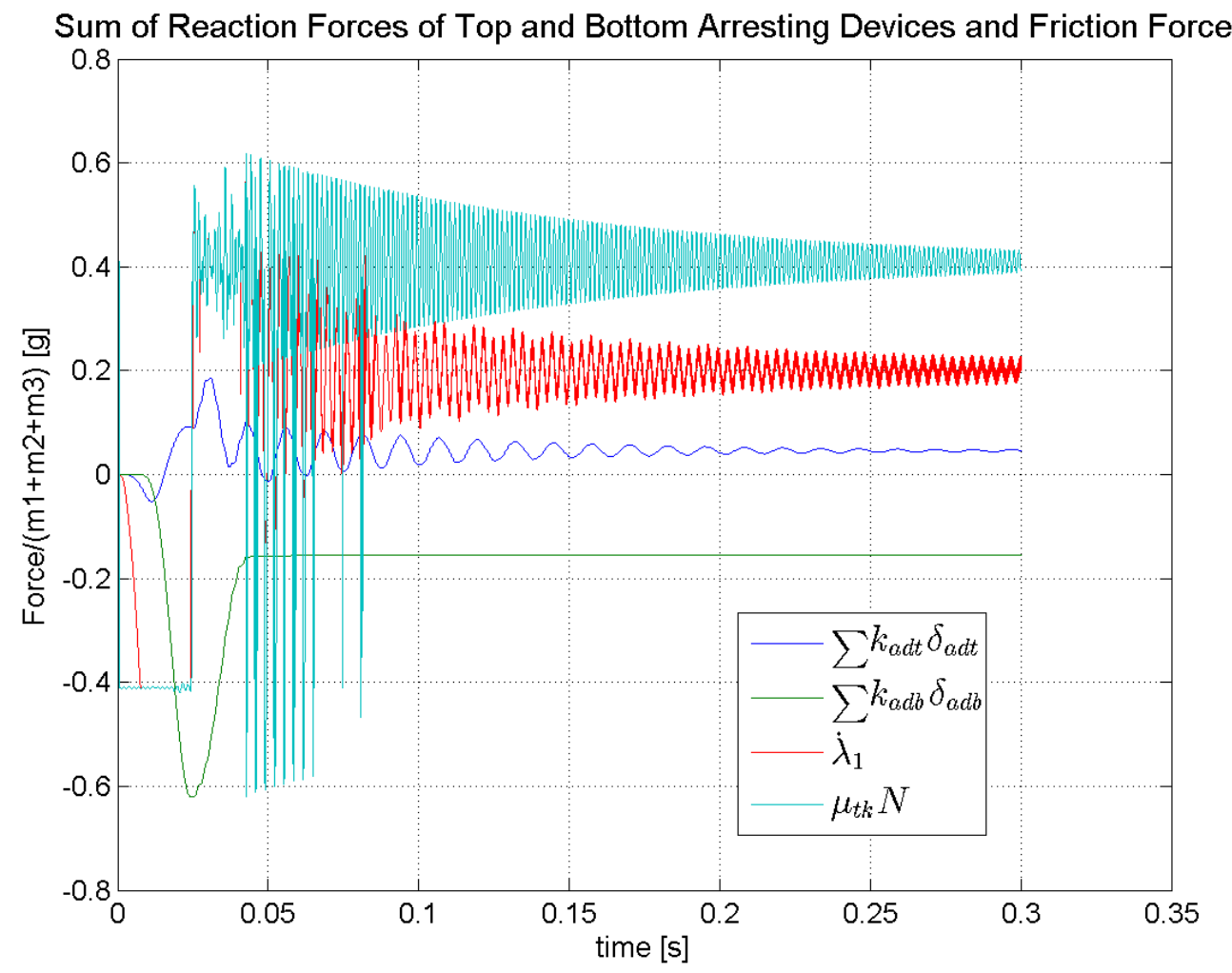

Figura 4.14: Reações (normalizadas) nas fixações superiores e inferiores da Parte Ativa e Atrito com o Fundo do tanque - Período de $30 \mathrm{~ms}$

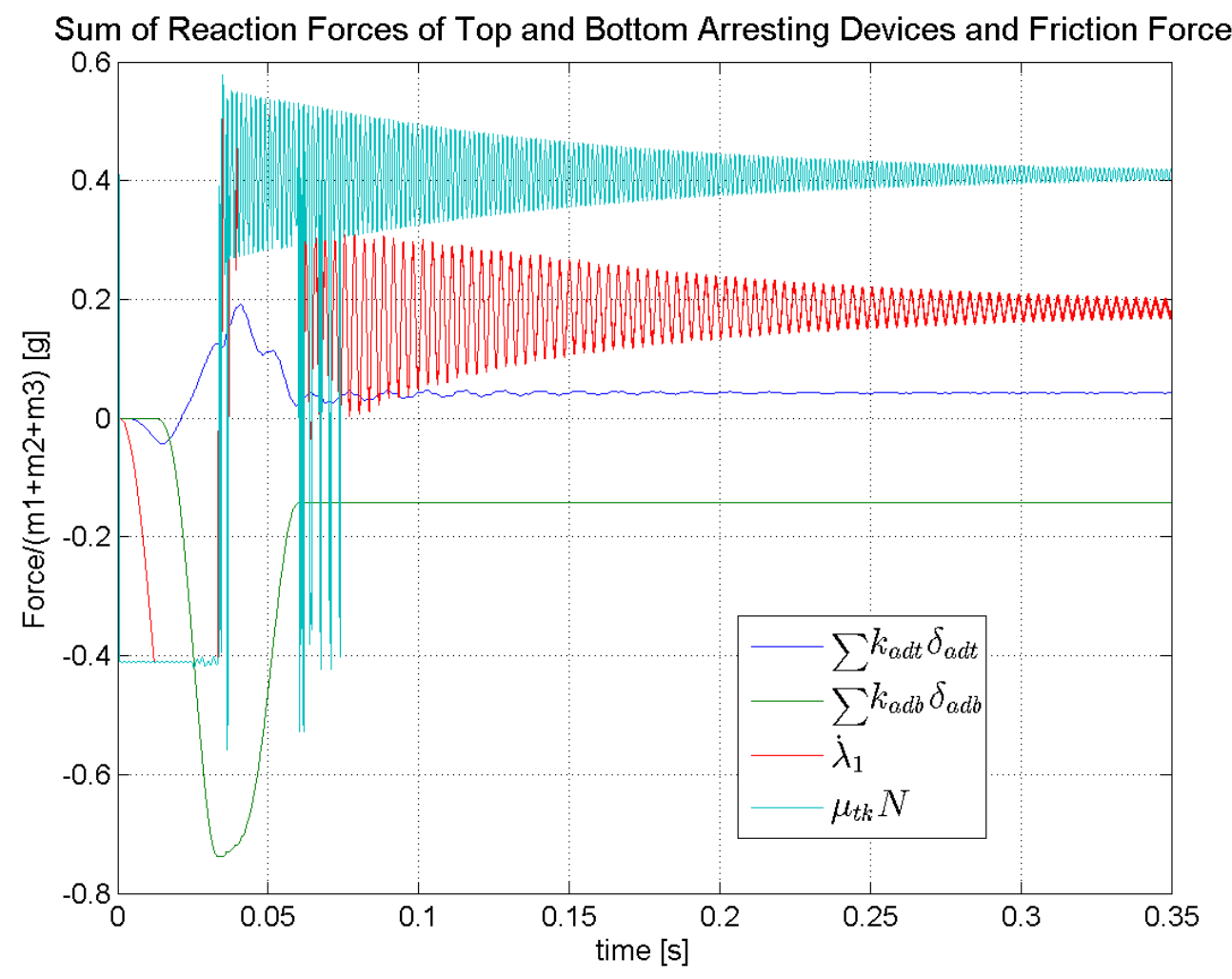

Figura 4.15: Reações (normalizadas) nas fixações superiores e inferiores da Parte Ativa e Atrito com o Fundo do tanque - Período de 50 ms 


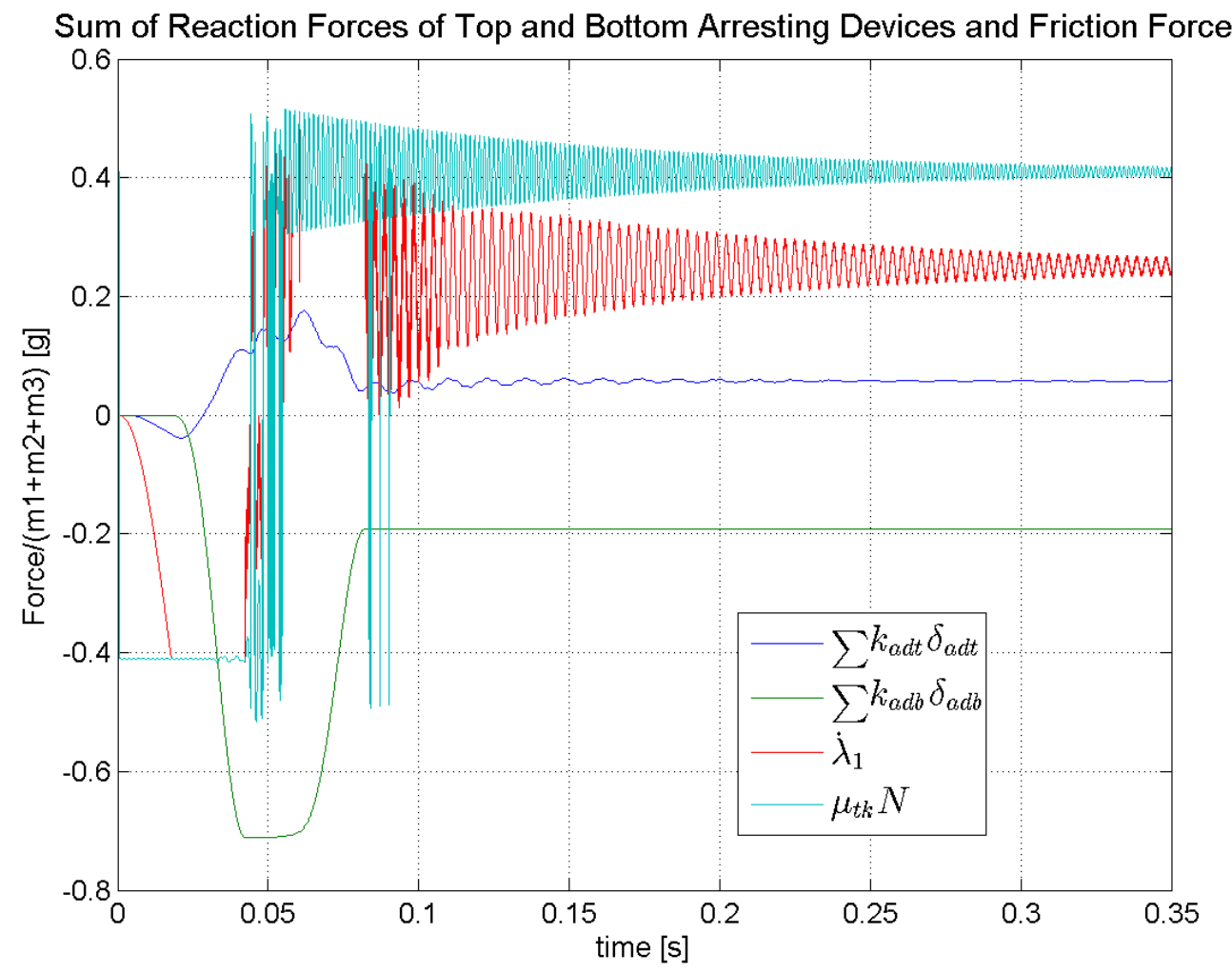

Figura 4.16: Reações (normalizadas) nas fixações superiores e inferiores da Parte Ativa e Atrito com o Fundo do tanque - Período de 75 ms

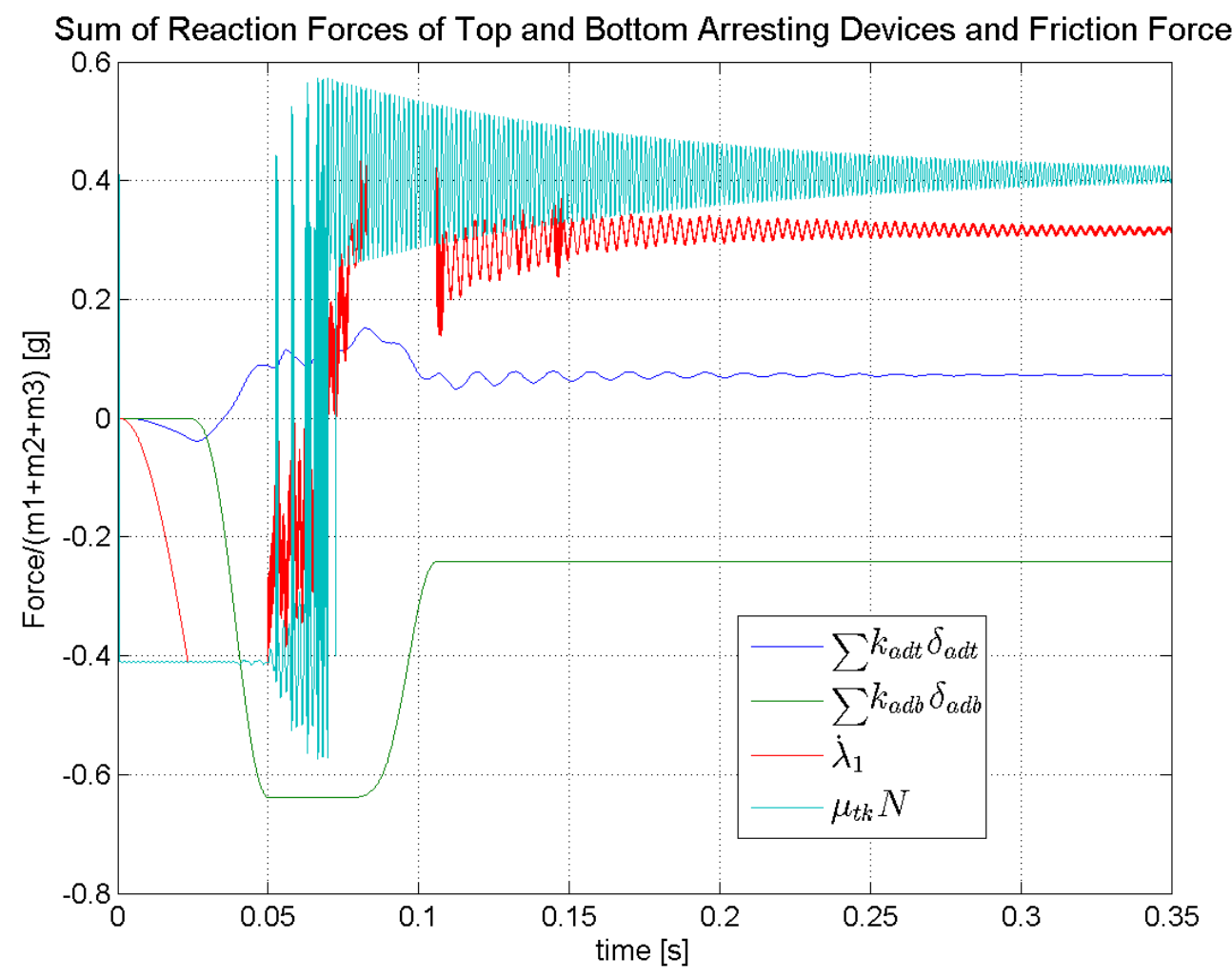

Figura 4.17: Reações (normalizadas) nas fixações superiores e inferiores da Parte Ativa e Atrito com o Fundo do tanque - Período de 100 ms 


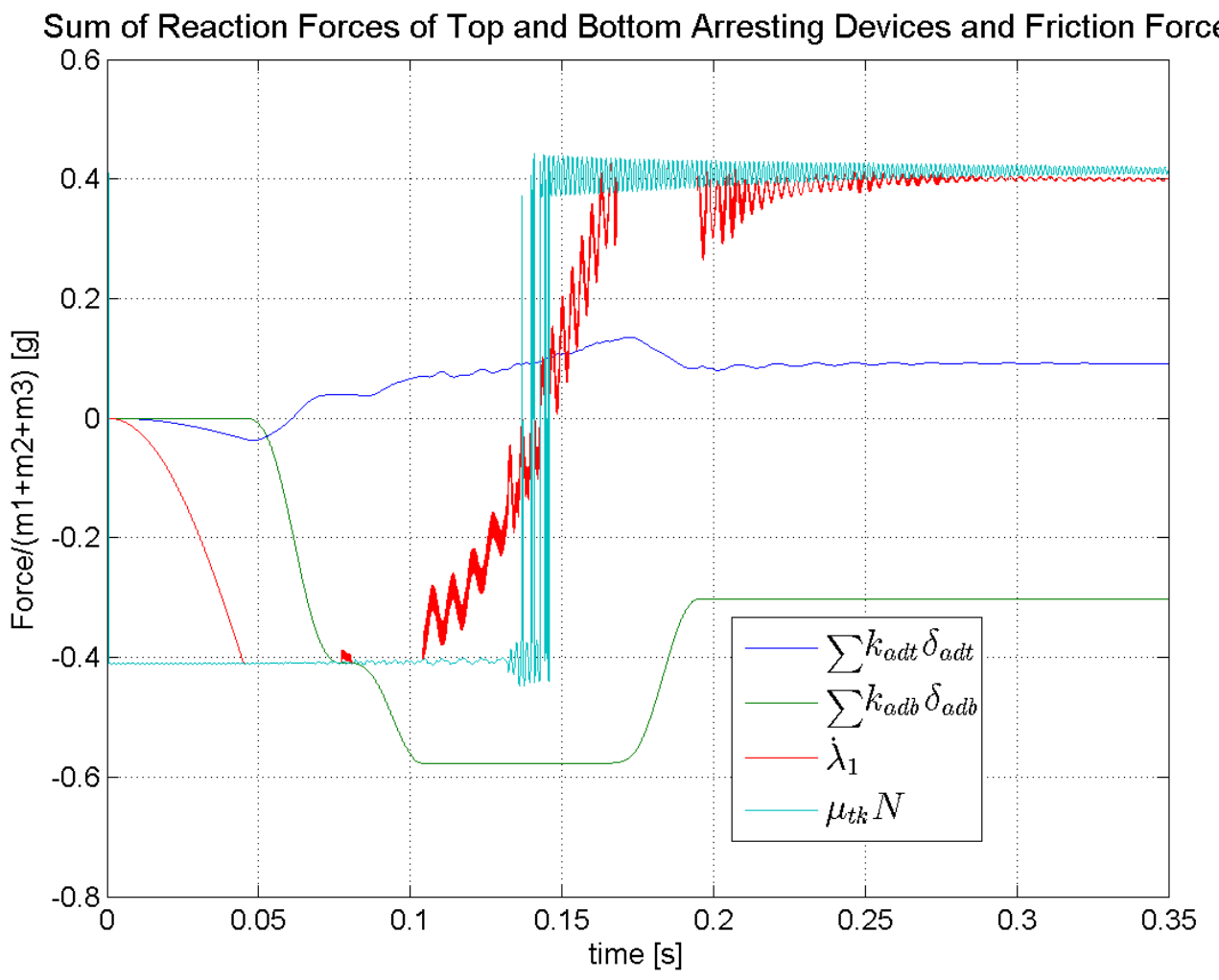

Figura 4.18: Reações (normalizadas) nas fixações superiores e inferiores da Parte Ativa e Atrito com o Fundo do tanque - Período de 200 ms

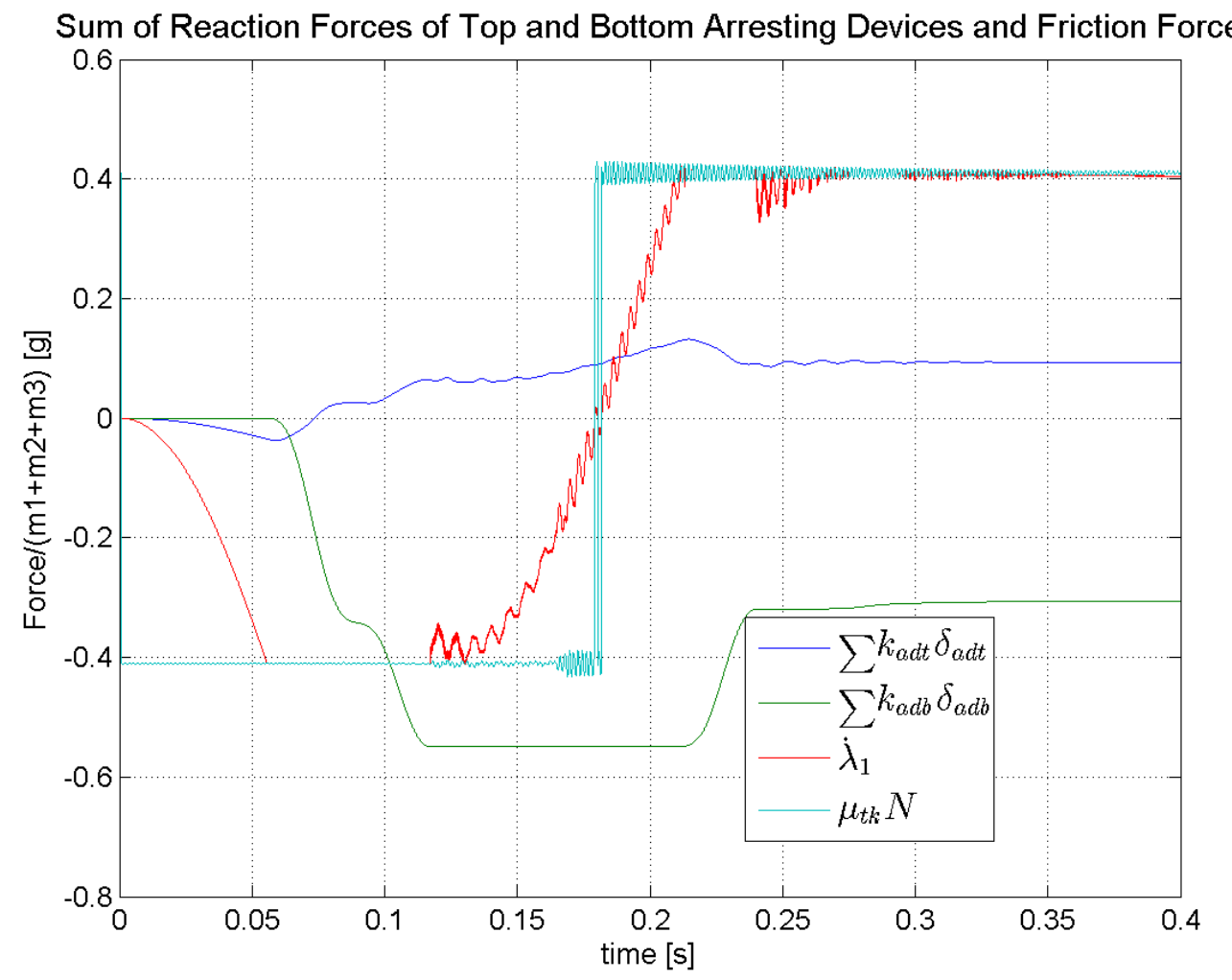

Figura 4.19: Reações (normalizadas) nas fixações superiores e inferiores da Parte Ativa e Atrito com o Fundo do tanque - Período de $250 \mathrm{~ms}$ 


\subsubsection{Discussões}

Nas figuras 4.2 a 4.10 estão apresentadas as acelerações horizontais de cada um dos cinco corpos do modelo. As acelerações dos corpos 1, 2 e 3 apresentam muito pouca diferença entre si, estando as curvas praticamente sobrepostas.

Presente em todas as figuras de 4.2 a 4.10, porém mais evidentes naquelas de menor duração de impacto, nota-se que, próximo de $0.4 g$, as acelerações dos corpos 1,2 e 3 deixam de acompanhar o sinal do veículo $\left(\ddot{x}_{5}\right)$, o que evidencia a ocorrência de escorregamento entre a parte ativa e o fundo do tanque.

Nota-se também a diferença na transmissibilidade do impacto do veículo com a variação da duração do mesmo. Para durações de impacto abaixo de $20 \mathrm{~ms}$, a aceleração percebida pela parte ativa do transformador é atenuada em relação à imposta ao veículo. Observa-se também que, principalmente em decorrência do escorregamento, o pico de aceleração da parte ativa está atrasado em relação ao sinal imposto.

Para durações de impacto entre 30 ms e 100 ms ocorre uma amplificação do sinal transmitido à parte ativa do transformador, com amplificação máxima observada de algo em torno de $25 \%$ para um período de impacto de $50 \mathrm{~ms}$.

Para as durações de $200 \mathrm{~ms}$ e $250 \mathrm{~ms}$ as acelerações da parte ativa acompanham o sinal imposto ao veículo com pequenas flutuações.

Já as acelerações da parte superior do tanque do transformador apresentam em todos os casos flutuações de maior amplitude em torno do sinal imposto ao veículo. Tal efeito é compreendido pelo fato de a parte superior ser consideravelmente flexível.

Podem-se observar os efeitos sobre as estruturas de fixação da parte ativa ao tanque nas figuras 4.11 a 4.19 .

As figuras 4.11 a 4.19 mostram os gráficos dos esforços horizontais que atuam sobre a parte ativa do transformador. Nesses gráficos os valores de força foram normalizados pela força peso da parte ativa com suas colunas extremas.

Estão indicados nos gráficos as soma das reações nas fixações inferiores, das fixações superiores e da força de atrito existente entre as sapatas da parte ativa e o fundo do tanque. Está representada também, a título de indicação, a máxima magnitude de força de atrito possível $\left(\mu_{t k} N\right)$.

Pode-se notar que os esforços que são reagidos pelas fixações inferiores são dependentes da duração do escorregamento da parte ativa $\left(F_{a t r}=\mu_{t k} N\right)$. Caso 
o tempo em que essa igualdade se verifica seja curto, há pouco repasse de força a essas fixações, aumentando a medida que esse período se estende.

Em decorrência desse fato, vê-se que a duração do escorregamento entre os corpos é, de certa forma, correlacionada com a duração do período de desaceleração do veículo.

Para períodos de desaceleração do veículo inferiores a $15 \mathrm{~ms}$, a força repassada às fixações inferiores não superam a força de atrito. A partir de $20 \mathrm{~ms}$ de duração do impacto, esse repasse de forças aumenta, tendo seu máximo em $50 \mathrm{~ms}$.

Nota-se também que gradativamente esse repasse máximo diminui a partir de $100 \mathrm{~ms}$.

Consequentemente ao fato de ter havido um primeiro escorregamento da parte ativa em relação ao fundo do transformador, em instantes subsequentes esse mesmo atrito tenta impedir o retorno da parte ativa à sua posição relativa original.

Para o caso de impacto com duração de $10 \mathrm{~ms}$, os esforços de inércia e das fixações não são suficientes para provocar um movimento de retorno da parte ativa. O mesmo fato não se observa em nenhum dos outros casos.

Entretanto, em nenhum dos casos é possível observar um retorno completo da parte ativa à sua posição original, tendo-se então um deslocamento residual.

Por sua vez, os esforços repassados às fixações superiores são de magnitude inferior aos observados no atrito e nas fixações inferiores.

Nota-se também flutuações em seu valores, possíveis de serem compreendidas pela existência do grau de liberdade de movimentação horizontal do tanque.

Apesar de ser possível intuir a partir dos gráficos, cabe, porém, aqui uma explicação sobre o sinal das reações das fixações superiores. Quando positivas, as forças das fixações superiores que atuam sobre a parte ativa agem no sentido contrário ao eixo horizontal.

Isto posto, ao se analisar as reações das fixações superiores com maior cuidado, nota-se que nos instantes iniciais da aplicação do carregamento, em vez de as mesmas impedirem a movimentação relativa da parte ativa, vê-se que que a parte ativa ajuda a transmitir o impacto à parte superior do tanque, sustentando-a. Este fato é observado em todos os casos de carregamento. 


\subsection{Avaliação dos Efeitos da Amplitude de Impac- tos}

Para este estudo foi aplicada sobre o veículo de transporte uma desaceleração tal que houvesse uma variação de velocidade de $490.5 \mathrm{~mm} / \mathrm{s}$ (variação de velocidade para um sinal de aceleração de $1 g$ com duração de $100 \mathrm{~ms}$ ), fazendo-o chegar ao repouso. Em outras palavras, uma variação fixa da energia cinética de translação horizontal do veículo. Com isso foram variadas a amplitude e a duração de desaceleração. A forma de onda pode ser vista na figura 4.1.

\subsubsection{Resultados de Acelerações Horizontais}

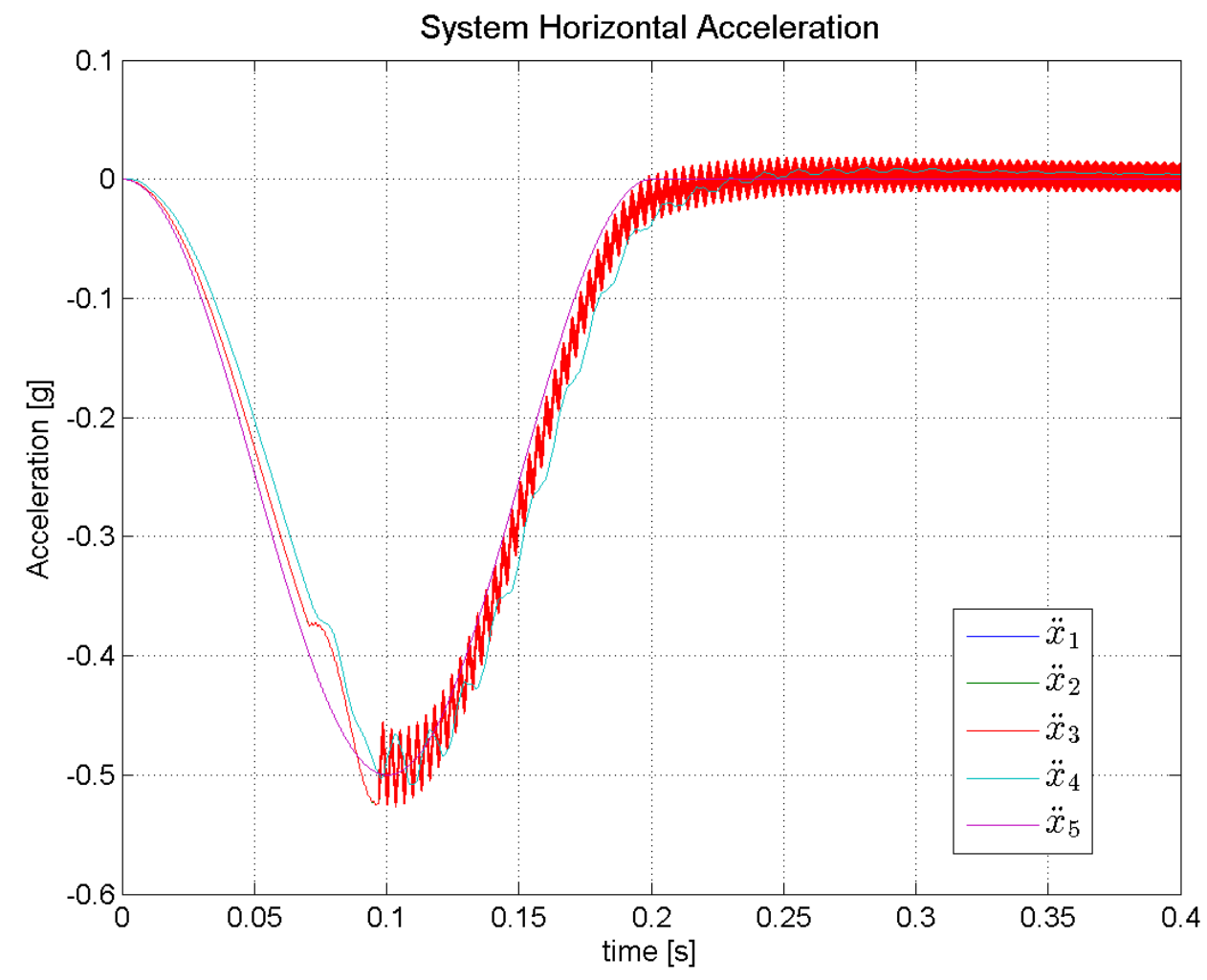

Figura 4.20: Acelerações Horizontais dos Corpos - Amplitude de 0.5gPeríodo de $200 \mathrm{~ms}$ 


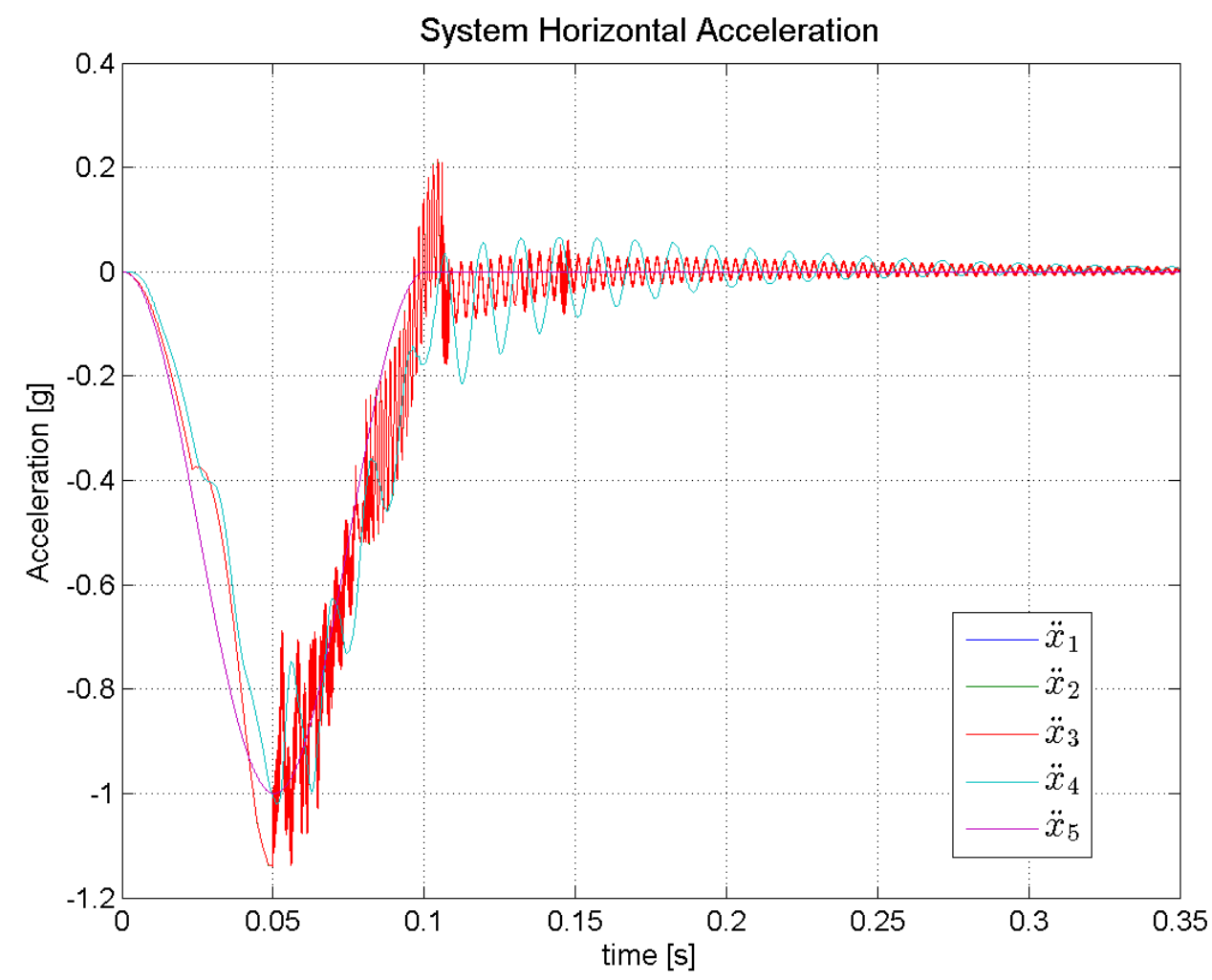

Figura 4.21: Acelerações Horizontais dos Corpos - Amplitude de $1.0 \mathrm{~g}$ Período de $100 \mathrm{~ms}$

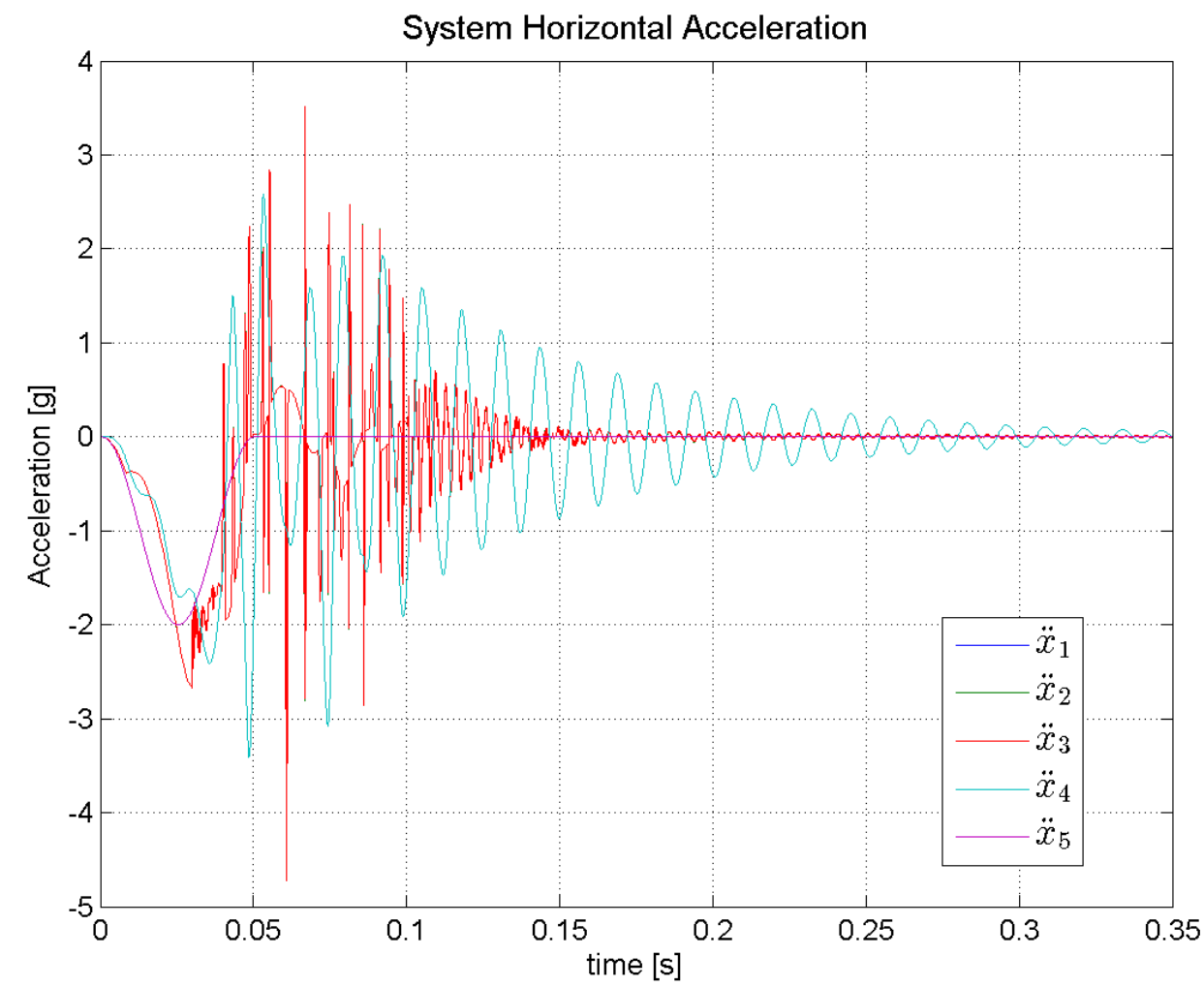

Figura 4.22: Acelerações Horizontais dos Corpos - Amplitude de $2.0 \mathrm{~g}$ Período de $50 \mathrm{~ms}$ 


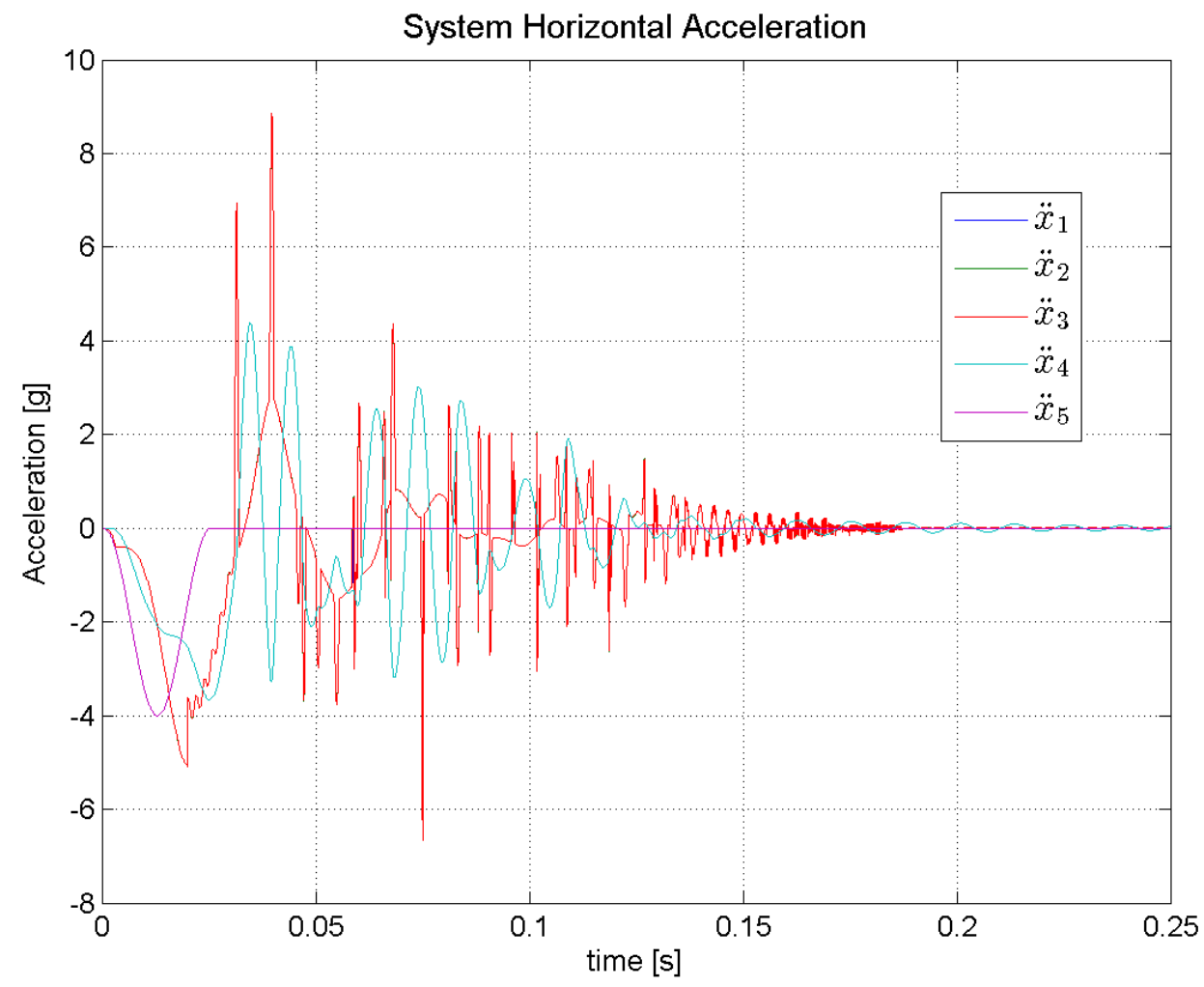

Figura 4.23: Acelerações Horizontais dos Corpos - Amplitude de $4.0 \mathrm{~g}$ Período de $25 \mathrm{~ms}$ 


\subsubsection{Resultados de Reações sobre a Parte Ativa}

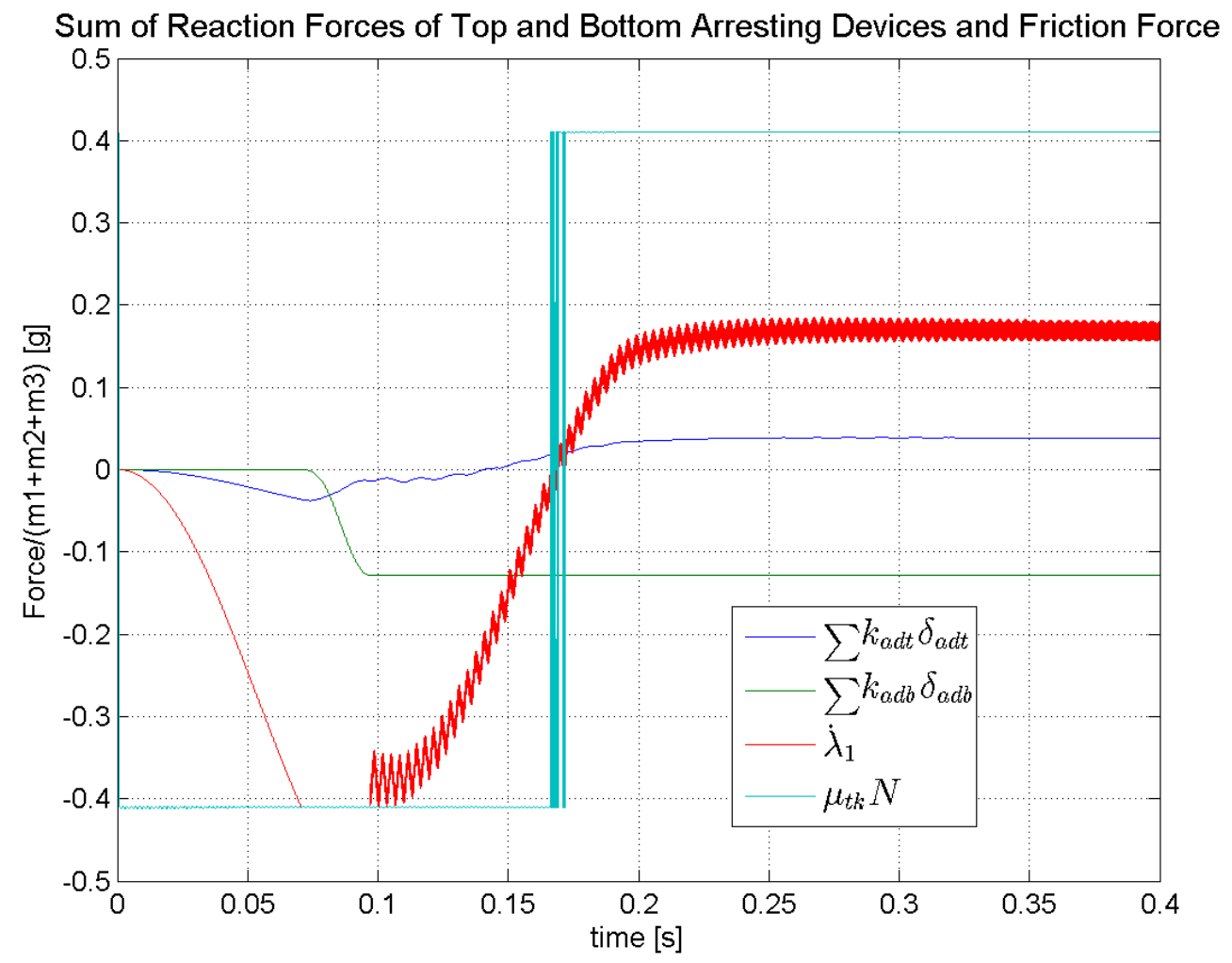

Figura 4.24: Reações (normalizadas) nas fixações superiores e inferiores da Parte Ativa e Atrito com o Fundo do tanque - Amplitude de $0.5 \mathrm{~g}$ - Período de $200 \mathrm{~ms}$ 


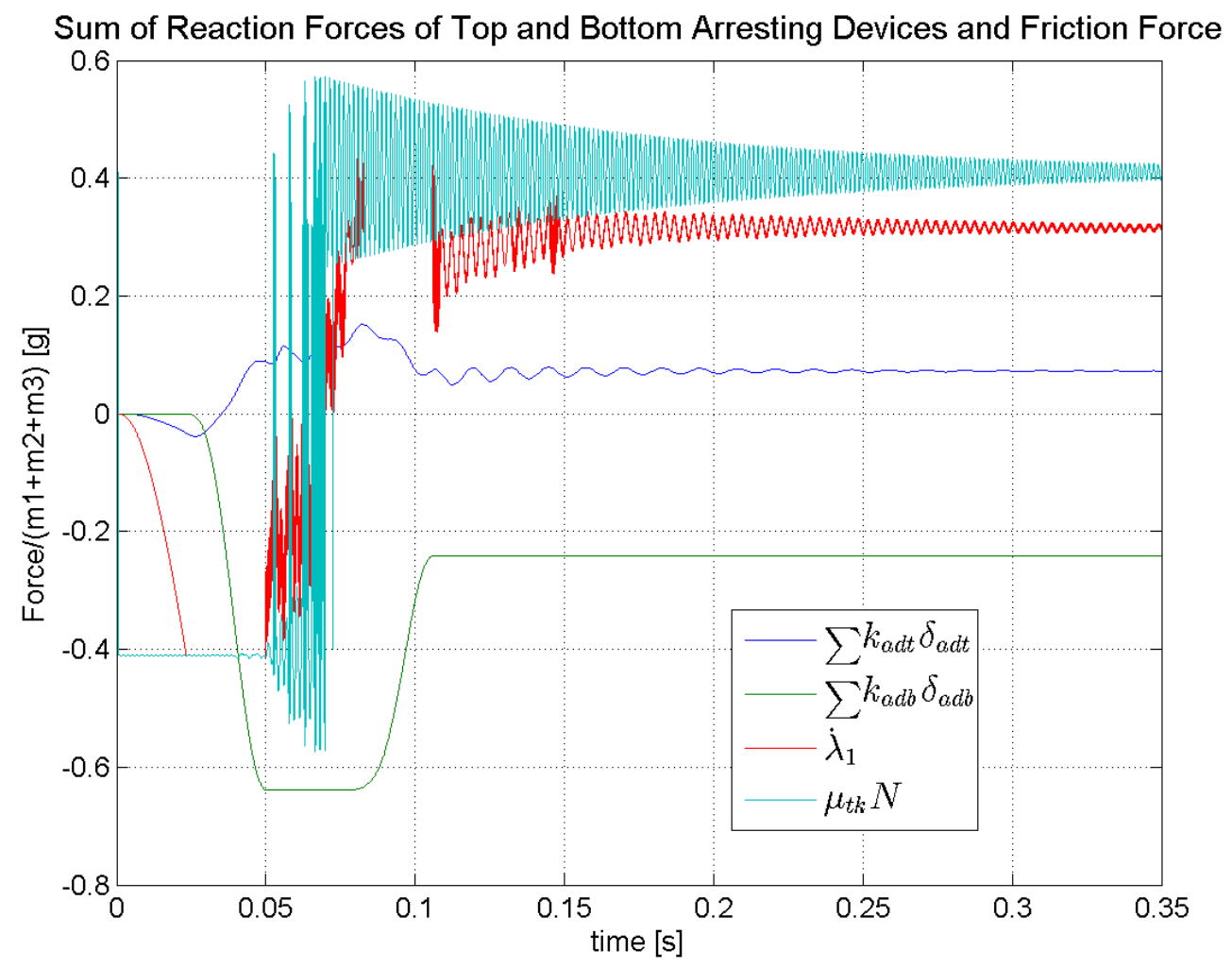

Figura 4.25: Reações (normalizadas) nas fixações superiores e inferiores da Parte Ativa e Atrito com o Fundo do tanque - Amplitude de $1.0 \mathrm{~g}$ - Período de $100 \mathrm{~ms}$

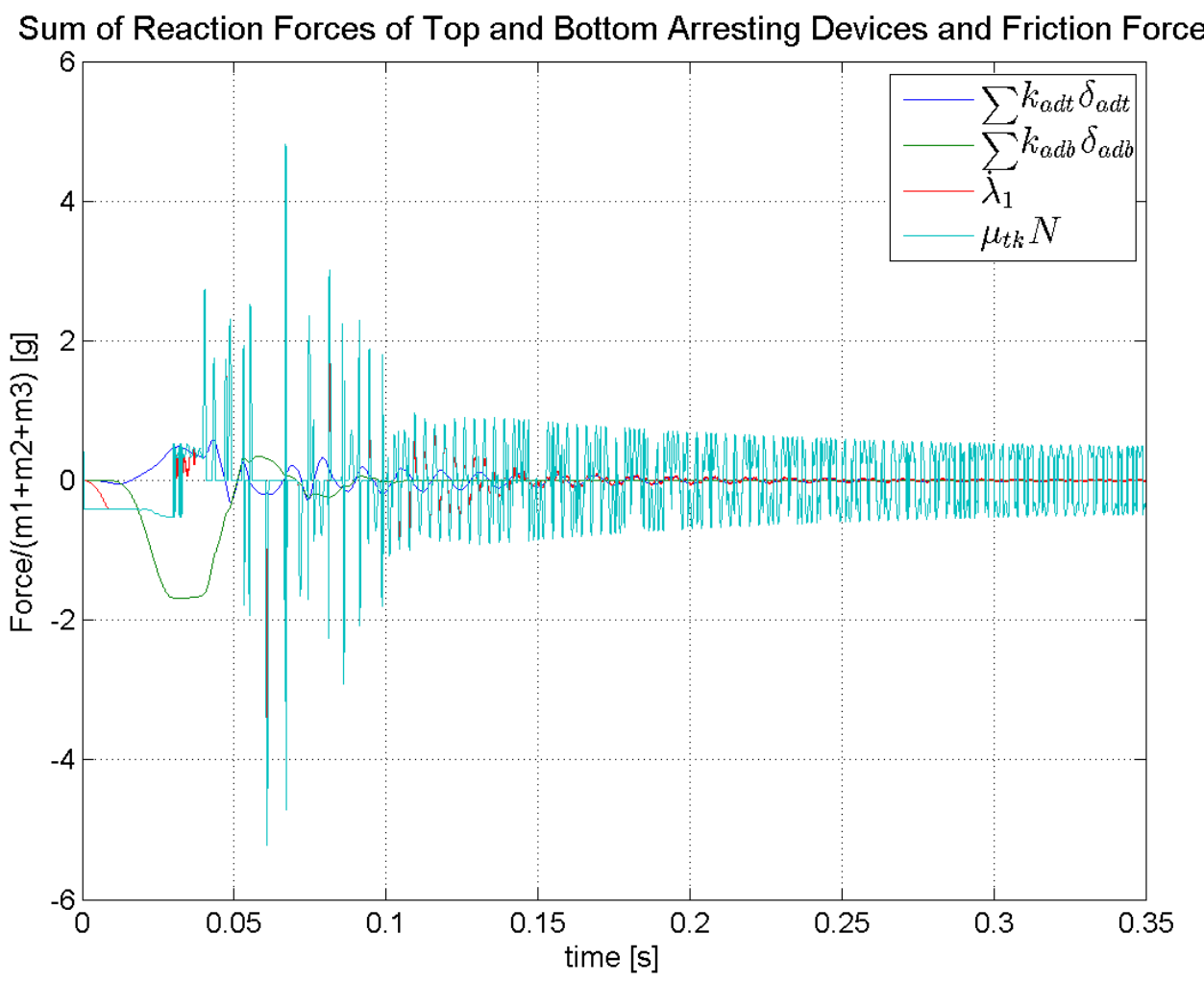

Figura 4.26: Reações (normalizadas) nas fixações superiores e inferiores da Parte Ativa e Atrito com o Fundo do tanque - Amplitude de $2.0 \mathrm{~g}$ - Período de $50 \mathrm{~ms}$ 


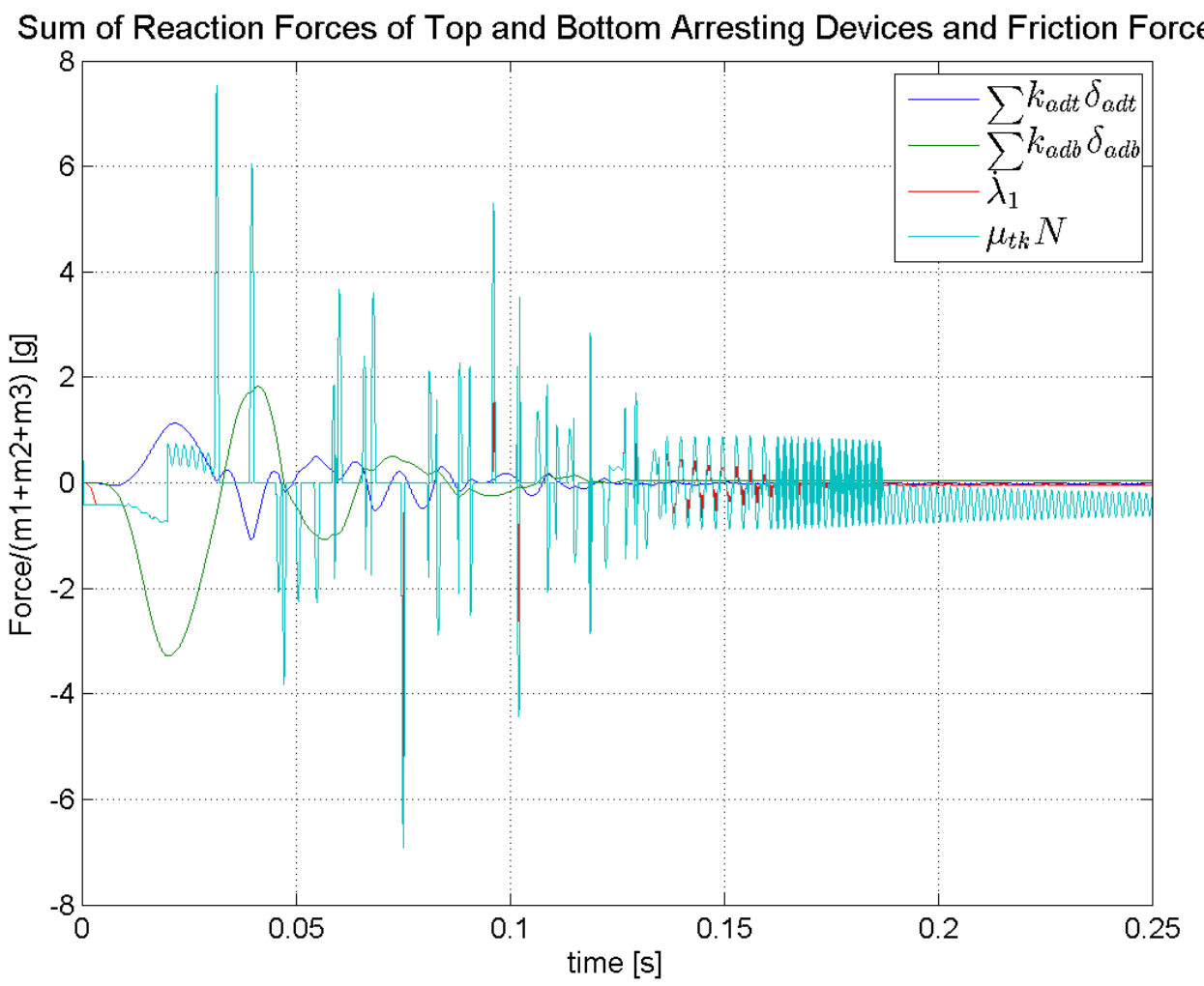

Figura 4.27: Reações (normalizadas) nas fixações superiores e inferiores da Parte Ativa e Atrito com o Fundo do tanque - Amplitude de $4.0 \mathrm{~g}$ - Período de $25 \mathrm{~ms}$ 


\subsubsection{Discussões}

Os gráficos de aceleração horizontal dos corpos vistos nas figuras 4.20 a 4.23 não permitem uma clara distinção entre quais efeitos se devem à duração do evento e quais se devem às amplitudes de aceleração.

Entretanto, são aqui apresentados para clarificar questões recentemente levantadas entre os fabricantes de transformador. De que tão importante quanto as amplitudes de aceleração, a variação de uma quantidade fixa de energia cinética pode indicar dano ao equipamento.

Pode-se notar que, se comparados aos observados na seção 4.2, aqueles com amplitude de aceleração acima de $2 g$ mostram não só valores de pico alternando de direção, como o próprio comportamento da média de aceleração da parte ativa é alternado, apresentando overshoot e undershoot.

Este fato indica a ocorrência de movimentação interna da parte ativa não somente no sentido do deslocamento do veículo, como também em sentido contrário.

Enquanto que para o impacto de $0.5 \mathrm{~g}$ em $200 \mathrm{~ms}$ houve uma ligeira amplificação do sinal de aceleração tanto na parte ativa quanto na parte superior do tanque, para todos os outros casos esta amplificação mostrou-se mais expressiva, o que também pôde ser observado na seção 4.2, quando a duração do sinal de desaceleração do tanque encontrava-se dentro de uma determinada faixa.

Neste caso, alia-se às curtas durações dos impactos o fato de que as altas amplitudes dos mesmos diminuam o papel desempenhado pelo atrito em conter o movimento da parte ativa em relação ao fundo do tanque, em comparação com o das fixações.

Como visto nas discussões da seção 4.2, as fixações inferiores somente começam a atuar a partir do momento em que o atrito estático foi vencido.

Analisando o atrito e as reações de fixação para cada um dos casos analisados, nota-se semelhança no aspecto geral dos resultados obtidos para o caso de $0.5 \mathrm{~g}$, visto na figura 4.24 com o verificado para o caso mostrado na figura 4.11.

Apesar da considerável diferença da duração de aplicação de carregamento nesses casos, vê-se que a baixa amplitude de impacto (figura 4.24) desempenhou papel semelhante ao da curta duração do impacto na redução do período em que o atrito entre as partes foi vencido.

Como já dito, em razão do curto período de escorregamento, o repasse de 
carregamento às fixações inferiores é reduzido.

As figuras 4.26 e 4.27, por sua vez mostram um comportamento diferente da força de atrito. Por um relativamente longo período durante e após o impacto, a força de atrito ainda encontra-se limitada pelo seu valor limite. Este fato permite que haja um deslocamento interno considerável da parte ativa, o que, para ambos os casos, implica em que quase a totalidade do carregamento inercial seja reagido pelas fixações inferiores.

Um outro ponto interessante de se notar nestes dois casos é que o sistema tende a se estabilizar após o impacto próximo às posições relativas iniciais. 


\subsection{Avaliação dos Efeitos da Velocidade de Trá- fego em Pista com Sonorizador}

Nesta seção são apresentados os resultados dos estudos considerando a aplicação de carregamento feita por meio de irregularidades de pista.

Foi utilizado para tal estudo o perfil de sonorizador, definido em (25). De acordo com essa resolução, o perfil de pista do sonorizador possui altura máxima de régua de $25 \mathrm{~mm}$ com espaçamento entre réguas de $80 \mathrm{~mm}$. Foram consideradas nessa análise 4 réguas.

Para o conjunto de transporte conforme especificado na seção 4.1, foram feitas simulações considerando a velocidade de tráfego do veículo variando de $30 \mathrm{~km} / \mathrm{h}$ a $90 \mathrm{~km} / \mathrm{h}$, em intervalos de $10 \mathrm{~km} / \mathrm{h}$.

\subsubsection{Resultados de Acelerações Verticais}

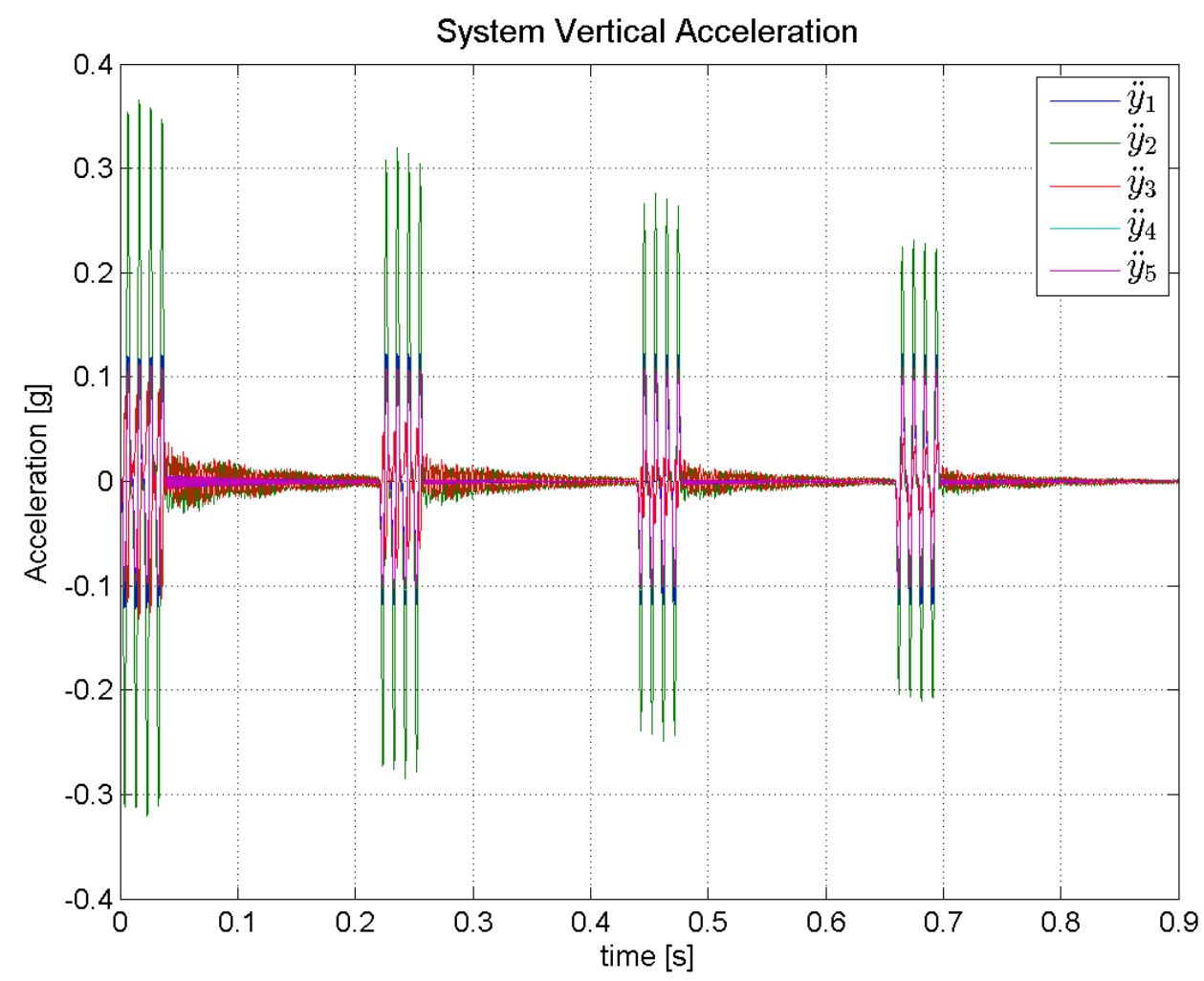

Figura 4.28: Acelerações verticais do sistema para tráfego com diferentes velocidades em pista com irregularidades - Velocidade de $30 \mathrm{~km} / \mathrm{h}$ 


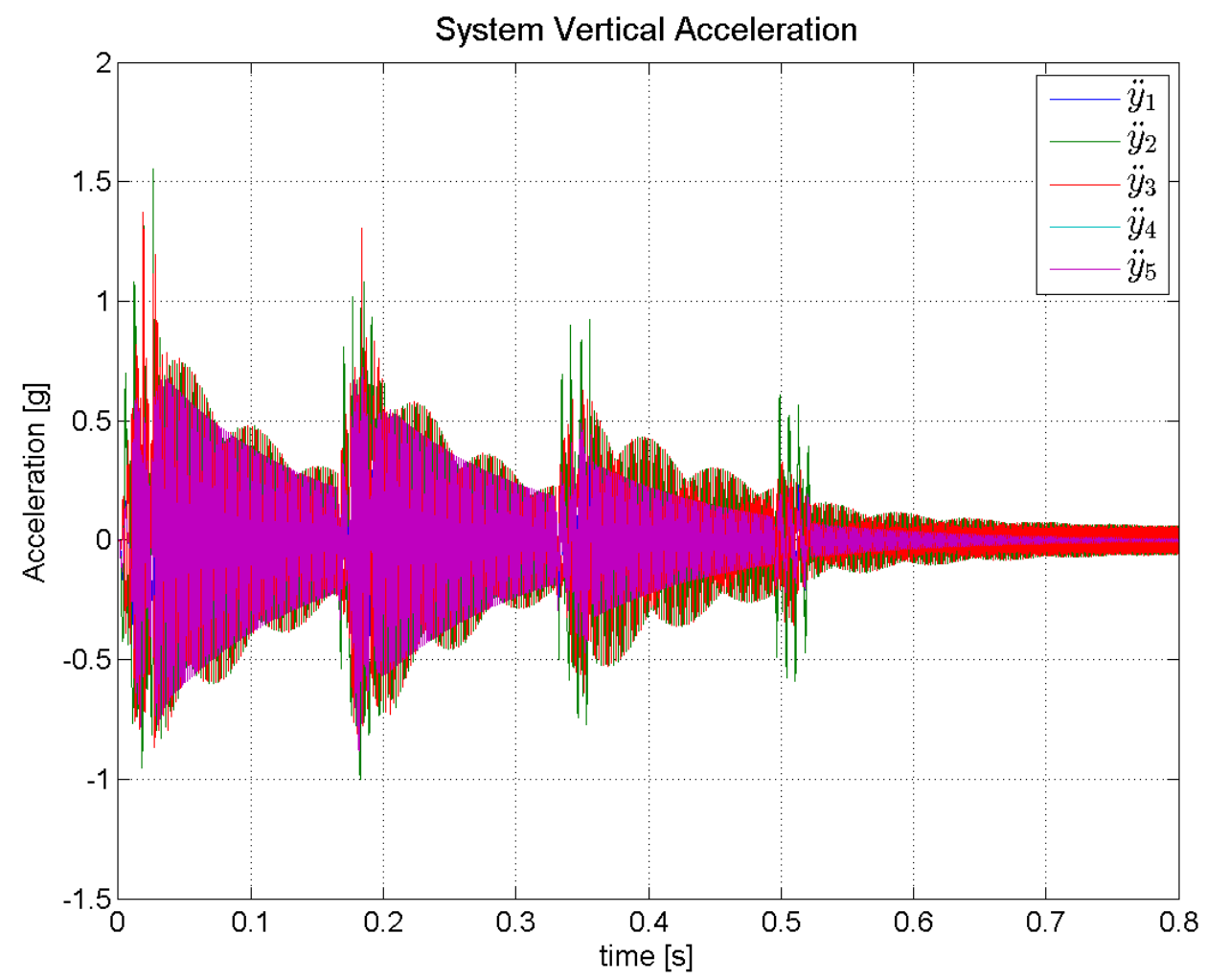

Figura 4.29: Acelerações verticais do sistema para tráfego com diferentes velocidades em pista com irregularidades - Velocidade de $40 \mathrm{~km} / \mathrm{h}$

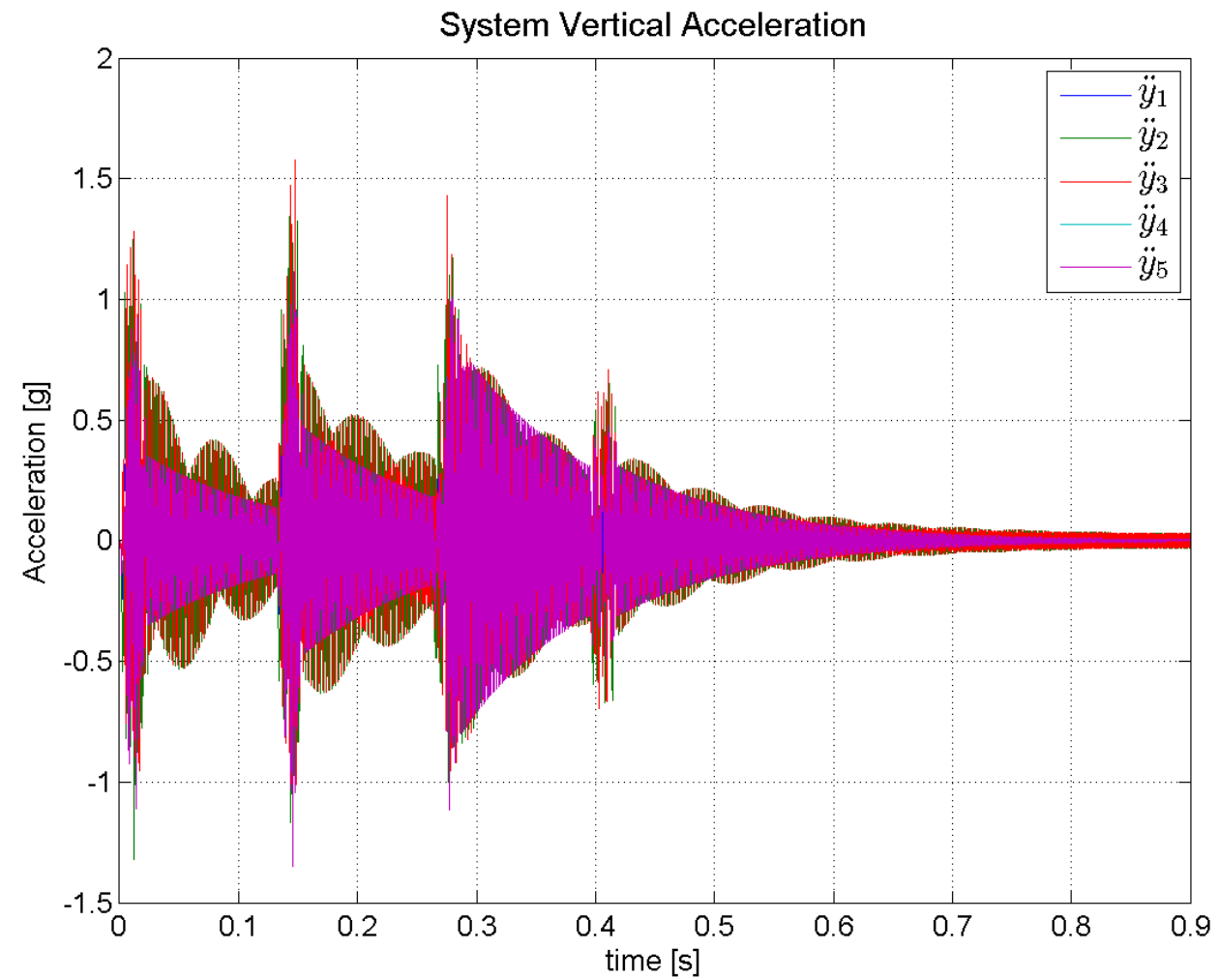

Figura 4.30: Acelerações verticais do sistema para tráfego com diferentes velocidades em pista com irregularidades - Velocidade de $50 \mathrm{~km} / \mathrm{h}$ 


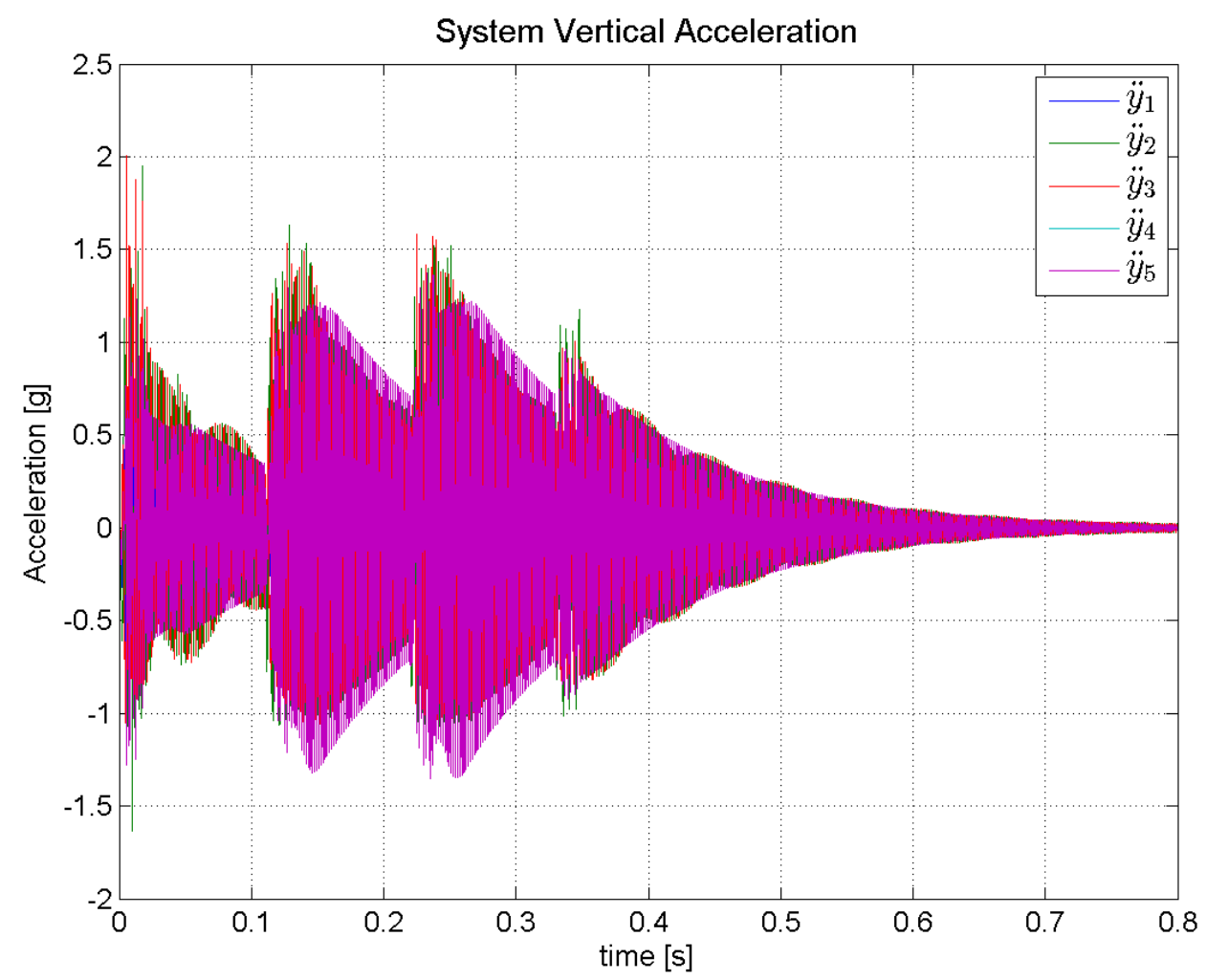

Figura 4.31: Acelerações verticais do sistema para tráfego com diferentes velocidades em pista com irregularidades - Velocidade de $60 \mathrm{~km} / \mathrm{h}$

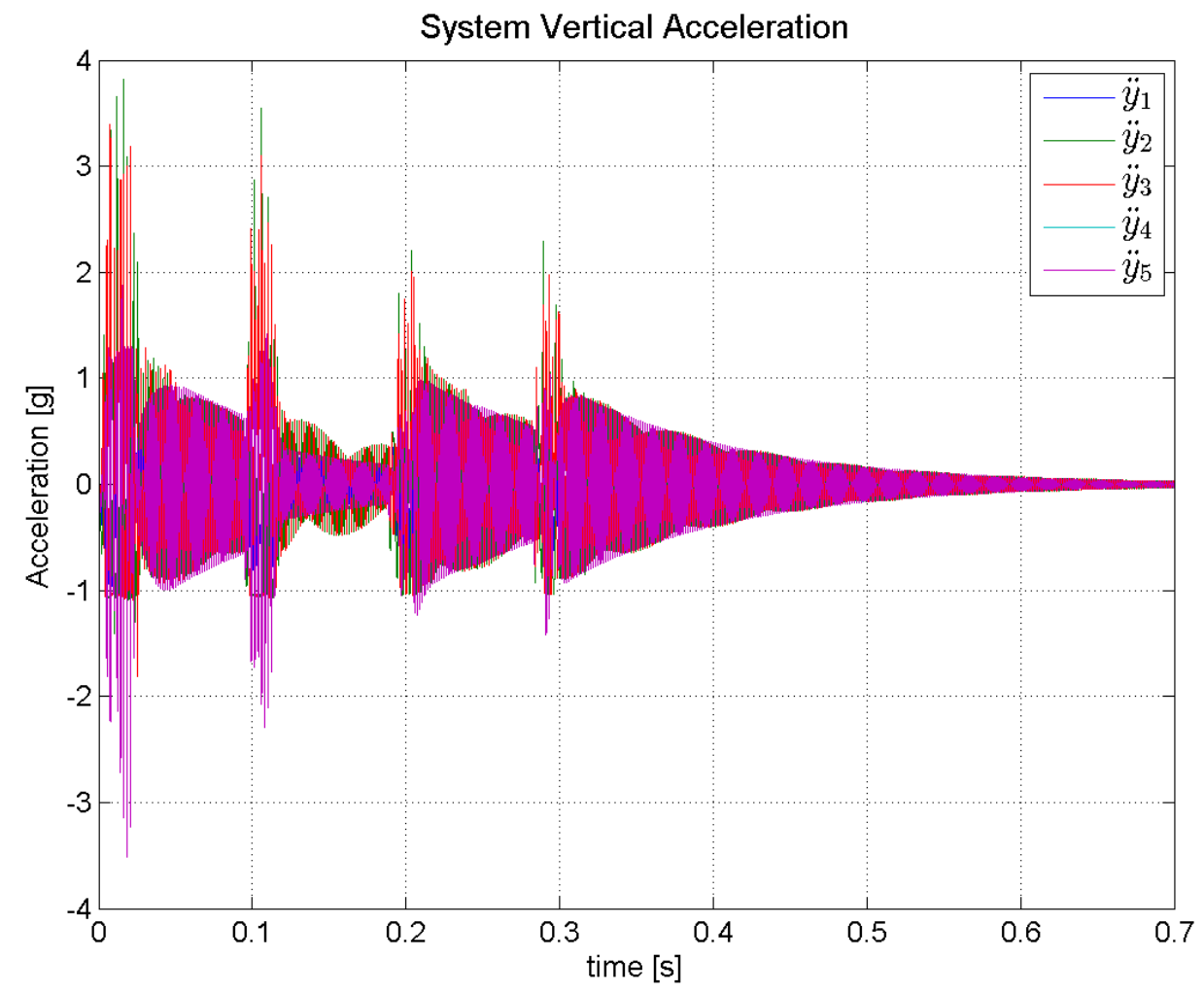

Figura 4.32: Acelerações verticais do sistema para tráfego com diferentes velocidades em pista com irregularidades - Velocidade de $70 \mathrm{~km} / \mathrm{h}$ 


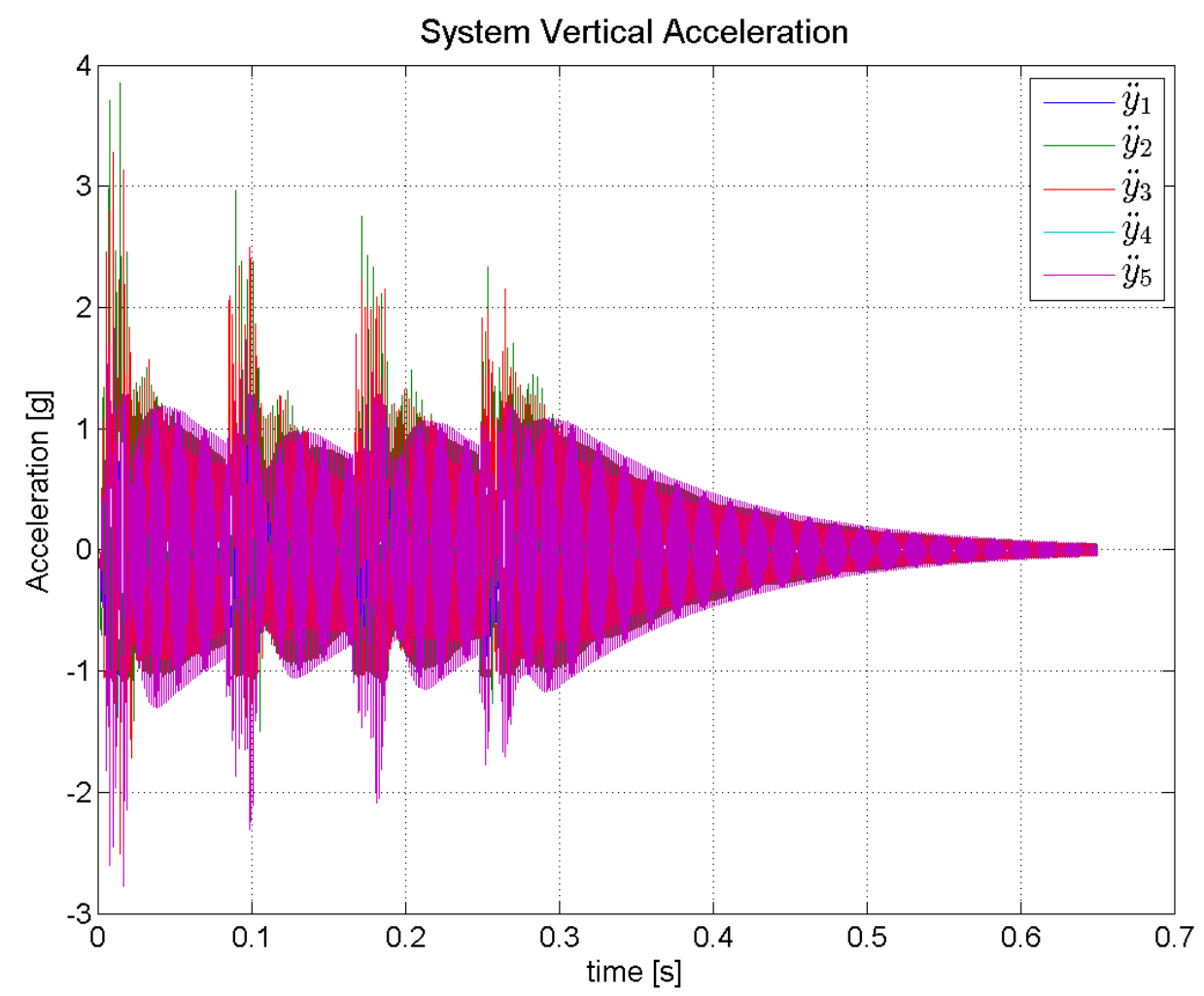

Figura 4.33: Acelerações verticais do sistema para tráfego com diferentes velocidades em pista com irregularidades - Velocidade de $80 \mathrm{~km} / \mathrm{h}$

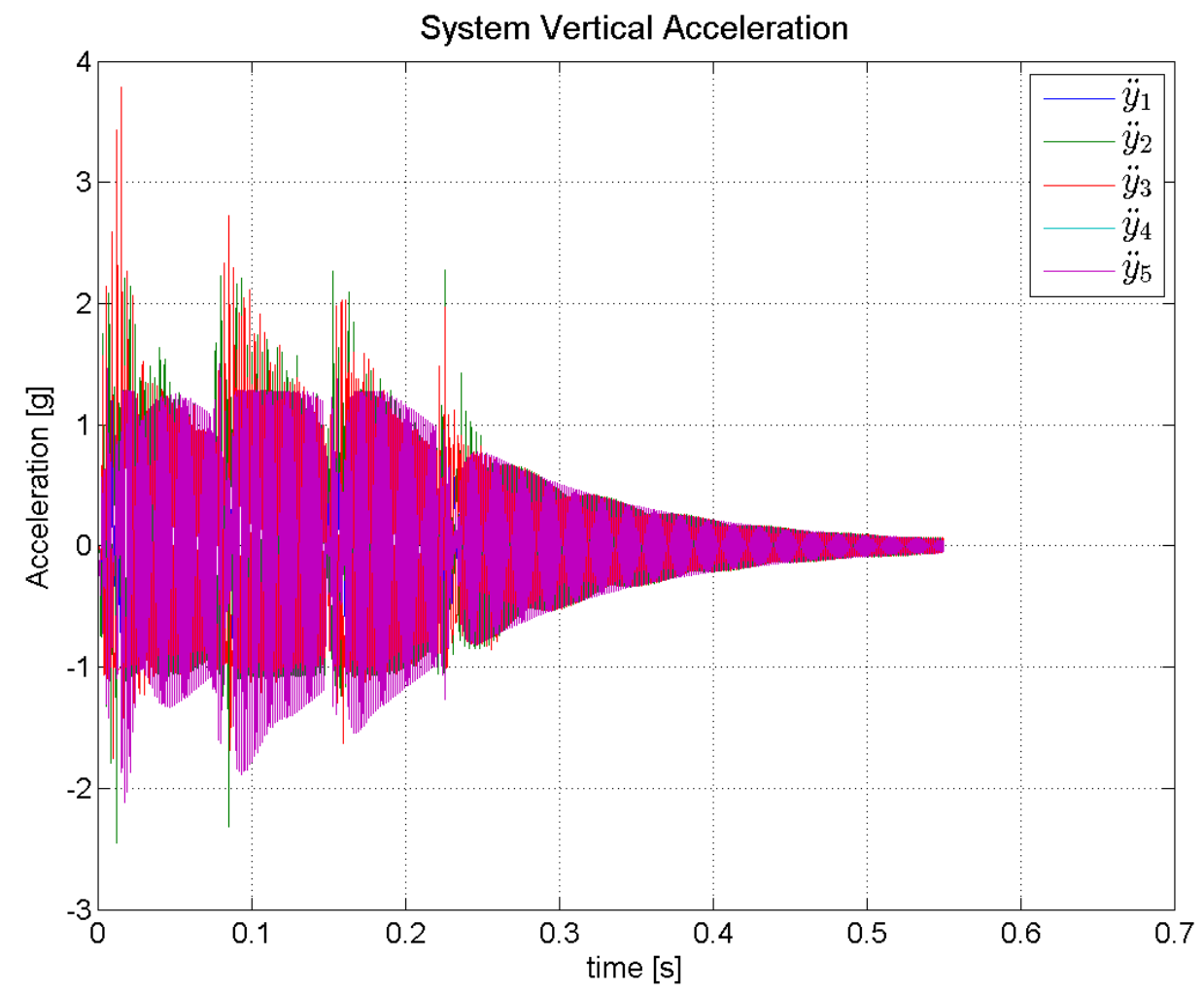

Figura 4.34: Acelerações verticais do sistema para tráfego com diferentes velocidades em pista com irregularidades - Velocidade de $90 \mathrm{~km} / \mathrm{h}$ 


\subsubsection{Resultados de Acelerações Horizontais}

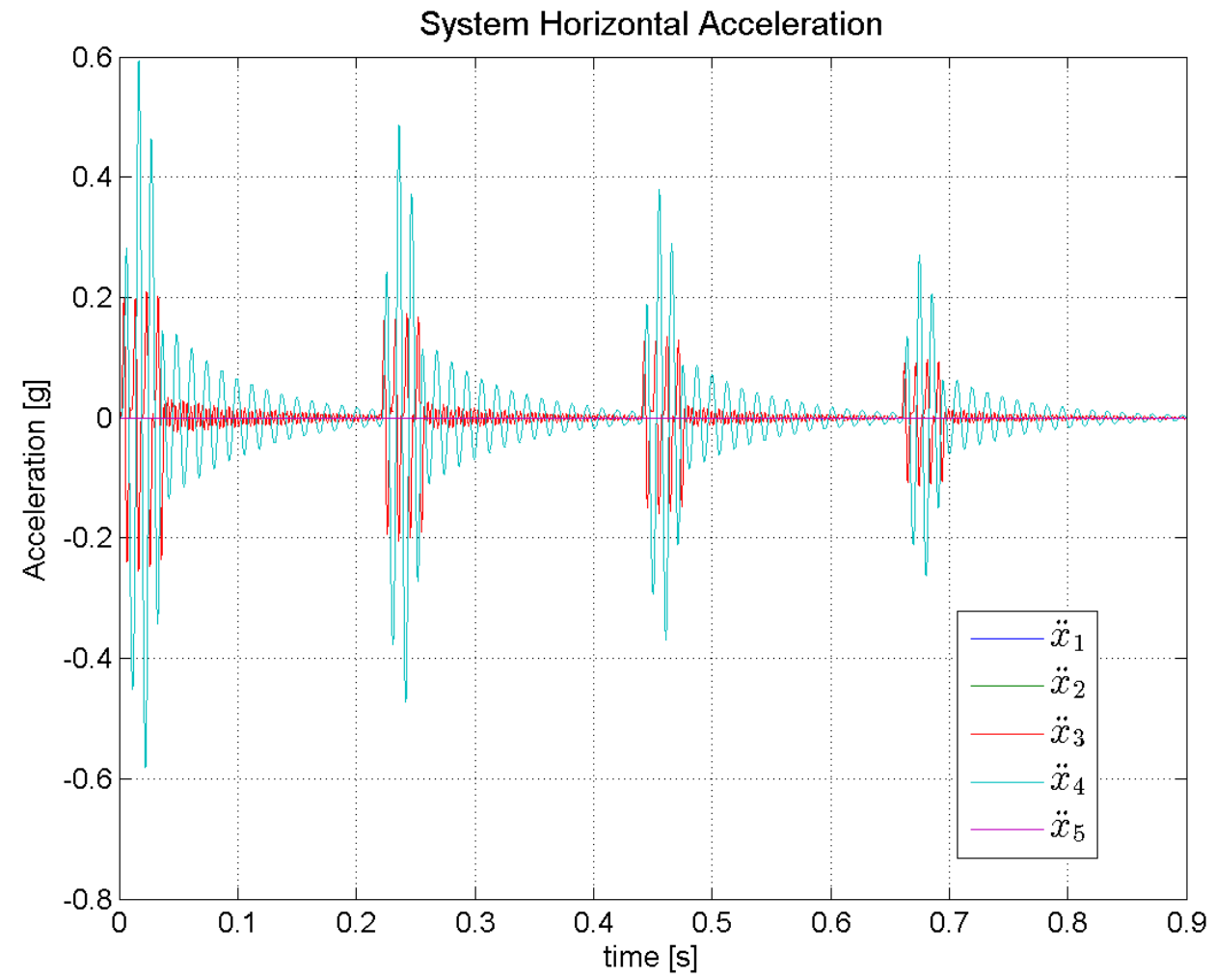

Figura 4.35: Acelerações horizontais do sistema para tráfego com diferentes velocidades em pista com irregularidades - Velocidade de $30 \mathrm{~km} / \mathrm{h}$ 


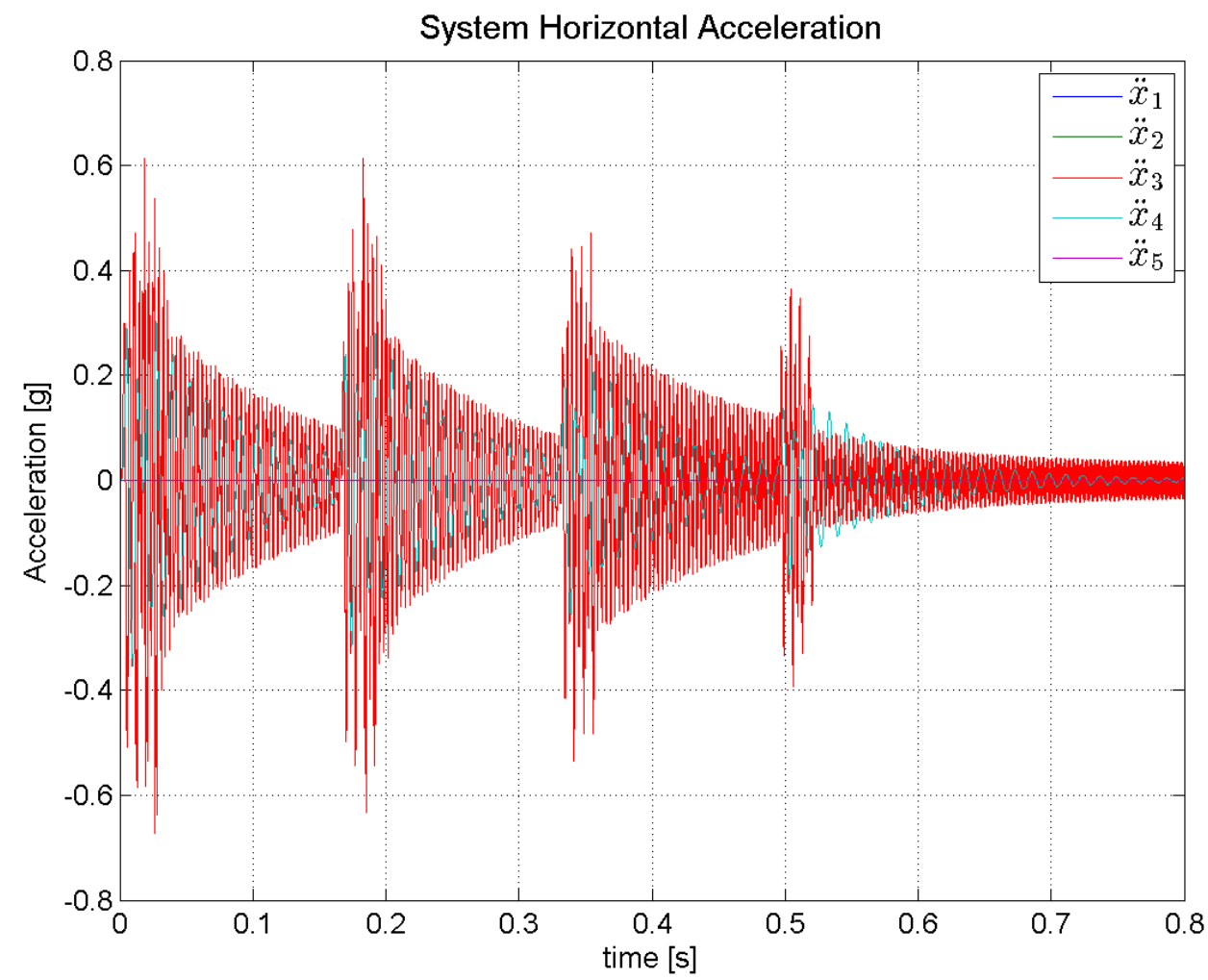

Figura 4.36: Acelerações horizontais do sistema para tráfego com diferentes velocidades em pista com irregularidades - Velocidade de $40 \mathrm{~km} / \mathrm{h}$

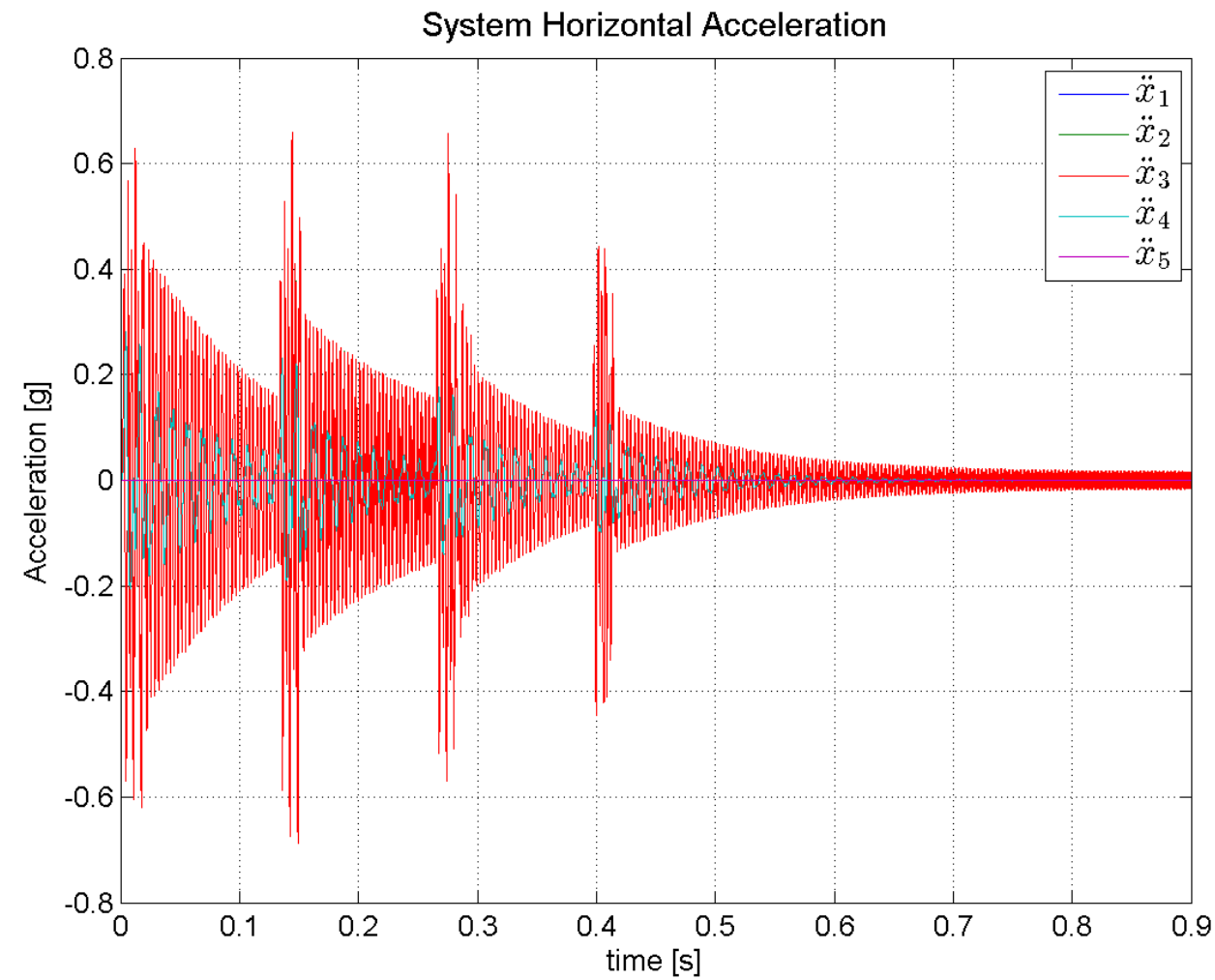

Figura 4.37: Acelerações horizontais do sistema para tráfego com diferentes velocidades em pista com irregularidades - Velocidade de $50 \mathrm{~km} / \mathrm{h}$ 


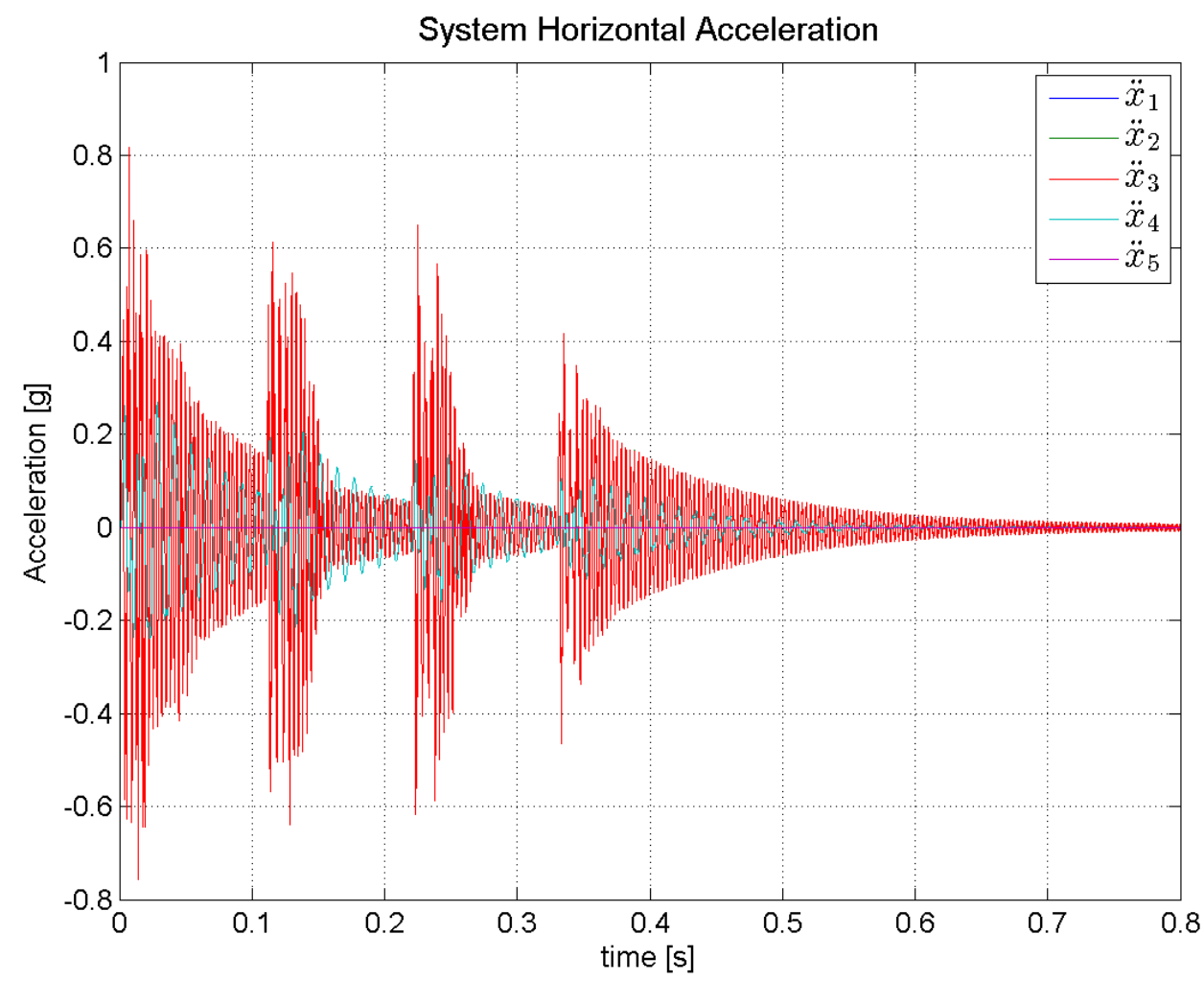

Figura 4.38: Acelerações horizontais do sistema para tráfego com diferentes velocidades em pista com irregularidades - Velocidade de $60 \mathrm{~km} / \mathrm{h}$

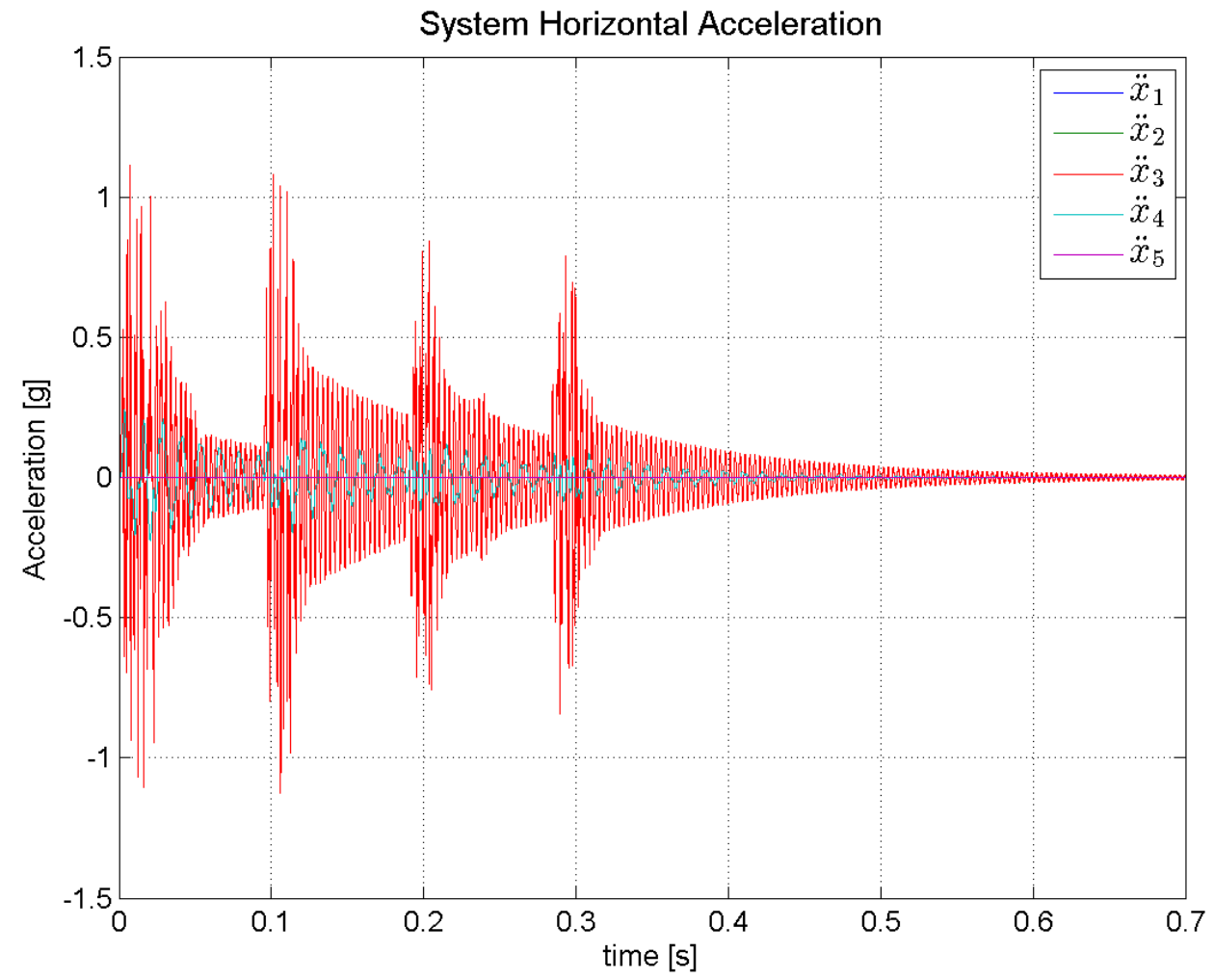

Figura 4.39: Acelerações horizontais do sistema para tráfego com diferentes velocidades em pista com irregularidades - Velocidade de $70 \mathrm{~km} / \mathrm{h}$ 


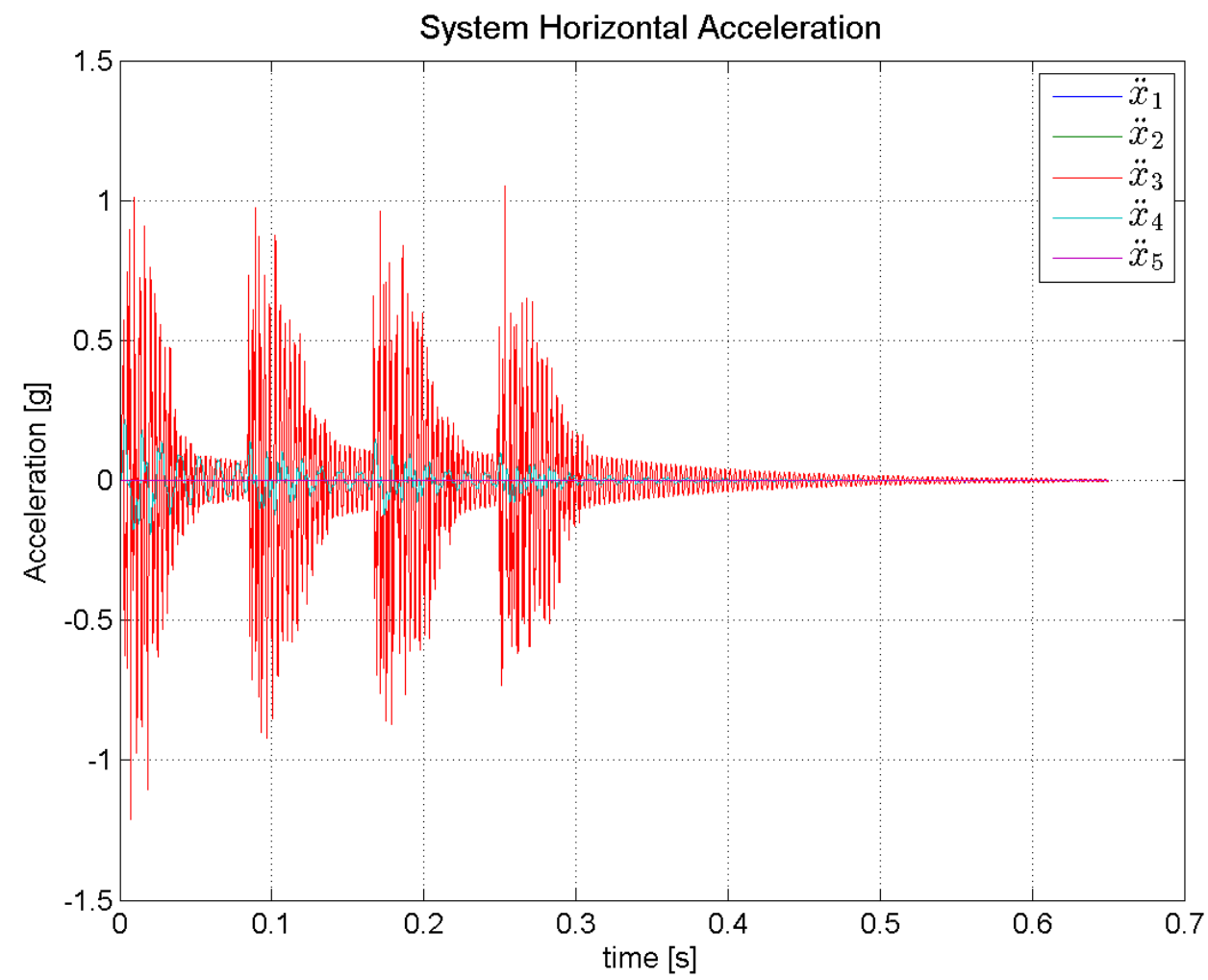

Figura 4.40: Acelerações horizontais do sistema para tráfego com diferentes velocidades em pista com irregularidades - Velocidade de $80 \mathrm{~km} / \mathrm{h}$

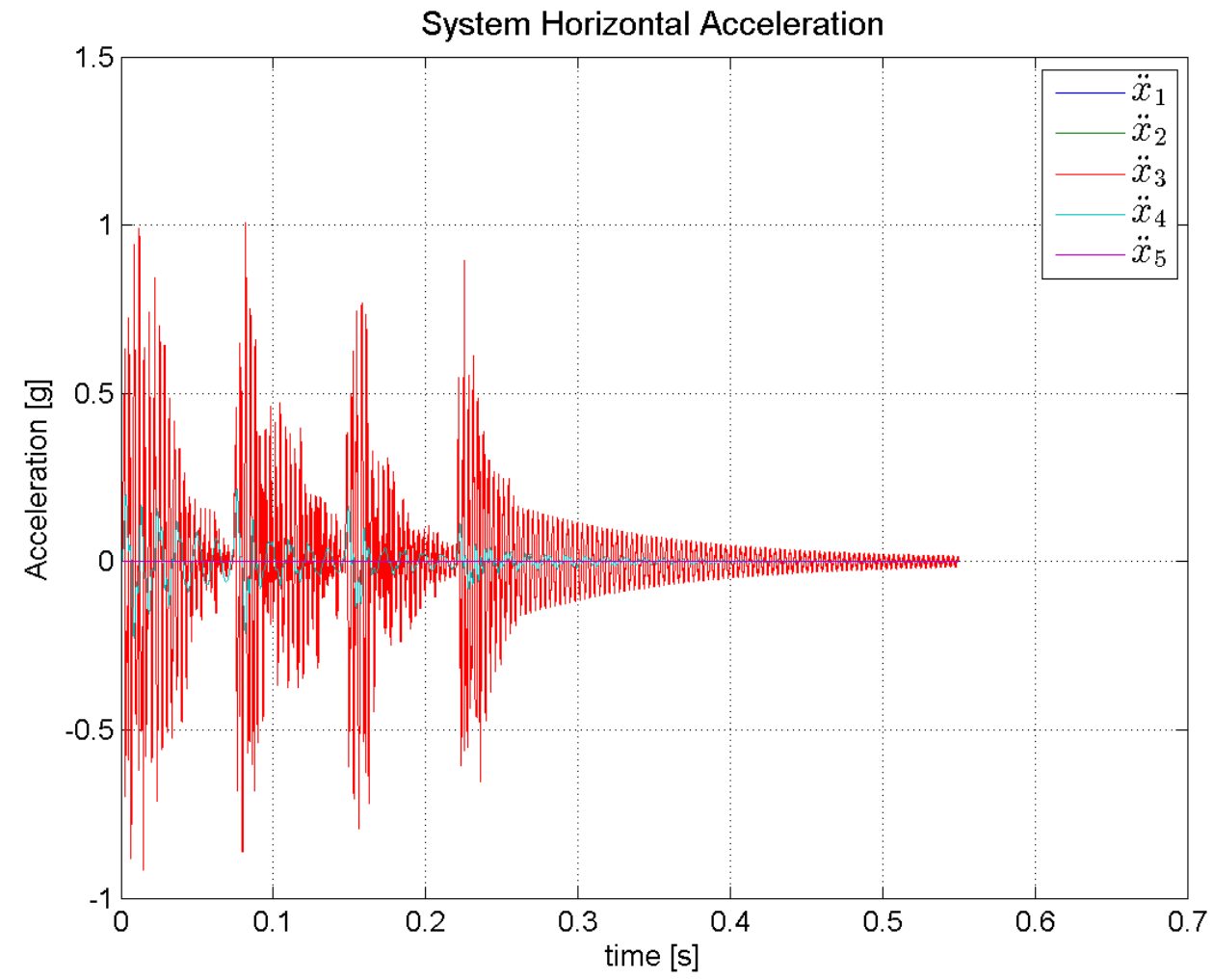

Figura 4.41: Acelerações horizontais do sistema para tráfego com diferentes velocidades em pista com irregularidades - Velocidade de $90 \mathrm{~km} / \mathrm{h}$ 


\subsubsection{Resultados de Reações sobre a Parte Ativa}

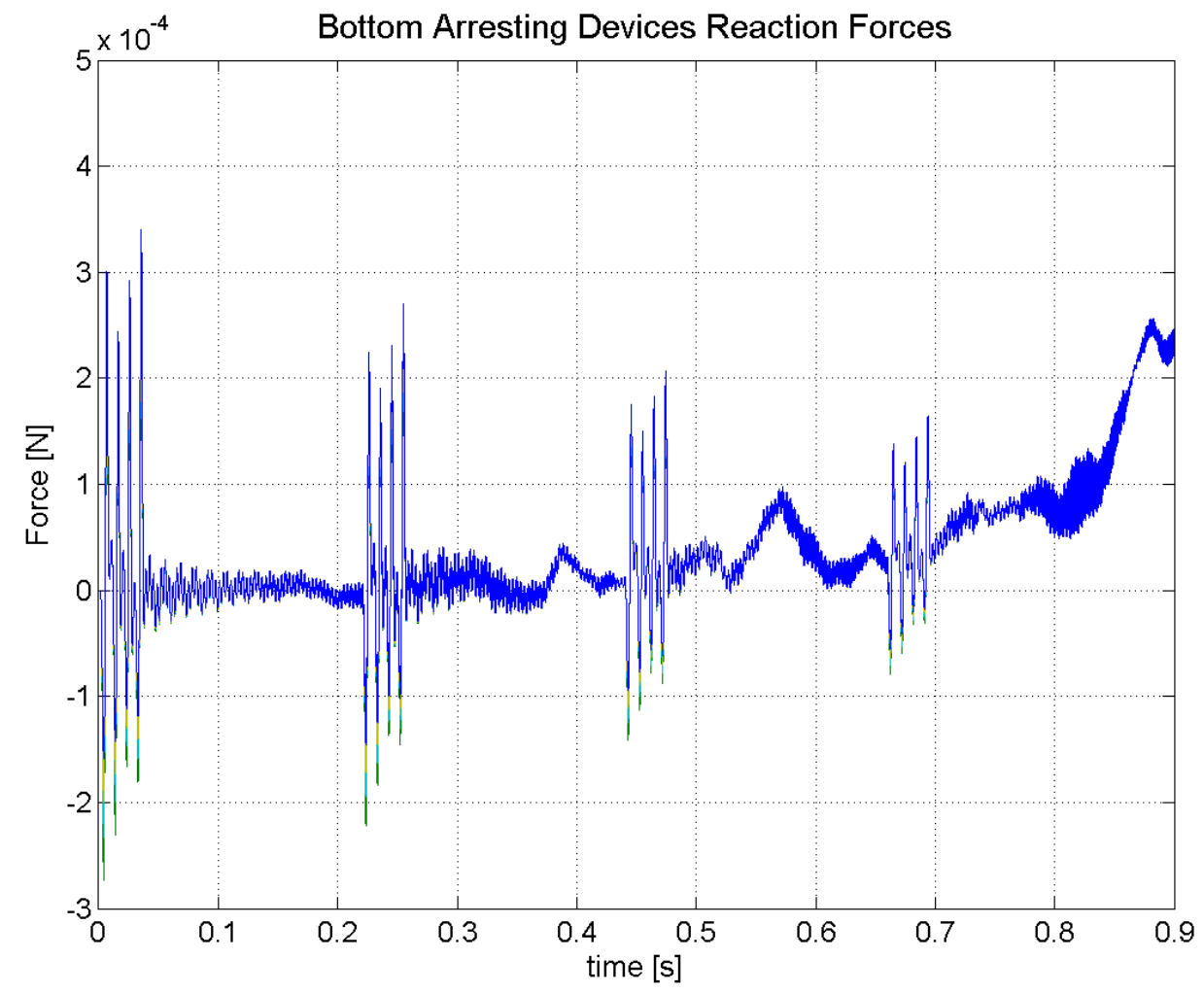

Figura 4.42: Reações em cada fixação inferior - Velocidade de $30 \mathrm{~km} / \mathrm{h}$

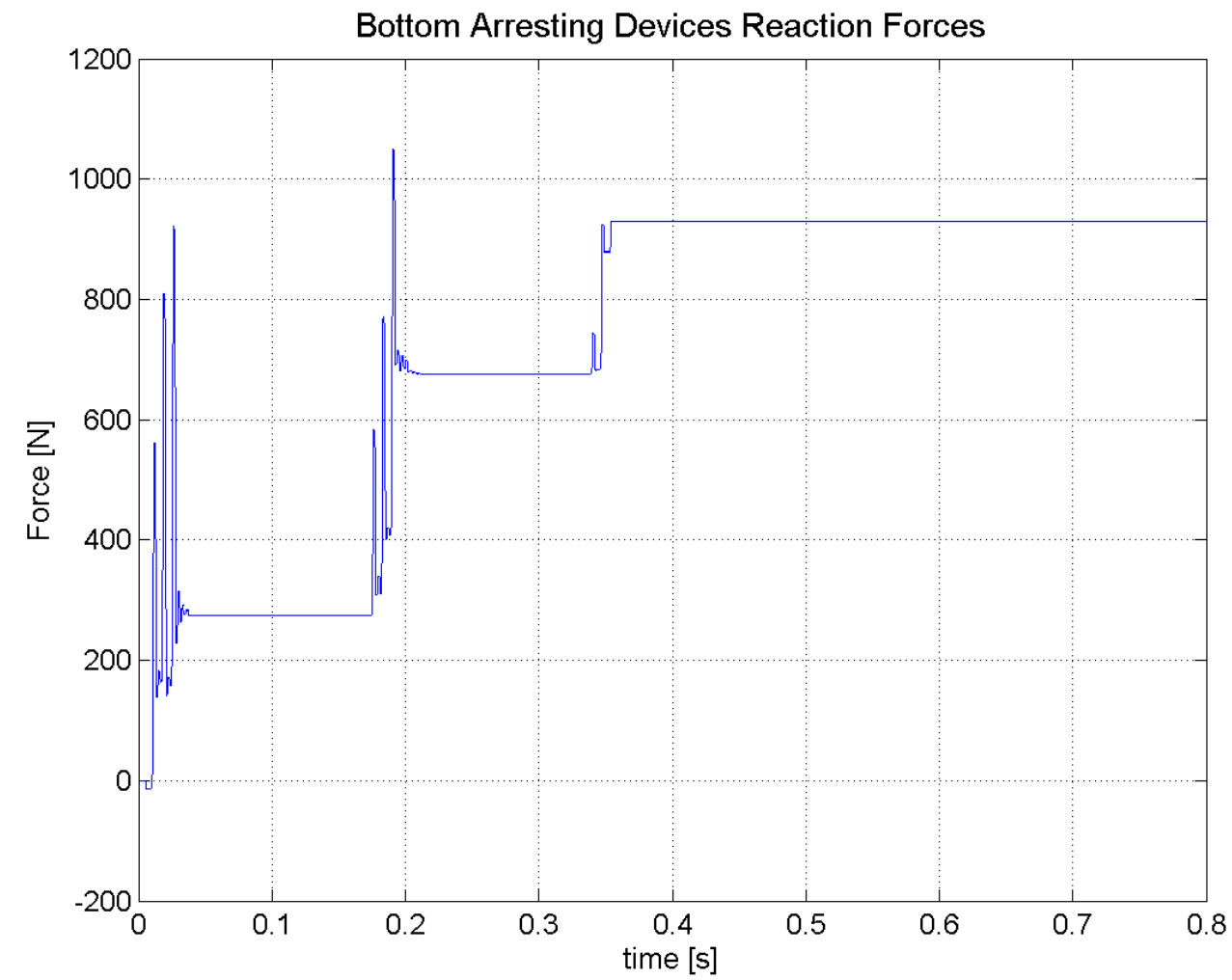

Figura 4.43: Reações em cada fixação inferior - Velocidade de $40 \mathrm{~km} / \mathrm{h}$ 


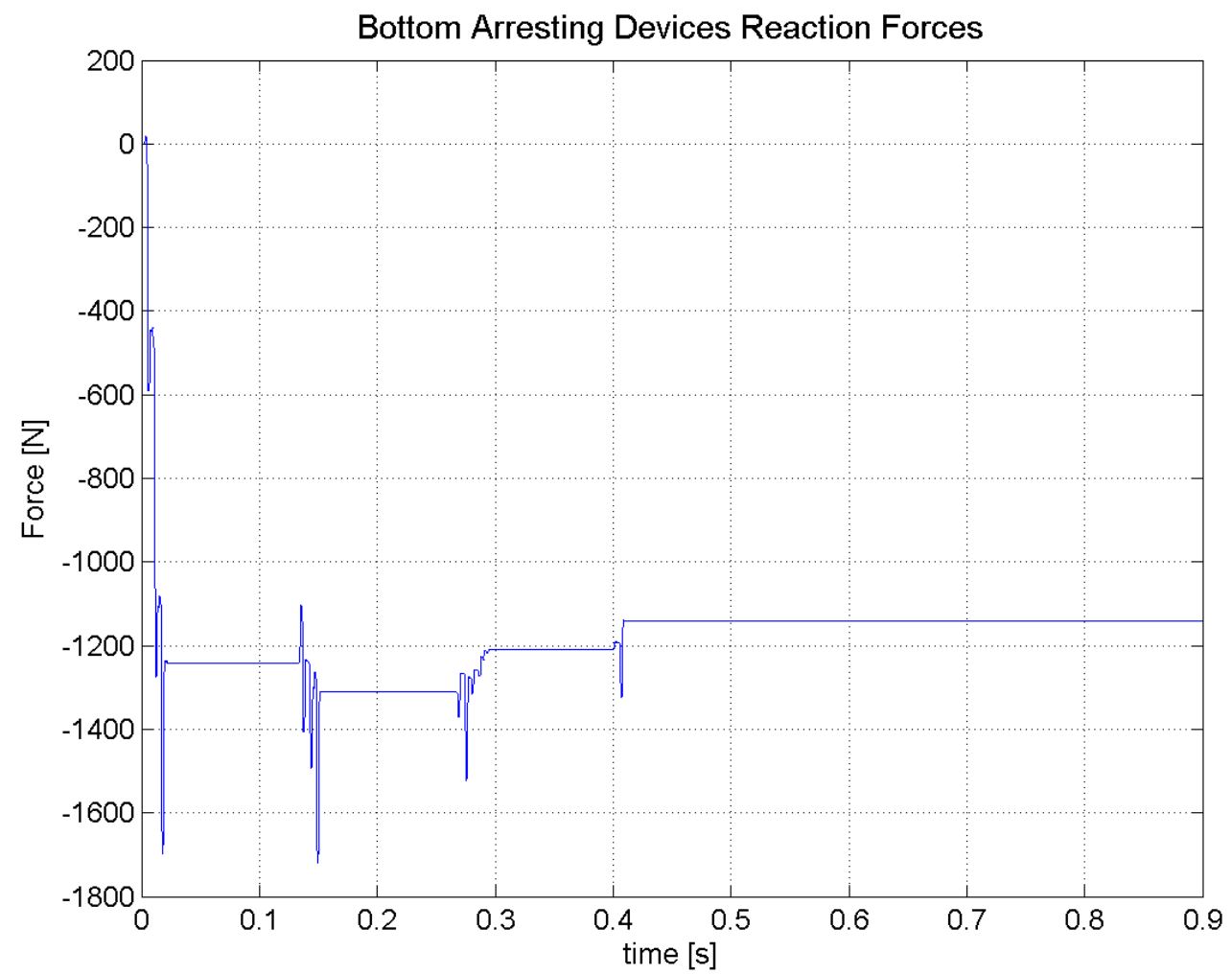

Figura 4.44: Reações em cada fixação inferior - Velocidade de $50 \mathrm{~km} / \mathrm{h}$

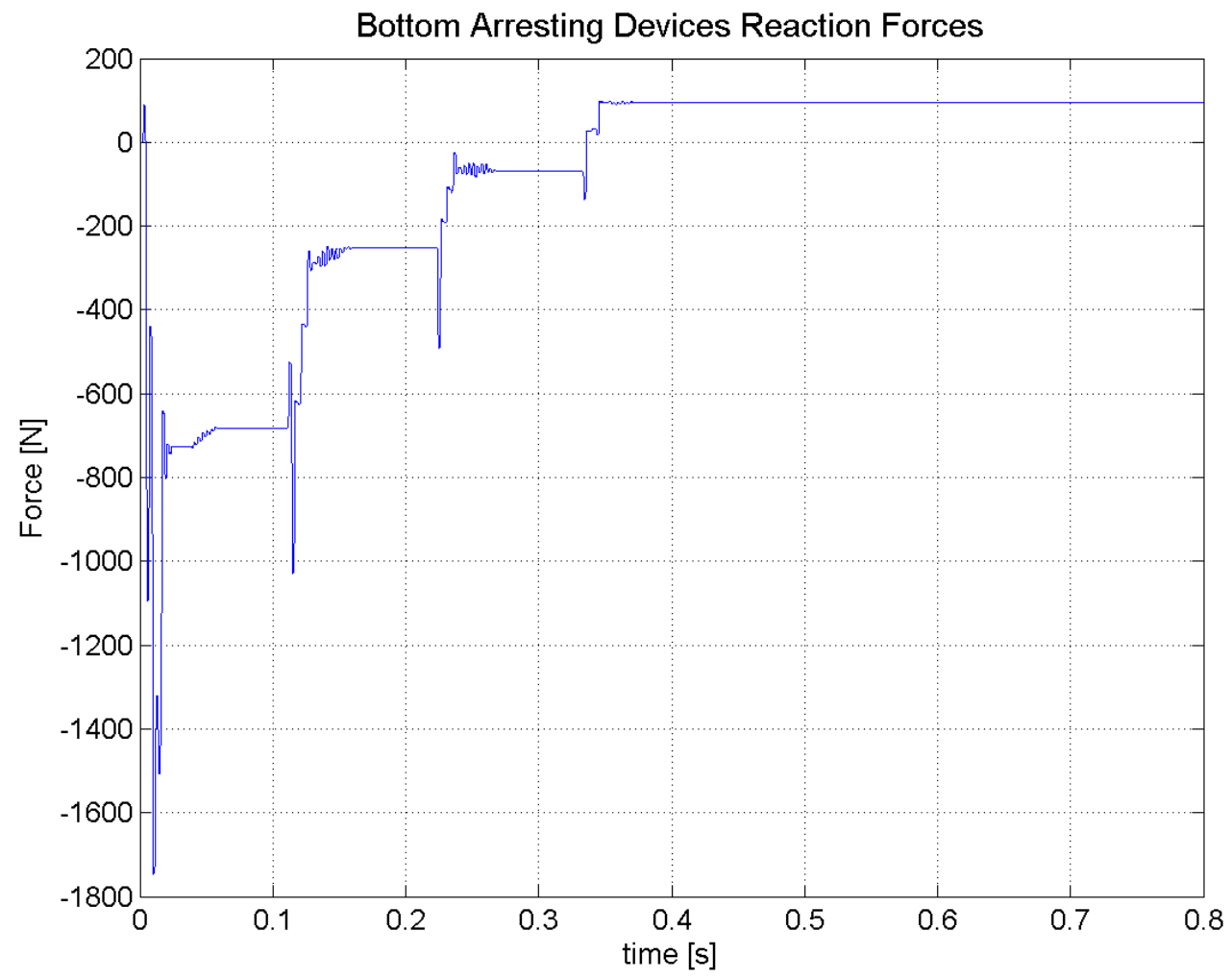

Figura 4.45: Reações em cada fixação inferior - Velocidade de $60 \mathrm{~km} / \mathrm{h}$ 


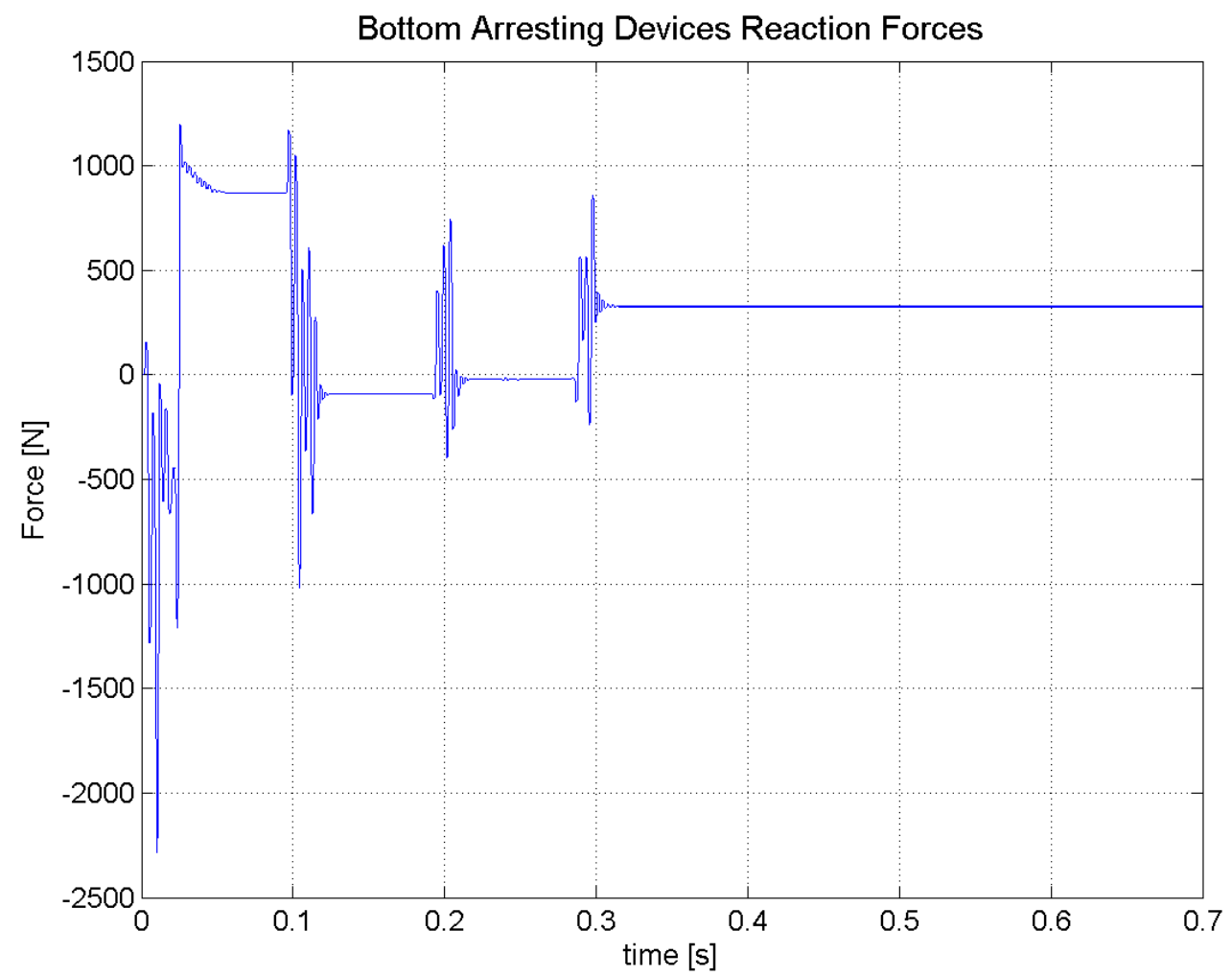

Figura 4.46: Reações em cada fixação inferior - Velocidade de $70 \mathrm{~km} / \mathrm{h}$

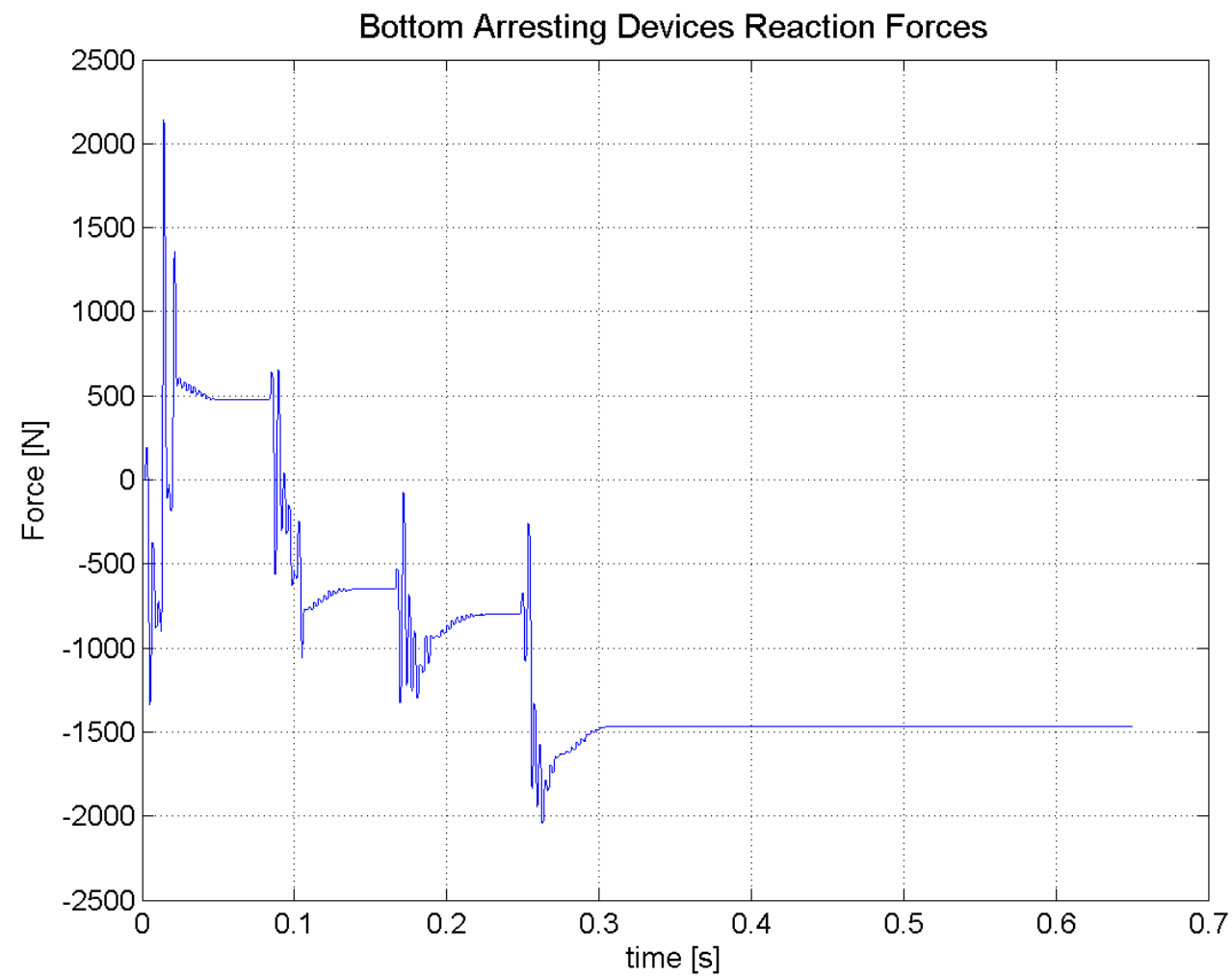

Figura 4.47: Reações em cada fixação inferior - Velocidade de $80 \mathrm{~km} / \mathrm{h}$ 


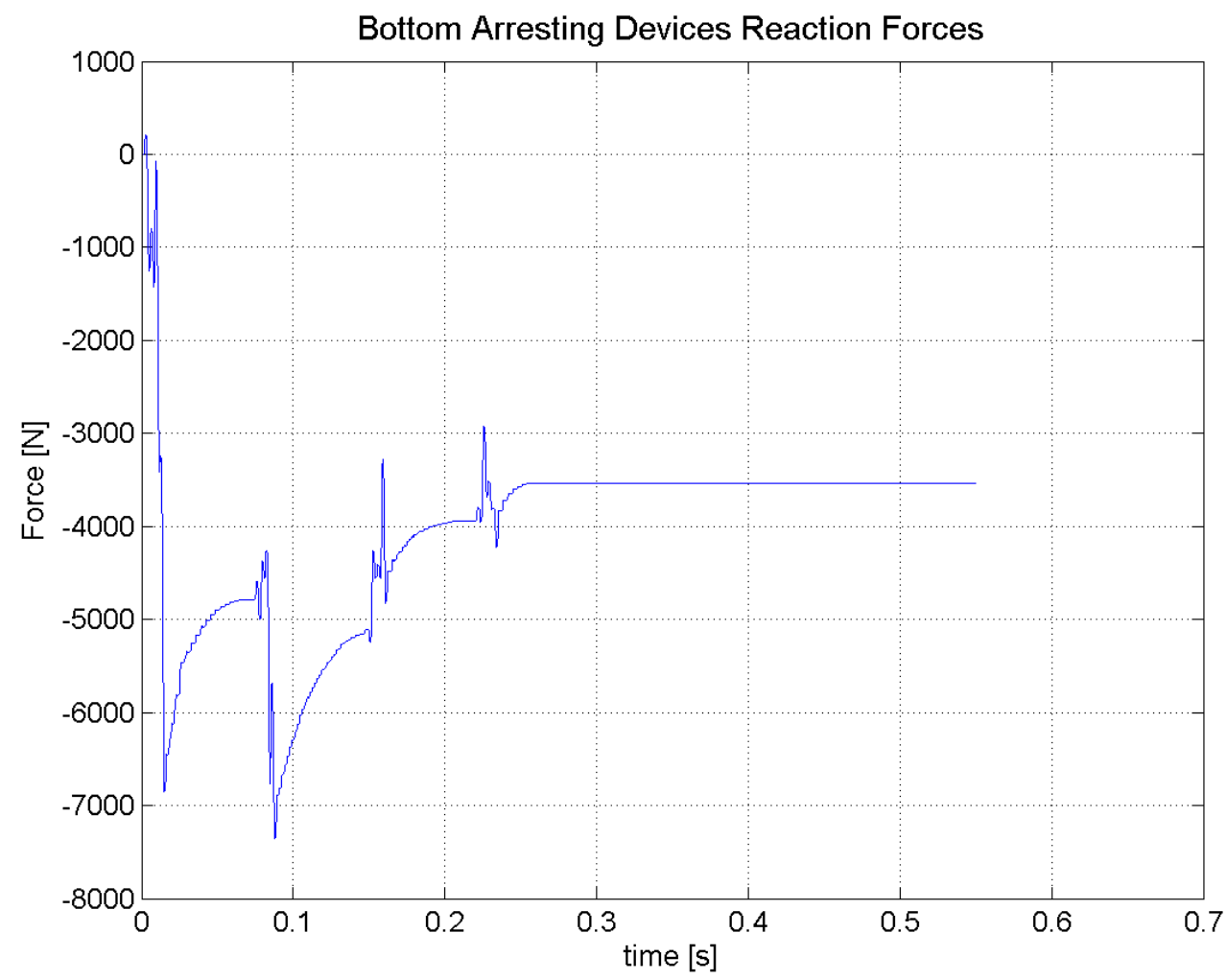

Figura 4.48: Reações em cada fixação inferior - Velocidade de $90 \mathrm{~km} / \mathrm{h}$ 


\subsubsection{Resultados de Força de Atrito}

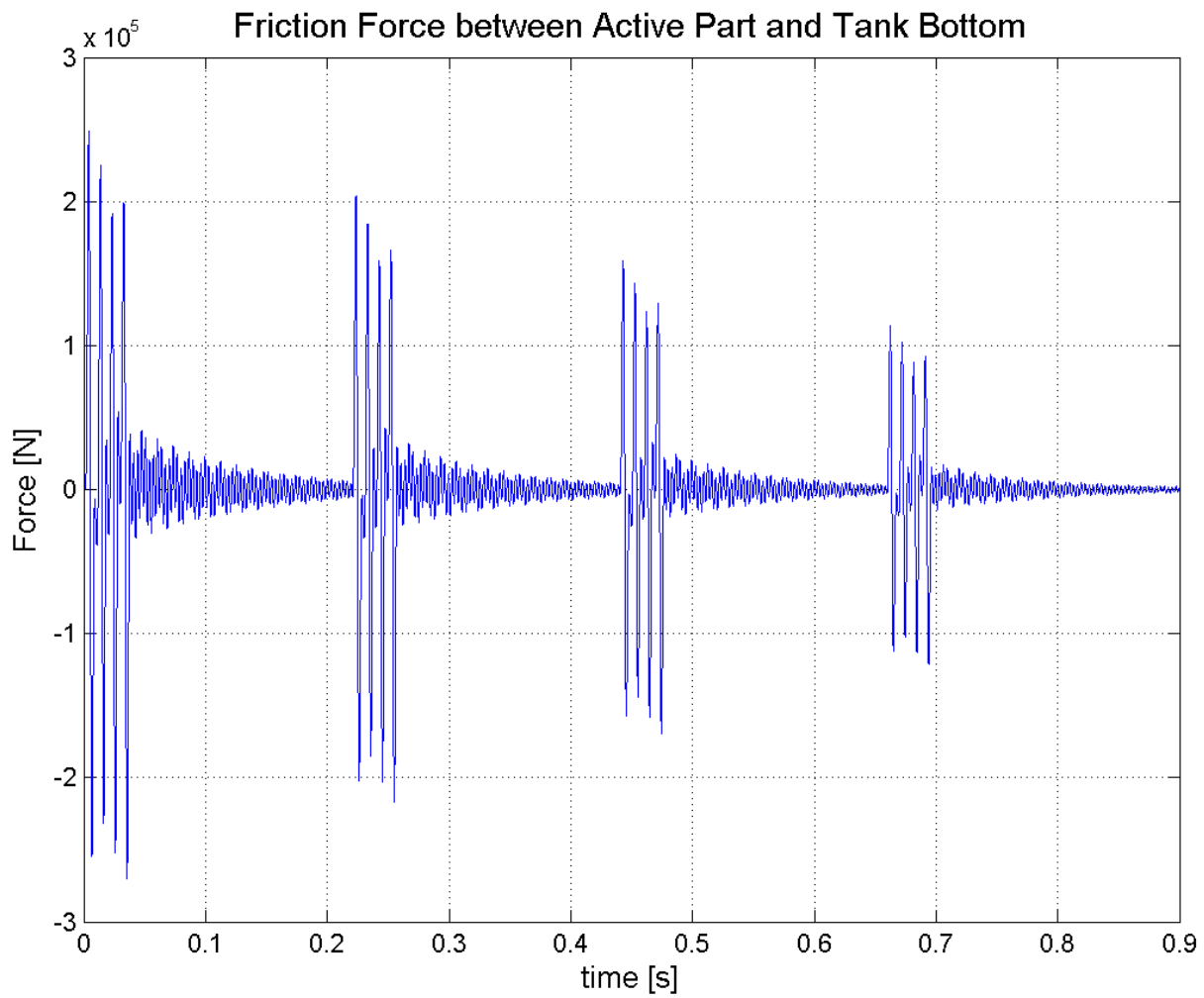

Figura 4.49: Força de atrito entre parte ativa e fundo - Velocidade de $30 \mathrm{~km} / \mathrm{h}$

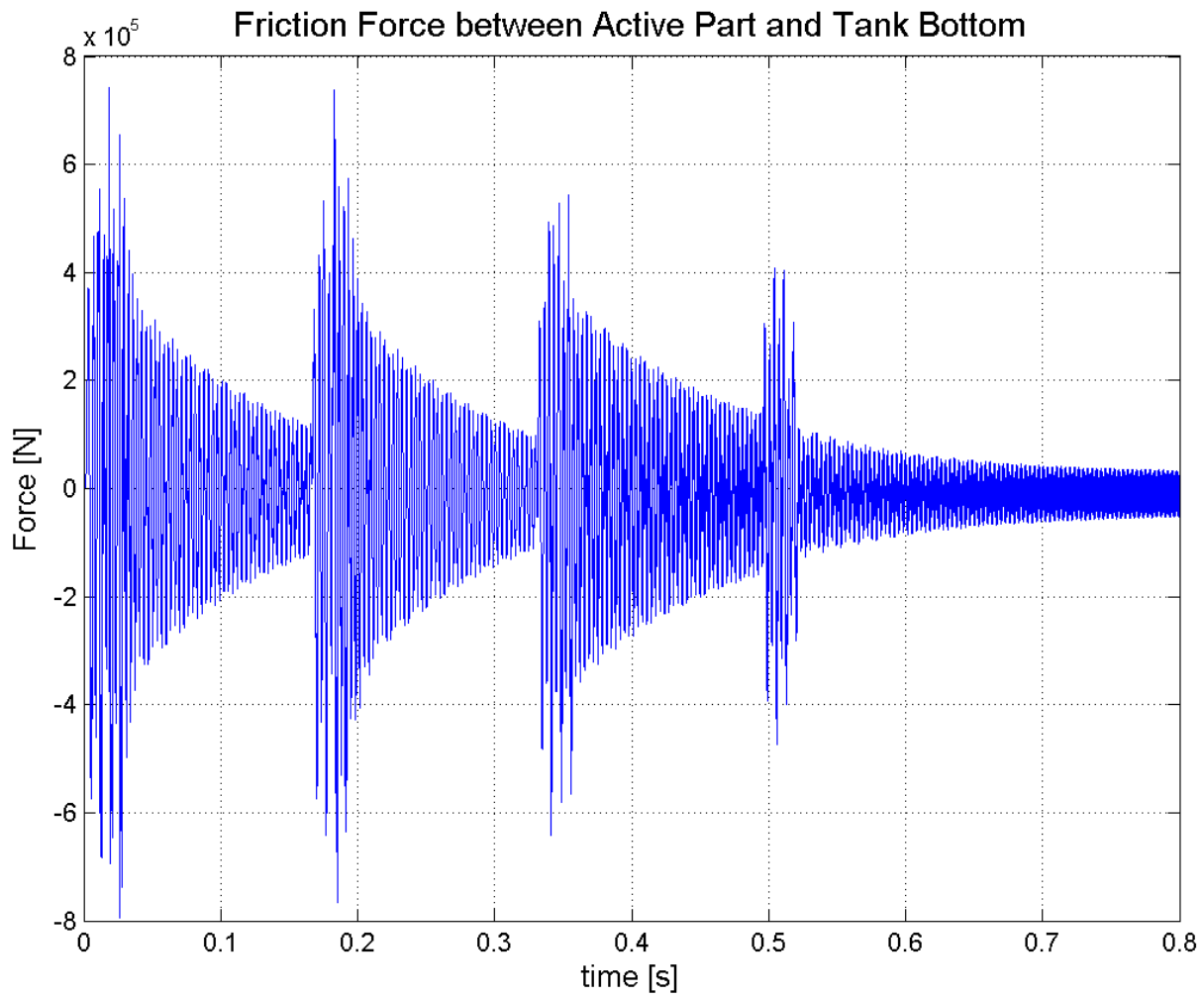

Figura 4.50: Força de atrito entre parte ativa e fundo - Velocidade de $40 \mathrm{~km} / \mathrm{h}$ 


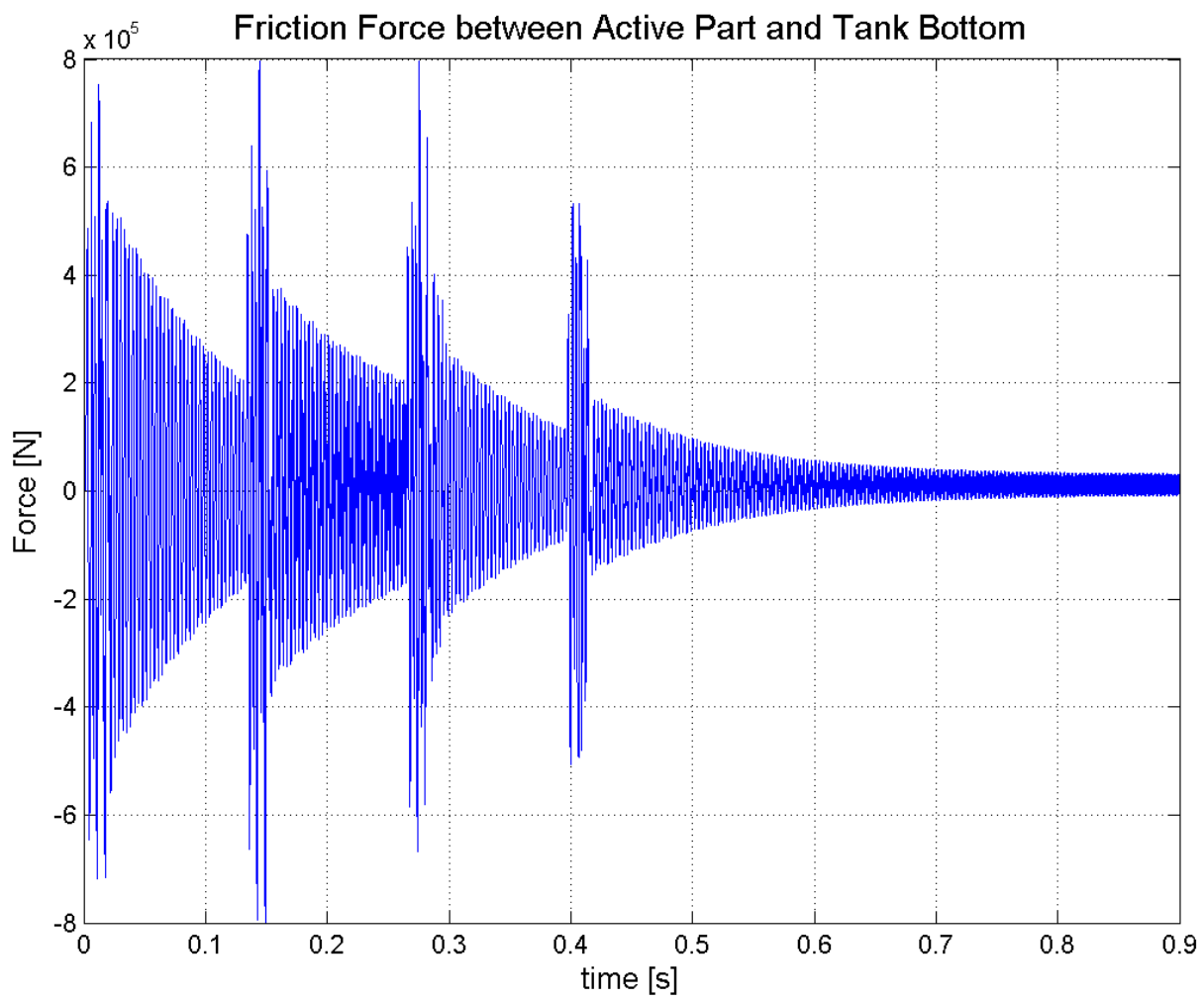

Figura 4.51: Força de atrito entre parte ativa e fundo - Velocidade de $50 \mathrm{~km} / \mathrm{h}$

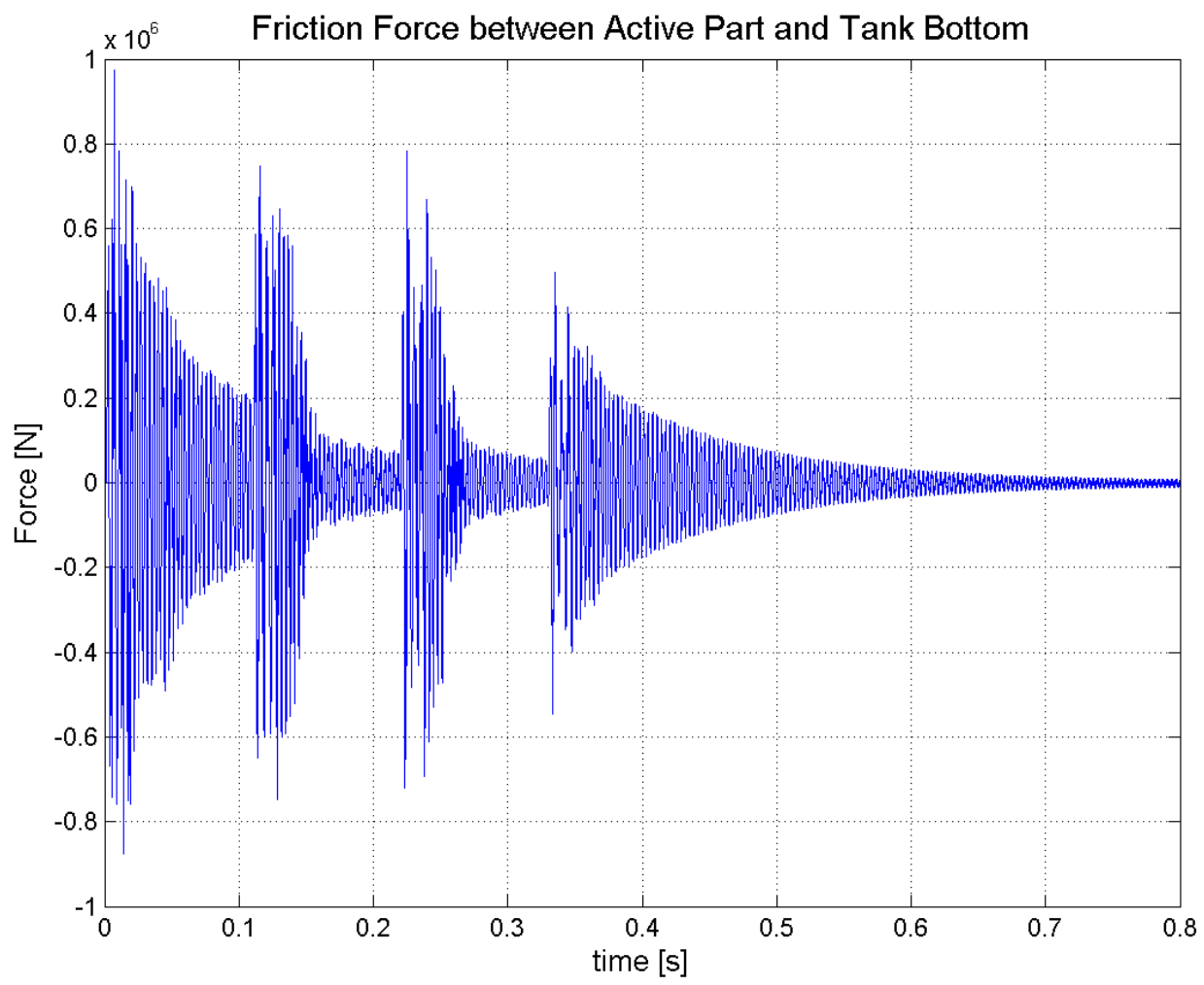

Figura 4.52: Força de atrito entre parte ativa e fundo - Velocidade de $60 \mathrm{~km} / \mathrm{h}$ 


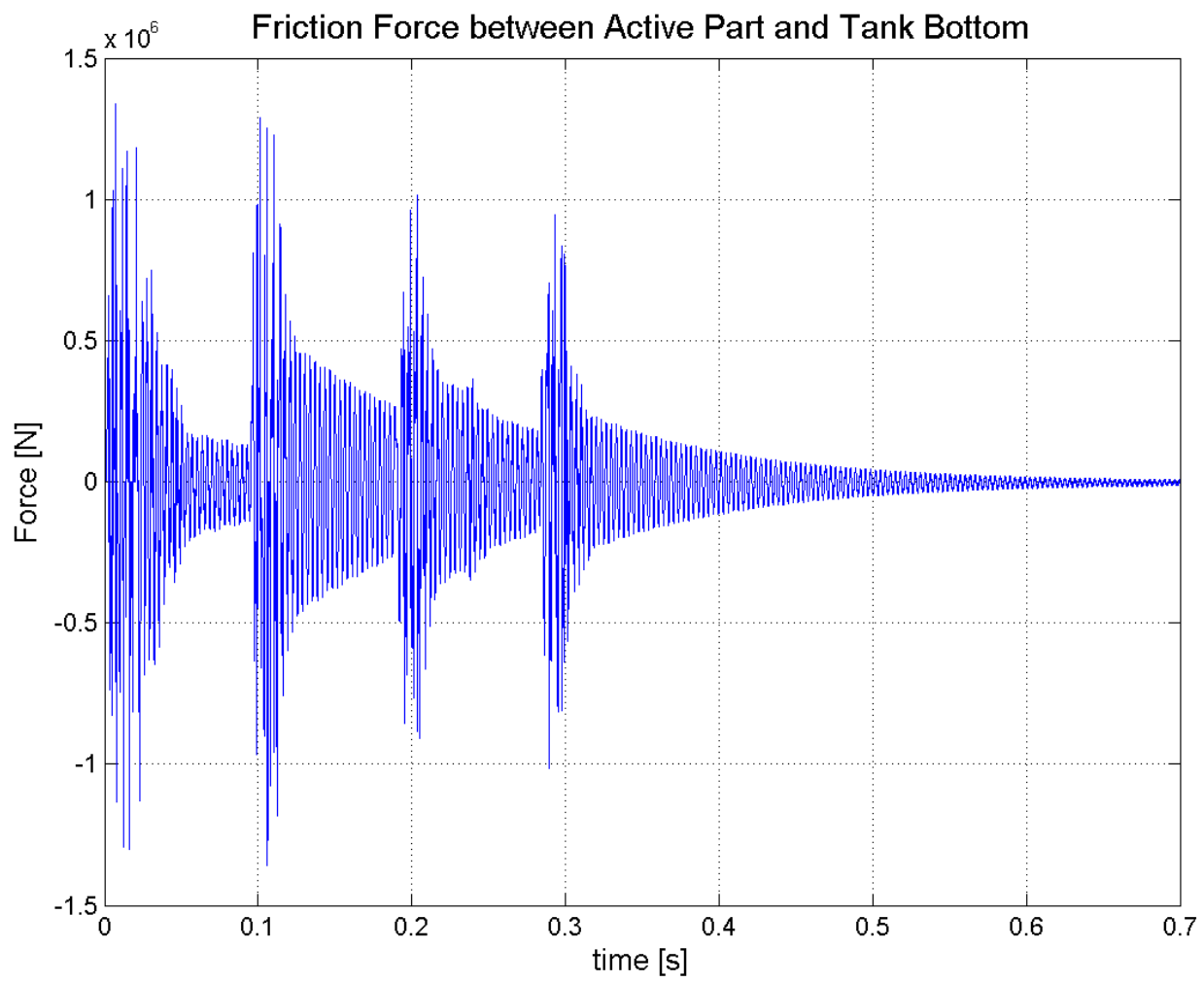

Figura 4.53: Força de atrito entre parte ativa e fundo - Velocidade de $70 \mathrm{~km} / \mathrm{h}$

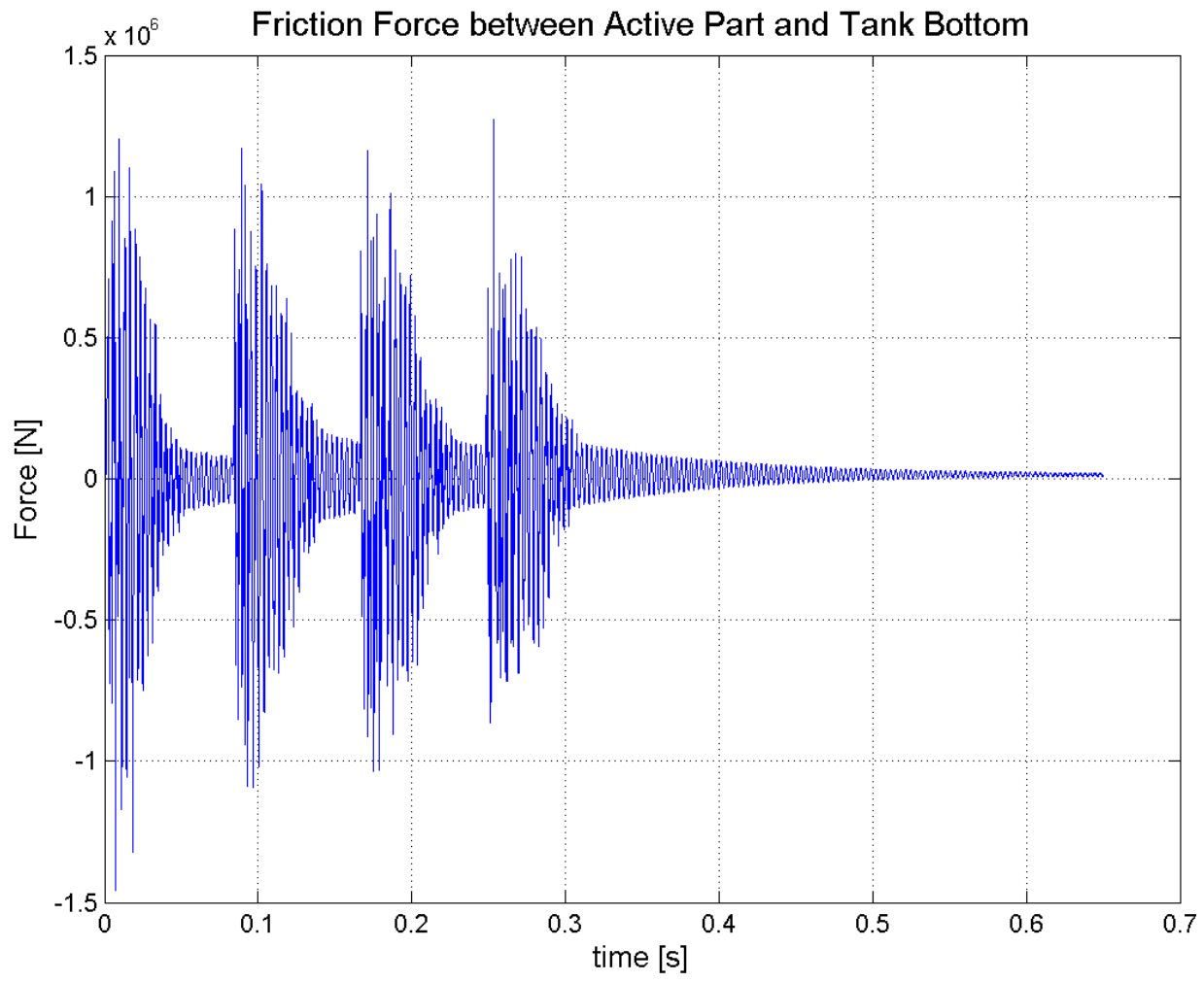

Figura 4.54: Força de atrito entre parte ativa e fundo - Velocidade de $80 \mathrm{~km} / \mathrm{h}$ 


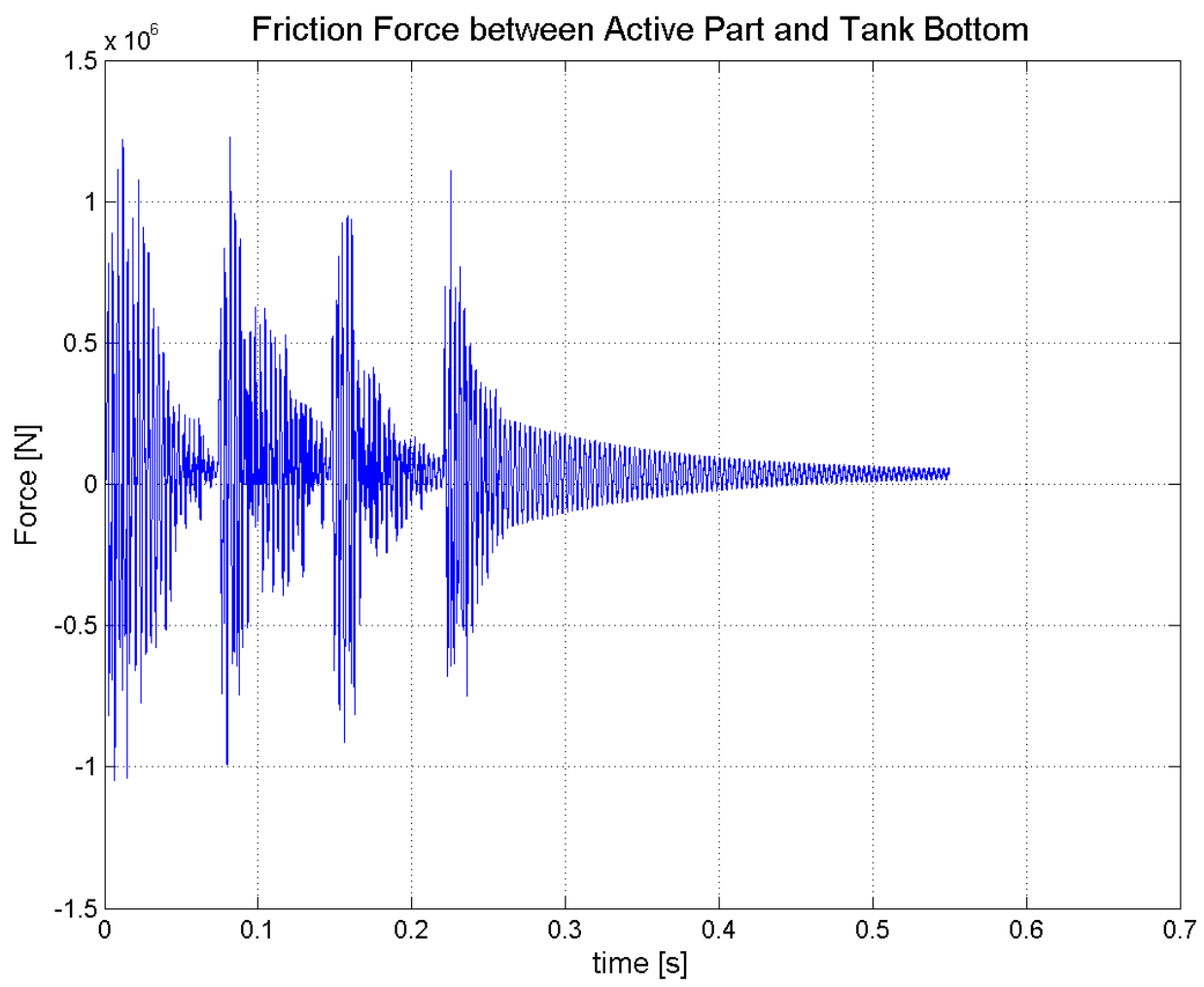

Figura 4.55: Força de atrito entre parte ativa e fundo - Velocidade de $90 \mathrm{~km} / \mathrm{h}$ 


\subsubsection{Discussões}

As figuras 4.28 a 4.34 fornecem os sinais de aceleração vertical dos corpos considerados no modelo.

Como naturalmente esperado, em todos os casos analisados, houve aumento da aceleração vertical dos corpos com o aumento da velocidade desenvolvida pelo veículo.

É interessante notar também que esse aumento foi mais significativo ao se variar a velocidade de tráfego de $30 \mathrm{~km} / \mathrm{h}$ para $40 \mathrm{~km} / \mathrm{h}$.

Outro fato interessante é que, especificamente para velocidade de $30 \mathrm{~km} / \mathrm{h}$, a aceleração vertical do veículo teve menor intensidade que as demais, diferentemente dos outros casos de velocidade de tráfego.

Já nas figuras 4.35 a 4.41, apesar de as variações de aceleração não serem tão significativas como as verificadas na direção vertical, nota-se novamente um comportamento distinto nos resultados obtidos para a velocidade de tráfego de $30 \mathrm{~km} / \mathrm{h}$.

É possível entender a diferença entre os resultados obtidos para o caso de velocidade de $30 \mathrm{~km} / \mathrm{h}$ dos demais ao se analisar os resultados dos esforços que surgem nas fixações inferiores da parte ativa, conforme mostrados nas figuras 4.42 a 4.48 .

Como se verifica na figura 4.42, a intensidade de esforços repassados a cada fixação inferior, neste caso, foi da ordem de $3 \cdot 10^{-4}$ N. Já para os outros casos de velocidade, para cada vez que um elemento da suspensão do veículo cruzava o obstáculo, havia uma variação do nível de carga repassado a cada fixação, com valores bem mais significativos que os do primeiro caso.

Esse nível mantinha-se constante até que o próximo eixo de suspensões fosse excitado pelo sonorizador.

Pode-se concluir que, à exceção do caso de velocidade de $30 \mathrm{~km} / \mathrm{h}$, a excitação da irregularidade da pista foi capaz de reduzir a força normal da parte ativa no tanque (ao acelerá-la verticalmente), permitindo que houvesse movimentação horizontal relativa entre os corpos.

Como comprovação dessa conclusão, nota-se a diferença nos valores de força de atrito, vistos nas figuras 4.49 a 4.55 , do caso de $30 \mathrm{~km} / \mathrm{h}$ para os demais. 


\subsection{Avaliação dos Efeitos da Rigidez das Sapatas em Pista com Sonorizador}

Nos casos analisados nessa seção, foi considerada uma velocidade de tráfego de $40 \mathrm{~km} / \mathrm{h}$ com o mesmo perfil de sonorizador definido na seção 4.4.

Foi considerada a possibilidade de variação da rigidez das sapatas da parte ativa, seja por adição de elementos flexíveis entre as mesmas e o fundo do tanque, seja por variações ocasionais na construção do equipamento.

\subsubsection{Resultado de Acelerações Verticais}

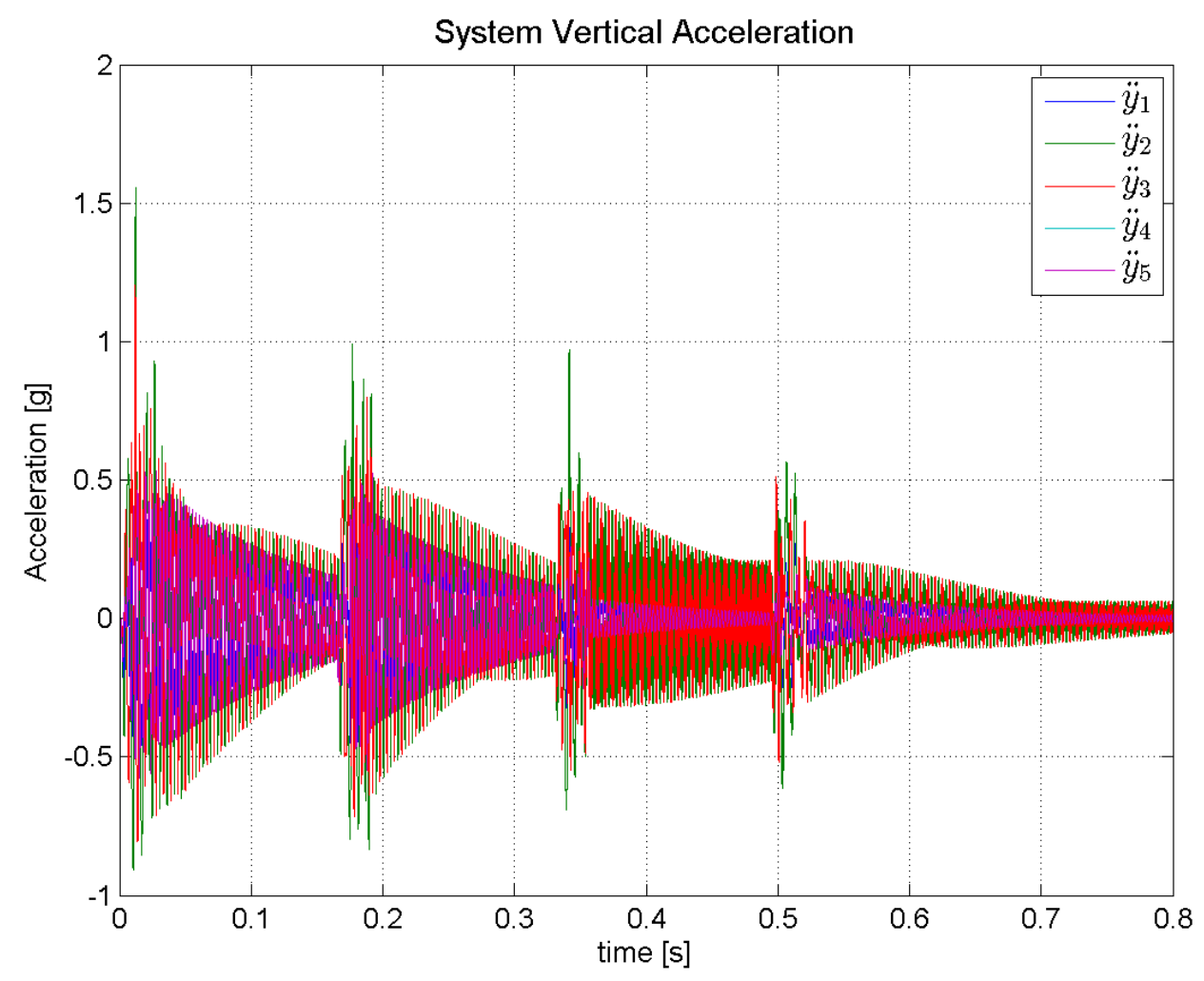

Figura 4.56: Acelerações verticais do sistema para tráfego em pista com irregularidades para diferentes valores de $k_{f}-33 \%$ da rigidez original da sapata 


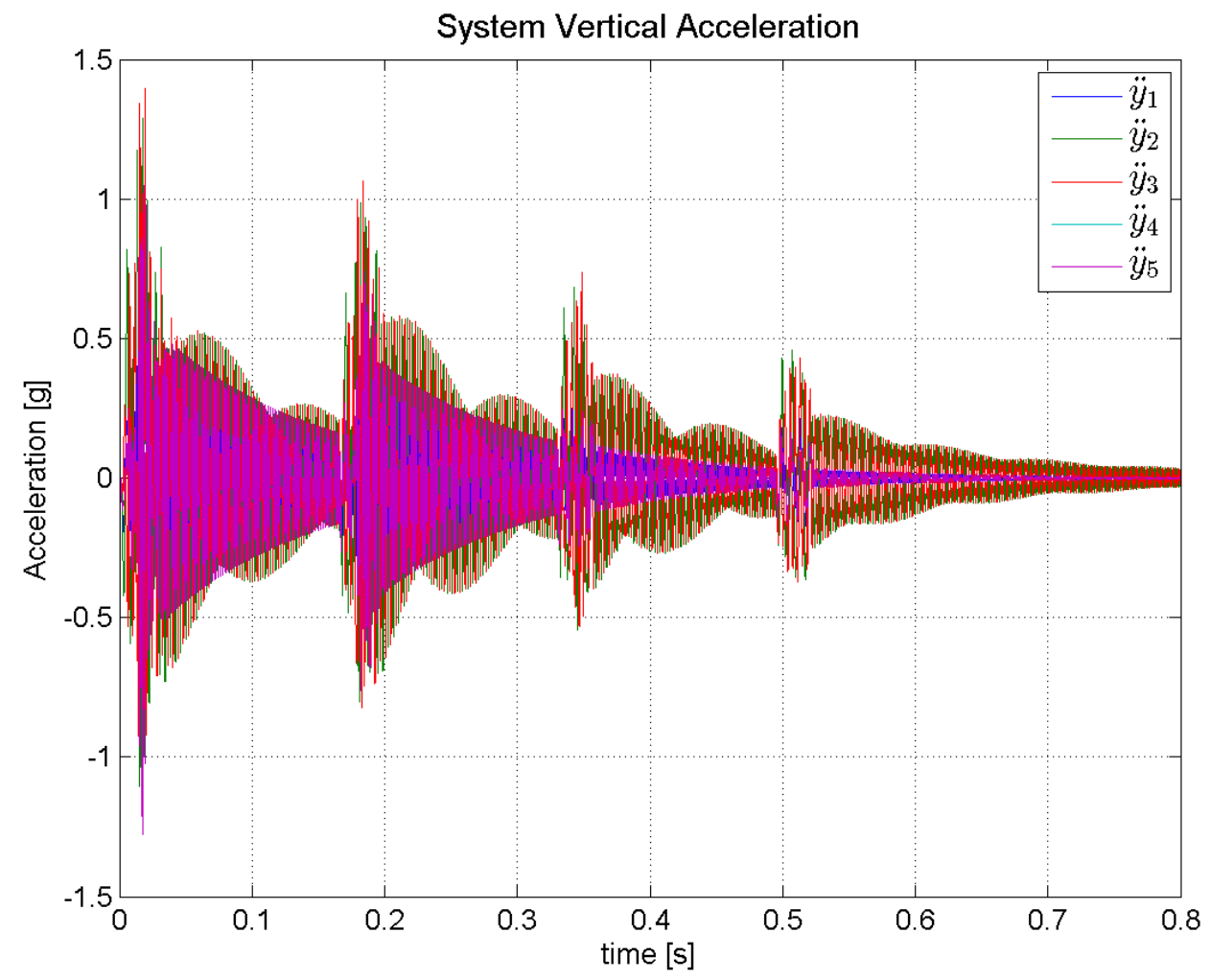

Figura 4.57: Acelerações verticais do sistema para tráfego em pista com irregularidades para diferentes valores de $k_{f}-66 \%$ da rigidez original da sapata

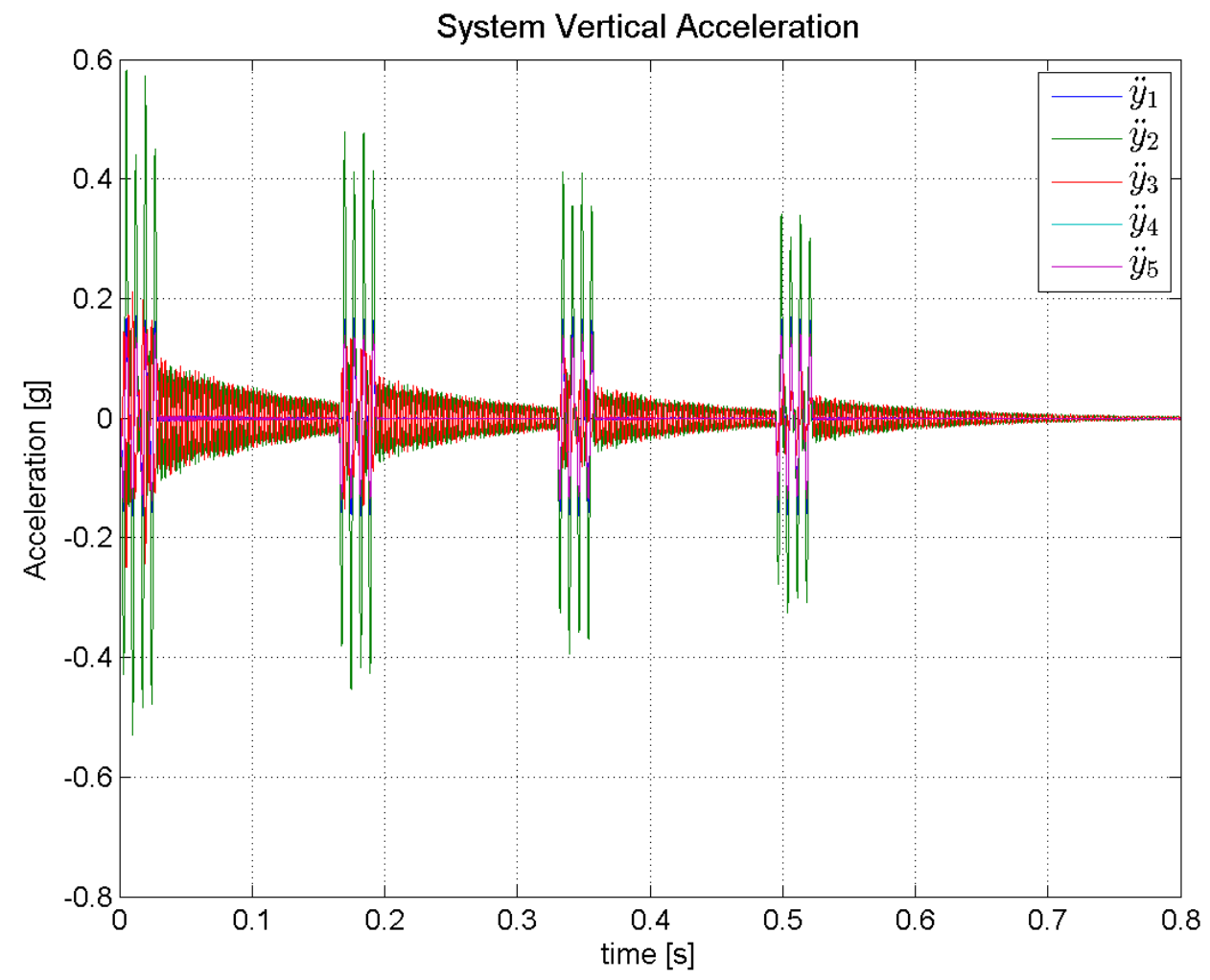

Figura 4.58: Acelerações verticais do sistema para tráfego em pista com irregularidades para diferentes valores de $k_{f}-133 \%$ da rigidez original da sapata 


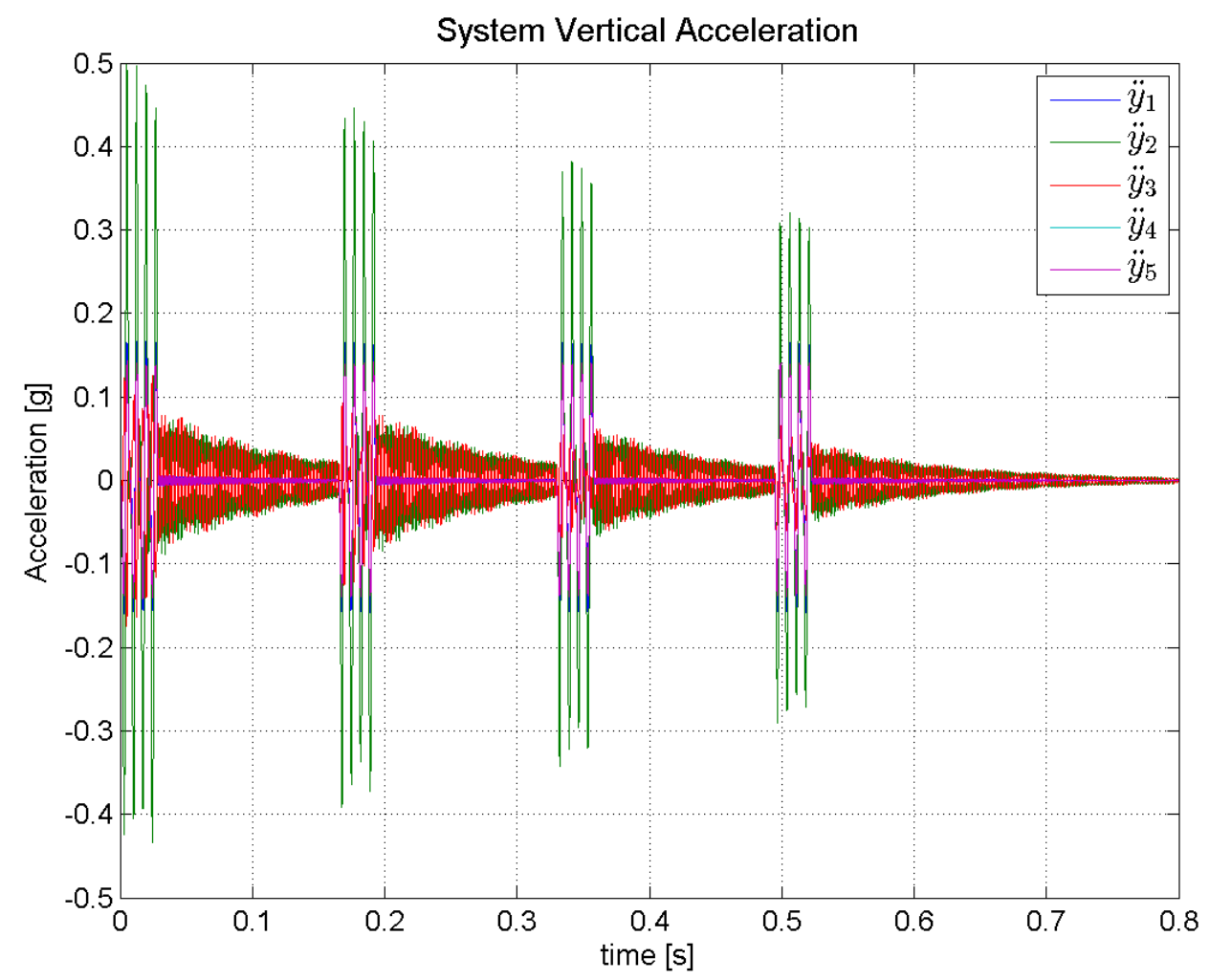

Figura 4.59: Acelerações verticais do sistema para tráfego em pista com irregularidades para diferentes valores de $k_{f}-166 \%$ da rigidez original da sapata 


\subsubsection{Resultados de Acelerações Horizontais}

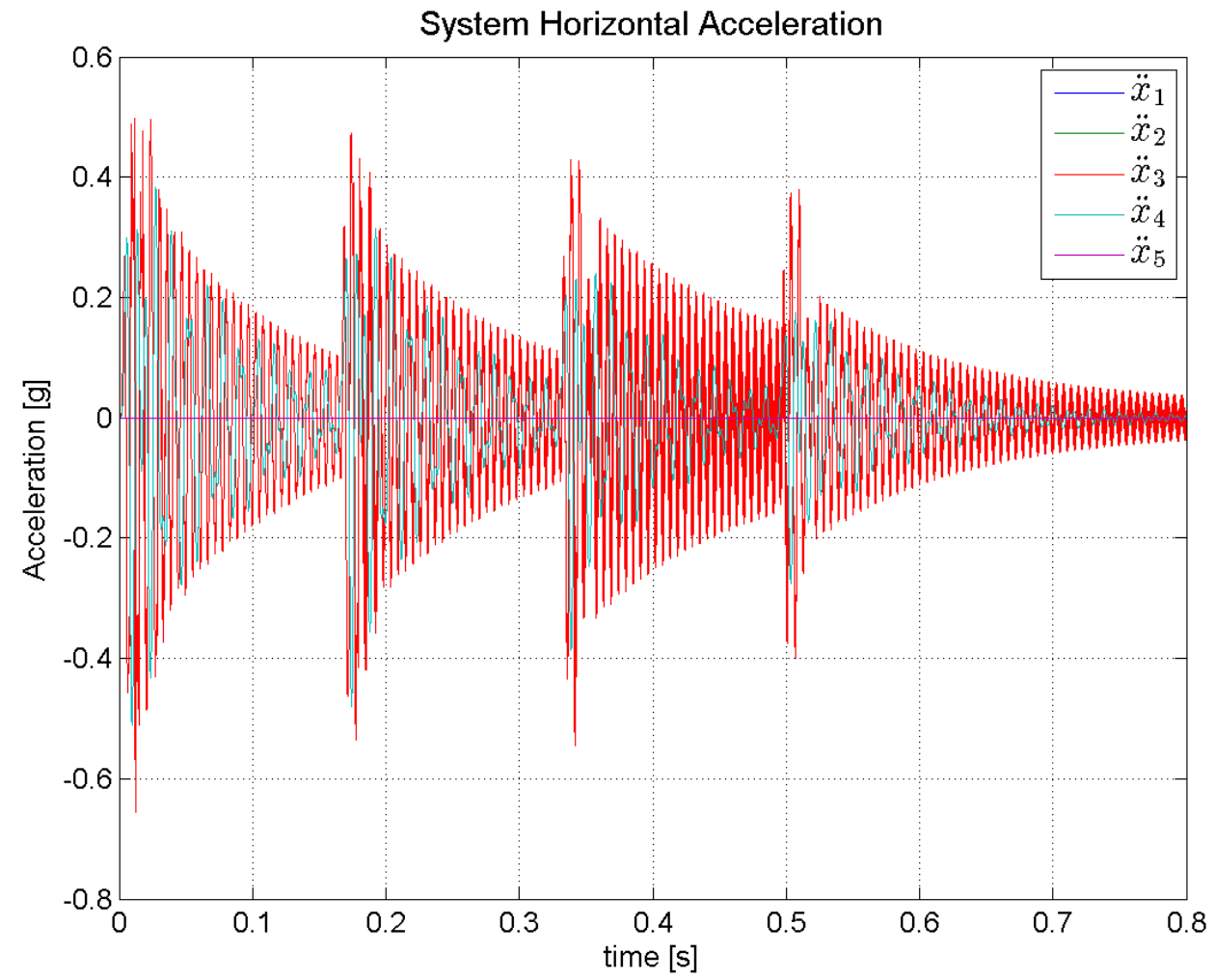

Figura 4.60: Acelerações horizontais do sistema para tráfego em pista com irregularidades para diferentes valores de $k_{f}-33 \%$ da rigidez original da sapata 


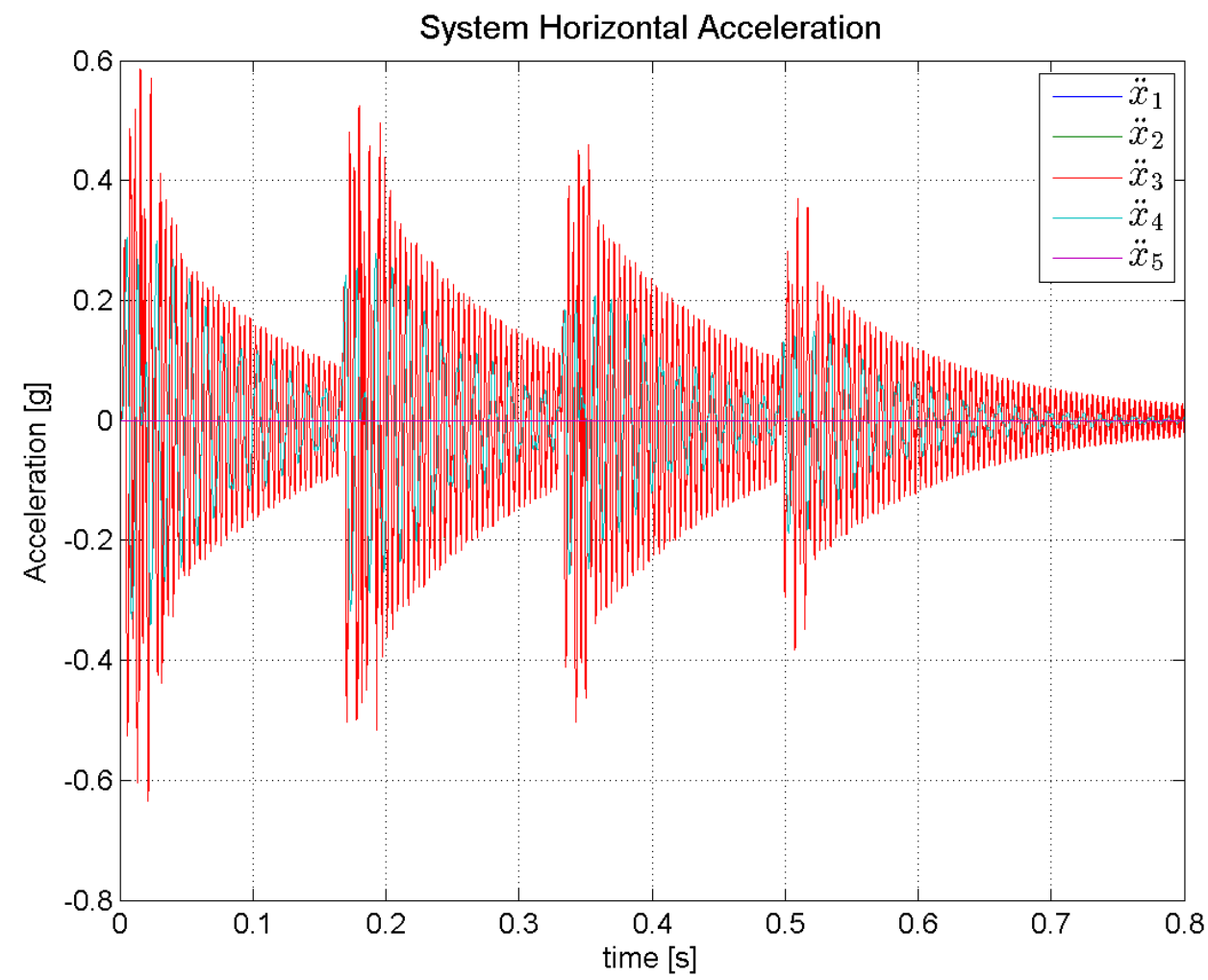

Figura 4.61: Acelerações horizontais do sistema para tráfego em pista com irregularidades para diferentes valores de $k_{f}-66 \%$ da rigidez original da sapata

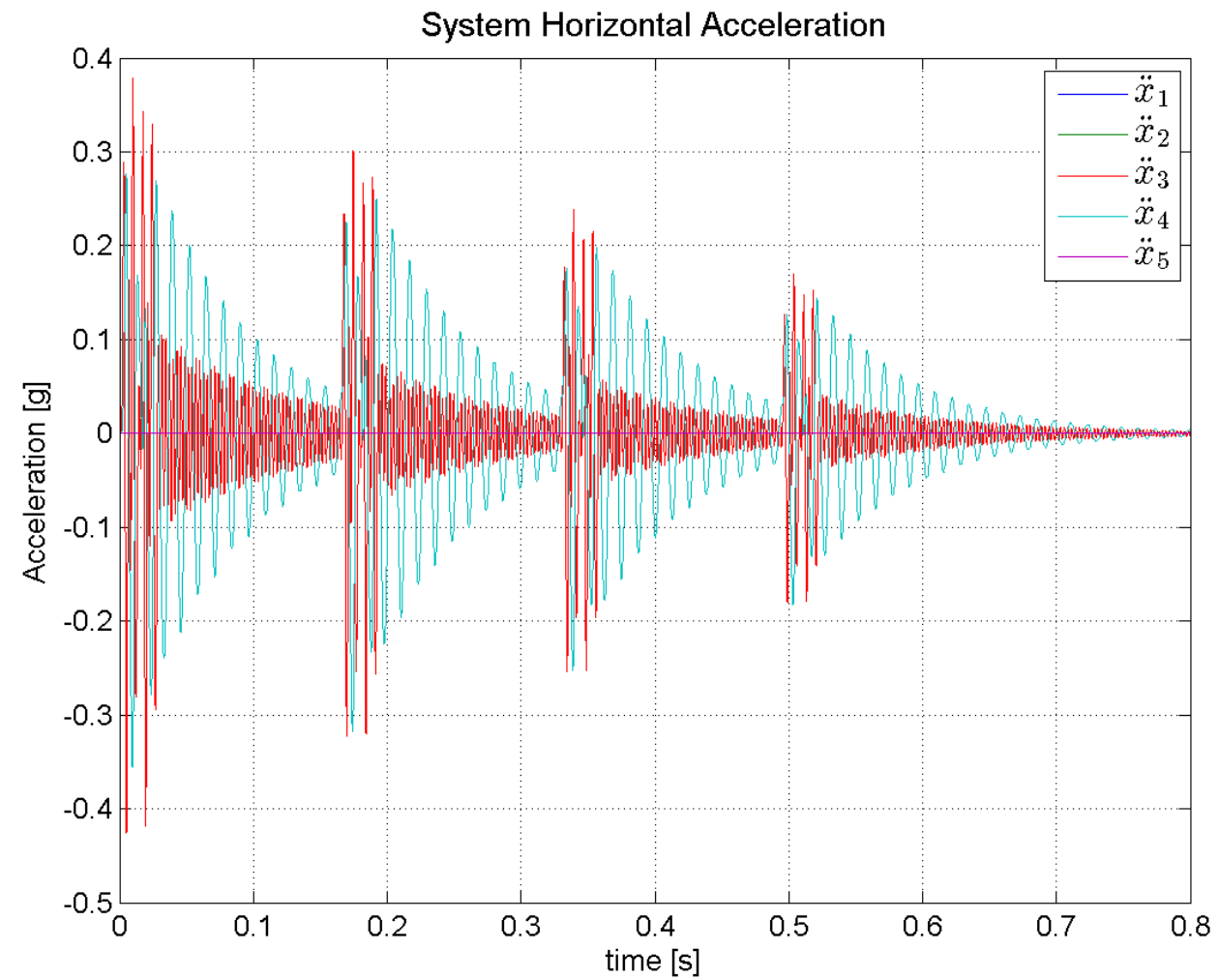

Figura 4.62: Acelerações horizontais do sistema para tráfego em pista com irregularidades para diferentes valores de $k_{f}-133 \%$ da rigidez original da sapata 


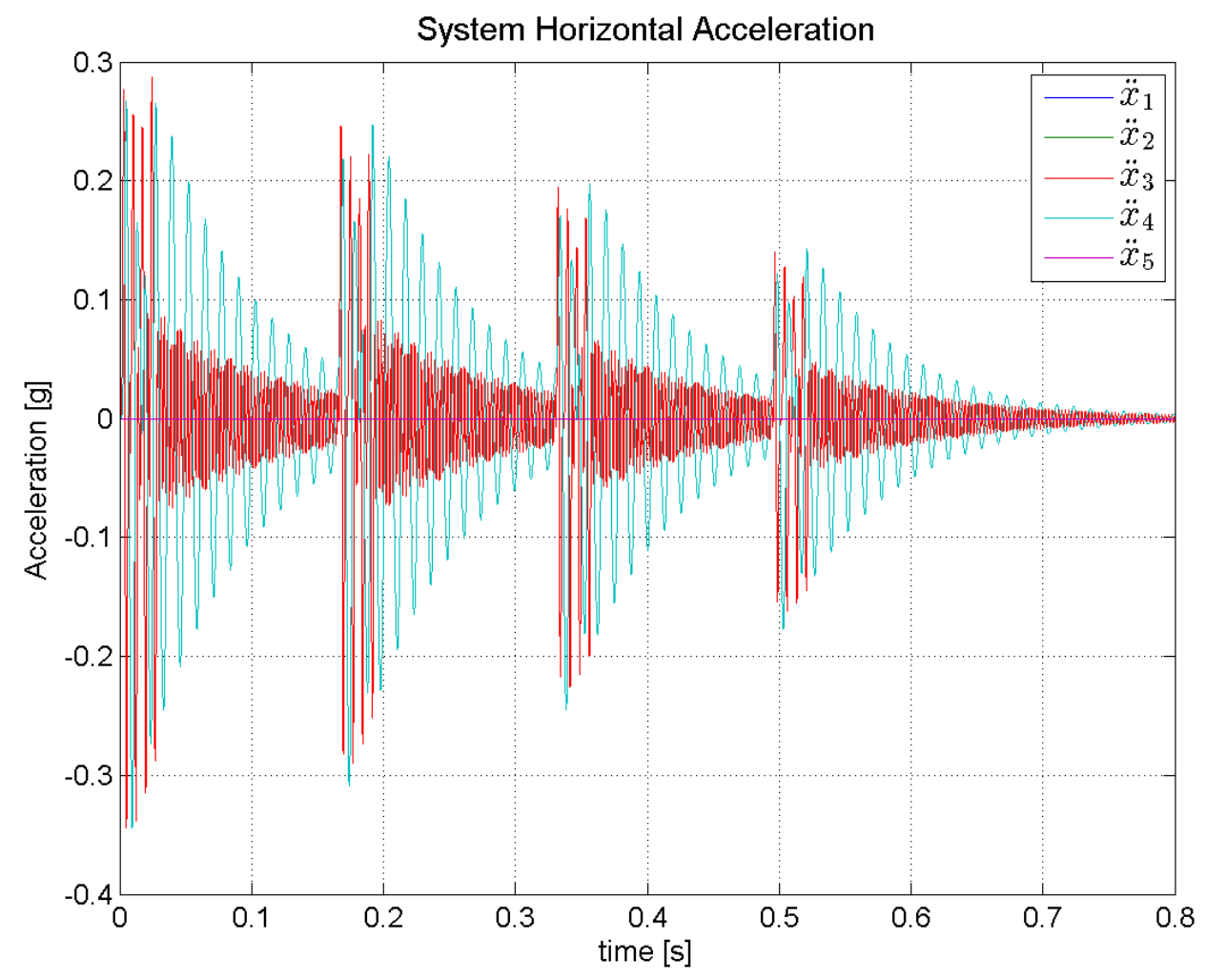

Figura 4.63: Acelerações horizontais do sistema para tráfego em pista com irregularidades para diferentes valores de $k_{f}-166 \%$ da rigidez original da sapata 


\subsubsection{Resultado de Reações sobre a Parte Ativa}

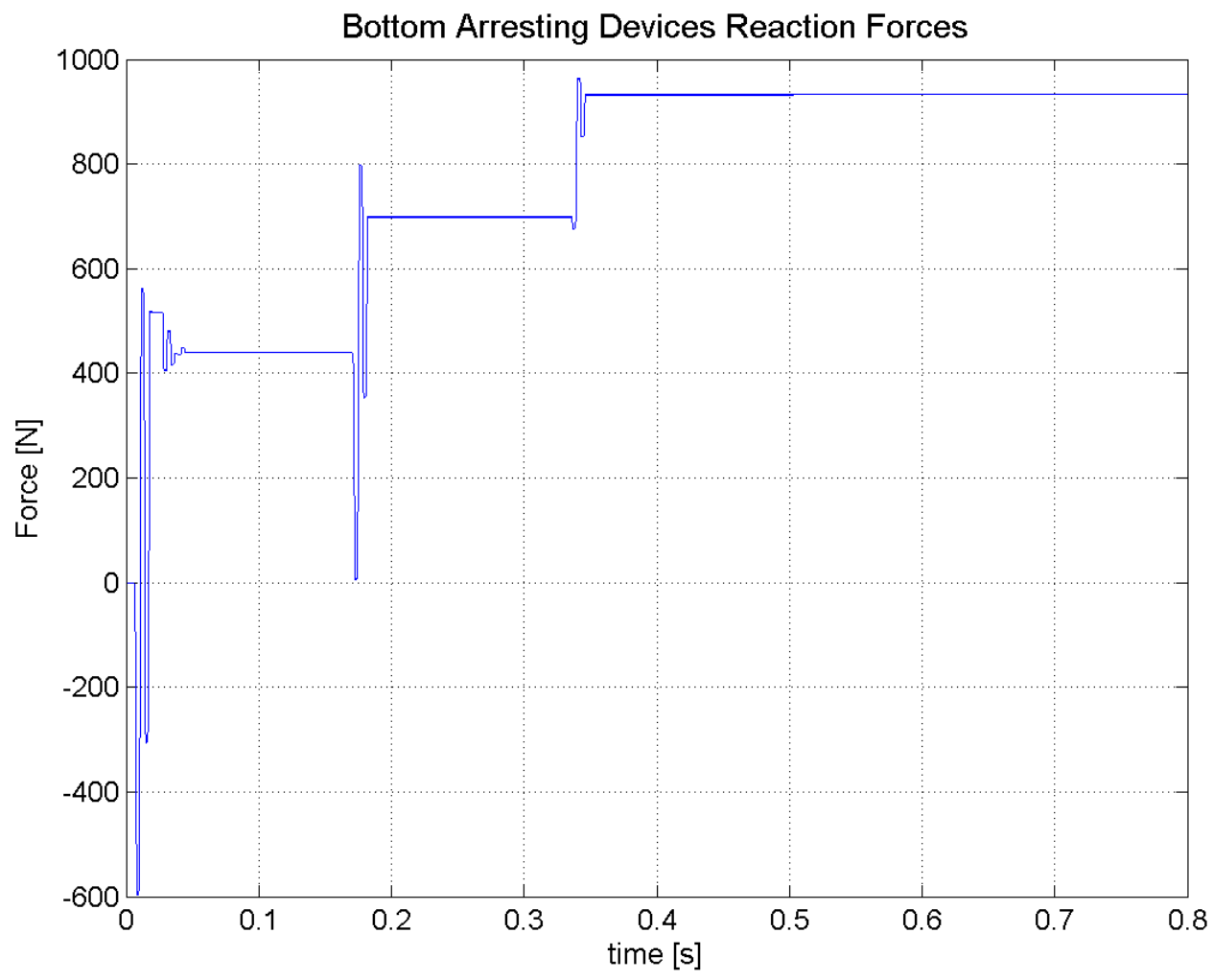

Figura 4.64: Reações em cada fixação inferior - 33\% da rigidez original da sapata 


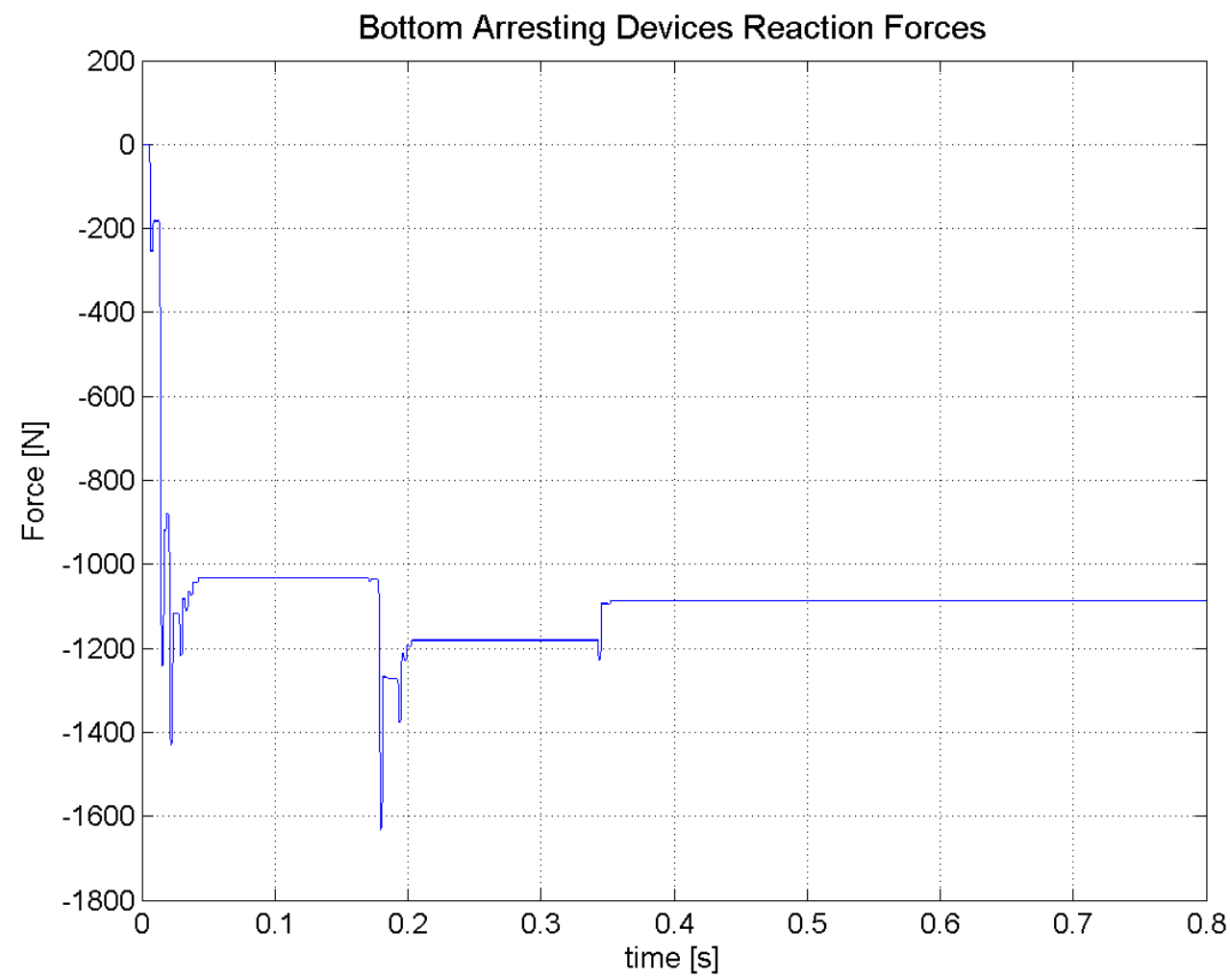

Figura 4.65: Reações em cada fixação inferior - $66 \%$ da rigidez original da sapata

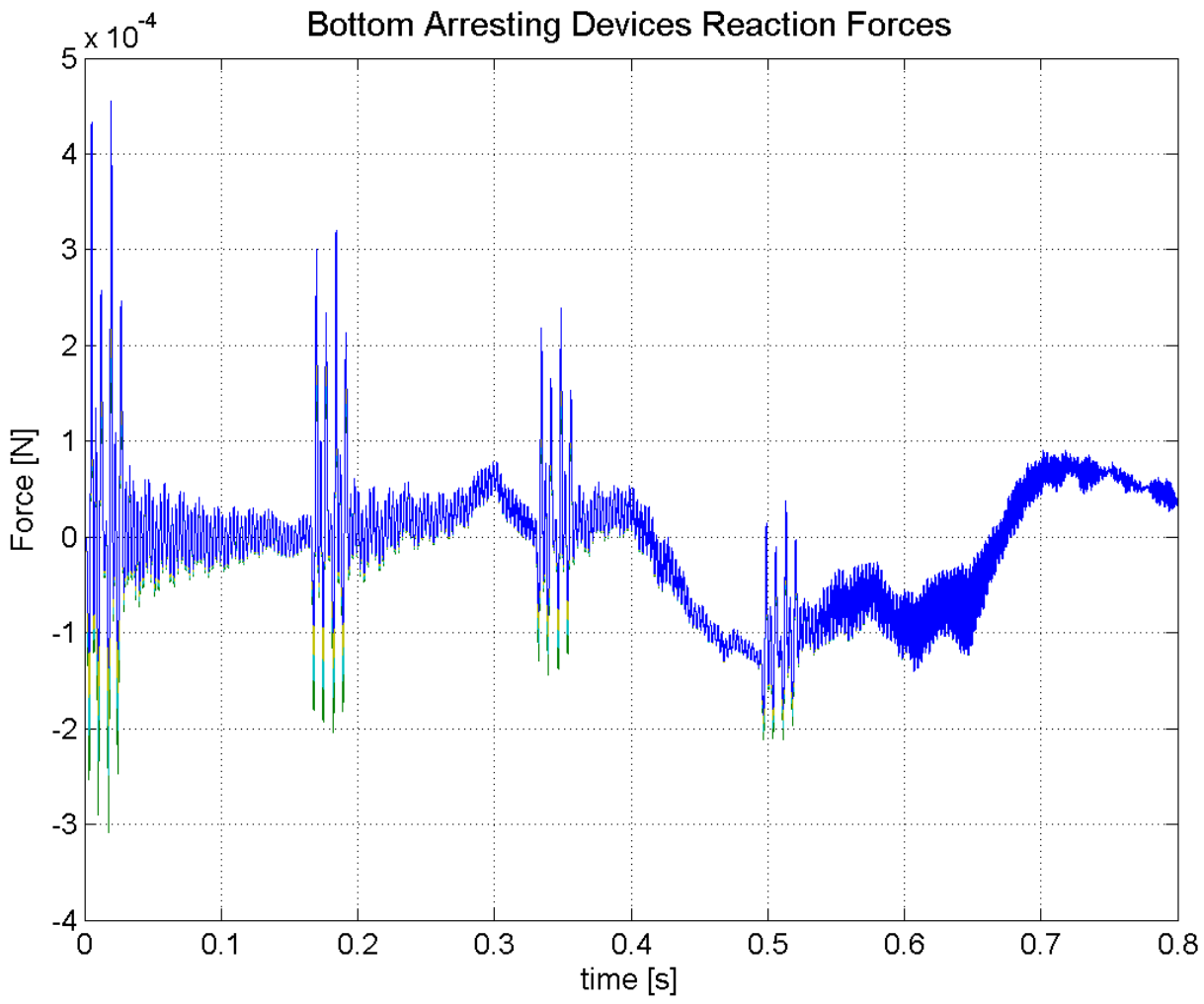

Figura 4.66: Reações em cada fixação inferior - $133 \%$ da rigidez original da sapata 


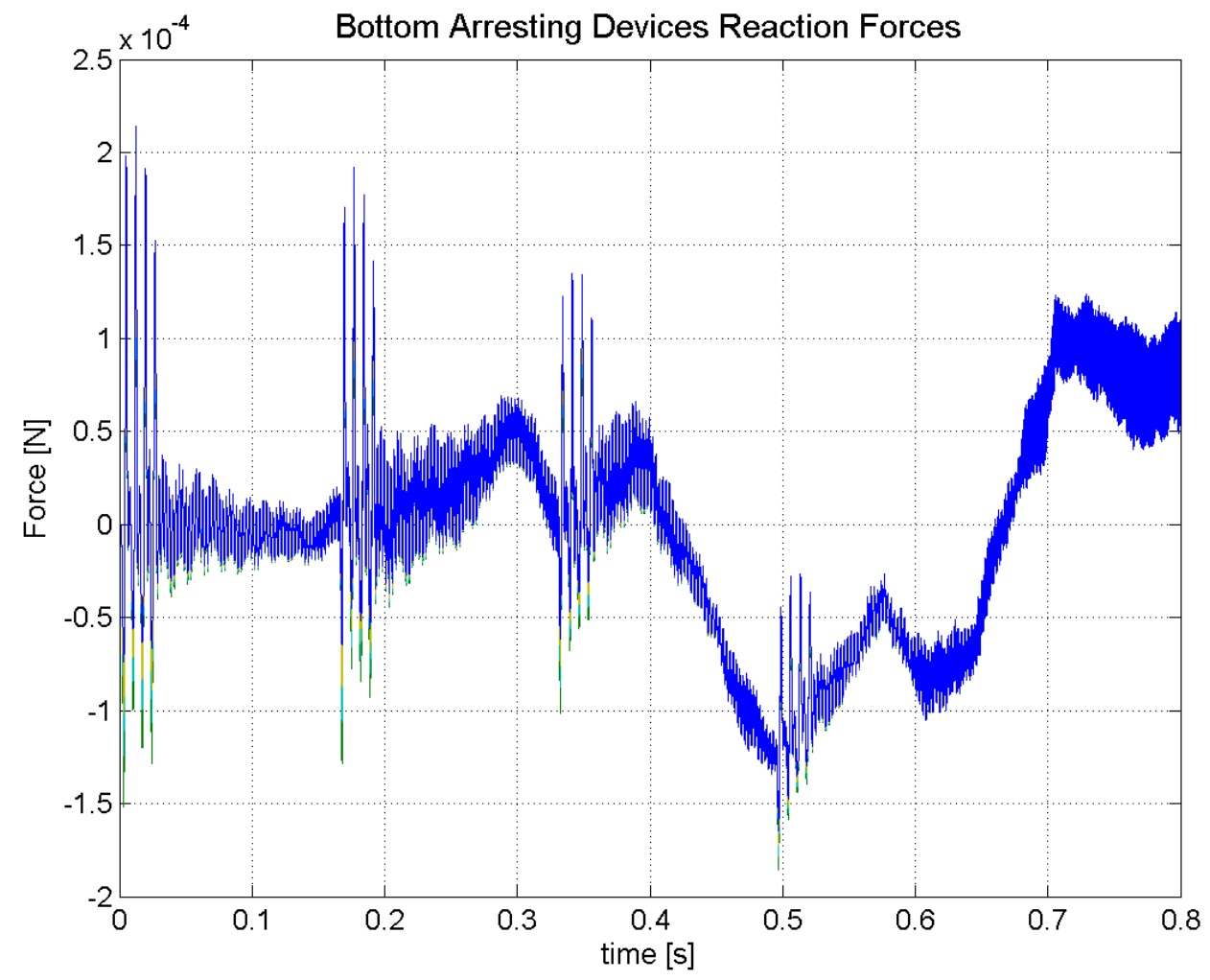

Figura 4.67: Reações em cada fixação inferior - 166\% da rigidez original da sapata 


\subsubsection{Resultados de Força de Atrito}

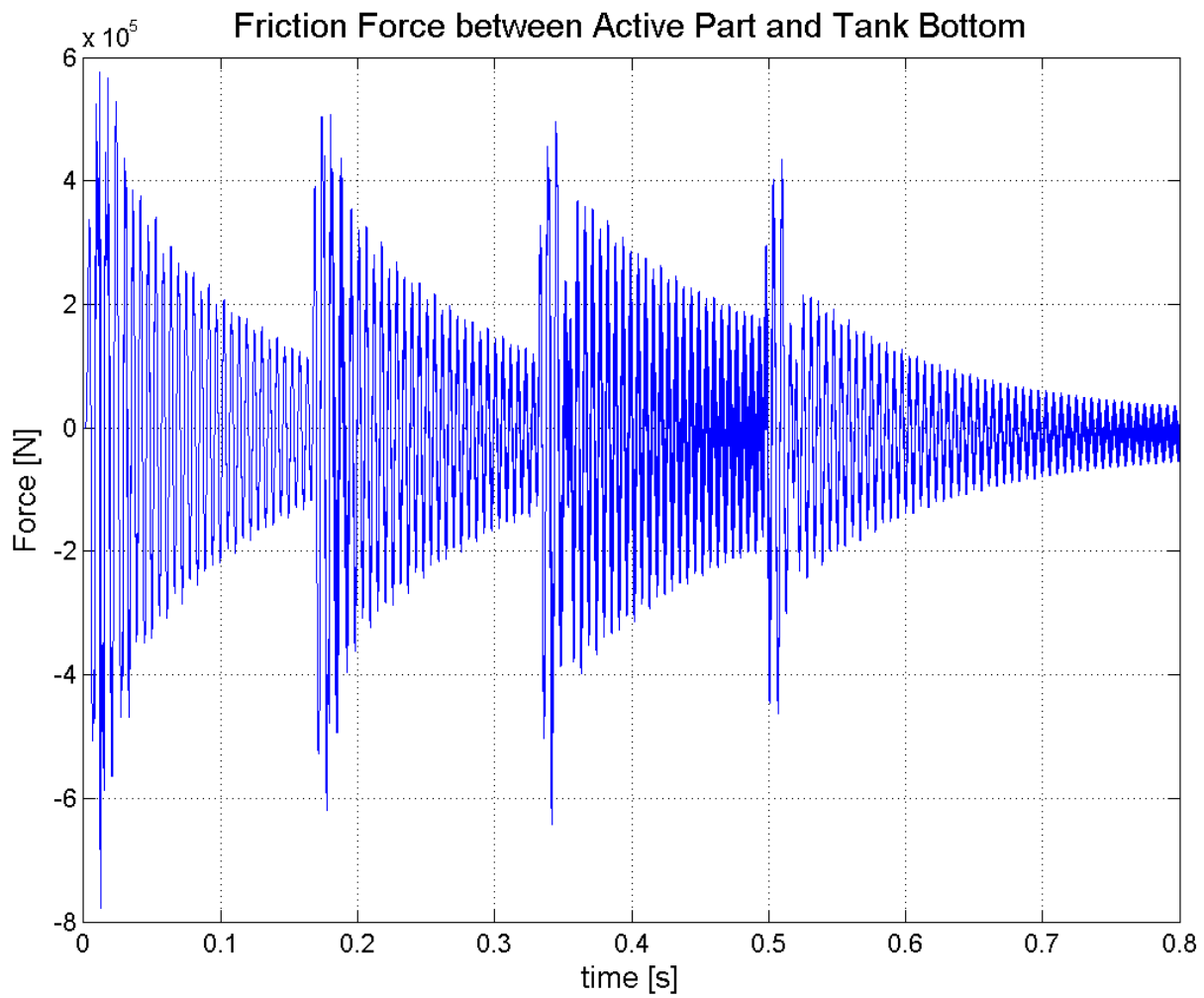

Figura 4.68: Força de atrito entre parte ativa e fundo - $33 \%$ da rigidez original da sapata 


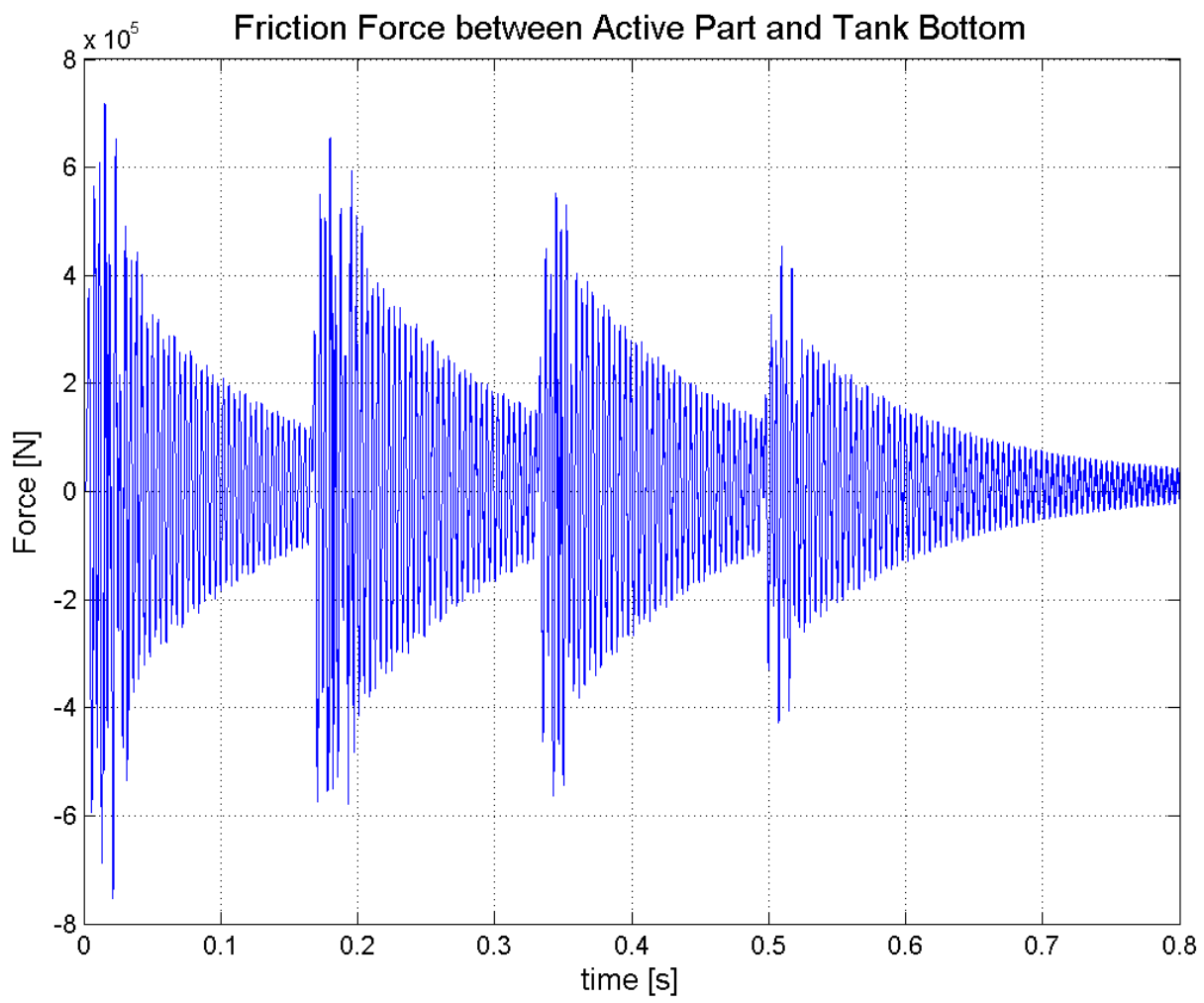

Figura 4.69: Força de atrito entre parte ativa e fundo - $66 \%$ da rigidez original da sapata

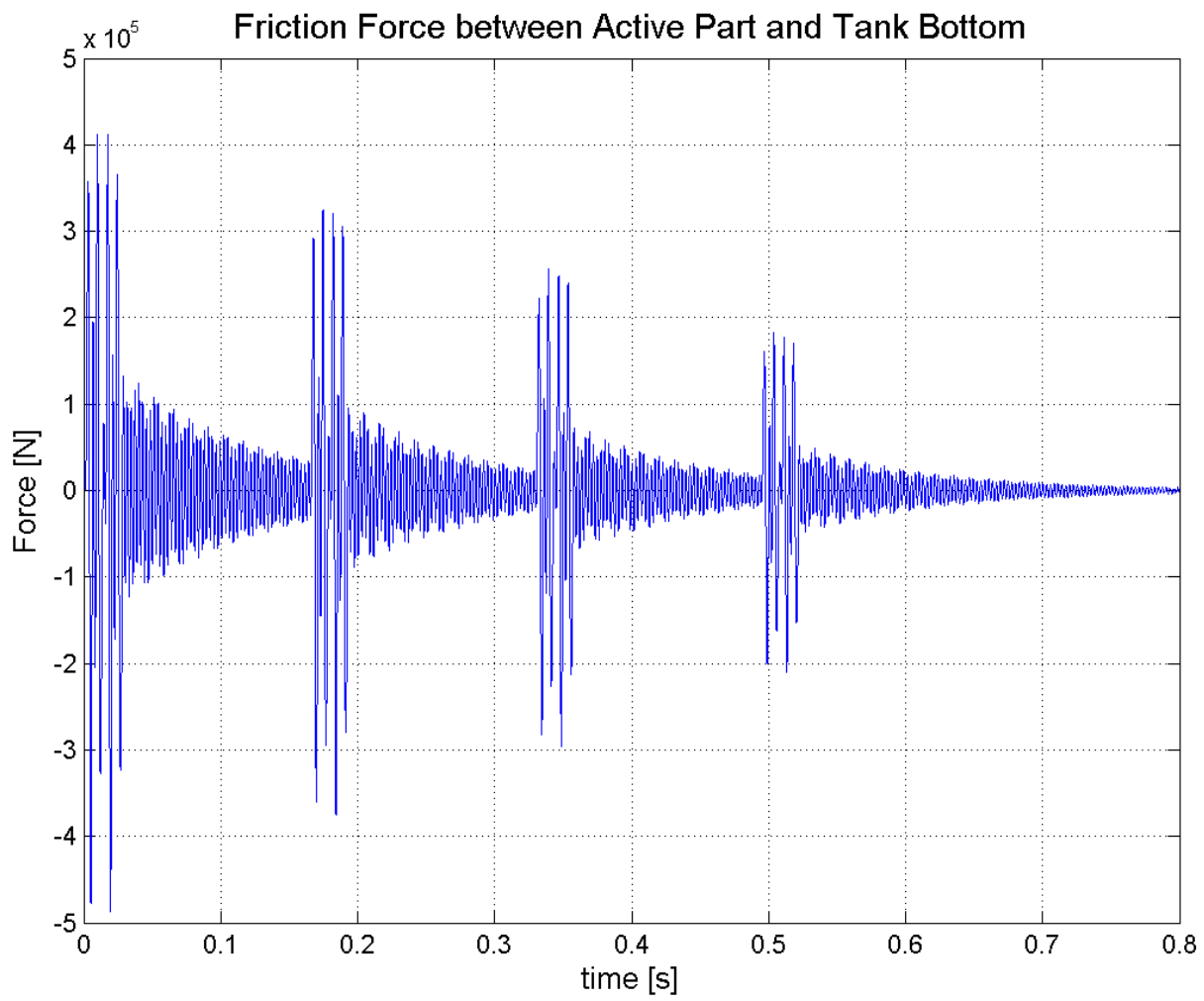

Figura 4.70: Força de atrito entre parte ativa e fundo - $133 \%$ da rigidez original da sapata 


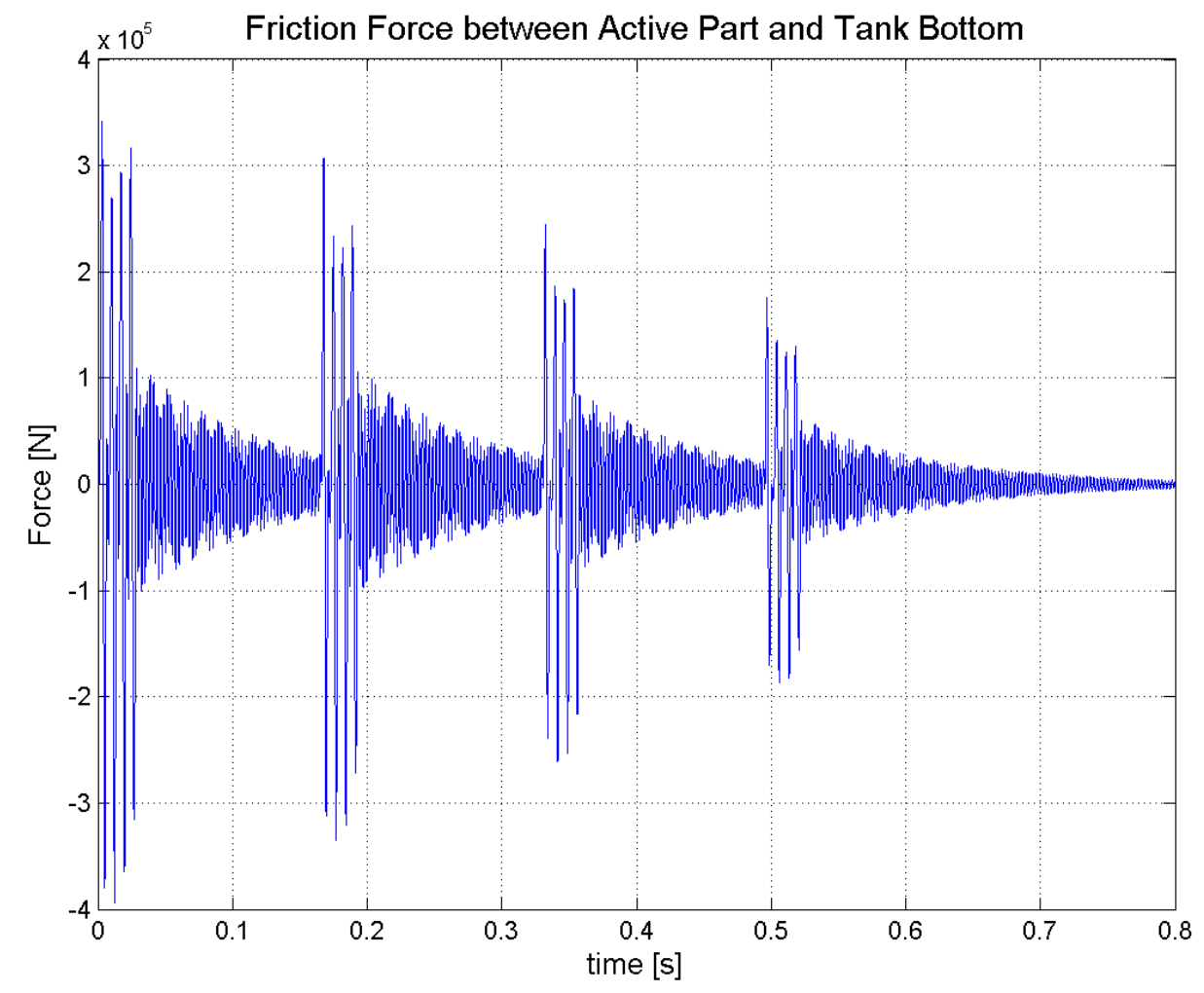

Figura 4.71: Força de atrito entre parte ativa e fundo - $166 \%$ da rigidez original da sapata 


\subsubsection{Discussões}

Nota-se que, ao se considerar valores menores de rigidez das sapatas, as acelerações verticais desenvolvidas pelo sistema mecânico, conforme observadas nas figuras 4.56 a 4.59, são maiores que aquelas vistas a medida que se aumenta a rigidez.

Verifica-se também essa diferença de comportamento nas acelerações horizontais, conforme se vê nas figuras 4.60 a 4.63 .

Sabe-se que a medida em que se aumenta a rigidez de um sistema mecânico, aumenta-se consequentemente suas frequências naturais. Em razão disto, temse também um aumento da faixa de frequências em que a transmissibilidade de vibrações é integral.

Entretanto, deve-se lembrar que, quanto maior a rigidez do sistema, menor é sua deflexão a cargas estáticas.

Se por um lado está sendo aumentada a banda de transmissibilidade integral do sistema mecânico, as amplitudes de vibração (e consequentemente as acelerações) são reduzidas com o aumento da rigidez.

Isto explica o fato da redução das acelerações para valores maiores de rigidez das sapatas.

Como consequência da redução das acelerações verticais, com o aumento da rigidez das sapatas diminui-se a movimentação relativa da parte ativa com o fundo. Logo, os esforços repassados às fixações inferiores são também reduzidos (vide figuras 4.64 a 4.67 ).

Também ocorre uma ligeira redução das forças de atrito, como vê-se nas figuras 4.68 a 4.71 . 


\section{Conclusão e Sugestões para Trabalhos Futuros}

Foi realizada neste trabalho a modelagem determinística da dinâmica de transformadores de potência em transporte. Com isso, foi possível obter estimativas mais realistas da transmissibilidade dos carregamentos a que o equipamento é sujeito durante seu transporte à planta.

O capítulo 2 apresenta em detalhes a descrição do sistema dinâmico aqui estudado. Por ser utilizado o formalismo lagrangiano na modelagem do sistema, foi dado enfoque específico a cada elemento com capacidade de armazenamento de energia potencial ou de dissipação viscosa.

Já o capítulo 3 apresenta a metodologia adotada para a resolução temporal do problema. É descrita a implementação da imposição de restrições ao movimento do sistema via método dos multiplicadores de Lagrange. Para aquelas restrições condicionalmente válidas (leia-se atrito seco), é feita a descrição da transição de estado.

O problema da sobreposição de chapas do núcleo na região do Step Lap é abordado ao se descrever a distribuição de tensões de cisalhamento sobre esta área e verificando como a mesma contribui para integridade de montagem do núcleo ferromagnético.

Por fim, é apresentado o problema inverso do deslizamento, sua difícil resolução computacional e métodos para a regularização das equações integrais desse problema.

Explora-se a capacidade de cálculo do modelo no capítulo 4. Nele foi avaliada a influência tanto de acelerações longitudinais do veículo quanto de variações no perfil da pista. Constatou-se a variação na transmissibilidade dos impactos ao equipamento em face da variação da duração dos mesmos. Verificou-se também a influência específica de um dos parâmetros construtivos para carregamentos decorrentes de variações no perfil da pista. 
Configurando integridade no presente estudo como sendo a capacidade do equipamento apresentar o mesmo desempenho (eletromagnético, no caso) verificado durante os testes de aceitação, é possível definir parâmetros mecânicos cuja variação indiquem mudança na performance do transformador em operação.

Como indicado nos modos de falha apresentados no capítulo 1, em termos de distâncias elétricas, a variação de posições relativas é um indicativo de possível dano introduzido ao equipamento.

Quando analisado o problema de deslizamento de chapas do núcleo, vê-se novamente o problema traduzido em termos de variação de posição relativa. Entretanto, diferentemente do problema de distâncias elétricas necessárias para que não haja quebra do meio isolante ao redor, a variação das posições relativas entre chapas resulta na variação da área sobreposta no Step Lap. Consequente a isso, altera-se a relutância magnética do núcleo e possivelmente as perdas (de potência por aquecimento) nessa parte do equipamento.

Tendo sido desenvolvida nesse trabalho uma ferramenta determinística de cálculo do transformador durante o transporte, é possível que se conheça a resposta do equipamento para um dado carregamento, ao se conhecer todos seus parâmetros construtivos. Entretanto, o projetista do equipamento tem em mãos nada além de estimativas de muitos desses parâmetros, quando as tem.

O que se discute a respeito do conhecimento dos parâmetros construtivos do equipamento aplica-se também, mais amplamente, ao conhecimento dos carregamentos mecânicos. Os dados obtidos por instrumentação do transformador com registradores de impacto comerciais revelam, no geral, a maneira como aquele sistema mecânico específico responde aos carregamentos que lhe são impostos. Como, na maioria das vezes, esses registradores de impacto são instalados no tanque do transformador, externamente, os sinais de aceleração que se observam são, necessariamente, ora amplificados, ora atenuados em relação ao sinal do carregamento original.

Assim sendo, nota-se aqui outro erro conceitual praticado na indústria, não só por considerar estes como carregamentos estáticos (uma vez que esta pesquisa demonstra a importância de considerá-los dinâmicos), como também por utilizar valores máximos (frequentes) observados em séries históricas. Em outras palavras, os valores que normalmente são praticados para o dimensionamento do transformador em transporte de acordo com o procedimento de carregamentos estáticos superestimam o real carregamento dinâmico. Tal consideração deve ser levada em conta no momento de atribuir a máxima aceleração desenvolvida pelo 
veículo.

Conforme se observou nas análises em que foi variado o valor de rigidez das sapatas da parte ativa, é possível que variações sensíveis da resposta do sistema dinâmico ocorram em decorrência de mudanças combinadas de parâmetros de projeto. Uma possível abordagem desse problema poderia ser feita utilizandose de Mapas de Poincaré para se analisar a estabilidade estrutural do sistema dinâmico e a aplicação do Método de Monte Carlo para se analisar a confiabilidade desse sistema.

Como sugestão para trabalhos futuros, é interessante um estudo mais detalhado dos modelos de atrito para o Step Lap, em conjunto com avaliações experimentais tanto para caracterização do atrito, como de equipamentos reais.

Melhorias para aceleração dos algoritmos de cálculo dos parâmetros de deslizamento das colunas do núcleo são também necessárias.

Por fim, uma vez que a simulação do sistema dinâmico se mostrou viável, sugere-se que a mesma possa ser adotada como prática na indústria, a fim de que haja antecipação em projeto do conhecimento de pontos frágeis durante o transporte do transformador. 


\section{Referências}

1 MOORE, H.; ALLAN, D. Theory and principles. In: Electric Power

Transformer Engineering. 1. ed. Boca Raton, USA: CRC Press LLC, 2004. cap. 1, p. 10-21.

2 SIM, H. J.; DIGBY, S. H. Equipment types: Power transformers. In:

Electric Power Transformer Engineering. 1. ed. Boca Raton, USA: CRC Press LLC, 2004. cap. 2, p. 23-44.

3 SECUE, J.; MOMBELLO, E. Sweep frequency response analysis (sfra) for the assessment of winding displacements and deformation in power transformers. Electric Power Systems Research, v. 78, n. 6, p. 1119 - 1128, 2008. ISSN 0378-7796. Disponível em: <http://www.sciencedirect.com/science/article/pii/S037877960700171X>.

4 Pleite, J.; GONZALEZ, C.; VAZQUEZ, J.; LAZARO, A. Power transformer core fault diagnosis using frequency response analysis. In: Electrotechnical Conference, 2006. MELECON 2006. IEEE Mediterranean. [S.l.: s.n.], 2006. p. $1126-1129$.

5 SECUE, J.; MOMBELLO, E. New methodology for diagnosing faults in power transformer windings through the sweep frequency response analysis (sfra). In: Transmission and Distribution Conference and Exposition: Latin America, 2008 IEEE/PES. [S.l.: s.n.], 2008. p. 1 -10.

6 PLEITE, J.; OLIAS, E.; BARRADO, A.; LAZARO, A.; VAZQUEZ, J. Transformer modeling for fra techniques. In: Transmission and Distribution Conference and Exhibition 2002: Asia Pacific. IEEE/PES. [S.l.: s.n.], 2002. I, p. $317-321$ vol.1.

7 DICK, E.; ERVEN, C. Transformer diagnostic testing by frequency response analysis. Power Apparatus and Systems, IEEE Transactions on, PAS-97, n. 6, p. $2144-2153$, nov. 1978. ISSN 0018-9510.

8 IEEE Guide for Installation and Maintenance of Liquid-Immersed Power Transformers. 2008, 1 -60 p.

9 HIHAT, N.; NAPIERALSKA-JUSZCZAK, E.; LECOINTE, J.; SYKULSKI, J.; KOMEZA, K. Equivalent permeability of step-lap joints of transformer cores: Computational and experimental considerations. Magnetics, IEEE Transactions on, v. 47, n. 1, p. $244-251$, jan. 2011. ISSN 0018-9464.

10 MECHLER, G.; GIRGIS, R. Magnetic flux distributions in transformer core joints. Power Delivery, IEEE Transactions on, v. 15, n. 1, p. 198 -203, jan. 2000. ISSN 0885-8977.

11 NAKATA, T.; TAKAHASHI, N.; KAWASE, Y. Magnetic performance of step-lap joints in distribution transformer cores. Magnetics, IEEE Transactions on, v. 18, n. 6, p. 1055 - 1057, nov. 1982. ISSN 0018-9464. 
12 LANCZOS, C. The Variational Principles of Mechanics. 1. ed. Toronto: University of Toronto Press, 1949. (Mathematical Expositions).

13 GOYAL, S. Planar Sliding of a Rigid Body with Dry Friction: Limit Surfaces and Dynamics of Motion. Tese (Doutorado) - Cornell University, Ithaca, NY, USA, 1989.

14 WEILER, K.; ATHERTON, P. Hidden surface removal using polygon area sorting. In: Proceedings of the 4th annual conference on Computer graphics and interactive techniques. New York, NY, USA: ACM, 1977. (SIGGRAPH '77), p. 214-222. Disponível em: <http://doi.acm.org/10.1145/563858.563896>.

15 WAngenheim, A. von; WAGNER, H. M. INE 5341 - Programa da Disciplina Computação Gráfica. 2009. Acessado em 15/02/2012. Disponível em: $<$ http://www.inf.ufsc.br/ grafica/CG3.pdf $>$.

16 VATTI, B. T. A generic solution to polygon clipping. Commun. ACM, ACM, New York, NY, USA, XXXV, n. 7, p. 56-63, 07 1992. ISSN 0001-0782. Disponível em: <http://doi.acm.org/10.1145/129902.129906>.

17 PRESS, W. H.; TEUKOLSKY, S. A.; VETTERLING, W. T.; FLANNERY, B. P. Numerical Recipes in $C++$ : the art of scientific computing. 3. ed. Cambridge, UK: Cambridge University Press, 2002.

18 MORÉ, J. J. The Levenberg-Marquardt algorithm: Implementation and theory. In: WATSON, G. A. (Ed.). Numerical Analysis. Berlin: Springer, 1977. p. $105-116$.

19 SHANBAG, S. Applied Computational Science

1. 2010. Acessado em 15/01/2012. Disponível em:

$<$ http://people.sc.fsu.edu/ sshanbhag/BulirschStoer.pdf $>$.

20 LIU, E. H. MIT OpenCourseWare / Mathematics / 18.304

Undergraduate Seminar in Discrete Mathematics, Spring 2006

/ Projects. 2011. Acessado em 15/01/2011. Disponível em:

$<$ http://ocw.mit.edu/courses/mathematics/18-304-undergraduate-seminar-indiscrete-mathematics-spring-2006/projects/xtrpltn_liu_xpnd.pdf $>$.

21 FELDMAN, J. Math 256/201 Home Page. 2011. Acessado em 15/01/2012. Disponível em: <http://www.math.ubc.ca/ feldman/m256/richard.pdf $>$.

22 EBERLY, D. Stability Analysis for Systems of Differential Equations. 2008. Acessado em 15/01/2012. Disponível em: $<$ http://www.geometrictools.com/Documentation/StabilityAnalysis.pdf $>$.

23 SILVA, E. C. N. PMR2420 - Notas de Aula. 2003. Acessado em 10/03/2012. Disponível em: <http://sites.poli.usp.br/d/pmr2420/a4-2420.pdf>.

24 WRIGGERS, P. Computational Contact Mechanics. 1. ed. West Sussex, England: John Wiley \& Sons, 2002.

25 RESOLUÇÃO $\mathrm{n}^{\circ}$ 39/98. CONSELHO NACIONAL DE TRÂNSITO, 1998. Acessado em 22/02/2013. Disponível em: <http://www.denatran.gov.br/download/Resolucoes/resolucao039_98.doc $>$. 